\title{
INJECTABLE HYDROGELS FOR CARTILAGE
}

\section{TISSUE ENGINEERING}

Rong Jin 


\section{Committee}

$\begin{array}{lll}\begin{array}{l}\text { Chairman: } \\ \text { Secretary }\end{array} & \text { Prof. dr. H. Brinksma } & \text { University of Twente } \\ \text { Promotor: } & \text { Prof. dr. G. van der Steenhoven } & \text { University of Twente } \\ \text { Assistant Promotores: } & \text { dr. P. J. Dijkstra } & \text { University of Twente } \\ & \text { dr. M. Karperien } & \text { University of Twente } \\ \text { Members: } & \text { Prof. dr. C. A. van Blitterswijk } & \text { University of Twente } \\ & \text { Prof. dr. P. Dubruel } & \text { University of Twente } \\ & & \text { (Belgium) } \\ & \text { Prof. dr. C. Koning } & \text { Eindhoven University of } \\ & & \text { Technology } \\ & \text { dr. W. J. A. Dhert } & \text { Utrecht University }\end{array}$

\section{Injectable hydrogels for cartilage tissue engineering}

\section{Rong Jin}

Ph.D. Thesis, with references; with summary in English and in Dutch

University of Twente, Enschede, the Netherlands

December 2009

The research described in this thesis was financially supported by the Dutch Program for Tissue Engineering (DPTE). Project number: DPTE 06732.

Copyright (C) 2009 by R. Jin. All rights reserved.

Printed by Wöhrmann Print Service, Zutphen, the Netherlands

ISBN 978-90-365-2920-4

DOI: $10.3990 / 1.9789036529204$ 


\title{
INJECTABLE HYDROGELS FOR CARTILAGE
}

\section{TISSUE ENGINEERING}

\author{
PROEFSCHRIFT
}

ter verkrijging van

de graad van doctor aan de Universiteit Twente,

op gezag van de rector magnificus

prof. dr. H. Brinksma,

volgens besluit van het College voor Promoties,

in het openbaar te verdedigen

op vrijdag 18 december 2009 om 13.15 uur

door

\section{Rong Jin}

geboren op 3 oktober 1981

te Shanghai, P. R. China 
Dit proefschrift is goedgekeurd door:

Promotor

Assistant Promotores:
Prof. dr. J. Feijen

dr. P. J. Dijkstra

dr. M. Karperien 


\section{Contents}

Chapter 1 General Introduction 1

Chapter 2 Injectable Hydrogels for Cartilage Tissue Engineering 7

Chapter 3 Synthesis and Characterization of Hyaluronic acid-PEG Hydrogels via Michael Addition: An Injectable Biomaterial for Cartilage Repair

Chapter 4 Enzyme-mediated Fast In-situ Formation of Hydrogels From Dextran-tyramine Conjugates

Chapter 5 Enzymatically Crosslinked Dextran-tyramine Hydrogels as Injectable Scaffolds for Cartilage Tissue Engineering

Chapter 6 Injectable Chitosan-based Hydrogels for Cartilage Tissue Engineering

Chapter 7 Chondrogenesis in Injectable Enzymatically Crosslinked Heparin/Dextran Hydrogels

Chapter 8 Enzymatically-Crosslinked Injectable Hydrogels Based on Biomimetic Dextran-Hyaluronic Acid Conjugates for Cartilage Tissue Engineering

Summary

Samenvatting

Acknowledgements

Curriculum Vitae 



\section{Chapter 1}

\section{General Introduction}

\subsection{Background}

\subsubsection{Cartilage}

Articular cartilage is a remarkably resilient, load bearing tissue in the human body. It covers the bone ends at a joint to cushion the bone and allows the joint to move easily without pain [1]. Articular cartilage tissue is highly hydrated and consists approximately of $70 \%$ of water and $30 \%$ of an extracellular matrix (ECM) [2]. The ECM comprises $60 \%$ of collagens (mainly collagen type II), $25-35 \%$ of proteoglycans, and $15-20 \%$ of noncollagenous proteins and glycoproteins (Figure 1.1) [3].
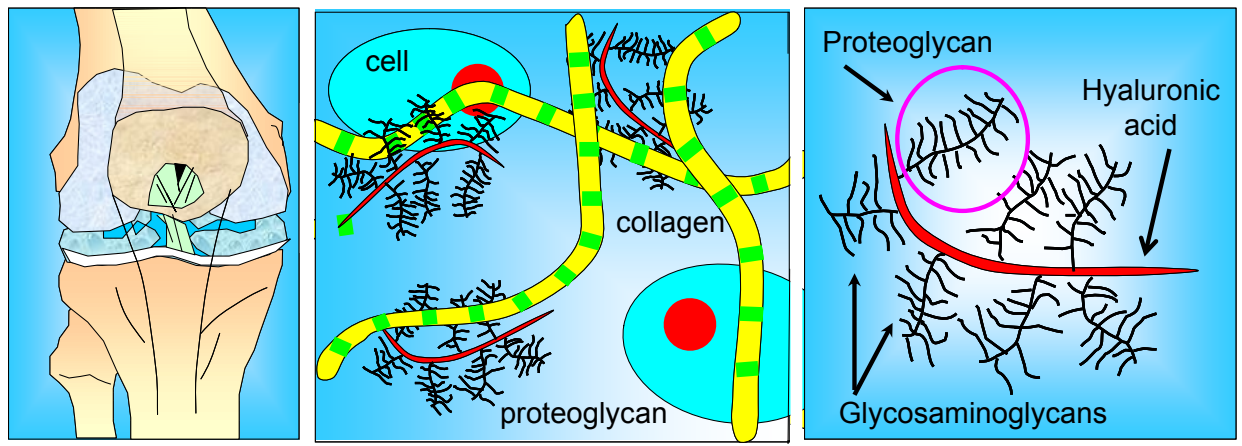

Figure 1.1. Cartilage (left), extracellular matrix (middle) and proteoglycans (right).

Cartilage tissue may be injured or damaged by trauma or disease, notably osteoarthritis. Damaged cartilage has a limited capacity of self-healing due to its avascular nature $[4,5]$. The current surgical options to treat damaged cartilage involve chondral shaving, osteochondral and perichondrial grafting, and total joint arthroplasty [6]. These approaches indeed may reduce pain or increase mobility, but are limited to elderly patients (revision surgery) or only afford short-term pain relief [7].

\subsubsection{Tissue engineering}

Tissue engineering provides an alternative approach to repair cartilage. It aims to develop biological substitutes that restore, maintain or improve tissue functions [8]. The 
typical tissue engineering paradigm utilizes a scaffold as a temporary support matrix for cell growth, differentiation and matrix production (Figure 1.2). Cartilage tissue is regarded well suitable for a tissue engineering approach in that it has a relatively simple structure. This view is based on a single cell type (chondrocytes) present, as well as low oxygen requirement and low cell-to-matrix ratio $(<5 \%$ cell volume density) [9, 10]. Therefore, tissue engineering of cartilage has received considerable attention over the past decades, and has been extensively studied for the treatment of traumas or cartilage-related diseases $[3,11,12]$.

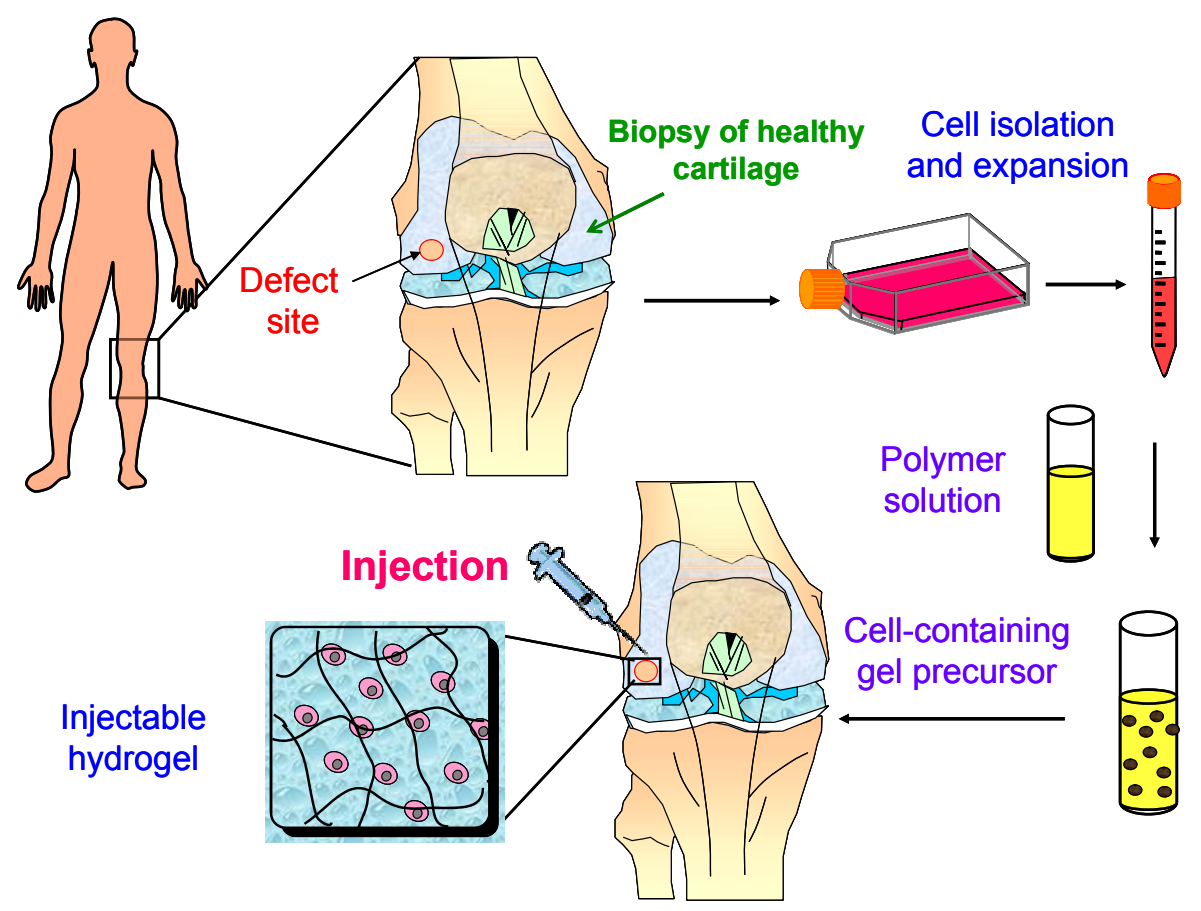

Figure 1.2. Representative diagram of cartilage tissue engineering.

\subsubsection{Hydrogel scaffolds}

The availability of biomimetic scaffolds is a prerequisite for successful cartilage regeneration. The scaffolds should be capable of mimicking biofunctions of the natural extracellular matrix. Consequently, they may enhance cell proliferation and support tissuespecific differentiation. Hydrogels, three-dimensional hydrophilic polymeric networks, have been widely investigated as scaffolds for cartilage tissue engineering [13]. Unlike other types of scaffolds such as foams, meshes and sponges, hydrogels have high water 
content, providing an environment similar to native cartilage. Besides, hydrogels allow for sufficient transportation of nutrients and waste products, which is essential for cell growth.

Hydrogels are preferably designed such that they will form in-situ and these systems are termed injectable hydrogels. They offer the advantages of good alignment with irregularly shaped defects and allow easy cell incorporation. Moreover, from the clinical point of view, implantation surgery can be avoided and replaced by a simple injection procedure.

\subsubsection{Enzymatic crosslinking}

Injectable hydrogels can be formed either by physical or chemical crosslinking. Recently, enzymatic crosslinking has attracted attention as a novel chemical crosslinking route for hydrogel formation. Generally, enzymatically-crosslinked hydrogels are formed under mild gelation conditions, which is preferred for cell incorporation. Peroxidases, particularly horseradish peroxidase (HRP), has been studied for use in enzymatic crosslinking via the oxidative polymerization of phenol derivatives [14-16]. In the reaction, HRP serves as an oxidoreductase that catalyzes the oxidation of phenol moieties using $\mathrm{H}_{2} \mathrm{O}_{2}$, eventually resulting in the coupling of phenols linked either via carbon-carbon bonds or carbonoxygen bonds (Figure 1.3) [16].

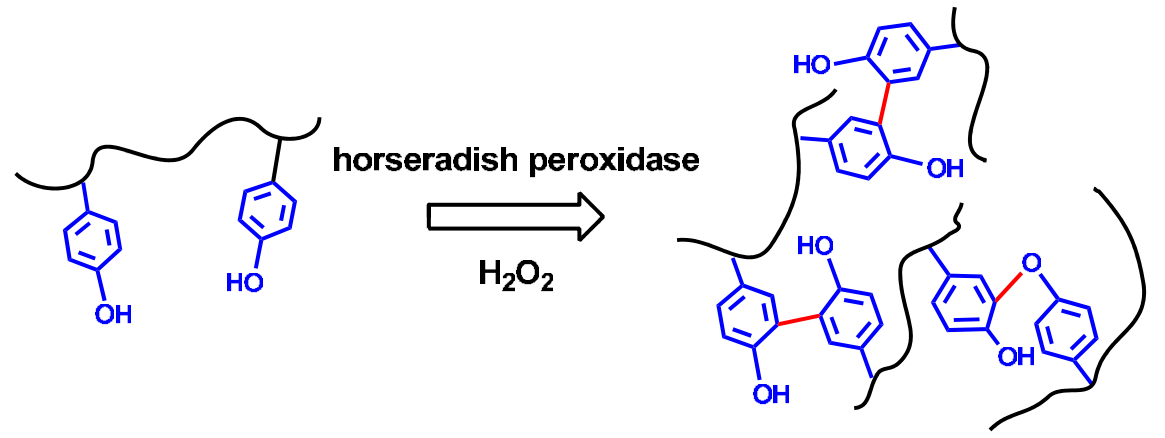

Figure 1.3. Enzymatic crosslinking of phenol derivatives using horseradish peroxidase and $\mathrm{H}_{2} \mathrm{O}_{2}$.

\subsection{Aim of the study}

The aim of the study described in this thesis was to design and prepare injectable hydrogels for cartilage tissue engineering. The hydrogel systems were expected to have short gelation times and good mechanical properties. Furthermore, the ability of these injectable hydrogels to function as a temporary ECM, including supporting chondrocyte survival, proliferation and differentiation, as well as directing matrix production, were also evaluated in vitro. 


\subsection{Outline of the thesis}

In this thesis, injectable enzymatically-crosslinked hydrogels based on polysaccharides as scaffolds for cartilage tissue engineering are described. The gelation times, degradation and mechanical properties, biocompatibility of the hydrogels, as well as the matrix production by chondrocytes in vitro were investigated in detail. Parts of the work in this thesis have been published in international peer-reviewed journals [17-19].

In Chapter 2 a literature overview is presented focusing on injectable hydrogels for cartilage tissue engineering, which includes criteria on hydrogel design, crosslinking methods and the potential applications for cartilage repair. This review aims to contribute to the understanding of the current status in this field.

In Chapter 3 the synthesis and characterization of poly(ethylene glycol)-hyaluronic acid hydrogels crosslinked via a Michael-type addition reaction is described. The influence of molecular weight, degree of substitution and polymer concentration on the gelation time, swelling and degradation, as well as the mechanical properties were studied. To evaluate the potential of these hydrogels for cartilage repair, bovine chondrocytes were incorporated into these gels. The cell viability and the neocartilage formation were examined in vitro.

In Chapter 4 two dextran-tyramine conjugates, i.e. dextran-tyramine linked by a urethane bond and by an ester-containing diglycolic group, are described. Dextran hydrogels were formed in situ by enzymatic crosslinking of dextran-tyramine conjugates and their mechanical, swelling and degradation properties were evaluated. In this study, we explored the potential of enzymatic crosslinking for in-situ hydrogel formation and demonstrated that this is an efficient way to obtain hydrogels, which are formed rapidly in situ and which have good mechanical properties.

In Chapter 5 the potential of injectable hydrogels from dextran-tyramine conjugates for cartilage tissue engineering applications is elucidated. Hydrogels with different molecular weights and dextrans conjugated with different numbers of tyramine groups were prepared. The viability and metabolic activity of incorporated chondrocytes in these hydrogels were determined using live-dead and MTT assays. The morphology of the chondrocytes and the formation of a cartilageous specific matrix in the cell/gel constructs were also examined.

A study dealing with the design of biodegradable, enzymatically crosslinkable chitosan derivatives is presented in Chapter 6. Water-soluble chitosan derivatives, chitosan-graftglycolic acid and phloretic acid, were explored for their potential as injectable hydrogels through enzymatic crosslinking using horseradish peroxidase and $\mathrm{H}_{2} \mathrm{O}_{2}$. The gelation and degradation rates of these newly developed chitosan-based hydrogels as well as their mechanical properties were determined. Additionally, the cytocompatibility of the gels and the morphology of incorporated chondrocytes in time were studied. 
Heparin, a natural glycosaminoglycan analog, was introduced into tyramine conjugated dextran hydrogels by enzymatically co-crosslinking with heparin-tyramine conjugates (Chapter 7). This study aimed to control the swelling and mechanical properties of the hydrogels through variation in composition and to elucidate the role of heparin on chondrocyte proliferation, differentiation and matrix production.

In Chapter 8 injectable biodegradable hydrogels based on biomimetic hyaluronic aciddextran conjugates are reported. To mimic the natural cartilage environment, the macromer was designed to be structurally mimicking the proteoglycans present in the ECM. Cell viability and chondrogenesis within these biomimetic hydrogels was evaluated by Livedead assay, immunofluorescent staining and biochemical analysis.

\subsection{References}

[1] Adkisson DH, Milliman CL, Kizer N. Method for Chondrocyte Expansion with Phenotype Retention. US 2008/0081369 A1, April 3, 2008.

[2] Barrere F, Mahmood TA, de Groot K, van Blitterswijk CA. Advanced Biomaterials for Skeletal Tissue Regeneration: Instructive and Smart Functions. Mater. Sci. Eng. R. 2008;59: 38-71.

[3] Lu L, Valenzuela RG, Yaszemski MJ. Articular Cartilage Tissue Engineering. ebiomed: J. Regen. Med. 2000;1: 99.

[4] Beris AE, Lykissas MG, Papageorgiou CD, Georgoulis AD. Advances in Articular Cartilage Repair. Injury 2005;36: S14-S23.

[5] Coutts R, Healey R, Ostrander R, Sah R, Goomer RA, D. Matrices for Cartilage Repair. Clin. Orthop. Relat. Res. 2001;S391: S271-279

[6] Woodfield TBF. Cartilage Tissue Engineering: Instructing Cell-Based Tissue Repair through Scaffold Design. University of Twente, 2004.

[7] Minas T, Nehrer S. Current Concepts in the Treatment of Articular Cartilage Defects. Orthop. 1997;20: 525-538.

[8] Langer R, Vacanti JP. Tissue Engineering. Science 1993;260: 920-926.

[9] Frenkel SR, Di Cesare PE. Scaffolds for Articular Cartilage Repair. Ann. Biomed. Eng. 2004;32: 26-34.

[10] Hunziker EB, Quinn TM, Hauselmann HJ. Quantitative Structural Organization of Normal Adult Human Articular Cartilage. Osteoarthr. Cartilage 2002;10: 564-572.

[11] Risbud MV, Sittinger M. Tissue Engineering: Advances in in Vitro Cartilage Generation. Trends Biotechnol. 2002;20: 351-356.

[12] Temenoff JS, Mikos AG. Review: Tissue Engineering for Regeneration of Articular Cartilage. Biomaterials 2000;21: 431-440.

[13] Hennink WE, van Nostrum CF. Novel Crosslinking Methods to Design Hydrogels. Adv. Drug Deliver. Rev. 2002;54: 13-36.

[14] Kobayashi S, Uyama H, Kimura S. Enzymatic Polymerization. Chem. Rev. 2001;101: 3793-3818.

[15] Sofia SJ, Singh A, Kaplan DL. Peroxidase-Catalyzed Crosslinking of Functionalized Polyaspartic Acid Polymers. J. Macromol. Sci. 2002;A39: 1151-1181.

[16] Fukuoka T, Uyama H, Kobayashi S. Polymerization of Polyfunctional Macromolecules: Synthesis of a New Class of High Molecular Weight Poly(amino 
acid)s by Oxidative Coupling of Phenol-Containing Precursor Polymers. Biomacromolecules 2005;5: 977-983.

[17] Jin R, Hiemstra C, Zhong Z, Feijen J. Enzyme-Mediated Fast in Situ Formation of Hydrogels from Dextran-Tyramine Conjugates. Biomaterials 2007;28: 2791-2800.

[18] Jin R, Moreira Teixeira LS, Dijkstra PJ, Karperien M, Zhong Z, Feijen J. Fast inSitu Formation of Dextran-Tyramine Hydrogels for in Vitro Chondrocyte Culturing. J. Control. Release 2008;132: e24-e26.

[19] Jin R, Moreira Teixeira LS, Dijkstra PJ, Karperien M, van Blitterswijk CA, Zhong $\mathrm{ZY}$, and Feijen J. Injectable Chitosan-Based Hydrogels for Cartilage Tissue Engineering. Biomaterials 2009;30: 2544-2551. 


\section{Chapter 2}

\section{Injectable Hydrogels for Cartilage Tissue Engineering}

\subsection{Introduction}

Tissue engineering (TE) represents a promising method to regenerate damaged cartilage tissues [1]. The concept of tissue engineering was proposed by Langer et al. in the early 1990's as “the application of the principles and methods of engineering and the life sciences toward the fundamental understanding of structure-function relationships in normal and pathological mammalian tissues and the development of biological substitutes that restore, maintain or improve tissue function" [1]. This strategy of tissue engineering generally involves the incorporation of the appropriate cells into a tissue-engineered scaffold, which serves as a temporary extracellular matrix (ECM) until cells produce the matrix in time, and finally newly formed tissue replaces the scaffold. The scaffold will play an important role in regulating cell migration, proliferation and ECM production $[2,3]$. The scaffolds should provide physical and biological properties such as sufficient mechanical strength, preventing cells from floating out of the defect, facilitating cell proliferation, cell signaling and stimulating matrix production by cells. Therefore, the macromolecular engineering of scaffolds is an essential requisite for successful cartilage tissue engineering.

There have been significant research efforts in the development of scaffolds over the past decade. The scaffolds commonly involved in tissue engineering are either solid-type substances like foams, meshes and sponges, or gel-like materials. Among these, hydrogels are one form of scaffolds that have been frequently applied in tissue engineering. The use of hydrogels can be traced back to 1960 when Wichterle and Lim first reported on crosslinked hydroxyethyl methacrylate (HEMA) hydrogels for biomedical use, in particular, as soft contact lenses [4]. Many hydrogels investigated so far were found to have desired traits such as high and tissue-like water content as well as excellent permeability for influx of nutrients and excretion of metabolites. Besides, it has been pointed out that hydrogels, unlike solid-type scaffolds, such as fibrous meshes and porous sponges, encapsulate and retain chondrocytes in a 3-D environment surrounded by gel matrix rather than promote attachment, preventing potential phenotype dedifferentiation [5]. These features make hydrogels especially suitable as engineered scaffolds for cartilage tissue engineering.

According to their handling properties, hydrogels can be categorized into preformed and injectable hydrogels (Figure 2.1). The preformed hydrogels are processed in vitro prior to 
cell seeding and in vivo implantation. On the other hand, injectable hydrogels can be implanted into the body in the form of a liquid which gels in situ. Importantly, cells and growth factors can be incorporated and suspended in the gel precursors prior to gelation [6], enabling homogenous cell seeding and easy implantation.

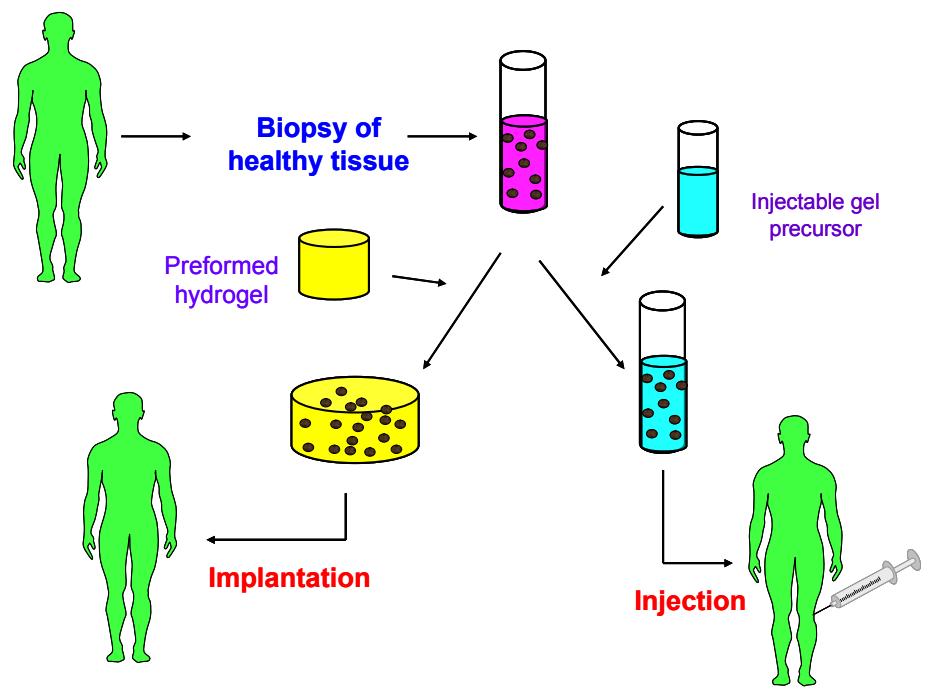

Figure 2.1. TE strategies using preformed and injectable hydrogels in combination with cell.

In this chapter, we focus on the design of injectable hydrogels and their applications in cartilage tissue engineering. The criteria for the design of injectable hydrogels in cartilage tissue engineering are outlined and the strategies for preparation of hydrogels are described.

\subsection{Hydrogel design}

Important requisites have to be met in the development of injectable hydrogels as scaffolds for cartilage tissue engineering. These requisites include biocompatibility, biodegradability, mechanical strength and multiple biofunctionality.

Biocompatible hydrogels should not induce an immune response and severe inflammation and have a negligible or a minor influence (e.g. temperature, $\mathrm{pH}$ value) on the surrounding tissue and cells inside the gel should survive and remain bioactive. Another requisite is that hydrogel formation takes place under physiological conditions at a temperature of $37{ }^{\circ} \mathrm{C}$ and a physiological $\mathrm{pH}$ of about 7.4. Organic solvents and harsh gelation conditions like strong bases or acids have to be avoided. Moreover, during the tissue regeneration process, degradation products leaching from or generated in the hydrogels should not accumulate in the body; instead they should be readily metabolized or excreted from the body. 
Biodegradability of hydrogels is another requisite for TE scaffolds. Biodegradable hydrogels may function as a temporary ECM until they are completely replaced by newly formed tissue. Degradation properties of hydrogels should be optimized to provide good cell migration [7] and to enable homogeneous ECM distribution [8-13]. Degradable hydrogels are generally derived from natural or synthetic biodegradable polymers or absorbable polymers [14]. Typical examples are hydrogels containing hyaluronic acid (HA) [15], collagen [16], chitosan [17] and poly(lactic acid), (PLA) [9, 10]. Degradation of hydrogels will generally lead to a loss in mechanical strength. Hence, the degradation rate of the gels needs to be carefully adjusted to match the rate of tissue formation. This rate can be controlled by the molecular weight of the polymers used, the crosslinking density of the gels and the introduction of hydrolytically unstable groups.

In the design of hydrogels as tissue-engineered scaffolds for cartilage repair, adequate mechanical support is a critical requirement. The native cartilage has a compressive modulus of approximately $0.79 \mathrm{MPa}$, a shear modulus of $0.68 \mathrm{MPa}$, and a tensile modulus in the range of 0.32 to $10.2 \mathrm{MPa}$ [18]. The scaffold should be mechanically strong in order to protect the seeded cells and the developing tissue as well as to withstand the physiologic load [19]. At the cellular scale, the mechanical properties of a scaffold are highly potent regulators of cell migration and their phenotype [20]. Recent work by Engler et al. showed that mesenchymal stem cells differentiated into various cell types depending on the elasticity of the polyacrylamide gel substrates on which they were cultured [21]. The moduli of hydrogels generally increase with increasing crosslinking density. However, an increase in mechanical moduli can result in decreased cell metabolic activity, giving an inferior biocompatibility [22].

Biofunctionality of hydrogels is essential to guide cellular behavior such as proliferation, differentiation and matrix production. It has been shown that an on-demand biofunctionality can be obtained by incorporation of growth factors into hydrogels to control cellular behavior [23]. In another approach hydrogels which do not contain growth factors are being designed, which structurally and functionally resemble the natural ECM. A straightforward method is the use of natural ECM components such as collagen, hyaluronic acid and fibrin to create hybrid hydrogels that are biocompatible and can provide appropriate signals to regulate cell behavior [24]. Besides, hydrogels modified with bioactive molecules can also elicit specific cellular functions and direct cell-cell and cellmaterials interactions. For example, hydrogels can promote cell adhesion and migration when they contain long chain ECM proteins such as fibronectin (FN) [25] and laminin (LN) [26]. Recently, short peptide sequences have been covalently conjugated to hydrogels, including Arg-Gly-Asp (RGD), Ile-Lys-Val-Ala-Val (IKVAV) and Tyr-Ile-Gly-Ser-Arg 
(YIGSR) since they are identified as dominant segments in receptor binding and host cell attachment [27].

\subsection{Crosslinking methods}

Hydrogels can be classified into chemical and physical gels according to their crosslinks present. In this section, we summarize various crosslinking approaches to prepare injectable hydrogels and discuss specific properties of the hydrogels, such as gelation time, mechanical modulus and biocompatibility, which are important for cartilage tissue engineering applications.

\subsubsection{Chemical crosslinking}

\subsubsection{Crosslinking by radical polymerization}<smiles>C=CC(=O)OC(C)C(=O)OCCC(C)C(=O)OC(C)C(=O)OC(C)C=C</smiles>

Poly(ethylene glycol)-co-oligo(lactide) acrylate<smiles>[R]OC(CC(O)CC)CC(O)CC(C)O</smiles><smiles>[R]CC(=O)CCC(=O)OCCOC(=O)CCC(=O)OCCOC(=O)C=C</smiles>

Poly(vinyl alcohol) with ester-containing acrylate groups

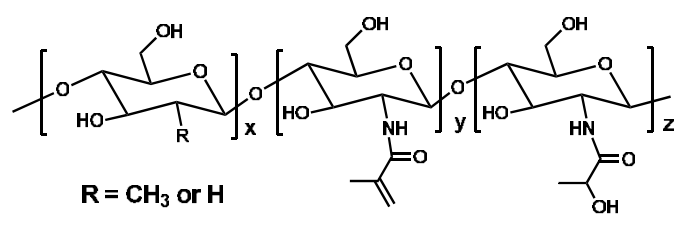

Methacrylated lactic acid-modified chitosan<smiles>CC(=O)COC(=O)/C=C/C(=O)OCCOCCO</smiles>

Poly(propylene fumarate-co-ethylene glycol)<smiles>C=CC(=O)OCC(=O)OC1C2CC3CC2CC1C3OC(C)(C)C</smiles>

Acrylated dextran

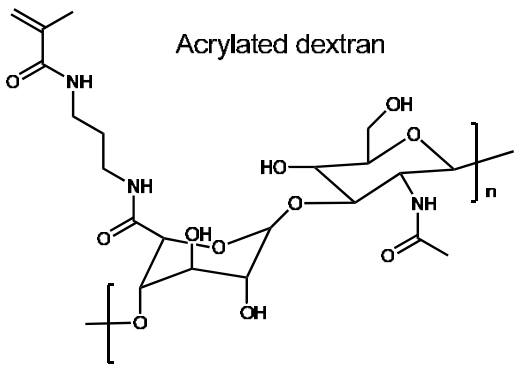

Methacrylated hyaluronic acid

Figure 2.2. Chemical structures of macromers used for the preparation of hydrogels by radical polymerization.

Free radical polymerization has been frequently used to prepare injectable hydrogels for tissue engineering applications [28, 29]. Vinyl-bearing macromers can be polymerized to 
form hydrogels using redox- or thermally-initiated polymerization as well as photopolymerization. Chemical structures of commonly used macromers, such as synthetic polymers like poly(vinyl alcohol) (PVA) and poly(ethylene glycol) (PEG) [8-10, 30, 31] and natural polymers like hyaluronic acid [32], chitosan [33] and dextran [34], are listed in Figure 2.2. The preparation of hydrogels by photo-initiation has the advantage of fast crosslinking rates upon exposure to UV irradiation. However, the disadvantage is that exposure of cells with UV at high intensity or for long times may have an adverse effect on cellular metabolic activity [35]. Moreover, local heat release during the crosslinking process may give rise to cellular necrosis [36]. So, the intensity of the UV light is limited to approximately $5-10 \mathrm{~mW} / \mathrm{cm}^{2}$ in order to prevent cell damage [37]. Besides, UV light has a limited penetration depth in tissues and polymerization in vivo is hampered due to the absorption of UV-light by the skin (>99\%) [37]. Alternatively, thermal- or redox- initiated polymerization can be applied. Several groups reported on hydrogels for tissue engineering using the redox-initiator N,N,N'N'-tetramethylene diamine (TEMED) and ammonium peroxydisulfate (APS) [17, 38]. Increasing the concentration of the initiator resulted in reduced gelation times and enhanced mechanical properties. However, a concomitant high cytotoxicity with low cell viability $(<30 \%)$ at high concentrations of initiator $(10 \mathrm{mM})$ was observed after a short cell culturing time of 4 days [17]. Therefore, a suitable method of free radical polymerization is necessary to arrive at appropriate hydrogels for cartilage tissue engineering.

\subsubsection{Crosslinking reactions through functional groups}

Injectable hydrogels can be prepared via reactions between functional groups present in the water-soluble monomers or macromonomers. Typical reactions are Schiff-base formation, Michael-type additions, peptide ligation as well as "click" chemistry by cycloaddition reactions (Table 2.1).

Schiff-base formation between an aldehyde and an amino group is often used to prepare crosslinked hydrogels [39, 40]. Glutaraldehyde as a crosslinker in this respect was frequently used (Figure 2.3a). However, glutaraldehyde is toxic even at low concentrations and may leach out into the body during matrix degradation, inhibiting cell growth [41]. To avoid the toxicity associated with the use of glutaraldehyde, aldehyde-containing compounds are coupled to a non-toxic polymer such as hyaluronic acid [42] (Figure 2.3b). Besides, reactive aldehyde groups can also be generated by oxidation of a polysaccharide such as dextran [39], hyaluronic acid [40] and alginate [43]. Since Schiff bases are prone to degradation via hydrolysis of imine bonds at low $\mathrm{pH}$ values. Addition of basic components like borax may facilitate Schiff-base formation, yielding relatively stable hydrogels with fast gelation [43]. 
Table 2.1. Summary of crosslinking methods via reactions between functional groups

\begin{tabular}{|c|c|l|l|}
\hline $\begin{array}{c}\text { Chemical } \\
\text { reactions }\end{array}$ & $\begin{array}{c}\text { Typical } \\
\text { functional } \\
\text { groups }\end{array}$ & \multicolumn{1}{|c|}{ Advantages } & \multicolumn{1}{c|}{ Limitations } \\
\hline $\begin{array}{c}\text { Schiff-base } \\
\text { formation }\end{array}$ & $\begin{array}{c}\text { Amine/ } \\
\text { hydrazide \& } \\
\text { aldehyde }\end{array}$ & $\begin{array}{l}\text { Easy incorporation } \\
\text { and crosslinking of } \\
\text { amine-bearing } \\
\text { peptides and proteins }\end{array}$ & $\begin{array}{l}\text { Aldehyde may induce side } \\
\text { reactions in the body. Schiff- } \\
\text { base linkages are usually } \\
\text { unstable at low pH. }\end{array}$ \\
\hline $\begin{array}{c}\text { Michael- } \\
\text { type } \\
\text { addition }\end{array}$ & $\begin{array}{c}\text { Acrylate/vinyl } \\
\text { sulfone \& } \\
\text { thiol/amine }\end{array}$ & $\begin{array}{l}\text { Mild reaction } \\
\text { conditions, tunable } \\
\text { properties, suitable for } \\
\text { cell encapsulation }\end{array}$ & $\begin{array}{l}\text { Unreacted thiol groups may } \\
\text { influence cell viability }\end{array}$ \\
\hline $\begin{array}{c}\text { Peptide } \\
\text { ligation }\end{array}$ & $\begin{array}{c}\text { N-terminal } \\
\text { cystein \& } \\
\text { aldehyde }\end{array}$ & $\begin{array}{l}\text { High substrate } \\
\text { specificity, efficient } \\
\text { crosslinking, mild } \\
\text { reaction conditions }\end{array}$ & $\begin{array}{l}\text { Complicated synthesis } \\
\text { procedures of peptides due to } \\
\text { protection and deprotection } \\
\text { steps. }\end{array}$ \\
\hline $\begin{array}{c}\text { Click } \\
\text { chemistry }\end{array}$ & $\begin{array}{c}\text { Azide \& } \\
\text { alkyne }\end{array}$ & $\begin{array}{l}\text { An efficient, high- } \\
\text { yield reaction }\end{array}$ & $\begin{array}{l}\text { Involvement of catalytic } \\
\text { amounts of potentially toxic Cu }\end{array}$ \\
\hline
\end{tabular}

\section{Polymer backbone}

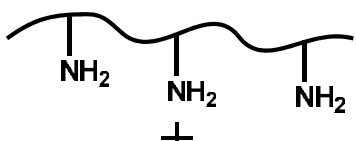<smiles>O=CCCCC=O</smiles>

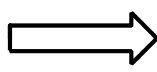

(a)

Glutaraldehyde

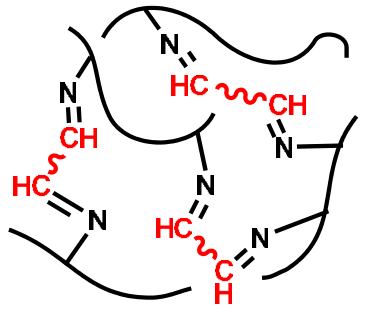

(b)
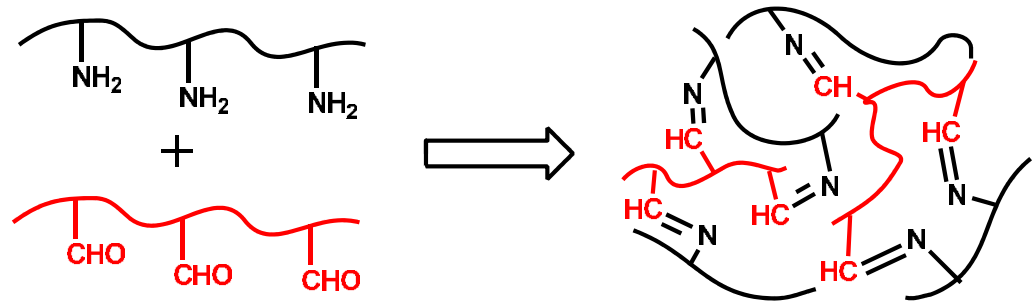

Figure 2.3. Aldehyde/amine-containing polymers to prepare hydrogels via Schiff base formation.

The Michael addition reaction between a nucleophile (e.g., an amine or a thiol group) and an electrophile (vinyl/acrylate/maleimide group) is another approach for preparation of injectable hydrogels (Figure 2.4). Hydrogels can be readily formed simply by mixing two 
polymers bearing nucleophilic and electrophilic groups. Many polymers such as hyaluronic acid [44-46], dextran [47, 48], PVA [49] and PEG [46, 50, 51] were conjugated with these groups to prepare hydrogels via Michael type addition reactions. Using this type of reaction thiol-bearing functional peptides (e.g. containing cystein) were also incorporated to yield biofunctional hydrogels, enhancing cell adhesion or matrix production [13, 51, 52]. Generally, the hydrogels that are prepared via Michael type addition reactions have gelation times of less than $0.5 \mathrm{~min}$ to about $1 \mathrm{~h}$, and moderate mechanical strength and their properties can be adjusted by tuning the reactivity of functional groups and crosslinking density [46-49]. Since Michael addition reactions generally take place at mild conditions, the reaction does not seriously influence cell viability during the hydrogel formation process. It was reported that incorporated cells in these type of hydrogels generally remained viable and survived from days to months, depending on the applied materials [6, 52]. However, some caution has to be taken in the use of an excess of thiol functional groups for unreacted thiols may cause cell death [53].
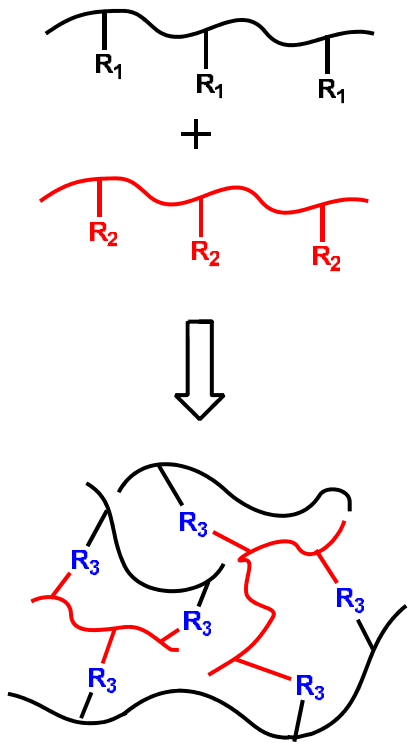
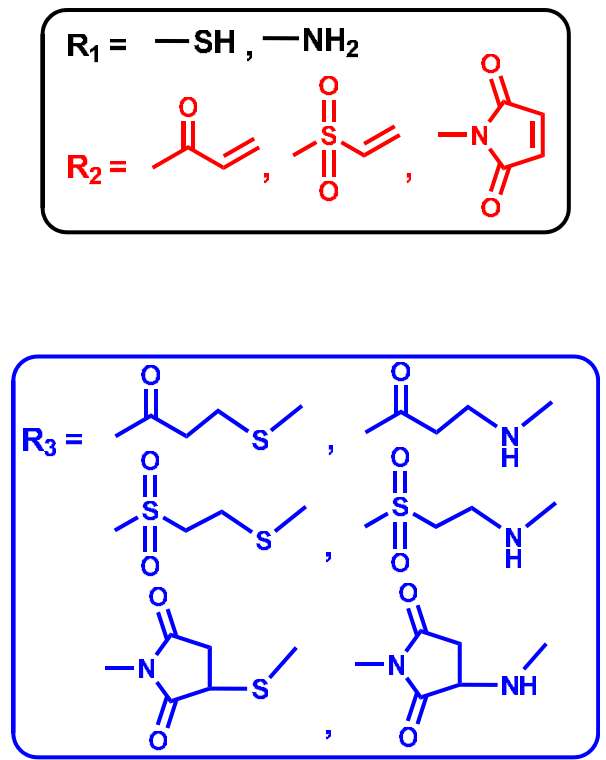

Figure 2.4. Strategy of injectable hydrogel preparation via Michael-type additions

Chemical peptide ligation is a particularly appealing approach for the synthesis of proteins and enzymes [54]. The reaction is based on the chemoselective reaction and ligation of two unprotected peptide segments. Recently, peptide ligation has been employed as a novel method to design injectable hydrogels. Wathier et al. described the preparation of hydrogels based on a reaction, in which aldehyde groups of PEG derivatives and $\mathrm{NH}_{2}-$ 
terminal cystein moieties of peptide dendrons were reacted to form thiazolidine rings (Figure 2.5a) [55]. The reactions were carried out under mild conditions and gelation took place within a few minutes. However, these hydrogels were intact for short periods of time (about 1 week) due to the reversible thiazolidine ring formation. Relatively stable hydrogels were prepared using PEG with end-capped ester-aldehyde groups instead of aldehyde groups via pseudoproline ring formation (Figure 2.5b) [56]. The hydrogels retained their shape and size with less than $10 \%$ weight loss for more than 6 months.

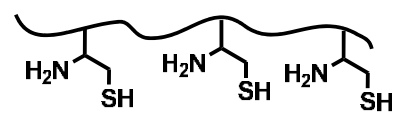

$+$<smiles>O=CCCOCCOCCC=O</smiles>

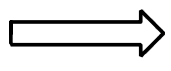

(a)<smiles>[13CH3]CC(N)CS</smiles><smiles>C=C=C</smiles>

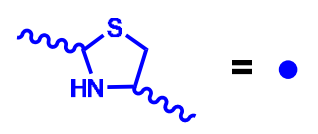

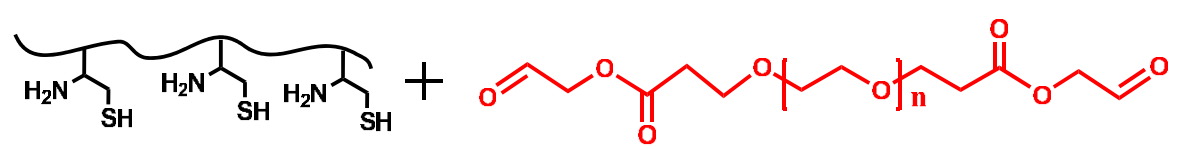

(b)

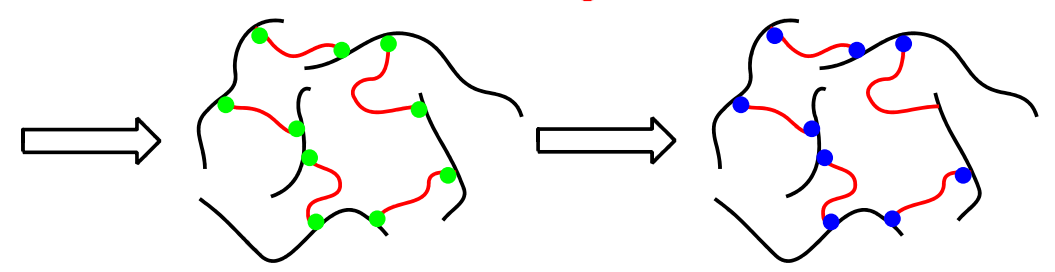<smiles>CC(=O)OCC(=O)[IH]C(C)(C)C</smiles>

Figure 2.5. Preparation of hydrogels via peptide ligation

Recently, attention has been drawn to "Click chemistry", a highly efficient, quantitative reaction [57]. This reaction can be carried out at physiological temperatures and $\mathrm{pH}$ by the copper-catalyzed 1,3-dipolar cyclo-addition of azide and alkyne moieties (Figure 2.6). A few attempts have been made to use click chemistry to synthesize polymer networks from functionalized synthetic polymers such as PVA [58], PEG [59], $\operatorname{poly}(N-$ 
isopropylacrylamide-co-hydroxyethyl methacrylate) (P(NIPAAm-co-HEMA)) [60] as well as natural polymers like hyaluronic acid [61]. It was shown that a low degree of substitution of polymers with active pendant groups was able to induce a fast gelation [58]. Although copper-catalyzed click chemistry could be performed inside living cells [62], copper is known to be toxic to most bacterial and mammalian cells [63]. The removal of copper catalyst from hydrogels may be a difficulty. Recently, efforts have been made in the search of copper-free click reactions as an alternative to the conventional copper-catalyzed click chemistry [63]. This could offer a new route to prepare hydrogels for tissue engineering.
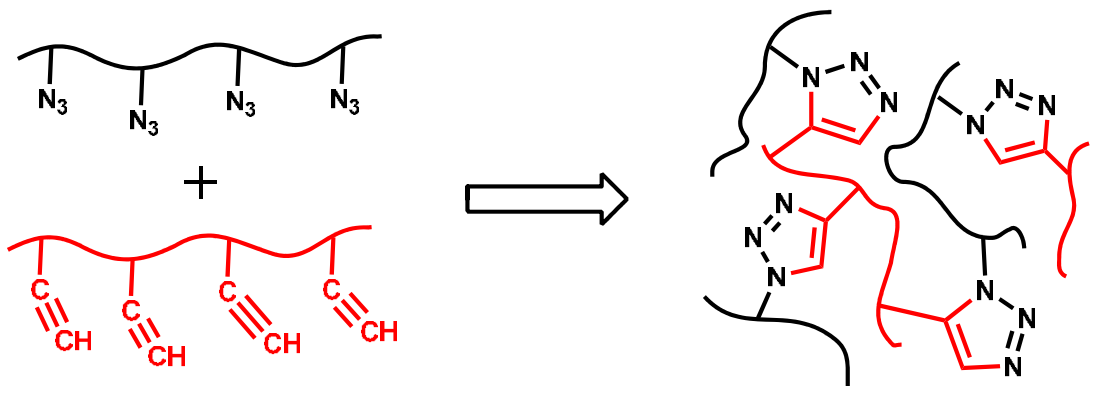

Figure 2.6. Preparation of hydrogels via click chemistry

\subsubsection{Crosslinking by enzymatic reactions}

An interesting and biologically compatible approach in generating injectable hydrogels is to take advantage of enzymes in the crosslinking reaction. Enzymes often exhibit a high degree of substrate specificity, potentially avoiding side reactions during crosslinking. Considering this advantage, it is possible to control and predict the gelation kinetics and increase the overall crosslinking rate by the concentration of the enzyme. One of the typical enzymes capable of catalyzing crosslinking reactions is transglutaminase (TG), a calciumdependent enzyme which appears to serve various roles such as crosslinking proteins in vivo [64]. TG-catalyzed covalent crosslinking occurs via the formation of an amide linkage between the carboxamide and primary amine residues in polymers or polypeptides (Figure 2.7a) [65]. Sperinde et al. first explored the use of TG in hydrogel formation and successful gelation stimulated researchers to study a variety of systems including PEG-peptide or polypeptide hydrogels [7, 64, 66-69]. It was shown that gelation times can be shortened to a few minutes by rationally designing peptide sequences with a significant increase in substrate specificity [69]. In addition, these hydrogels demonstrated good adhesive properties which make them applicable as surgical tissue adhesives [7]. Another enzyme that was recently explored for hydrogel formation is horseradish peroxidase (HRP) (Figure 2.7b). HRP is a single-chain $\beta$-type hemoprotein that catalyzes the coupling of phenols or 
aniline derivatives in the presence of hydrogen peroxide [70]. Kaplan et al. showed that poly(aspartic acid)s conjugated with phenol groups can be crosslinked with HRP and $\mathrm{H}_{2} \mathrm{O}_{2}$ to give hydrogels [71]. Similar approaches have been adopted to design hydrogels based on hyaluronic acid [6, 72], cellulose [73] and alginate [74]. In this thesis, HRP-mediated crosslinking of injectable hydrogels based on dextran, chitosan, hyaluronic acid as well as heparin can be found in Chapters 4-8.

(a)

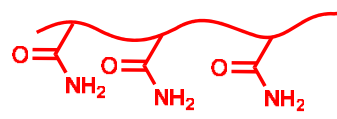

$+$

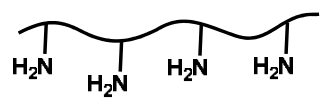

transglutaminase
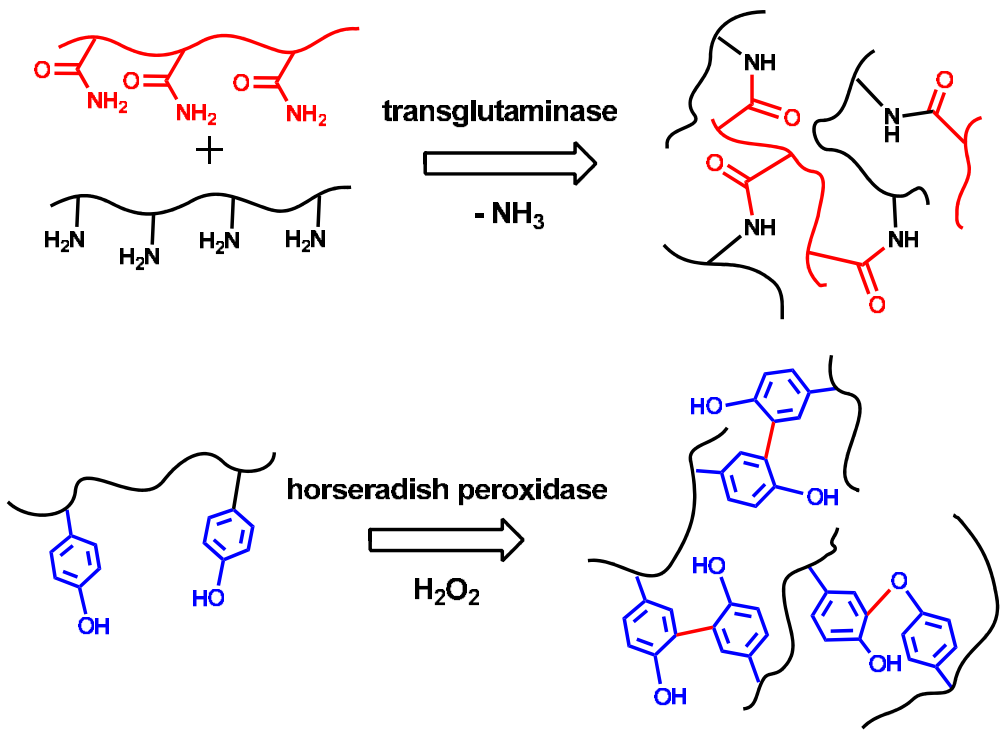

(b)

Figure 2.7. Enzymatic crosslinking of (a) poly(ethylene glycol) or polypeptide conjugates or (b) polysaccharide conjugates.

\subsubsection{Physical crosslinking}

\subsubsection{Crosslinking by stereocomplexation}

Enantiomeric mixtures of polylactides (D- and L-PLA) co-crystallize into a stereocomplex [75, 76] and were used in the design of injectable hydrogels. Hydrogel formation occurs by mixing two water-soluble polymers containing PLLA and PDLA blocks [77]. For example, Feijen and coworkers reported on stereocomplexed hydrogels based on PEG-PLLA and PEG-PDLA block copolymers [77-79]. Generally, hydrogels based on multi-arm block PEG-PLA copolymers show shorter gelation times and higher moduli than the triblock PEG-PLA copolymers (Figure 2.8) [78]. In another study, Hennink and coworkers reported on the research of stereocomplexed hydrogels based on dextran grafted with monodisperse L-lactic acid and D-lactic acid oligomers, respectively. At least eleven lactic acid units in the grafts appeared necessary for hydrogel formation $[80,81]$. 

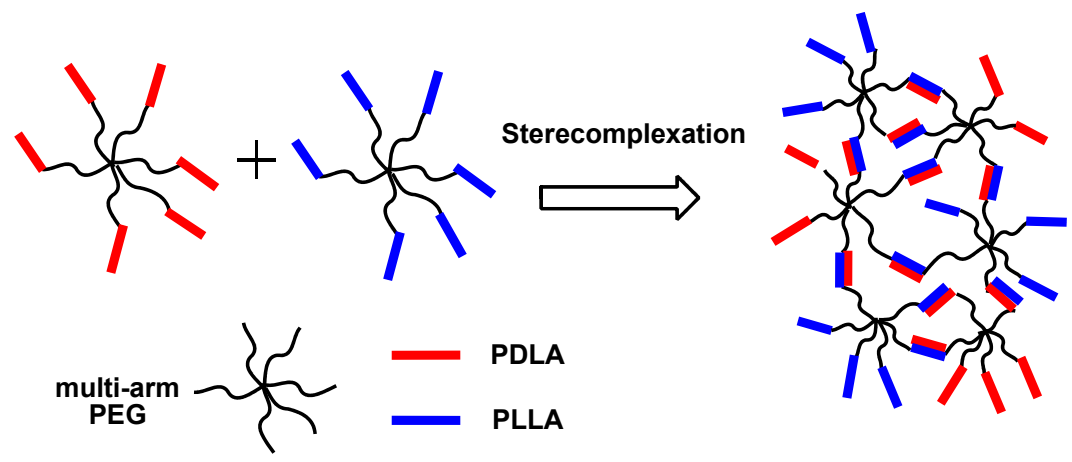

Figure 2.8. Stereocomplexed hydrogels based on PEG-PLA star block copolymers.

\subsubsection{Thermo-gelation}

Thermo-sensitive hydrogels have been studied for many years [82]. The process is triggered by hydrophobic interactions upon a change in temperature [41]. Thermosensitive hydrogels based on poly(ethylene oxide)-poly(propylene oxide)-poly(ethylene oxide) (PEO-PPO-PEO, known as Pluronics) and poly(N-isopropylacrylamide) (PNIPAAm) have been extensively studied. However, non-degradability and potential cytotoxicity of these gels limit their applications in tissue engineering. For example, it was shown that a significant decrease in cell viability of HepG2 cells in a 10\% (w/w) Pluronic F127 solution was evident. Cell encapsulation in F127 hydrogels at concentrations ranging from 15 to $20 \%(\mathrm{w} / \mathrm{w})$ resulted in complete cell death within 5 days [83]. Alternatively, biodegradable thermo-sensitive hydrogels such as block or graft copolymer containing hydrophilic PEO moieties and hydrophobic PLA moieties have low cytotoxicity [84, 85]. In another approach, thermosensitive biodegradable gels were prepared from naturally occurring polymers such as gelatin and agarose. Besides, water-soluble polymers like polysaccharides can be modified with a hydrophobic moiety to prepare physical hydrogels. A variety of temperature-sensitive hydrogel systems are described in literature and the reader is referred to some recent reviews [82, 86-88].

\subsubsection{Crosslinking by self assembly}

Supramolecular self-assembly is a powerful concept in the design of injectable hydrogels. The coiled-coil, one of the basic folding patterns of native proteins, has been utilized to design physically crosslinked hydrogels. Gelation is triggered by the formation of coiledcoils, which takes place when protein folding domains consisting of two or more helices wind together to form a superhelix [89]. Kopeček et al. developed a series of selfassembled hydrogels containing coiled-coil protein motifs. In these systems, coiled-coil 
protein motifs were either non-covalently or covalently grafted to a synthetic N-(2hydroxypropyl)methacrylamide (HPMA) copolymer backbone, resulting in hybrid hydrogels (Figure 2.9) [90-93]. The gelation process was influenced by the length and the number of coiled-coil grafts per chain. The results suggested that at least four heptads were needed to achieve hydrogel formation and gelation occurred in time periods ranging from a few minutes to several days [91]. Moreover, by changing the structural specificity of coiled-coils, gelation in PBS at concentrations as low as $0.1 \mathrm{wt} \%$ appeared possible [90]. In similar approaches, hydrogels were prepared from block polypeptides [94-97]. The gelation process of hydrogels from polypeptide amphiphiles depended not only on the overall amphiphilic nature of the polypeptides, but also on the chain conformation ( $\alpha$-helix, $\beta$ strand, or random coil) [96]. The thermal stability and self-assembling properties of these hydrogels are related to hydrophobic and electrostatic interactions, which can be controlled by manipulating the amino acid sequences and block length of the coiled-coil domains [94, 95].
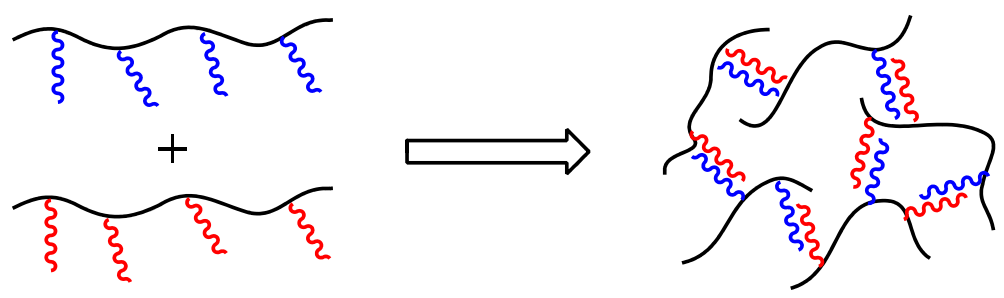

Figure 2.9. Hydrogel formation through coiled-coil association.

\subsubsection{Crosslinking by inclusion complexation}

Inclusion complexes between cyclodextrin (CD) and guest molecules represent a type of physical crosslinking that was exploited for network formation. Cyclodextrins are cyclic oligosaccharides linked by $\alpha$-1,4-glucosidic linkages. The three subtypes, $\alpha-, \beta$ - and $\gamma$-CDs consisting of six, seven and eight glucopyranose units, respectively, have a relatively hydrophobic interior cavity and a relatively hydrophilic outer surface [98]. This important characteristic gives CDs the unique ability to form complexes in which lipophilic guest molecules are surrounded by the hydrophobic environment of the cavity. Hennink et al. recently reported PEG hydrogels based on inclusion complexes between $\beta$-CD and cholesterol linked to the end groups of PEG (Figure 2.10) [99]. The stability of the gels was influenced by temperature since they showed significantly lower storage moduli at $37{ }^{\circ} \mathrm{C}$ than at $4{ }^{\circ} \mathrm{C}$. Hydrogels formed by inclusion complexes between adamantyl-containing copolymers and CD dimers were described by Kretschmann et al. [100]. In addition to complexation with guest molecules, complex formation also takes place between $\mathrm{CD}$ and 
polymers such as poly( $\varepsilon$-caprolactone) (PCL) and PEG [101]. For example, $\alpha$-CDs were used to act as a gelator for the preparation of PLA-PEG-PLA and PEO-poly([R]-3hydroxybutyrate)-PEO (PEO-PHB-PEO) hydrogels, resulting in a rapid gelation [102, 103].
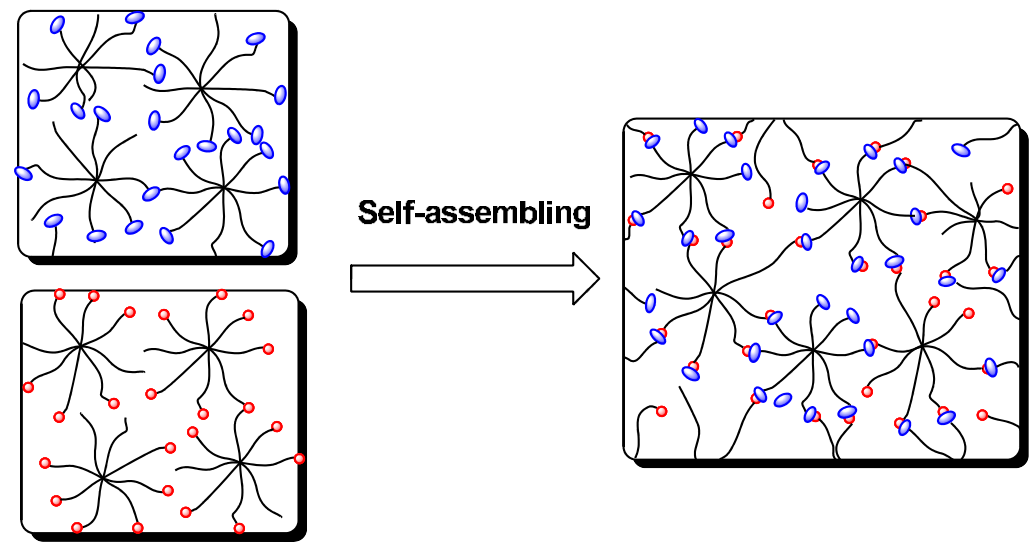

Figure 2.10. Hydrogel based on inclusion complexes between cholesterol (sphere) and $\alpha$-CD (ellipse) moieties coupled to star-shaped 8-arm PEG [99].

\subsubsection{Combining physical and chemical crosslinking}

Due to the reversible interactions present in physically in-situ formed hydrogels, they generally have lower mechanical properties than chemical hydrogels. Although mechanical properties can be improved through an increasing crosslinking density and molecular weight of polymers, also the viscosity of hydrogel precursors increases, leading to difficulties in handling. For chemically in-situ formed hydrogels, the mechanical properties are much higher, but their preparation usually involves biologically unfavorable compounds, which lead to nonbiocompatible materials. A proper combination of physical and chemical crosslinking offers the possibility of obtaining injectable materials with improved physical and mechanical properties without compromising biocompatibility. This idea has been demonstrated in the design of in situ forming hydrogels by combining stereocomplexation and photopolymerization (Figure 2.11) [37]. As an example, when an 8-arm PEG-PLLA and an 8-arm PEG-PDLLA were partly functionalized with methacrylate groups, stereocomplexed hydrogels were obtained upon mixing. These hydrogels can be postcrosslinked by UV-irradiation. These double-crosslinked hydrogels showed increased mechanical moduli and prolonged degradation times as compared to hydrogels that were formed only by stereocomplexation. Importantly, it was noted that the photopolymerization could take place at much lower initiator concentrations $(0.003 \mathrm{wt} \%)$ than conventional photocrosslinked systems $(0.05 \mathrm{wt} \%)$, which greatly reduced the possibility of substantial 
heating effects and damage to the cells. Similar approaches are combinations of thermogelation, inclusive complexation, stereocomplexation, ligand-receptor interaction, Michael addition reactions and/or photopolymerization [53, 102-112]. The advantages of combining two crosslinking mechanisms in one hydrogel system include fast gelation, controlled hydrogel properties and improved biocompatibility with cells and proteins.
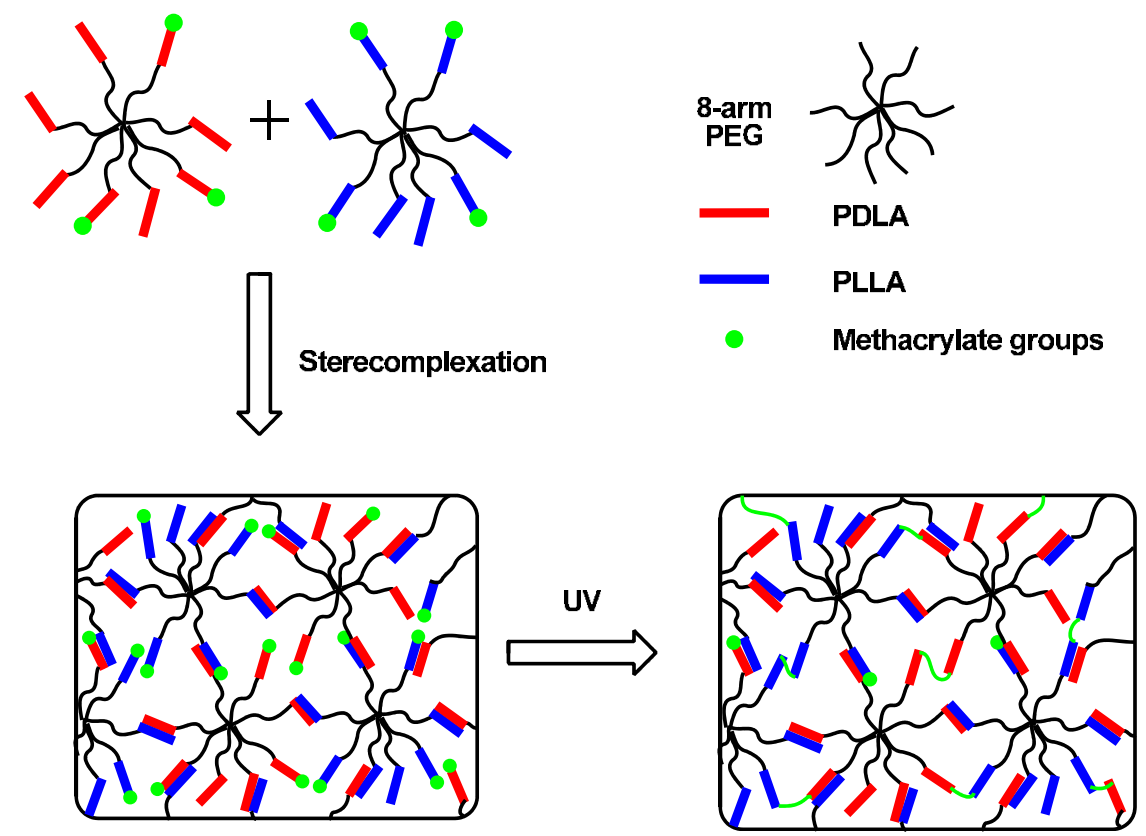

Figure 2.11. Schematic representation of the preparation of hydrogels based on methacrylated PEGPDLA and PEG-PLLA by stereocomplexation and post-UV irradiation [37].

\subsection{Applications in cartilage tissue engineering}

A Cartilage is a flexible connective tissue in which chondrocytes are sparsely distributed in an extracellular matrix rich in proteoglycans (PGs) and collagen fibers. Cartilage has a limited capacity for self-repair due to its avascular nature and the low mitotic activity of chondrocytes. The chondrocyte is the only cell type in articular cartilage and is responsible for the synthesis and maintenance of the resilient extracellular matrix. Chondrocytes readily undergo a dedifferentiation process during monolayer culturing and lose their phenotype. When cultured in hydrogels, dedifferentiated chondrocytes were found to be able to redifferentiate [113], as shown by their rounded morphology and the production of ECM molecules such as type II collagen and sulfated GAGs [22]. 


\subsubsection{Factors influencing cartilage regeneration}

Injectable hydrogels enable a perfect match with irregular cartilage defects and good alignment with the surrounding tissues. Therefore, they are promising materials that can function as scaffolds for chondrocyte culturing and cartilage regeneration. Several factors may influence the cell viability, recovery or the maintenance of the chondrocytic phenotype, and correspondingly play an important role in cartilage tissue engineering.

Chemical compositions of injectable hydrogels have been studied to explore their influence on cartilage tissue engineering. For example, Elisseeff et al. studied the cellular toxicity of transdermal photopolymerization on chondrocytes [114]. There was a significant decrease in the chondrocyte viability when the initiator concentration was increased from $0.012 \%$ to $0.036 \%$ or higher. In another study, Chung et al. noticed that a higher macromer concentration potentially compromised cell viability and growth [115]. Besides, a higher polymer concentration also resulted in a decreased accumulation of matrix components such as proteoglycans and collagen type II [116].

Recent studies showed that the degradation properties of the gels may have a significant influence on the matrix production and distribution as well. Degradable hydrogels induced a more homogenous distribution of GAG than non-degradable hydrogels [8]. However, in fast degrading hydrogels void spaces are generally present before new matrix formation has taken place $[9,10]$. Therefore, the degradation rate of hydrogels needs to be tailored by the combination of degradable main chain linkages and crosslinks [8-12].

Poor integration of neocartilage with native cartilage tissue is a major obstacle to cartilage regeneration. One main strategy is to take advantage of the presence of collagen type II in native cartilage that can chemically react with functional groups of the gel precursor molecules. For example, tissue-initiated polymerization was carried out between acrylate groups in polymerizable PEGDA macromers and tyrosine groups in collagen when exposed to light and an oxidative reagent like $\mathrm{H}_{2} \mathrm{O}_{2}$, resulting in improved tissue adhesion and integration [117] (Figure 2.12a). In another approach, adhesion and integration with native cartilage was achieved using aldehyde functionalized methacrylated chondroitin sulfate (CSMA) which was covalently attached to collagen via Schiff-base formation [118] (Figure 2.12b). The CSMA layer was further polymerized by photo-crosslinking of PEGDA to give a gel/cartilage integrated scaffold.

\subsubsection{Biofunctionality}

Understanding of the tissue structure and composition can lead to a rational material design, targeted towards mimicking the underlying biological cues and specific chemistry of cartilage. Generally, injectable hydrogels have been prepared from either synthetic polymers, or natural as well as naturally-derived polymers. However, synthetic polymers 
allow structural and compositional variations in the design of hydrogels, but mostly lack the necessary bio-functionality. Hydrogels prepared from natural polymers encounter problems in batch-to-batch differences. Proteins and peptides are easily denatured by proteases or elicit immune responses in the body. These opportunities and limitations have been a motivation to develop hybrid injectable hydrogels with tightly defined physical, chemical and biological properties by the combination of synthetic polymers with biomimetic natural polymers or peptide/protein sequences.

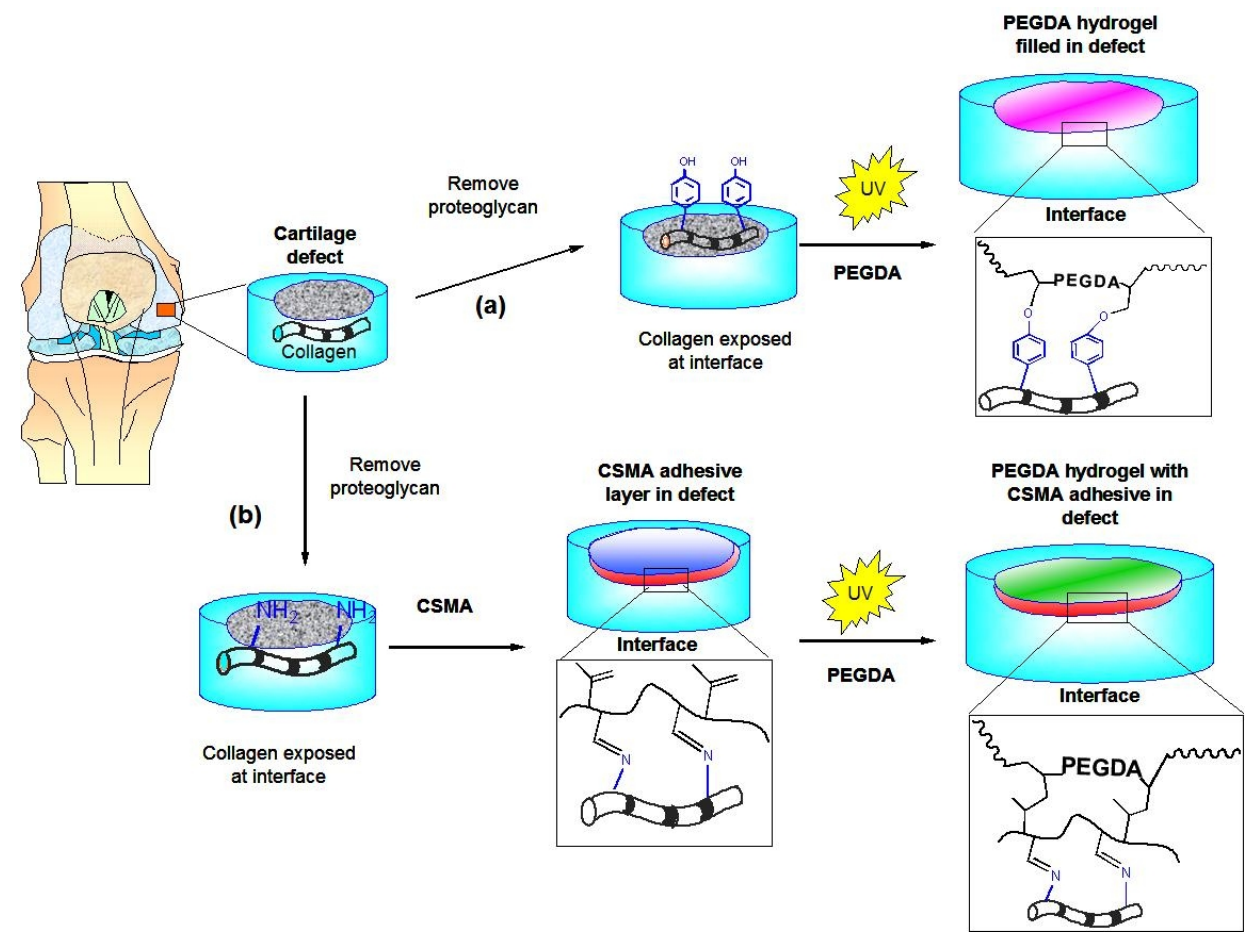

Figure 2.12. Strategy for hydrogel-cartilage integration by (a) tissue-initiated photopolymerization or (b) Schiff-base formation.

Figure 2.13 illustrates commonly used approaches to prepare hybrid injectable hydrogels. One approach is the preparation of hybrid copolymers and subsequent crosslinking (Figure 2.13a). For example, Lee et al. reported on the preparation of proteins (collagen, albumin and fibrinogen) conjugated with acrylated PEG and subsequent hydrogel formation by photopolymerization [119]. Enzymatic biodegradation and structural properties of these hydrogels were easily controlled. The modified protein maintained its cell-adhesive properties and supported proteolytic degradability based on the specific characteristics of the protein backbone. Another approach is the crosslinking of mixtures of natural polymers/peptides and synthetic polymers (Figure 2.13b). For example, proteolytically degradable hydrogels based on synthetic polymers and protease-sensitive peptide sequences 
were reported $[7,13,51,120,121]$. These peptide sequences are susceptible to local degradation upon excretion of cell-surface proteases and the degradation rate of the hydrogel can be tailored by enzyme specificity to the peptide sequences [121]. The advantage of hybrid injectable hydrogels is that multiple functionalities can be included in one gel system such as tunable physical properties, proteolytic degradation properties and enhanced extracellular matrix production. Table 2.2 lists typical examples of injectable hybrid hydrogels for cartilage tissue engineering applications.

Table 2.2. Typical examples of injectable hybrid hydrogels for cartilage applications.

\begin{tabular}{|c|c|l|c|}
\hline $\begin{array}{c}\text { Synthetic } \\
\text { polymer }\end{array}$ & $\begin{array}{c}\text { Biomimetic } \\
\text { natural moiety }\end{array}$ & \multicolumn{1}{|c|}{ Functionality } & Ref. \\
\hline PEG & RGD & $\begin{array}{l}\text { Promoting chondrocyte-specific } \\
\text { differentiation and morphogenesis } \\
\text { and cartilage tissue development }\end{array}$ & {$[122]$} \\
\hline PEG & $\begin{array}{c}\text { MMP-sensitive } \\
\text { peptide }\end{array}$ & $\begin{array}{l}\text { Proteolytic degradability, enhanced } \\
\text { gene expression of type II collagen } \\
\text { and aggrecan }\end{array}$ & {$[52]$} \\
\hline PVA or & $\begin{array}{c}\text { Chondroitin } \\
\text { sulfate }\end{array}$ & $\begin{array}{l}\text { Balance between modulus and } \\
\text { swelling of hydrogels, enhanced } \\
\text { matrix production }\end{array}$ & {$[30,123]$} \\
\hline PEG & $\begin{array}{c}\text { Collagen-mimic } \\
\text { peptide }\end{array}$ & $\begin{array}{l}\text { Retention of ECM production } \\
\text { inside hydrogel via collagen } \\
\text { binding, enhanced chondrogenesis }\end{array}$ & {$[119,124]$} \\
\hline $\begin{array}{c}\text { Pluronic } \\
\text { F127 }\end{array}$ & $\begin{array}{c}\text { Hyaluronic acid, } \\
\text { RGD }\end{array}$ & $\begin{array}{l}\text { Improved cellular adhesion and } \\
\text { proliferation, increased matrix } \\
\text { production }\end{array}$ & {$[125]$} \\
\hline
\end{tabular}

(a) Injectable hybrid hydrogels prepared from hybrid copolymers [119, 125, 126]

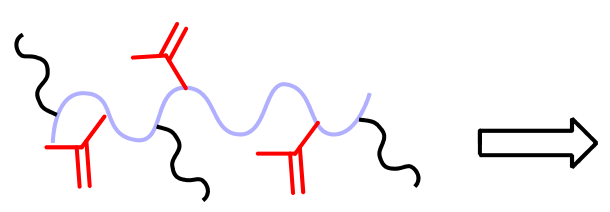

Methacrylated HA-g-Pluronic F127

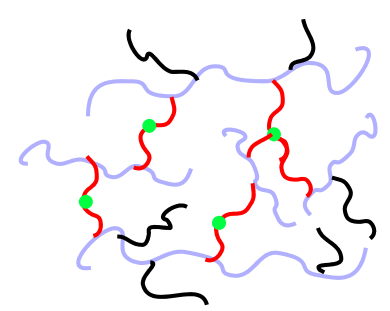

$=-\mathrm{CH}_{2} \mathrm{CH}\left(\mathrm{CH}_{3}\right)^{-}$

(Figure 2.13 continued) 
(Figure 2.13 continued)

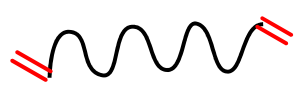

PEG diacrylate
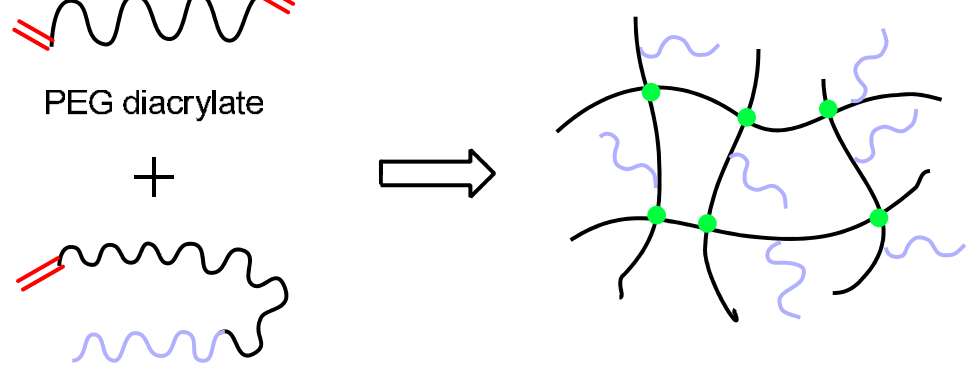

PEG-collagen mimic

peptide (CMP) acrylate

PEGylated collagen, fibrin, albumin

(b) Injectable hybrid hydrogels prepared from natural and synthetic polymers [52, 127]

$$
\text { NUN }
$$

PEG diacrylate

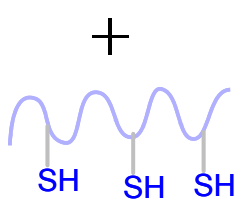

Thiolated heparin

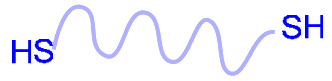

MMP-sensitive peptide
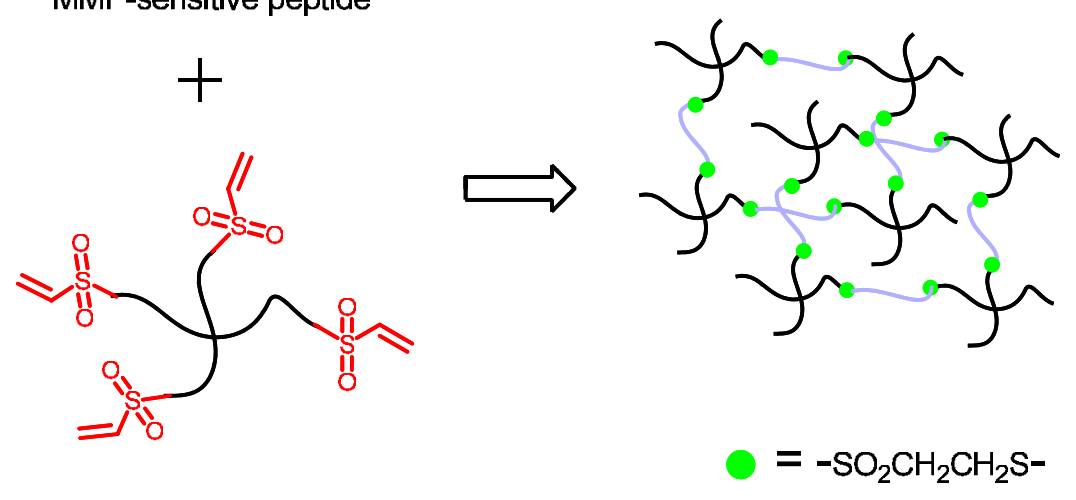

4-arm PEG vinyl sulfone

Figure 2.13. Commonly used approaches in the preparation of hybrid injectable hydrogels. 


\subsubsection{Growth factors}

During the cartilage regeneration process growth factors play a crucial role in regulating cellular proliferation, differentiation, migration, and gene expression. Besides, they have large influences on the communication between cells and their microenvironment. A number of growth factors have been studied and include bone morphogenetic protein (BMP), transforming growth factor (TGF), insulin-like growth factor (IGF) and basic fibroblast growth factor (bFGF). Their main functions in cartilage regeneration are summarized in Table 2.3. For example, the BMP family can stimulate mitosis and matrix production by chondrocytes and induce chondrogenesis of mesenchymal cells, triggering them to differentiate and maintain a chondrogenic phenotype [128, 129]. TGF- $\beta$ not only enhances chondrocyte proliferation, but also increases the synthesis of proteoglycans [65, $130]$.

Table 2.3. Delivery of growth factors using injectable hydrogels for cartilage regeneration

\begin{tabular}{|c|c|c|c|}
\hline Growth factor & Function & Hydrogel & Ref. \\
\hline BMP & $\begin{array}{l}\text { Inducing chondrogenesis; } \\
\text { Stimulating cartilage formation }\end{array}$ & Alginate & [131] \\
\hline TGF- $\beta$ & $\begin{array}{l}\text { Regulation of cell proliferation } \\
\text { and differentiation; Stimulating } \\
\text { production of proteoglycans and } \\
\text { other matrix components }\end{array}$ & OPF & [132] \\
\hline IGF & $\begin{array}{l}\text { Promotion of cartilage tissue } \\
\text { formation }\end{array}$ & PEODM & [133] \\
\hline bFGF & $\begin{array}{l}\text { Potent modulator of cell } \\
\text { proliferation, motility, } \\
\text { differentiation, and survival; } \\
\text { initiation of chondrogenesis }\end{array}$ & $\begin{array}{l}\text { P(NIPAAm- } \\
\text { co-AAc) }\end{array}$ & [134] \\
\hline
\end{tabular}

Direct administration of growth factors is commonly associated with problems such as a short biological half-life and easy diffusion. Injectable hydrogels offer significant opportunities for controlled local delivery of such biomolecules. These bioactive agents can be easily incorporated into hydrogels prior to gelation and their release kinetics can be adjusted on demand by the crosslinking density and stability of the networks. The disadvantages of in situ incorporation, however, is the potential damage of proteins during the gelation process [135] or the occurrence of an initial burst release [136]. To circumvent these disadvantages, growth factors can be incorporated into microparticles which can be 
added to the hydrogel precursor solutions (Figure 2.14b). Microparticles can be prepared either from synthetic polymers (e.g. PGA, PLA, and PLGA) or from natural polymers (e.g. gelatin) [130]. For example, Holland et al. reported on TGF- $\beta 1$-loaded-gelatin particles which were incorporated in oligo(poly(ethylene glycol) fumarate) hydrogels [137]. In vitro release experiments showed a suppressed burst release and prolonged delivery of TGF- $\beta 1$ [137]. Besides, when chondrocytes or MSCs were embedded, an increased cellular proliferation and enhanced chondrocyte-specific gene expression was observed for the hydrogels containing TGF-loaded-gelatin particles [65, 132].

(a)

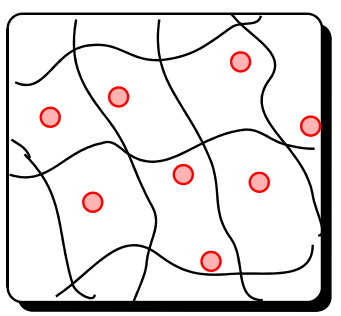

(b)

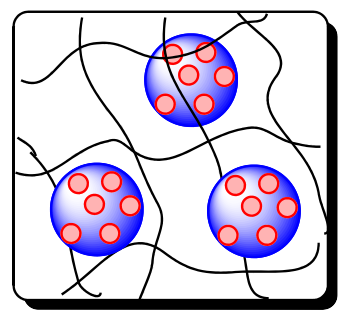

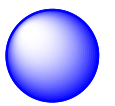

Microparticle

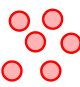

Growth factor

Figure 2.14. Schematic representation of methods for encapsulating growth factors either by (a) direct incorporation or (b) preloading into microparticles

\subsubsection{In vivo studies}

Many injectable hydrogels so far prepared for cartilage tissue engineering have been studied in vitro, however, only a few reports have appeared on their performance in vivo. Before clinical application, injectable hydrogels need to be systematically evaluated in animal models. A summary of in vivo studies on injectable hydrogels for cartilage regeneration is presented in Table 2.4.

Early in vivo studies generally focused on the ability of cell-seeded injectable hydrogels to generate cartilaginous tissue after subcutaneous implantation/injection in mouse models. For example, Elisseeff et al. implanted chondrocyte-incorporated PEO-based hydrogels, and showed that the chondrocytes survived during the photopolymerization process and proliferated without any sign of necrosis [138]. However, partial chondrocyte dedifferentiation and undesired fibro-cartilaginous tissue formation were observed in these gels after 6 weeks' in vivo. To retain the chondrocyte phenotype and improve cartilage regeneration, ECM components and bioactive molecules were incorporated into hydrogels. $\mathrm{Na}$ et al. showed that cartilage-specific ECM production was significantly higher in P(NIPAAm-co-AAc) hydrogels containing HA and TGF- $\beta 3$ compared to those without the growth factor or HA [139, 140]. 
Table 2.4. Injectable hydrogels for in vivo cartilage tissue engineering

\begin{tabular}{|c|c|c|c|}
\hline Hydrogel (+/-cell) & Animal model & Outcome & Ref. \\
\hline $\begin{array}{l}\text { PEODM-PEO } \\
\text { (+bovine } \\
\text { chondrocytes })\end{array}$ & $\begin{array}{l}\text { Subcutaneous } \\
\text { implantation in } \\
\text { athymic mice }\end{array}$ & $\begin{array}{l}\text { Chondrocytes survived implantation } \\
\text { and photopolymerization. } \\
\text { Fibrocartilage tissue containing } \\
\text { collagen type I and type II, and } \\
\text { glycosaminoglycans were formed } \\
\text { after } 6 \text { weeks. }\end{array}$ & [138] \\
\hline $\begin{array}{l}\text { Chitosan-GP- } \\
\text { glucosamine }(+ \\
\text { primary calf } \\
\text { chondrocytes })\end{array}$ & $\begin{array}{l}\text { Subcutaneous } \\
\text { injection in } \\
\text { nude mice }\end{array}$ & $\begin{array}{l}\text { Chitosan gels supported cartilage } \\
\text { matrix accumulation by cells } 48 \text { days } \\
\text { after injection. }\end{array}$ & [141] \\
\hline $\begin{array}{l}\text { P(NIPAAm- } c o- \\
\text { AAc)/HA (+ rabbit } \\
\text { chondrocytes or } \\
\text { rabbit MSC) }\end{array}$ & $\begin{array}{l}\text { Subcutaneous } \\
\text { injection in } \\
\text { nude mice }\end{array}$ & $\begin{array}{l}\text { The hydrogel containing HA and GF } \\
\text { showed enhanced ECM } \\
\text { accumulation and chondrogenic gene } \\
\text { expression at } 8 \text { weeks after injection. }\end{array}$ & $\begin{array}{c}{[139,} \\
140]\end{array}$ \\
\hline $\begin{array}{l}\text { Hyaluronic acid }(+ \\
\text { swine auricular } \\
\text { chondrocytes) }\end{array}$ & $\begin{array}{l}\text { Subcutaneous } \\
\text { implantation in } \\
\text { nude mice }\end{array}$ & $\begin{array}{l}\text { Neocartilage was produced and } \\
\text { evenly distributed in the gels after } 6 \\
\text { weeks. The } \mathrm{P} 0 \text { and } \mathrm{P} 1 \text { chondrocytes } \\
\text { produced neocartilage tissue that } \\
\text { resembled native auricular cartilage } \\
\text { after } 12 \text { weeks. }\end{array}$ & $\begin{array}{l}{[15,} \\
142]\end{array}$ \\
\hline $\begin{array}{l}\text { PEGDA with } \\
\text { methacrylated } \\
\text { chondroitin sulfate } \\
\text { as adhesive }\end{array}$ & $\begin{array}{l}\text { Goat chondral } \\
\text { defects }\end{array}$ & $\begin{array}{l}\text { Defects treated with chondroitin } \\
\text { sulfate adhesive and hydrogel } \\
\text { showed improved cartilage repair } \\
\text { compared to an empty, untreated } \\
\text { defect after } 6 \text { months. }\end{array}$ & [118] \\
\hline $\begin{array}{l}\text { Chitosan-GP- } \\
\text { glucosamine }\end{array}$ & $\begin{array}{l}\text { Rabbit } \\
\text { (osteo)chondra } \\
\text { l defects }\end{array}$ & $\begin{array}{l}\text { Chitosan gel can reside at least } 1 \text { day } \\
\text { in a full-thickness chondral defect } \\
\text { and for at least } 1 \text { week in a mobile } \\
\text { osteochondral defect. }\end{array}$ & [141] \\
\hline $\begin{array}{l}\text { Hyaluronic acid- } \\
\text { gelatin-PEGDA (+ } \\
\text { autologous MSC) }\end{array}$ & $\begin{array}{l}\text { Rabbit } \\
\text { osteochondral } \\
\text { defect }\end{array}$ & $\begin{array}{l}\text { Defects were completely filled with } \\
\text { elastic, firm, translucent cartilage at } \\
12 \text { weeks and showed superior } \\
\text { integration of the repair tissue with } \\
\text { the cartilage. }\end{array}$ & {$[143]$} \\
\hline $\begin{array}{l}\text { Elastin-like } \\
\text { polypeptide }\end{array}$ & $\begin{array}{l}\text { Goat chondral } \\
\text { defects }\end{array}$ & $\begin{array}{l}\text { ELP formed stable, well-integrated } \\
\text { gels and supported cell infiltration } \\
\text { and matrix synthesis } 3 \text { months after } \\
\text { injection. These hydrogels degraded } \\
\text { rapidly. }\end{array}$ & [144] \\
\hline
\end{tabular}


Recent studies have been directed to injectable hydrogels for cartilage regeneration in animal models like rabbit and goat. Hoemann et al. tested the residence of injectable hydrogels in rabbit joints and showed that injectable chitosan/glycerol phosphate gels could reside at least 1 day in a full-thickness chondral defect, and at least 1 week in a mobile osteochondral defect [141]. Liu et al. described osteochondral defect repair in a rabbit model using a synthetic ECM composed of hyaluronic acid and gelatin [143]. At 12 weeks, the defects were completely filled with elastic, firm, translucent cartilage and showed good integration of the repair tissue with the surrounding cartilage.

\subsection{Conclusion}

Novel crosslinking methods provide significant opportunities for the design of injectable hydrogels with multifunctional properties on demand for cartilage tissue engineering applications. The fast progress in molecular biology inspires researchers to design smart and biofunctional injectable hydrogels. Polymer composition and structures, hydrogel forming methods, degradation properties, mechanical strength and biocompatibility are of significant importance. Artificial extracellular matrices combining injectable hydrogel scaffolds, cells and growth factors hold great promise for cartilage tissue engineering, and pave the way for regenerated cartilage. 


\subsection{Abbreviations}

\begin{tabular}{|c|c|c|c|}
\hline APS & ammonium peroxydisulfate & PEODM & $\begin{array}{l}\text { poly(ethylene glycol) } \\
\text { dimethacrylate }\end{array}$ \\
\hline bFGF & $\begin{array}{l}\text { basic fibroblast growth } \\
\text { factor }\end{array}$ & PEO & poly(ethylene oxide) \\
\hline BMP & bone morphogenetic protein & PG & proteoglycan \\
\hline $\mathrm{CD}$ & cyclodextrin & PGA & poly(glycolic acid) \\
\hline CSMA & $\begin{array}{l}\text { methacrylated chondroitin } \\
\text { sulfate }\end{array}$ & PHB & poly([R]-3-hydroxybutyrate) \\
\hline ECM & extracellular matrix & PLA & poly(lactic acid)/polylactide \\
\hline ELP & elastin-like polypeptide & PLLA & Poly(L-lactic acid) \\
\hline $\mathrm{FN}$ & fibronectin & PNIPAAm & poly(N-isopropylacrylamide) \\
\hline GAG & glycosaminoglycan & $\begin{array}{l}\text { P(NIPAAm- } \\
\text { co-AAc) }\end{array}$ & $\begin{array}{l}\text { poly }(N \text {-isopropylacrylamide - } \\
\text { co-acrylic acid })\end{array}$ \\
\hline GF & growth factor & $\begin{array}{l}\text { P(NIPAAm- } \\
\text { co-HEMA) }\end{array}$ & $\begin{array}{l}\text { poly }(N \text {-isopropylacrylamide- } \\
\text { co-hydroxyethyl methacrylate) }\end{array}$ \\
\hline GP & $\beta$-glycerol phosphate & $\begin{array}{l}\mathrm{P}(\mathrm{PF}-\mathrm{co}- \\
\mathrm{EG})\end{array}$ & $\begin{array}{l}\text { poly (propylene fumarate-co- } \\
\text { ethylene glycol) }\end{array}$ \\
\hline HA & hyaluronic acid & PPO & poly(propylene oxide) \\
\hline HEMA & hydroxyethyl methacrylate & PVA & poly(vinyl alcohol) \\
\hline HPMA & $\begin{array}{l}\text { N-(2-hydroxypropyl) - } \\
\text { methacrylamide }\end{array}$ & SELP & silk-elastin like polypeptide \\
\hline HRP & horseradish peroxidase & TA & tyramine \\
\hline IGF & insulin-like growth factor & $\mathrm{TE}$ & tissue engineering \\
\hline $\mathrm{LN}$ & laminin & TEMED & $\begin{array}{l}\text { N,N,N'N'-tetramethylene } \\
\text { diamine }\end{array}$ \\
\hline MMP & matrix metalloproteinase & TG & transglutaminase \\
\hline NVP & $\mathrm{N}$-vinyl-2-pyrrolidone & & \\
\hline $\mathrm{OPF}$ & $\begin{array}{l}\text { oligo[poly(ethylene glycol) } \\
\text { fumarate] }\end{array}$ & TGF & transforming growth factor \\
\hline PCL & $\operatorname{poly}(\varepsilon$-caprolactone $)$ & VEGF & $\begin{array}{l}\text { vascular endothelial growth } \\
\text { factor }\end{array}$ \\
\hline PDLA & Poly(D-lactic acid) & & \\
\hline PEG & poly(ethylene glycol) & & \\
\hline PEGDA & $\begin{array}{l}\text { poly(ethylene glycol) } \\
\text { diacrylate }\end{array}$ & & \\
\hline
\end{tabular}




\subsection{References}

[1] Langer R, Vacanti JP. Tissue Engineering. Science 1993;260: 920-926.

[2] Yang S, Leong K-F, Du Z, Chua C-K. The Design of Scaffolds for Use in Tissue Engineering. Part I. Traditional Factors. Tissue Eng. 2001;7: 679-689.

[3] Drury JL, Mooney DJ. Hydrogels for Tissue Engineering: Scaffold Design Variables and Applications. Biomaterials 2003;24: 4337-4351.

[4] Wichterle O, Lim D. Hydrophilic Gels for Biological Use. Nature 1960;185: 117118.

[5] Kuo CK, Li W-J, Mauck RL, Tuan RS. Cartilage Tissue Engineering: Its Potential and Uses. Curr. Opin. Rheumatol. 2006;18: 64-73.

[6] Kim J, Kim IS, Cho TH, Lee KB, Hwang SJ, Tae G, Noh I, Lee SH, Park Y, and Sun K. Bone Regeneration Using Hyaluronic Acid-Based Hydrogel with Bone Morphogenic Protein-2 and Human Mesenchymal Stem Cells. Biomaterials 2007;28: 1830-1837.

[7] Raeber GP, Lutolf MP, Hubbell JA. Molecularly Engineered Peg Hydrogels: A Novel Model System for Proteolytically Mediated Cell Migration. Biophys. J. 2005;89: 1374-1388.

[8] Bryant SJ, Anseth KS. Hydrogel Properties Influence ECM Production by Chondrocytes Photoencapsulated in Poly(ethylene Glycol) Hydrogels. J. Biomed. Mater. Res. 2002;59: 63-72.

[9] Bryant SJ, Anseth KS. Controlling the Spatial Distribution of ECM Components in Degradable Peg Hydrogels for Tissue Engineering Cartilage. J. Biomed. Mater. Res. A 2003;64A: 70-79.

[10] Martens PJ, Bryant SJ, Anseth KS. Tailoring the Degradation of Hydrogels Formed from Multivinyl Poly(ethylene glycol) and Poly(vinyl alcohol) Macromers for Cartilage Tissue Engineering. Biomacromolecules 2003;4: 283-292.

[11] Bryant SJ, Durand KL, Anseth KS. Manipulations in Hydrogel Chemistry Control Photoencapsulated Chondrocyte Behavior and Their Extracellular Matrix Production. J. Biomed. Mater. Res. A 2003;67A: 1430-1436.

[12] Bryant SJ, Bender RJ, Durand KL, Anseth KS. Encapsulating Chondrocytes in Degrading Peg Hydrogels with High Modulus: Engineering Gel Structural Changes to Facilitate Cartilaginous Tissue Production. Biotechnol. Bioeng. 2004;86: 747-755.

[13] Lutolf MP, Lauer-Fields JL, Schmoekel HG, Metters AT, Weber FE, Fields GB, and Hubbell JA. Synthetic Matrix Metalloproteinase-Sensitive Hydrogels for the Conduction of Tissue Regeneration: Engineering Cell-Invasion Characteristics. Proc. Natl. Acad. Sci. USA 2003;100: 5413-5418.

[14] Kamath KR, Park K. Biodegradable Hydrogels in Drug Delivery. Adv. Drug Deliver. Rev. 1993;11: 59-84.

[15] Burdick JA, Chung C, Jia X, Randolph MA, Langer R. Controlled Degradation and Mechanical Behavior of Photopolymerized Hyaluronic Acid Networks. Biomacromolecules 2005;6: 386-391.

[16] Ibusuki S, Halbesma GJ, Randolph MA, Redmond RW, Kochevar IE, Gill TJ. Photochemically Cross-Linked Collagen Gels as Three-Dimensional Scaffolds for Tissue Engineering. Tissue Eng. 2007;13: 1995-2001.

[17] Hong Y, Song H, Gong Y, Mao Z, Gao C, Shen J. Covalently Crosslinked Chitosan Hydrogel: Properties of in Vitro Degradation and Chondrocyte Encapsulation. Acta Biomater. 2007;3: 23-31. 
[18] Lu L, Valenzuela RG, Yaszemski MJ. Articular Cartilage Tissue Engineering. ebiomed: J. Regen. Med. 2000;1: 99-114.

[19] Lu L, Zhu X, Valenzuela RG, Currier BL, Yaszemski MJ. Biodegradable Polymer Scaffolds for Cartilage Tissue Engineering. Clin. Orthop. Relat. Res. 2001;391S: S251-S270.

[20] Breuls RGM, Jiya TU, Smit TH. Scaffold Stiffness Influences Cell Behavior: Opportunities for Skeletal Tissue Engineering. Open Orthop. J. 2008;2: 103-109.

[21] Engler AJ, Sen S, Sweeney HL, Discher DE. Matrix Elasticity Directs Stem Cell Lineage Specification. Cell 2006;126: 677-689.

[22] Chung C, Burdick JA. Engineering Cartilage Tissue. Adv. Drug Deliver. Rev. 2008;60: 243-262.

[23] Narine K, Wever OD, Valckenborgh DV, Francois K, Bracke M, Desmet S, Mareel M, and Nooten GV. Growth Factor Modulation of Fibroblast Proliferation, Differentiation, and Invasion: Implications for Tissue Valve Engineering. Tissue Eng. 2006;12: 2707-2716.

[24] Malafaya PB, Silva GA, Reis RL. Natural-Origin Polymers as Carriers and Scaffolds for Biomolecules and Cell Delivery in Tissue Engineering Applications. Adv. Drug Deliver. Rev. 2007;59: 207-233.

[25] Nuttelman CR, Mortisen DJ, Henry SM, Anseth KS. Attachment of Fibronectin to Poly(Vinyl Alcohol) Hydrogels Promotes NIH3T3 Cell Adhesion, Proliferation, and Migration. J. Biomed. Mater. Res. 2001;57: 217-223.

[26] Stabenfeldt SE, Garcia AJ, LaPlaca MC. Thermoreversible Laminin-Functionalized Hydrogel for Neural Tissue Engineering. J. Biomed. Mater. Res. A 2006;77A: 718725.

[27] Shin H, Jo S, Mikos AG. Biomimetic Materials for Tissue Engineering. Biomaterials 2003;24: 4353-4364.

[28] Ifkovits JL, Burdick JA. Review: Photopolymerizable and Degradable Biomaterials for Tissue Engineering Applications. Tissue Eng. 2007;13: 2369-2385.

[29] Nguyen KT, West JL. Photopolymerizable Hydrogels for Tissue Engineering Applications. Biomaterials 2002;23: 4307-4314.

[30] Bryant SJ, Davis-Arehart KA, Luo N, Shoemaker RK, Arthur JA, Anseth KS. Synthesis and Characterization of Photopolymerized Multifunctional Hydrogels: Water-Soluble Poly(vinyl alcohol) and Chondroitin Sulfate Macromers for Chondrocyte Encapsulation. Macromolecules 2004;37: 6726-6733.

[31] Mawad D, Martens PJ, Odell RA, Poole-Warren LA. The Effect of Redox Polymerisation on Degradation and Cell Responses to Poly(vinyl alcohol) Hydrogels. Biomaterials 2007;28: 947-955.

[32] Park YD, Tirelli N, Hubbell JA. Photopolymerized Hyaluronic Acid-Based Hydrogels and Interpenetrating Networks. Biomaterials 2003;24: 893-900.

[33] Hong Y, Mao Z, Wang H, Gao C, Shen J. Covalently Crosslinked Chitosan Hydrogel Formed at Neutral Ph and Body Temperature. J. Biomed. Mater. Res. A 2006;79A: 913-922.

[34] Kim SH, Won CY, Chu CC. Synthesis and Characterization of Dextran-Based Hydrogel Prepared by Photocrosslinking. Carbohydr. Polymer 1999;40: 183-190.

[35] Bryant SJ, Nuttelman CR, Anseth KS. Cytocompatibility of Uv and Visible Light Photoinitiating Systems on Cultured NIH3T3 Fibroblasts in Vitro. J. Biomater. Sci. Polym. Ed. 2000;11: 439-457. 
[36] Lukaszczyk J, Smiga M, Jaszcz K, Adler H-JP, Jähne E, Kaczmarek M. Evaluation of Oligo(ethylene glycol) Dimethacrylates Effects on the Properties of New Biodegradable Bone Cement Compositions. Macromol. Biosci. 2005;5: 64-69.

[37] Hiemstra C, Zhou W, Zhong Z, Wouters M, Feijen J. Rapidly in Situ Forming Biodegradable Robust Hydrogels by Combining Stereocomplexation and Photopolymerization. J. Am. Chem. Soc. 2007;129: 9918-9926.

[38] Zhu W, Ding J. Synthesis and Characterization of a Redox-Initiated, Injectable, Biodegradable Hydrogel. J. Appl. Polym. Sc. 2006;99: 2375-2383.

[39] Maia J, Ferreira L, Carvalho R, Ramos MA, Gil MH. Synthesis and Characterization of New Injectable and Degradable Dextran-Based Hydrogels. Polymer 2005;46: 9604-9614.

[40] Lee KY, Alsberg E, Mooney DJ. Degradable and Injectable Poly(aldehyde guluronate) Hydrogels for Bone Tissue Engineering. J. Biomed. Mater. Res. 2001;56: 228-233.

[41] Hennink WE, van Nostrum CF. Novel Crosslinking Methods to Design Hydrogels. Adv. Drug Deliver. Rev. 2002;54: 13-36.

[42] Bulpitt P, Aeschlimann D. New Strategy for Chemical Modification of Hyaluronic Acid: Preparation of Functionalized Derivatives and Their Use in the Formation of Novel Biocompatible Hydrogels. J. Biomed. Mater. Res. 1999;47: 152-169.

[43] Balakrishnan B, Jayakrishnan A. Self-Cross-Linking Biopolymers as Injectable in Situ Forming Biodegradable Scaffolds. Biomaterials 2005;26: 3941-3951.

[44] Riley CM, Fuegy PW, Firpo MA, Zheng Shu X, Prestwich GD, Peattie RA. Stimulation of in Vivo Angiogenesis Using Dual Growth Factor-Loaded Crosslinked Glycosaminoglycan Hydrogels. Biomaterials 2006;27: 5935-5943.

[45] Zheng Shu X, Liu Y, Palumbo FS, Luo Y, Prestwich GD. In Situ Crosslinkable Hyaluronan Hydrogels for Tissue Engineering. Biomaterials 2004;25: 1339-1348.

[46] Vanderhooft JL, Mann BK, Prestwich GD. Synthesis and Characterization of Novel Thiol-Reactive Poly(ethylene glycol) Cross-Linkers for Extracellular-MatrixMimetic Biomaterials. Biomacromolecules 2007;8: 2883-2889.

[47] Hiemstra C, vanderAa LJ, Zhong Z, Dijkstra PJ, Feijen J. Novel in Situ Forming, Degradable Dextran Hydrogels by Michael Addition Chemistry: Synthesis, Rheology, and Degradation. Macromolecules 2007;40: 1165-1173.

[48] Hiemstra C, vanderAa LJ, Zhong Z, Dijkstra PJ, Feijen J. Rapidly in Situ-Forming Degradable Hydrogels from Dextran Thiols through Michael Addition. Biomacromolecules 2007;8: 1548-1556.

[49] Tortora M, Cavalieri F, Chiessi E, Paradossi G. Michael-Type Addition Reactions for the in Situ Formation of Poly(vinyl alcohol)-Based Hydrogels. Biomacromolecules 2007;8: 209-214.

[50] Metters A, Hubbell J. Network Formation and Degradation Behavior of Hydrogels Formed by Michael-Type Addition Reactions. Biomacromolecules 2005;6: 290-301.

[51] Lutolf MP, Raeber GP, Zisch AH, Tirelli N, Hubbell JA. Cell-Responsive Synthetic Hydrogels. Adv. Mater. 2003;15: 888-892.

[52] Park Y, Lutolf MP, Hubbell JA, Hunziker EB, Wong M. Bovine Primary Chondrocyte Culture in Synthetic Matrix Metalloproteinase-Sensitive Poly(ethylene glycol)-Based Hydrogels as a Scaffold for Cartilage Repair. Tissue Eng. 2004;10: 515-522.

[53] Salinas CN, Cole BB, Kasko AM, Anseth KS. Chondrogenic Differentiation Potential of Human Mesenchymal Stem Cells Photoencapsulated within 
Poly(ethylene glycol)-Arginine-Glycine-Aspartic Acid-Serine Thiol-Methacrylate Mixed-Mode Networks. Tissue Eng. 2007;13: 1025-1034.

[54] Cotton GJ, Muir TW. Peptide Ligation and Its Application to Protein Engineering. Chem. Biol. 1999;6: R247-R256.

[55] Wathier M, Jung PJ, Carnahan MA, Kim T, Grinstaff MW. Dendritic Macromers as in Situ Polymerizing Biomaterials for Securing Cataract Incisions. J. Am. Chem. Soc. 2004;126: 12744-12745.

[56] Wathier M, Johnson CS, Kim T, Grinstaff MW. Hydrogels Formed by Multiple Peptide Ligation Reactions to Fasten Corneal Transplants. Bioconjugate Chem. 2006;17: 873-876.

[57] Rostovtsev VV, Green LG, Fokin VV, Sharpless KB. A Stepwise Huisgen Cycloaddition Process: Copper(I)-Catalyzed Regioselective "Ligation" Of Azides and Terminal Alkynes. Angew. Chem. Int. Edit. 2002;41: 2596-2599.

[58] Ossipov DA, Hilborn J. Poly(vinyl alcohol)-Based Hydrogels Formed By "Click Chemistry". Macromolecules 2006;39: 1709-1718.

[59] Malkoch M, Vestberg R, Gupta N, Mespouille L, Dubois P, Mason AF, Hedrick JL, Liao Q, Frank CW, Kingsbury K, and Hawker CJ. Synthesis of Well-Defined Hydrogel Networks Using Click Chemistry. Chem. Comm. 2006 2774-2776.

[60] Xu X-D, Chen C-S, Wang Z-C, Wang G-R, Cheng S-X, Zhang X-Z, and Zhuo R-X. "Click" Chemistry for in Situ Formation of Thermoresponsive P(NIPAAm-CoHEMA)-Based Hydrogels. J. Polym. Sci. A 2008;46: 5263-5277.

[61] Crescenzi V, Cornelio L, DiMeo C, Nardecchia S, Lamanna R. Novel Hydrogels Via Click Chemistry: Synthesis and Potential Biomedical Applications. Biomacromolecules 2007;8: 1844-1850.

[62] Speers AE, Cravatt BF. Profiling Enzyme Activities in Vivo Using Click Chemistry Methods. Chem. Biol. 2004;11: 535-546.

[63] Johnson JA, Baskin JM, Bertozzi CR, Koberstein JT, Turro NJ. Copper-Free Click Chemistry for the in Situ Crosslinking of Photodegradable Star Polymers. Chem. Comm. 2008 3064-3066.

[64] Sanborn TJ, Messersmith PB, Barron AE. In Situ Crosslinking of a Biomimetic Peptide-Peg Hydrogel Via Thermally Triggered Activation of Factor Xiii. Biomaterials 2002;23: 2703-2710.

[65] Park H, Temenoff JS, Holland TA, Tabata Y, Mikos AG. Delivery of TGF-[Beta]1 and Chondrocytes Via Injectable, Biodegradable Hydrogels for Cartilage Tissue Engineering Applications. Biomaterials 2005;26: 7095-7103.

[66] Sperinde JJ, Griffith LG. Synthesis and Characterization of Enzymatically-CrossLinked Poly(ethylene glycol) Hydrogels. Macromolecules 1997;30: 5255-5264.

[67] Sperinde JJ, Griffith LG. Control and Prediction of Gelation Kinetics in Enzymatically Cross-Linked Poly(ethylene glycol) Hydrogels. Macromolecules 2000;33: 5476-5480.

[68] McHale MK, Setton LA, Chilkoti A. Synthesis and in Vitro Evaluation of Enzymatically Cross-Linked Elastin-Like Polypeptide Gels for Cartilaginous Tissue Repair. Tissue Eng. 2005;11: 1768-1779.

[69] Au A, Ha J, Polotsky A, Krzyminski K, Gutowska A, Hungerford DS, and Frondoza CG. Thermally Reversible Polymer Gel for Chondrocyte Culture. J. Biomed. Mater. Res. A 2003;67A: 1310-1319.

[70] Kobayashi S, Uyama H, Kimura S. Enzymatic Polymerization. Chem. Rev. 2001;101: 3793-3818. 
[71] Sofia SJ, Singh A, Kaplan DL. Peroxidase-Catalyzed Crosslinking of Functionalized Polyaspartic Acid Polymers. J. Macromol. Sci. Phys. B 2002;A39: 1151-1181.

[72] Kurisawa M, Chung JE, Yang YY, Gao SJ, Uyama H. Injectable Biodegradable Hydrogels Composed of Hyaluronic Acid-Tyramine Conjugates for Drug Delivery and Tissue Engineering. Chem. Comm. 2005 4312-4314.

[73] Ogushi Y, Sakai S, Kawakami K. Synthesis of Enzymatically-gellable Carboxymethylcellulose for Biomedical Applications. J. Biosci. Bioeng. 2007;104: 30-33.

[74] Sakai S, Kawakami K. Synthesis and Characterization of Both Ionically and Enzymatically Cross-Linkable Alginate. Acta Biomater. 2007;3: 495-501.

[75] Loomis GL, Murdoch JR, Gardner KH. Polylactide Stereocomplexes. Polym. Prepr. (Am. Chem. Soc. Div. Polym. Chem.) 1990;31: 55.

[76] Tsuji H, Hyon SH, Y. Ikada. Stereocomplex Formation between Enantiomeric Poly (lactic acid)s. Macromolecules 1991;24: 2719-2724.

[77] Grijpma D, Feijen J. Hydrogels by Stereo-Complexation of Water-Soluble PLLAPEO-PLLA and PDLA-PEO-PDLA Triblock-Copolymers. J. Control. Release 2001;72: 247-249.

[78] Hiemstra C, Zhong Z, Li L, Dijkstra PJ, Feijen J. In-Situ Formation of Biodegradable Hydrogels by Stereocomplexation of PEG-(PLLA) 8 and PEG(PDLA) $)_{8}$ Star Block Copolymers. Biomacromolecules 2006;7: 2790-2795.

[79] Hiemstra C, Zhong Z, Dijkstra PJ, Feijen J. Stereocomplex Mediated Gelation of PEG-(PLA) $)_{2}$ and PEG-(PLA) 8 Block Copolymers. Macromol. Symp. 2005;224: 119-132.

[80] de Jong SJ, De Smedt SC, Wahls MWC, Demeester J, Kettenes-van den Bosch JJ, Hennink WE. Novel Self-Assembled Hydrogels by Stereocomplex Formation in Aqueous Solution of Enantiomeric Lactic Acid Oligomers Grafted to Dextran. Macromolecules 2000;33: 3680-3686.

[81] de Jong SJ, van Eerdenbrugh B, van Nostrum CF, Kettenes-van den Bosch JJ, Hennink WE. Physically Crosslinked Dextran Hydrogels by Stereocomplex Formation of Lactic Acid Oligomers: Degradation and Protein Release Behavior. J. Control. Release 2001;71: 261-275.

[82] Ruel-Gariepy E, Leroux J-C. In Situ-Forming Hydrogels--Review of TemperatureSensitive Systems. Eur. J. Pharm. Biopharm. 2004;58: 409-426.

[83] Khattak SF, Bhatia SR, Roberts SC. Pluronic F127 as a Cell Encapsulation Material: Utilization of Membrane-Stabilizing Agents. Tissue Eng. 2005;11: 974-983.

[84] Jeong B, Bae YH, Lee DS, Kim SW. Biodegradable Block Copolymers as Injectable Drug-Delivery Systems. Nature 1997;388: 860-862.

[85] Jeong B, Lee KM, Gutowska A, An YH. Thermogelling Biodegradable Copolymer Aqueous Solutions for Injectable Protein Delivery and Tissue Engineering. Biomacromolecules 2002;3: 865-868.

[86] Jeong B, Kim SW, Bae YH. Thermosensitive Sol-Gel Reversible Hydrogels. Adv. Drug Deliver. Rev. 2002;54: 37-51.

[87] Klouda L, Mikos AG. Thermoresponsive Hydrogels in Biomedical Applications. Eur. J. Pharm. Biopharm. 2008;68: 34-45.

[88] He C, Kim SW, Lee DS. In Situ Gelling Stimuli-Sensitive Block Copolymer Hydrogels for Drug Delivery. J. Control. Release 2008;127: 189-207.

[89] Yu YB. Coiled-Coils: Stability, Specificity, and Drug Delivery Potential. Adv. Drug Deliver. Rev. 2002;54: 1113-1129. 
[90] Yang J, Xu C, Wang C, Kopecek J. Refolding Hydrogels Self-Assembled from N(2-Hydroxypropyl)Methacrylamide Graft Copolymers by Antiparallel Coiled-Coil Formation. Biomacromolecules 2006;7: 1187-1195.

[91] Yang J, Xu C, Kopeckova P, Kopecek J. Hybrid Hydrogels Self-Assembled from Hpma Copolymers Containing Peptide Grafts. Macromol. Biosci. 2006;6: 201-209.

[92] Wang C, Stewart RJ, KopeCek J. Hybrid Hydrogels Assembled from Synthetic Polymers and Coiled-Coil Protein Domains. Nature 1999;397: 417-420.

[93] Wang C, Kopecek J, Stewart RJ. Hybrid Hydrogels Cross-Linked by Genetically Engineered Coiled-Coil Block Proteins. Biomacromolecules 2001;2: 912-920.

[94] Xu C, Kopeček J. Genetically Engineered Block Copolymers: Influence of the Length and Structure of the Coiled-Coil Blocks on Hydrogel Self-Assembly. Pharm. Res. 2008;25: 674-682.

[95] Xu C, Breedveld V, Kopecek J. Reversible Hydrogels from Self-Assembling Genetically Engineered Protein Block Copolymers. Biomacromolecules 2005;6: 1739-1749.

[96] Nowak AP, Breedveld V, Pakstis L, Ozbas B, Pine DJ, Pochan D, and Deming TJ. Rapidly Recovering Hydrogel Scaffolds from Self-Assembling Diblock Copolypeptide Amphiphiles. Nature 2002;417: 424-428.

[97] Pakstis LM, Ozbas B, Hales KD, Nowak AP, Deming TJ, Pochan D. Effect of Chemistry and Morphology on the Biofunctionality of Self-Assembling Diblock Copolypeptide Hydrogels. Biomacromolecules 2004;5: 312-318.

[98] Uekama K, Hirayama F, Irie T. Cyclodextrin Drug Carrier Systems. Chem. Rev. 1998;98: 2045-2076.

[99] van de Manakker F, vander Pot M, Vermonden T, van Nostrum CF, Hennink WE. Self-Assembling Hydrogels Based on beta-Cyclodextrin/Cholesterol Inclusion Complexes. Macromolecules 2008;41: 1766-1773.

[100] Kretschmann O, Choi SW, Miyauchi M, Tomatsu I, Harada A, Ritter H. Switchable Hydrogels Obtained by Supramolecular Cross-Linking of Adamantyl-Containing LCST Copolymers with Cyclodextrin Dimers. Angew. Chem. Int. Edit. 2006;45: 4361-4365.

[101] Loethen S, Kim J-M, Thompson DH. Biomedical Applications of Cyclodextrin Based Polyrotaxanes. Polym. Rev. 2007;47: 383 - 418.

[102] Wei H, He J, Sun L-g, Zhu K, Feng Z-g. Gel Formation and Photopolymerization During Supramolecular Self-Assemblies of [Alpha]-CDs with LA-PEG-LA Copolymer End-Capped with Methacryloyl Groups. Eur. Polym. J. 2005;41: 948957.

[103] Li J, Li X, Ni X, Wang X, Li H, Leong KW. Self-Assembled Supramolecular Hydrogels Formed by Biodegradable PEO-PHB-PEO Triblock Copolymers and [Alpha]-Cyclodextrin for Controlled Drug Delivery. Biomaterials 2006;27: 41324140.

[104] Cellesi F, Tirelli N, Hubbell JA. Towards a Fully-Synthetic Substitute of Alginate: Development of a New Process Using Thermal Gelation and Chemical CrossLinking. Biomaterials 2004;25: 5115-5124.

[105] Kim MR, Park TG. Temperature-Responsive and Degradable Hyaluronic Acid/Pluronic Composite Hydrogels for Controlled Release of Human Growth Hormone. J. Control. Release 2002;80: 69-77. 
[106] Niu G, Zhang H, Song L, Cui X, Cao H, Zheng Y, Zhu S, Yang Z, and Yang H. Thiol/Acrylate-Modified PEO-PPO-PEO Triblocks Used as Reactive and Thermosensitive Copolymers. Biomacromolecules 2008.

[107] Robb SA, Lee BH, McLemore R, Vernon BL. Simultaneously Physically and Chemically Gelling Polymer System Utilizing a Poly(NIPAAm-Co-Cysteamine)Based Copolymer. Biomacromolecules 2007;8: 2294-2300.

[108] Lee JB, Yoon JJ, Lee DS, Park TG. Photo-Crosslinkable, Thermo-Sensitive and Biodegradable Pluronic Hydrogels for Sustained Release of Protein. J. Biomater. Sci. Polym. Ed. 2004;15: 1571-1583.

[109] Yoon JJ, Chung HJ, Park TG. Photo-Crosslinkable and Biodegradable Pluronic/Heparin Hydrogels for Local and Sustained Delivery of Angiogenic Growth Factor. J. Biomed. Mater. Res. A 2007;83A: 597-605.

[110] Vermonden T, Fedorovich NE, van Geemen D, Alblas J, van Nostrum CF, Dhert WJA, and Hennink WE. Photopolymerized Thermosensitive Hydrogels: Synthesis, Degradation, and Cytocompatibility. Biomacromolecules 2008;9: 919-926.

[111] Chung HJ, Lee Y, Park TG. Thermo-Sensitive and Biodegradable Hydrogels Based on Stereocomplexed Pluronic Multi-Block Copolymers for Controlled Protein Delivery. J. Control. Release 2008;127: 22-30.

[112] Seal BL, Panitch A. Physical Matrices Stabilized by Enzymatically Sensitive Covalent Crosslinks. Acta Biomater. 2006;2: 241-251.

[113] Benya PD, Shaffer JD. Dedifferentiated Chondrocytes Reexpress the Differentiated Collagen Phenotype When Cultured in Agarose Gels. Cell 1982;30: 215-224.

[114] Elisseeff J, Anseth K, Sims D, McIntosh W, Randolph M, Langer R. Transdermal Photopolymerization for Minimally Invasive Implantation. Proc. Natl. Acad. Sci. USA 1999;96: 3104-3107.

[115] Chung C, Mesa J, Randolph MA, Yaremchuk M, Burdick JA. Influence of Gel Properties on Neocartilage Formation by Auricular Chondrocytes Photoencapsulated in Hyaluronic Acid Networks. J. Biomed. Mater. Res. A 2006;77A: 518-525.

[116] Sontjens SHM, Nettles DL, Carnahan MA, Setton LA, Grinstaff MW. Biodendrimer-Based Hydrogel Scaffolds for Cartilage Tissue Repair. Biomacromolecules 2006; 7: 310-316.

[117] Wang DA, Williams CG, Yang F, Elisseeff JH. Enhancing the Tissue-Biomaterial Interface: Tissue-Initiated Integration of Biomaterials. Adv. Funct. Mater. 2004;14: 1152-1159.

[118] Wang D-A, Varghese S, Sharma B, Strehin I, Fermanian S, Gorham J, Fairbrother DH, Cascio B, and Elisseeff JH. Multifunctional Chondroitin Sulphate for Cartilage Tissue-Biomaterial Integration. Nat. Mater. 2007;6: 385-392.

[119] Lee HJ, Lee J-S, Chansakul T, Yu C, Elisseeff JH, Yu SM. Collagen Mimetic Peptide-Conjugated Photopolymerizable Peg Hydrogel. Biomaterials 2006;27: 52685276.

[120] Chau Y, Luo Y, Cheung ACY, Nagai Y, Zhang S, Kobler JB, Zeitels SM, and Langer R. Incorporation of a Matrix Metalloproteinase-Sensitive Substrate into SelfAssembling Peptides - a Model for Biofunctional Scaffolds. Biomaterials 2008;29: 1713-1719.

[121] Levesque SG, Shoichet MS. Synthesis of Enzyme-Degradable, Peptide-CrossLinked Dextran Hydrogels. Bioconjugate Chem. 2007;18: 874-885. 
[122] Hwang NS, Varghese S, Zhang Z, Elisseeff J. Chondrogenic Differentiation of Human Embryonic Stem Cell-Derived Cells in Arginine-Glycine-AspartateModified Hydrogels. Tissue Eng. 2006;12: 2695-2706.

[123] Bryant SJ, Arthur JA, Anseth KS. Incorporation of Tissue-Specific Molecules Alters Chondrocyte Metabolism and Gene Expression in Photocrosslinked Hydrogels. Acta Biomater. 2005; 1: 243-252.

[124] Lee HJ, Yu C, Chansakul T, Hwang NS, Varghese S, Yu SM, and Elisseeff JH. Enhanced Chondrogenesis of Mesenchymal Stem Cells in Collagen Mimetic Peptide-Mediated Microenvironment. Tissue Eng. A 2008;14: 1843-1851.

[125] Lee H, Park TG. Photo-Crosslinkable, Biomimetic, and Thermo-Sensitive Pluronic Grafted Hyaluronic Acid Copolymers for Injectable Delivery of Chondrocytes. J. Biomed. Mater. Res. A 2009;88A: 797-806.

[126] Gonen-Wadmany M, Oss-Ronen L, Seliktar D. Protein-Polymer Conjugates for Forming Photopolymerizable Biomimetic Hydrogels for Tissue Engineering. Biomaterials 2007;28: 3876-3886.

[127] Kim M, Shin Y, Hong B-H, Kim Y-J, Chun J-S, Tae G, and Kim YH. In Vitro Chondrocyte Culture in a Heparin-Based Hydrogel for Cartilage Regeneration. Tissue Eng. C In press.

[128] Kessler MW, Grande DA. Tissue Engineering and Cartilage. Organogenesis 2008;4: 28-32.

[129] Yuji H, Rocky ST, Lillian S. Distinct Functions of Bmp4 and Gdf5 in the Regulation of Chondrogenesis. J. Cell Biochem. 2004;91: 1204-1217.

[130] Lee S-H, Shin H. Matrices and Scaffolds for Delivery of Bioactive Molecules in Bone and Cartilage Tissue Engineering. Adv. Drug Deliver. Rev. 2007;59: 339-359.

[131] Park Y, Sugimoto M, Watrin A, Chiquet M, Hunziker EB. Bmp-2 Induces the Expression of Chondrocyte-Specific Genes in Bovine Synovium-Derived Progenitor Cells Cultured in Three-Dimensional Alginate Hydrogel. Osteoarthr. Cartilage 2005; 13: 527-536.

[132] Park H, Temenoff JS, Tabata Y, Caplan AI, Mikos AG. Injectable Biodegradable Hydrogel Composites for Rabbit Marrow Mesenchymal Stem Cell and Growth Factor Delivery for Cartilage Tissue Engineering. Biomaterials 2007;28: 3217-3227.

[133] Elisseeff J, McIntosh W, Fu K, Blunk T, Langer R. Controlled-Release of IGF-I and TGF-beta1 in a Photopolymerizing Hydrogel for Cartilage Tissue Engineering. J. Orthop. Res. 2001;19: 1098-1104.

[134] Park KH, Na K. Effect of Growth Factors on Chondrogenic Differentiation of Rabbit Mesenchymal Cells Embedded in Injectable Hydrogels. J. Biosci. Bioeng. 2008;106: 74-79.

[135] Lin C-C, Sawicki SM, Metters AT. Free-Radical-Mediated Protein Inactivation and Recovery During Protein Photoencapsulation. Biomacromolecules 2007;9: 75-83.

[136] Chung Y-I, Ahn K-M, Jeon S-H, Lee S-Y, Lee J-H, Tae G. Enhanced Bone Regeneration with BMP-2 Loaded Functional Nanoparticle-Hydrogel Complex. J. Control. Release 2007;121: 91-99.

[137] Holland TA, Tabata Y, Mikos AG. In Vitro Release of Transforming Growth Factor-[beta]1 from Gelatin Microparticles Encapsulated in Biodegradable, Injectable Oligo(poly(ethylene glycol) fumarate) Hydrogels. J. Control. Release 2003;91: 299-313.

[138] Elisseeff J, Anseth K, Sims D, McIntosh W, Randolph M, Yaremchuk M, and Langer R. Transdermal Photopolymerization of Poly (ethylene oxide)-Based 
Injectable Hydrogels for Tissue-Engineered Cartilage. Plast. Reconstr. Surg. 1999;104: 1014-1022.

[139] Na K, Kim S, Woo D-G, Sun BK, Yang HN, Chung H-M, and Park K-H. Synergistic Effect of TGF[beta]-3 on Chondrogenic Differentiation of Rabbit Chondrocytes in Thermo-Reversible Hydrogel Constructs Blended with Hyaluronic Acid by in Vivo Test. J. Biotechnol. 2007;128: 412-422.

[140] Na K, Park K-H. Injectable Thermo-Sensitive Hydrogels Blended Hyaluronic Acid Including Transforming Growth Factors for Neocartilage Formation in Vivo Test. Tissue Eng. Regen. Med. 2008;5: 482-487.

[141] Hoemann CD, Sun J, Légaré A, McKee MD, Buschmann MD. Tissue Engineering of Cartilage Using an Injectable and Adhesive Chitosan-Based Cell-Delivery Vehicle. Osteoarthr. Cartilage 2005;13: 318-329.

[142] Chung C, Mesa J, Miller GJ, Randolph MA, Gill TJ, Burdick JA. Effects of Auricular Chondrocyte Expansion on Neocartilage Formation in Photocrosslinked Hyaluronic Acid Networks. Tissue Eng. 2006;12: 2665-2673.

[143] Liu Y, Shu XZ, Prestwich GD. Osteochondral Defect Repair with Autologous Bone Marrow-Derived Mesenchymal Stem Cells in an Injectable, in Situ, Cross-Linked Synthetic Extracellular Matrix. Tissue Eng. 2006;12: 3405-3416.

[144] Nettles DL, Kitaoka K, Hanson NA, Flahiff CM, Mata BA, Hsu EW, Chilkoti A, and Setton LA. In Situ Crosslinking Elastin-Like Polypeptide Gels for Application to Articular Cartilage Repair in a Goat Osteochondral Defect Model. Tissue Eng. A 2008;14: 1133-1140. 


\section{Chapter 3}

\section{Synthesis and Characterization of Hyaluronic acid-PEG Hydrogels via Michael Addition: An Injectable Biomaterial for Cartilage Repair *}

Injectable hydrogels based on hyaluronic acid (HA) and poly(ethylene glycol) (PEG) were designed as biodegradable matrices for cartilage tissue engineering. Solutions of HA conjugates containing thiol functional groups (HA-SH) and PEG-vinylsulfone (PEG-VS) macromers were crosslinked via Michael addition to form a three-dimensional network under physiological conditions. Gelation times varied from $14 \mathrm{~min}$ to less than $1 \mathrm{~min}$, depending on the molecular weight of the HA-SH and PEG-VS, degree of substitution (DS) of the HA-SH and the total polymer concentration. In the presence of $100 \mathrm{U} / \mathrm{mL}$ of hyaluronidase, when the polymer concentration was increased from 2 to $6 \%(w / v)$, the degradation time increased from 3 to 15 days. Hydrogels with a homogeneous distribution of cells were obtained when chondrocytes were mixed with the precursor solutions. Culturing cell-hydrogel constructs, prepared from HA185k-SH with a DS of 28 and crosslinked with PEG5k-4VS for 3 weeks in vitro, revealed that the cells were viable and that cell division took place. Gel-cell matrices degraded in approximately 3 weeks as shown by a significant decrease in dry gel mass. At day 21, glycosaminoglycans and collagen type II were found to accumulate in hydrogels. These results indicate that these injectable hydrogels have a high potential for cartilage tissue engineering.

\subsection{Introduction}

Over the past decades, hydrogels have been extensively studied as temporary scaffolds for cartilage regeneration [1-3]. Hydrogels are three-dimensional, hydrophilic, polymeric networks absorbing and retaining a large amount of water, resembling the properties of native cartilage [4]. Moreover, hydrogels have a high permeability for nutrients, and watersoluble metabolites, allowing cell survival and supporting cellular growth. The

\footnotetext{
* This chapter has been published: Rong Jin, Liliana S. Moreira Teixeira, Anita Krouwels, Pieter J. Dijkstra, Clemens A. van Blitterswijk, Marcel Karperien and Jan Feijen, Acta Biomaterialia, sumitted.
} 
incorporation of chondrocytes or stem cells into hydrogels is a promising repair strategy for cartilage [5-8].

In such a strategy, preformed hydrogels with a permanent shape generally need to be surgically implanted into the cartilage defects. However, good attachment and integration of the preformed hydrogel in native cartilage is not easily realized because the defects usually have an irregular shape. Alternatively, injectable hydrogels, which are implanted via injection of a viscous polymer solution which subsequently gels in situ at the defect site, offer an opportunity to circumvent this problem. These injectable hydrogels allow a homogenous encapsulation of chondrocytes and bioactive molecules during the gelation process which may facilitate the formation of a new matrix.

One of the most studied methods to induce hydrogel formation at a cartilage defect site is photocrosslinking of vinyl functionalized polymers e.g. poly(ethylene glycol) (PEG) di(meth)acrylate [9-12]. Elisseeff et al. pioneered on injectable PEG-based hydrogels via transdermal photopolymerization for cartilage repair in vitro and in vivo and showed that neocartilage was formed after 7 weeks [11]. In another study, Bryant et al. fabricated biodegradable hydrogels based on PEG and polylactide (PLA) via photocrosslinking and examined neocartilage formation in the hydrogels at different degradation rates [13-15]. One of the limitations of the photocrosslinking method to prepare injectable hydrogels is the potential cytotoxicity of photo-initiators and UV light on cells $[11,16]$. Besides, the transmittance of UV light through the skin decreases with increasing skin thickness and no UV light penetrates the human skin when the thickness is above $2 \mathrm{~mm}$ [11]. Thus for hydrogel formation by photopolymerization in a cartilage defect, UV light needs to be placed in close proximity of the defect.

Another approach to prepare injectable hydrogels as artificial cartilage matrices is the use of the Michael-type addition reaction to crosslink precursor macromers. Crosslinks are formed via addition reactions between nucleophiles (e.g., thiol groups) and electrophiles (e.g., vinyl/acrylate groups) [17]. By this approach, Park et al. reported on branched PEGvinylsulfone macromers that were crosslinked with thiol-bearing MMP-sensitive peptides to form a 3-dimensional network in situ under physiological conditions [18]. Gene expression experiments by real-time RT-PCR demonstrated the expression of type II collagen and aggrecan by chondrocytes. Recently, our group prepared injectable hydrogels based on vinyl sulfone conjugated dextrans and PEG thiols via the Michael addition reaction [19, 20]. Since cells do not adhere to dextran and PEG [21, 22], the hydrogels are expected not to facilitate the attachment of chondrocytes within the gels during the cartilage regeneration process.

Hyaluronic acid (HA), consisting of disaccharide units of glucuronic acid and Nacetylglucosamine [23], is a key glycosaminoglycan (GAG) component distributed 
throughout the ECM of cartilage and is a major constituent of synovial fluid. HA is a biodegradable polysaccharide which can be metabolized via enzymatic hydrolysis by hyaluronidase (HAse), an enzyme present in various mammalian tissues [24]. HA may interact with chondrocytes through surface receptors like CD44, enabling modulation of cell activity such as migration, proliferation and differentiation as well as matrix secretion [25-27]. Therefore, HA is considered as a promising material for cell delivery in cartilage regeneration. Various reports on injectable HA-based hydrogels for cartilage repair have been published with photocrosslinking as a gelation method [12, 28-32]. To the best of our knowledge, only a few studies in cartilage tissue engineering make use of HA-based hydrogels that are prepared by the Michael addition method. For example, Liu et al. reported on HA-based hydrogels via Michael addition reactions between thiolated HA, thiolated gelatin, and acrylated PEG for the repair of osteochondral defects in a rabbit model [33]. The results showed that defects filled with Mesenchymal Stem Cells (MSC) seeded hydrogels resulted in an elastic, firm, translucent cartilage with good integration with the surrounding cartilage.

In this study, HA-based hydrogels were prepared via the Michael type addition of thiolated HA (HA-SH) and 4-arm PEG-vinylsulfone (PEG-4VS). We focused our attention on factors important for successful application of an injectable hydrogel like gelation rate, enzymatic degradation profile, and mechanical moduli. The degree of substitution of HA$\mathrm{SH}$, the molecular weight of $\mathrm{HA}$ and PEG, as well as concentration of the precursor solutions were taken into account. Biocompatibility, biodegradability, cytotoxicity and cartilage formation were studied in vitro by cell culture experiments using bovine chondrocytes incorporated inside the gels.

\subsection{Materials and methods}

Materials. Hyaluronic acid sodium salt (HA), N-(3-dimethylaminopropyl)- $N$ 'ethylcarbodiimide hydrochloride (EDAC), $N$-hydroxysuccinimide (NHS), dithiothreitol (DTT), calcium hydride $\left(\mathrm{CaH}_{2}\right)$ and divinyl sulfone (DVS) were purchased from Fluka. Sodium hydride $(\mathrm{NaH})$ and glacial acetic acid were obtained from Aldrich and SigmaAldrich, respectively. Hyaluronidase (Type VIII, lyophilized powder, 298 units/mg) was purchased from Sigma and used without further purification. The 4-arm poly(ethylene glycol)s (4-arm PEG, $\mathrm{M}_{\mathrm{n}, \mathrm{MALDI}}=1.06 \times 10^{4} \mathrm{~g} / \mathrm{mol}, \mathrm{M}_{\mathrm{w}} / \mathrm{M}_{\mathrm{n}}=1.02$, denoted as PEG10k, and $\mathrm{M}_{\mathrm{n}, \mathrm{MALDI}}=5.11 \times 10^{3} \mathrm{~g} / \mathrm{mol}, \mathrm{M}_{\mathrm{w}} / \mathrm{M}_{\mathrm{n}}=1.04$, denoted as PEG5k) were purchased from Jenkem Technology Co., LTD. All PEGs were dried by azeotropic distillation of toluene. Toluene was previously dried over sodium wire followed by distillation. Dichloromethane was dried 
over calcium hydride and distilled before use. Phosphate buffered saline (PBS, pH 7.4) was purchased from Invitrogen. All other solvents were used as received.

Degradation and thiolation of hyaluronic acid. HA of low molecular weight was obtained by degradation of commercially available HA $\left(\sim 1.8 \times 10^{6} \mathrm{~g} / \mathrm{mol}\right.$ by viscosity measurement) in acidic solutions. In a typical example, high molecular weight HA (5 g) was dissolved in $500 \mathrm{~mL}$ of distilled water, and the $\mathrm{pH}$ of the solution was adjusted to ca. 0.5 by the addition of $4 \mathrm{M} \mathrm{HCl}$. The degradation was carried out at $37{ }^{\circ} \mathrm{C}$ with continuous stirring for $3 \mathrm{~d}$. Subsequently, the $\mathrm{pH}$ of the solution was adjusted to 7 by the addition of $4 \mathrm{M} \mathrm{NaOH}$. The solution was dialyzed against water (MWCO 6000-8000) and freeze-dried to give the degraded HA as a white foam. The molecular weight of the degraded HA was determined by a viscosity measurement [34] and calculated to be approximately $45 \mathrm{~kg} / \mathrm{mol}$. A similar procedure was applied for the degradation of $\mathrm{HA}$ in an $\mathrm{HCl}$ solution at $\mathrm{pH} 1$. After dialysis against water (MWCO 12000-14000) and free-drying, HA with a molecular weight of approximately $185 \mathrm{~kg} / \mathrm{mol}$ was obtained.

Conjugation of HA was carried out using a one-pot synthesis procedure [35]. Typically, HA45k (200 mg) was dissolved in $20 \mathrm{~mL}$ of water. To the solution, a three molar excess (relative to the carboxylic acid groups in HA) of EDAC (287 mg, $1.5 \mathrm{mmol}$ ) and NHS (172 $\mathrm{mg}, 1.5 \mathrm{mmol}$ ) were added and the $\mathrm{pH}$ of the solution was adjusted to $4-5$ by the addition of $4 \mathrm{M} \mathrm{HCl}$. After $2 \mathrm{~h}$, cystamine dihydrochloride $(337 \mathrm{mg}, 1.5 \mathrm{mmol}$ ) was added. After 2 days, the reaction was stopped by neutralizing the solution with the addition of $4 \mathrm{M} \mathrm{NaOH}$. DTT (2.3 g, $15 \mathrm{mmol}$ ) was dissolved in $5 \mathrm{~mL}$ of water and added to the mixture. After the mixture was stirred for $24 \mathrm{~h}$ under $\mathrm{N}_{2}$, the $\mathrm{pH}$ of the reaction mixture was adjusted to $\mathrm{pH} 5$ by the addition of $4 \mathrm{M} \mathrm{HCl}$. The solution was first dialyzed (MWCO 12000-14000) against dilute $\mathrm{HCl}(\mathrm{pH}$ ) containing $4 \mathrm{~g} / \mathrm{L} \mathrm{NaCl}$ followed by dialysis against dilute $\mathrm{HCl}(\mathrm{pH}$ ). After dialysis, the $\mathrm{pH}$ of the solution was readjusted to 7 by the addition of $1 \mathrm{M} \mathrm{NaOH}$ and then quickly immersed in liquid $\mathrm{N}_{2}$. The conjugated HA containing free thiol groups (denoted as HA-SH) was obtained as a white foam by freeze-drying. The degree of substitution of free thiol groups (DS, Ellman method) [36] was 10. Yield: 90\%. ${ }^{1} \mathrm{H}$ NMR $\left(\mathrm{D}_{2} \mathrm{O}\right): \delta=4.5$ ( $\mathrm{HA}$ anomeric proton), 3.0-4.1 (HA ring protons), $2.6\left(\mathrm{NH}-\mathrm{CH}_{2}-\mathrm{CH}_{2}-\mathrm{SH}\right.$ ),

\section{$2.4\left(\mathrm{NH}-\mathrm{CH}_{2}-\underline{\mathrm{C}}_{2}-\mathrm{SH}\right), 1.9\left(\mathrm{NHCOCH}_{3}\right)$.}

Synthesis of poly(ethylene glycol) vinyl sulfone. PEG vinyl sulfone (denoted as PEGVS) was synthesized from 4-arm PEG and divinyl sulfone according to a modified procedure reported by Hubbell et al. [37]. Typically, 4-arm PEG (2 g, $0.8 \mathrm{mmol} \mathrm{OH})$ was dissolved in $30 \mathrm{~mL}$ of dichloromethane under a nitrogen atmosphere. To the solution, 10 $\mathrm{mL}$ of dichloromethane containing sodium hydride $(96 \mathrm{mg}, 4 \mathrm{mmol}$ ) was added and the reaction mixture was stirred for $1 \mathrm{~h}$. After hydrogen evolution, the mixture was added dropwise to $20 \mathrm{~mL}$ of a dichloromethane solution containing divinyl sulfone $(4.7 \mathrm{~g}, 40$ 
mmol) under a nitrogen atmosphere. The reaction mixture was stirred for $3 \mathrm{~d}$ in the dark. After neutralization with glacial acetic acid to a $\mathrm{pH}$ of 7 , the mixture was filtrated and the filtrate was concentrated. The product was recovered by precipitation in cold diethyl ether and purified by ultrafiltration (MWCO 1000). The final product was obtained by freezedrying. The degree of end group conversion was calculated to be $98 \%$ from ${ }^{1} \mathrm{H}$ NMR. Yield: $72 \%$. ${ }^{1} \mathrm{H}$ NMR $\left(\mathrm{CD}_{3} \mathrm{Cl}\right): \delta=3.2-3.3\left(-\mathrm{O}-\underline{\mathrm{C}}_{2}-\mathrm{CH}_{2}-\mathrm{SO}_{2}-\right)$, 3.6-3.7 (-C $\left.\underline{\mathrm{H}}_{2}-\underline{\mathrm{C}}_{2}-\mathrm{O}-\right), 3.8-3.9$ (O- $\left.\mathrm{CH}_{2}-\underline{\mathrm{C}}_{2}-\mathrm{SO}_{2}-\right), 6.1$ ( $\left.\underline{\mathrm{CH}}_{2}=\mathrm{CH}-\right), 6.4\left(\mathrm{C}_{2}=\mathrm{CH}-\right), 6.8\left(\mathrm{CH}_{2}=\mathrm{C} \underline{\mathrm{H}}-\right)$.

Polymer characterizations. ${ }^{1} \mathrm{H}$ NMR $(300 \mathrm{MHz})$ spectra were recorded on a Varian Inova spectrometer (Varian, Palo Alto, USA). Samples of 10-20 mg each were prepared and dissolved in $0.8 \mathrm{~mL}$ of $\mathrm{D}_{2} \mathrm{O}$ or $\mathrm{CD}_{3} \mathrm{Cl}$. The signals of non deuterated solvent residues were used as a reference for the ${ }^{1} \mathrm{H}$ NMR chemical shifts and were set at $\delta 4.79$ and 7.26 for water and chloroform, respectively. The degree of end group conversion of PEG-VS was calculated from ${ }^{1} \mathrm{H}$ NMR spectra by comparing the integrals of signals at $\delta 3.6-3.7$ (PEG main chain protons) and $\delta$ 6.1-6.8 (vinyl sulfone protons). The number of free thiol groups of HA-SH was determined by the Ellman method [36]. The absorption at $412 \mathrm{~nm}$ of diluted HA-SH (in PBS) was recorded using a Cary 300 Bio UV-Visible Spectrophotometer (Varian) and the free thiol concentration was calculated using a calibration curve derived from a series of mercaptoethanol solutions.

Hydrogel formation and gelation time. To determine the gelation time, $200 \mu \mathrm{L}$ samples of HA-SH and PEG-VS (molar ratio of thiol to vinyl sulfone was kept at 1.2 unless otherwise mentioned) in PBS were mixed in vials by vortexing and kept at $37{ }^{\circ} \mathrm{C}$. The concentration is defined as the total dry weight of both PEG-VS and HA-SH per volume of buffer. The time to form a gel (denoted as gelation time) was determined using the vial tilting method. No flow within 1 min upon inverting the vial was regarded as the gel state. The experiments were performed in triplicate.

Swelling and degradation. Hydrogel samples $(0.4 \mathrm{~mL})$ were prepared in vials according to the procedure described above and accurately weighed $\left(\mathrm{W}_{\mathrm{i}}\right)$. Subsequently, $2 \mathrm{~mL}$ of chondrocyte expansion medium (DMEM with 10\% FBS, $10 \mathrm{mM}$ HEPES, $0.1 \mathrm{mM}$ nonessential amino acid, $0.2 \mathrm{mM}$ ascorbic acid, $100 \mathrm{U} / \mathrm{ml}$ penicillin, $100 \mu \mathrm{g} / \mathrm{ml}$ streptomycin and $0.4 \mathrm{mM}$ proline) containing $100 \mathrm{U} / \mathrm{mL}$ hyaluronidase (HAse) was applied on top of the hydrogels followed by incubation at $37^{\circ} \mathrm{C}$. At regular time intervals, the medium was removed from the samples and the hydrogels were weighed $\left(\mathrm{W}_{\mathrm{t}}\right)$. The swelling ratio of hydrogels was calculated from the equation $\mathrm{W}_{\mathrm{t}} / \mathrm{W}_{\mathrm{i}} \times 100 \%$. The degradation time was defined as the time needed for the gel to disappear $\left(\mathrm{W}_{t}=0\right)$. The medium was replaced twice a week and the experiments were performed in triplicate.

Rheological analysis. Rheological experiments were carried out with a MCR 301 rheometer (Anton Paar) using parallel plates $\left(25 \mathrm{~mm}\right.$ diameter, $0^{\circ}$ ) configuration at $37^{\circ} \mathrm{C}$ in 
the oscillatory mode. In a typical example, $350 \mu \mathrm{L}$ of HA-SH and PEG-VS in PBS were mixed using a double syringe $(2.5 \mathrm{~mL}, 1: 1$ volume ratio) equipped with a mixing chamber (Mixpac). After the samples were applied to the rheometer, the upper plate was immediately lowered to a measuring gap size of $1 \mathrm{~mm}$, and the measurement started. To prevent water evaporation, a layer of oil was introduced around the polymer sample. The storage modulus $\left(\mathrm{G}^{\prime}\right)$ was recorded at a frequency of $1 \mathrm{~Hz}$ and a strain of $1 \%$.

In situ chondrocyte incorporation. Chondrocytes from bovine cartilage were isolated as previously described and used in passage 2 [38]. A $4.5 \%(\mathrm{w} / \mathrm{v})$ stock solution of HA185k-SH DS28 in sterilized PBS was exposed to UV (Bio-Rad Gel Doc 2000). A 6.9\% $(\mathrm{w} / \mathrm{v})$ stock solution of PEG5k-4VS in medium was sterilized via filtration through a filter with a pore size of $0.22 \mu \mathrm{m}$. To incorporate chondrocytes, $0.2 \mathrm{~mL}$ of the PEG5k-4VS stock solution was mixed with $0.2 \mathrm{~mL}$ chondrocyte/medium suspension and subsequently $0.4 \mathrm{~mL}$ of the HA185k-SH DS 28 stock solution was added. The resulting solutions were gently mixed. The final concentration of the hydrogel was $4 \%(\mathrm{w} / \mathrm{v})$ and the cell seeding density in the gels was $5 \times 10^{6}$ cells $/ \mathrm{mL}$. For cytotoxicity and degradation studies, the cell/gel constructs were cultured in a chondrocyte expansion medium. To assess matrix production by the chondrocytes, the constructs were cultured in a chondrocyte differentiation medium composed of DMEM high glucose with $0.1 \mu \mathrm{M}$ dexamethasone (Sigma), $100 \mu \mathrm{g} / \mathrm{mL}$ sodium pyruvate (Sigma), $0.2 \mathrm{mM}$ ascorbic acid, $50 \mathrm{mg} / \mathrm{mL}$ insulin-transferrin-selenite (ITS+Premix, BD biosciences), $100 \mathrm{U} / \mathrm{ml}$ penicillin, $100 \mu \mathrm{g} / \mathrm{ml}$ streptomycin and $10 \mathrm{ng} / \mathrm{mL}$ transforming growth factor $\beta 3$ (TGF- $\beta 3, R \& D$ system). The samples were incubated in a humidified atmosphere of $5 \% \mathrm{CO}_{2}$ at $37^{\circ} \mathrm{C}$. The medium was replaced every 2 or 3 days.

Cytotoxicity assay. To investigate chondrocyte viability in the hydrogels, a fluorescence Live/Dead assay (Invitrogen) was used. At days 1, 7 and 14, the hydrogel constructs were rinsed with PBS and stained with calcein AM/ethidium homodimer, according to the manufacturer's instructions. Hydrogel/cell constructs were visualized using fluorescence microscopy (Zeiss). As a result living cells fluoresce green and the nuclei of dead cells red. Quantification of total DNA in the cell/gel constructs (50 $\mu \mathrm{L}$ of each) was performed with a CyQuant dye kit (Molecular Probes) following the manufacturer's instructions using a fluorescent plate reader (Perkin Elmer) at an excitation of $480 \mathrm{~nm}$ and an emission of 520 $\mathrm{nm}$. Data ( $\mathrm{n}=3$, measured in triplicate) are expressed as mean \pm standard deviation (SD).

Hydrogel degradation in the presence of chondrocytes. Gel/cell constructs of $0.1 \mathrm{~mL}$ were prepared in a culture plate as described above and weighed $\left(\mathrm{W}_{\mathrm{ci}}\right)$. About $2 \mathrm{~mL}$ of chondrocyte expansion medium was added to each gel (the gel was fully immersed in the medium) and the constructs were incubated in a humidified atmosphere of $5 \% \mathrm{CO}_{2}$ at $37^{\circ} \mathrm{C}$. The medium was replaced every 2-3 days and the cell/gel constructs were weighed at regular time intervals $\left(\mathrm{W}_{\mathrm{ct}}\right)$. The swelling ratio of the constructs was calculated from the 
equation $\mathrm{W}_{\mathrm{ct}} / \mathrm{W}_{\mathrm{ci}} \times 100 \%$. Afterwards, the constructs were washed extensively with water to remove salts and then freeze-dried. The freeze-dried samples were weighed $\left(\mathrm{W}_{\text {cdt }}\right)$. The degradation profiles of the hydrogels with chondrocytes were determined from the remaining dry gel masses. HA185k-SH DS 28/PEG5k-4VS hydrogels without cells cultured under the same condition were used as a control.

Matrix production. For histological analysis, samples were fixed in $10 \%$ formalin for 1 $\mathrm{h}$, embedded in paraffin, and processed using standard histological procedures. Sections (5 $\mu \mathrm{m}$ thick) were stained for chondroitin sulfate (CS) using an immunofluorescent staining. Briefly, the hydrogel sections were rehydrated with xylene and series of ethanol (from $100 \%$ until 70\%). The slides were left in distilled water for 10 minutes. The samples were incubated with $0.5 \mathrm{U} / \mathrm{ml}$ Chondroitinase ABC (Sigma) (diluted in PBS $+1 \%$ BSA (Sigma)) to expose the chondroitin sulfate epitopes for $1 \mathrm{~h}$, and afterwards rinsed with PBS. Then the samples were treated with anti-chondroitin-6-sulfate (clone MK-302, Chemicon) (1:50) in PBS $+1 \%$ BSA overnight at $4^{\circ} \mathrm{C}$, followed by rinsing with PBS. A negative sample was included without primary antibody (replaced by PBS). All the samples were incubated with goat anti-mouse IgG labeled with Alexa Fluor 488 (1:100 in PBS+1\% BSA) (Invitrogen) for $1 \mathrm{~h}$ at room temperature. Counterstaining of nuclei was performed with DAPI for $10 \mathrm{~min}$. The samples were washed with distilled water and the slides were embedded with VECTASHIELD Mounting Medium (Vector Laboratories, Burlingame, CA) for further visualization under the fluorescence microscope (Zeiss).

The production of collagen type II was investigated using immunofluorescent staining of Col2A1. After rehydration, the samples were treated with $10 \mathrm{mM}$ citric acid buffer ( $\mathrm{pH}$ 6.0) for 10 minutes, and then were washed with PBS/BSA 1\%. Sections were incubated overnight with a Col2A1 monoclonal antibody (Purified mouse immunoglobulin IgG1, clone 3HH1-F9, Abnova, diluted at 1:100 in PBS/BSA 1\%). After washing twice for 5 min in PBS/BSA 1\%, sections were incubated with Alexa Fluor 488-Goat anti-Mouse IgG1 $(\gamma 1)$ (Invitrogen, Molecular Probes, 1:1000) for 1 hour. After extensive washes, the sections were embedded with VECTASHIELD Mounting Medium supplemented with DAPI (Vector Laboratories, Burlingame, CA).

To quantitatively analyze the GAG production in the hydrogels a dimethylmethylene blue (DMMB) assay was performed. The constructs were taken from the chondrocyte differentiation medium after 1, 14 and 21 days. Samples were washed with PBS and frozen at $-80{ }^{\circ} \mathrm{C}$ overnight. After freeze drying, the constructs were digested using proteinase-K (Sigma) at $56{ }^{\circ} \mathrm{C}(>16 \mathrm{~h})$. The amount of GAG was determined spectrophotometrically after reaction with dimethylmethylene blue (DMMB, Sigma-Aldrich). The intensity of color change was quantified immediately in a microplate reader (Bio-TEK Instruments) by measuring the absorbance at $540 \mathrm{~nm}$. The amount of GAG was calculated using a standard 
curve of chondroitin sulphate A or B (Sigma-Aldrich). The total collagen content was determined using the hydroxyproline assay [39]. Aliquots of digested solutions were hydrolyzed in $6 \mathrm{M} \mathrm{HCl}$ at $100^{\circ} \mathrm{C}$ for $24 \mathrm{~h}$, dried under vacuum and resuspended in buffer ( $0.16 \mathrm{M}$ citric acid, $0.8 \% \mathrm{v} / \mathrm{v}$ glacial acetic acid, $0.6 \mathrm{M}$ sodium acetate, $0.57 \mathrm{M}$ sodium hydroxide, $20 \% \mathrm{v} / \mathrm{v}$ n-propanol, $\mathrm{pH}$ 6.0). The hydroxyproline content was determined via a colorimetric assay by reaction with chloramine $\mathrm{T}$ and dimethylaminobenzaldehyde. All values were corrected for the background staining of gels without cells and normalized to DNA content (expressed as GAG or collagen $(\mu \mathrm{g}) / \mathrm{DNA}(\mu \mathrm{g})$ ). Data $(\mathrm{n}=3$, measured in triplicate) are expressed as mean \pm standard deviation (SD).

Statistical analysis. Statistical differences between the experimental data of two groups were analyzed using a Student's $t$-test. Those among three or more groups were analyzed using the One-way Analysis of Variance (ANOVA) with Turkey's post-hoc analysis. Statistical significance was set to a $p$ value $\leq 0.05$. Results are presented as mean \pm standard deviation.

\subsection{Results and discussion}

\subsubsection{Synthesis and characterization of HA-SH and PEG-VS}

Low molecular weight HAs were prepared by hydrolytic degradation of a high molecular weight HA $\left(\sim 1.8 \times 10^{6} \mathrm{~g} / \mathrm{mol}\right)$ in acidic solutions and were purified by exhaustive dialysis and isolated after freeze-drying. The molecular weights of these HAs were approximately $185 \mathrm{k}$ and $45 \mathrm{k}$, as determined by viscosity measurements. Thiolated hyaluronic acids (HA$\mathrm{SHs}$ ) were prepared in a two-step reaction shown in Figure 3.1.

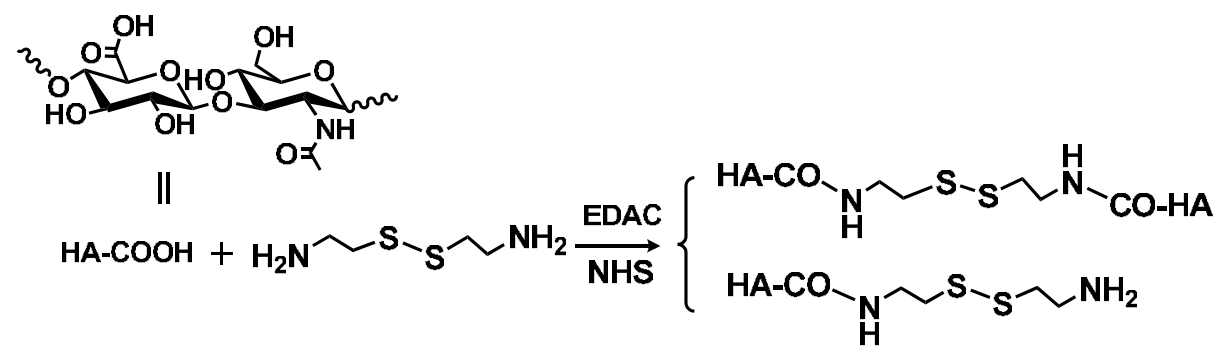

(1)

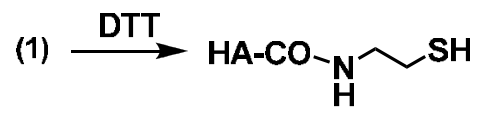

Figure 3.1. Conjugation of hyaluronic acid to prepare HA-SH. 
The hyaluronic acids were modified by reacting the carboxylic groups of HA with the amine groups of cystamine dihydrochloride (Cys) using EDAC/NHS activation at an optimal $\mathrm{pH}$ of 4-5 at room temperature [40]. During the reaction, the solution became turbid or formed a gel. Subsequently, disulfide bonds were cleaved using an excess amount of the reductive reagent DTT at a $\mathrm{pH}$ of 7-8 for $24 \mathrm{~h}$. The final product (HA-SH) was purified by dialysis and isolated after freeze-drying in a yield of over $90 \%$ (Table 3.1 ). The ${ }^{1} \mathrm{H}$ NMR spectrum of HA-SH showed two signals at $\delta 2.4$ and 2.6 (Figure 3.2, peaks 2 and 3 ), belonging to the methylene protons of the cysteamine moieties. The degree of substitution (DS), defined as the number of free thiol groups per 100 repeat units of HA, was determined by an Ellman test. The DS of HA-SH increased from 10 to 28 when the molar feed ratio of $\mathrm{COOH} / \mathrm{Cys}$ was increased from 1:3 to 1:6 (Table 3.1).

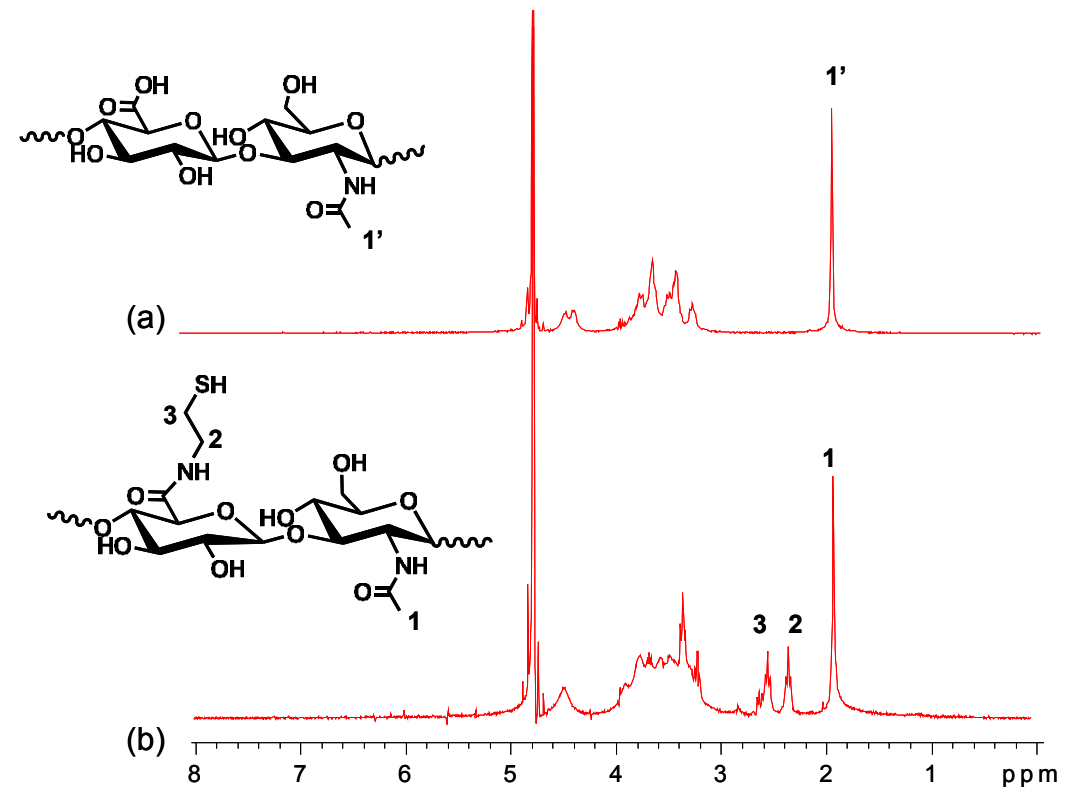

Figure 3.2. ${ }^{1} \mathrm{H}$ NMR spectra of (a) HA-SH and (b) unmodified HA in $\mathrm{D}_{2} \mathrm{O}$

Vinyl sulfone functionalized poly(ethylene glycol) (PEG-VS) was synthesized by a single step reaction between 4-arm PEG $\left(\mathrm{M}_{\mathrm{n}}, 5,000\right.$ or $\left.10,000 \mathrm{~g} / \mathrm{mol}\right)$ and an excess amount of divinyl sulfone (DVS, molar ratio of DVS to PEG hydroxyl groups was 50) in the presence of $\mathrm{NaH}$ in dichloromethane. The PEG-VS was purified by precipitation and ultrafiltration, and finally obtained in solid form after freeze-drying in yields of $80-90 \%$. The degree of end group conversion was determined from ${ }^{1} \mathrm{H}$ NMR spectra by comparing the integrals of signals at $\delta$ 3.6-3.7 (PEG main chain protons) and $\delta$ 6.1-6.8 (vinyl sulfone protons). High conversions ( $>94 \%$ ) were obtained for 4 -arm PEGs with molecular weights of 5,000 and 10,000 g/mol (denoted as PEG5k-4VS and PEG10k-4VS), respectively. 
Table 3.1. Molecular weight (MW) of HA and degree of substitution of thiolated HA.

\begin{tabular}{l|c|c|c|c}
\hline \multirow{2}{*}{ Sample code } & $\begin{array}{r}\text { MW (kg/mol) } \\
\text { of starting HA }\end{array}$ & $\begin{array}{c}\text { Molar feed ratio } \\
\text { of COOH/Cys }\end{array}$ & DS & Yield \\
\hline HA185k-SH DS 10 & \multirow{2}{*}{$185 \pm 42$} & $1: 3$ & 10 & $90 \%$ \\
\cline { 3 - 5 } HA185k-SH DS 28 & \multirow{2}{*}{$45 \pm 7$} & $1: 6$ & 28 & $95 \%$ \\
\cline { 3 - 5 } HA45k-SH DS 11 & $1: 3$ & 11 & $94 \%$ \\
\hline HA45k-SH DS 27 & & $1: 6$ & 27 & $96 \%$ \\
\hline
\end{tabular}

\subsubsection{Hydrogel formation and gelation time}

Hydrogels were formed in situ via Michael addition between the HA-SH and the PEG4VS in PBS at $37^{\circ} \mathrm{C}$. The molar ratio of thiol groups to vinyl sulfone groups was kept at 1.2. The polymer concentration was defined as the total dry weight of both PEG-VS and HA$\mathrm{SH}$ per volume of buffer. The gelation time was determined by the vial tilting method. The influence of molecular weight, DS and polymer concentration on the gelation times of hydrogels was first determined.

In Figure 3.3a the gelation times of HA185k-SH with a DS of 10 or 28 and HA45k-SH with a DS of 27 crosslinked with PEG10k-4VS as a function of the polymer concentration ranging from 2 to $6 \%(\mathrm{w} / \mathrm{v})$ is depicted. The gelation times were significantly reduced with increasing polymer concentration $(p<0.05)$, which could be attributed to an increase in the number of functional groups per volume of gel precursor. The gelation times of HA$\mathrm{SH} / \mathrm{PEG10k-4VS}$ hydrogels decreased with an increasing molecular weight of HA from $45 \mathrm{k}$ to $185 \mathrm{k}$ at similar DS values $(p<0.05)$. For example, at a polymer concentration of $4 \%$ $(\mathrm{w} / \mathrm{v})$, the gelation time is about $8 \mathrm{~min}$ for HA45k-SH DS27/PEG10k-4VS, but $4 \mathrm{~min}$ for HA185k-SH DS28/PEG10k-4VS. This was most likely due to the higher number of thiol groups per HA molecule in HA185k-SH DS28 than in HA45k-SH DS27. However, at a high polymer concentration of $6 \%(\mathrm{w} / \mathrm{v})$ only a minor difference in the gelation times was observed for the hydrogels prepared from HA185k-SH DS28 and HA45k-SH DS27. The HA45k-SH DS11 was not able to form a hydrogel with PEG10k-4VS at polymer concentrations ranging from 2 to $6 \%$ (w/v) (data not shown). On the other hand, hydrogels prepared from HA185k-SH and PEG10k-4VS with DS 10 and 28 revealed similar gelation times of about $4 \mathrm{~min}$ at a polymer concentration of $4 \%$ (w/v) (Figure 3.3a). 
The influence of the PEG-VS molecular weight on the gelation time when crosslinked with HA185k-SH DS 28 at concentrations of 2 to $6 \%(\mathrm{w} / \mathrm{v})$ is shown in Figure $3.3 \mathrm{~b}$. The gelation time for those hydrogels decreased from 4 min to less than 1 min with increasing polymer concentrations. At the same polymer concentrations, PEG5k-4VS gave faster gelation than PEG10k-4VS, which may be due to the higher number of crosslinks present in PEG5k-4VS hydrogels.

In general, the HA-SH/PEG-4VS hydrogels showed shorter gelation times (less than about $5 \mathrm{~min}$ ) than hydrogels based on dithiol peptides/PEG-4VS (about $13 \mathrm{~min}$ ) [37], HAthiol/PEG diacrylate (ca. 5-30 min) and HA-thiol/PEG dimethacrylate (several days) under physiological conditions [41]. More recently, we reported on hydrogels prepared from thiolated dextran and 4-arm PEG tetra-acrylate. The gelation times of those systems are similar to the HA-SH/PEG-VS hydrogels described here, but at higher polymer concentrations $(10-20 \%(\mathrm{w} / \mathrm{v}))$ [19]. The relatively fast gelation of HA-SH/PEG-VS hydrogels at low polymer concentrations may be attributed to a higher reactivity of vinyl sulfone groups compared to (meth)acrylate groups [19, 20]. Fast gelation is preferred especially for injectable hydrogels, since slow gelation in vivo may result in diffusion of hydrogel precursors or bioactive molecules to surrounding areas or failure of gel formation. Besides, a heterogeneous incorporation of cells in the gel may occur due to the gravity.
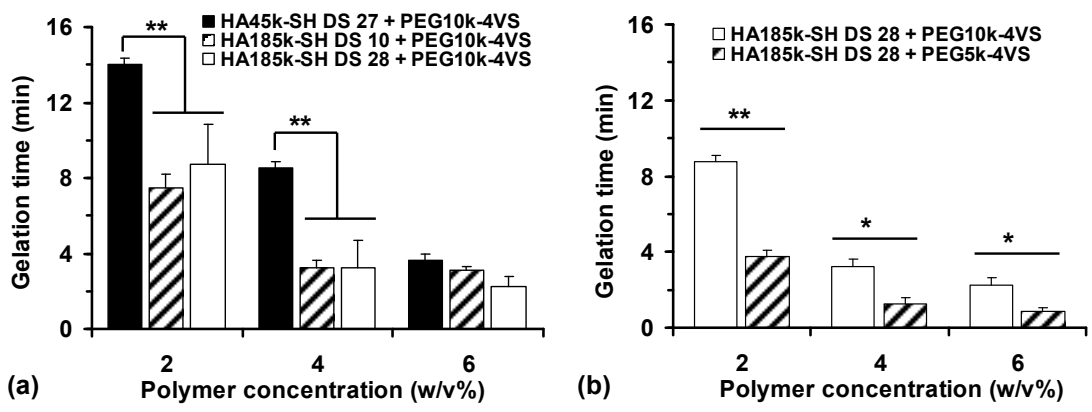

Figure 3.3. Gelation times determined by the vial tilting method after mixing solutions of HA-SH and PEG-4VS (molar ratio of SH to VS is 1.2) in PBS at $37^{\circ} \mathrm{C}(\mathrm{n}=3)$. (a) HA45k-SH DS 27, HA185k-SH DS 10 and HA185k-SH DS 28 with PEG10k-4VS as a function of polymer concentration; (b) HA185k-SH DS 28 with PEG10k-4VS and PEG5k-4VS as a function of polymer concentration. (* $p<0.05, * * p<0.01)$

\subsubsection{Swelling and degradation of hydrogels by hyaluronidase}

It is well known that HA is readily biodegraded by hyaluronidase (HAse) [42]. To study the swelling and degradation profiles of the hydrogels from HA-SH and PEG-4VS, $2 \mathrm{~mL}$ of chondrocyte expansion medium containing $100 \mathrm{U} / \mathrm{mL}$ HAse was applied on top of $0.4 \mathrm{~mL}$ of the hydrogels. The hydrogels were kept at $37{ }^{\circ} \mathrm{C}$ and their weights were monitored at 
regular intervals. The swelling ratios of the hydrogels at day $\mathrm{t}$ were calculated by rationing the weight of the swollen gel to the initial gel weight $\left(\mathrm{W}_{t} / \mathrm{W}_{\mathrm{i}} \times 100 \%\right)$. The swelling and degradation profiles of hydrogels from HA185k-SH DS 28 and PEG5k-4VS in the presence of the HAse as a function of time are presented in Figure 3.4a. In general, swelling ratios of the hydrogels first increased and then gradually decreased until complete degradation. The continuous swelling during the first time period was attributed to an increasing uptake of medium by the hydrogels during the enzymatic degradation process. In time degraded fragments became soluble and released from the gels. At a certain time point, the increase in the swelling is overtaken by the gel weight loss, which results in a decrease of the swelling ratio. The degradation time was defined as the time required to completely dissolve at least one of three hydrogel samples. At a low polymer concentration of $2 \%$ $(\mathrm{w} / \mathrm{v})$, the hydrogel was completely degraded at day 6 , while at higher polymer concentrations of 4 and $6 \%(\mathrm{w} / \mathrm{v})$, the gels were completely degraded at day 10 and 15 , respectively. The prolonged degradation times of the hydrogels with higher polymer concentrations results from the higher crosslinking densities (defined as the number of crosslinks per volume of gels) in the gels.
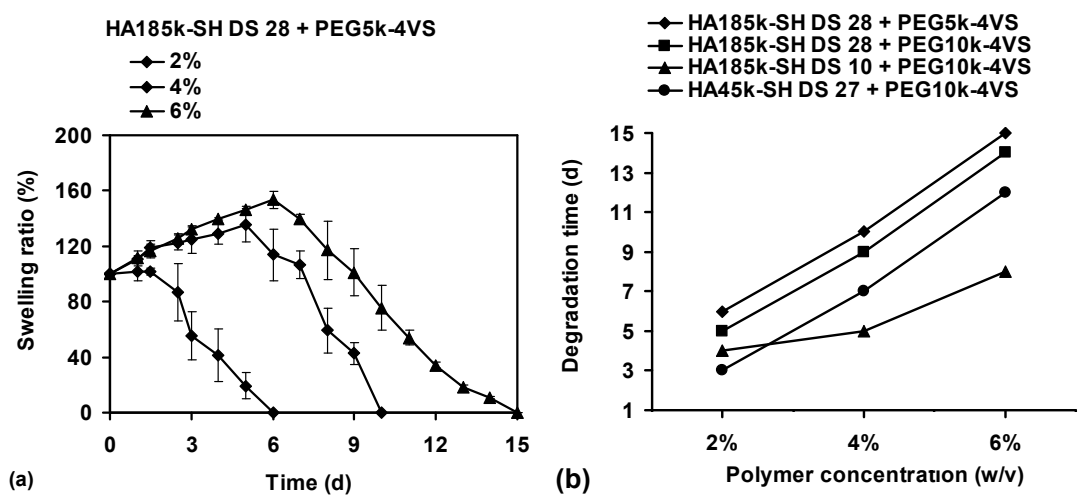

Figure 3.4. Swelling and degradation profiles of hydrogels prepared from HA-SH and PEG-4VS (molar ratio of SH to VS is 1.2) exposed to $100 \mathrm{U} / \mathrm{ml}$ HAse in expansion medium at $37^{\circ} \mathrm{C}(\mathrm{n}=3)$. (a) HA185k-SH DS 28 with PEG5k-4VS at polymer concentrations of 2, 4 and $6 \%(w / v)$; (b) Plots of degradation times of HA-SH / PEG-4VS hydrogels as a function of polymer concentration.

The molecular weight of the HA significantly influenced the degradation time of the hydrogels (Figure 3.4b). The hydrogels prepared from HA185k-SH DS 28 showed longer degradation times than those prepared from HA45k-SH DS 27 at the same polymer concentrations (5-14 d vs. 3-12 d). Moreover, degradation profiles of the hydrogels were also affected by the degree of substitution, rather than the molecular weight of the PEG. The hydrogels from HA185k-SH with a DS 28 clearly showed longer degradation times than those from HA185k-SH with DS 10 (6-15 d vs. 4-8 d). However, hydrogels prepared 
from HA185k-SH DS 28 and crosslinked with either PEG5k-4VS or PEG10k-4VS showed comparable degradation times (6-15 d vs. 5-14 d).

The in vivo degradation is dependent on the actual local enzyme concentration in cartilage tissue [43]. The HAse concentration $(100 \mathrm{U} / \mathrm{ml})$ used in this study is not representative for the concentration of HAse in vivo. Consequently, the results presented in Figure $3.4 \mathrm{~b}$ only show the dependence of gel composition and polymer concentrations.

\subsubsection{Rheological analysis}

The mechanical properties of the HA-SH/PEG-VS hydrogels were studied by oscillatory rheology experiments at $37^{\circ} \mathrm{C}$. PBS solutions of HA-SH and PEG-4VS were mixed using a double syringe equipped with a mixing chamber and quickly applied to the rheometer. The kinetics of the gelation was followed by monitoring the storage modulus ( $\left.G^{\prime}\right)$ and loss modulus (G") in time. The storage modulus gradually increased after mixing solutions of HA185k-SH DS 28 and PEG-4VS in PBS at a polymer concentration of 4\% (w/v) (Figure 3.5a). The crosslinking process was assumed to be completed when the $G$ ' and G' reached a plateau after $25 \mathrm{~min}$. The plateau modulus values of the hydrogels from HA185k-SH and PEG-4VS were recorded at $30 \mathrm{~min}$, as presented in Figure 3.5b. The G' plateau values of hydrogels prepared from HA185k-SH crosslinked with PEG10k-4VS ranged from 768 to $1030 \mathrm{~Pa}$ with the DS of thiol groups from 10 to 28. Moreover, storage moduli of 1610 and $1030 \mathrm{~Pa}$ were observed for hydrogels of HA185k-SH crosslinked with PEG5k-4VS and PEG10k-4VS at the same DS and polymer concentration. However, changes in the DS and molecular weight of PEG did not significantly influence the loss modulus of the hydrogels. Generally, the damping factors (defined as $G^{\prime} / G^{\prime}$ ) were in the range $0.01-0.02$, indicating the viscoelastic nature of these hydrogels.
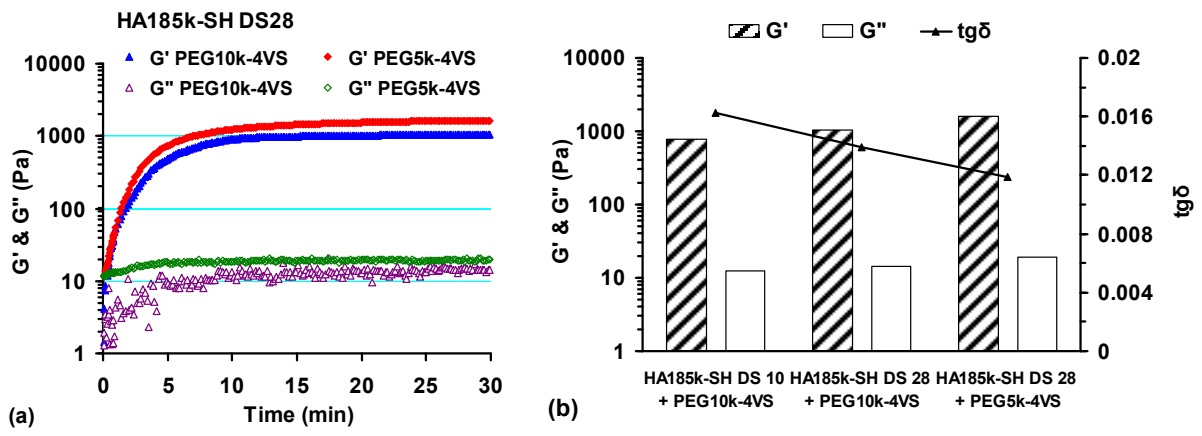

Figure 3.5. Rheological analysis of hydrogels of HA185k-SH crosslinked with PEG-4VS (molar ratio of SH to VS is 1.2) at a polymer concentration of $4 \%(\mathrm{w} / \mathrm{v})$ in PBS at $37{ }^{\circ} \mathrm{C}(\mathrm{n}=1)$. (a) Storage (G') and loss (G”) modulus as a function of time after mixing HA185k-SH DS 28 with PEG5k-4VS or PEG5k-4VS; (b) (G') and loss (G”) modulus plateau values as well as damping factors $\left(\operatorname{tg} \delta=G^{\prime \prime} / G^{\prime}\right)$ of hydrogels from HA185k-SH and PEG-4VS. 


\subsubsection{Cytotoxicity}

The biocompatibility of the HA-SH/PEG-VS hydrogels was evaluated by incorporating chondrocytes in $4 \%(\mathrm{w} / \mathrm{v})$ gels and examining their cell viability with Live-dead assay. Hydrogels from HA185k-SH DS 28 and PEG5k-4VS were chosen due to their relative shorter gelation time and higher mechanical properties compared to other HA-SH/PEG-VS hydrogels. The cytotoxicity results at day 1, 7 and 14 are shown in Figure 3.6. Live cells fluoresce green and dead cells fluoresce red. It was clearly seen that the chondrocytes were distributed homogeneously inside hydrogels and over $95 \%$ of the cells remained viable. It is worth mentioning that chondrocytes maintained their characteristic round shapes and cell division was observed (noted by arrows) after culturing for 2 weeks.
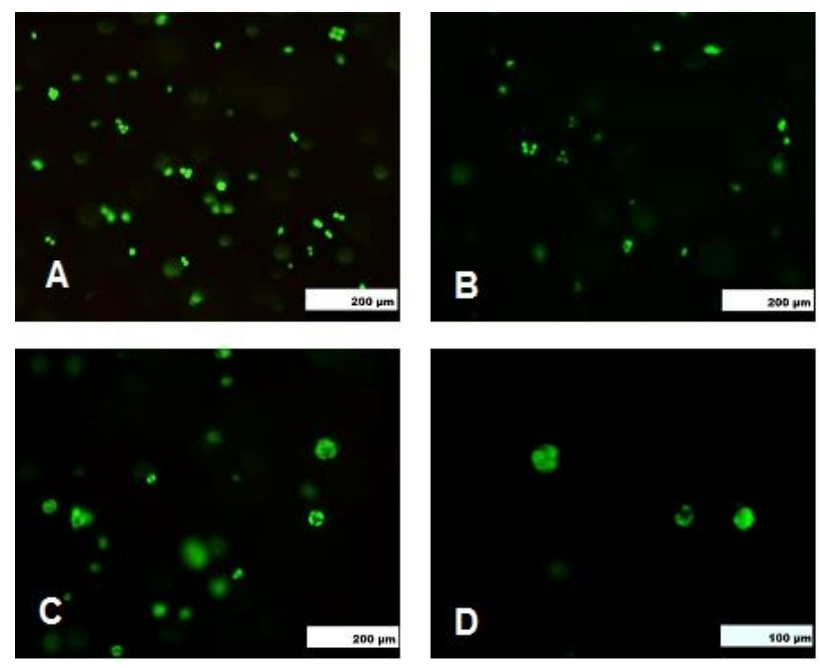

Figure 3.6. Live-dead assay showing homogeneous incorporation of chondrocytes in the $4 \%(\mathrm{w} / \mathrm{v})$ hydrogels from HA185k-SH crosslinked with PEG-4VS after 1 (A), 7 (B) and 14 (C and D) in culture (chondrocytes division indicated in Fig.6D). Cells were stained with calcein AM/Ethidium Homodimer. Chondrocyte seeding density was $5 \times 10^{6}$ cells $/ \mathrm{ml}$.

Quantitative evaluation of the cell viability was performed by CyQuant DNA assay (Figure 3.7). The results showed that during the first week, the DNA content per sample increased, indicative for the chondrocytes proliferation. However, a significant decrease in DNA content was observed after 14 days. When the DNA content was normalized to the dry gel mass, values increased from day 1 to day $7(p<0.05)$ and afterwards remained statistically constant $(p>0.05)$. Taken together with the results from the Live-dead assay, it is suggested that the decrease in the DNA content per gel after 14 days could be attributed to cell release into the medium during gel degradation. 


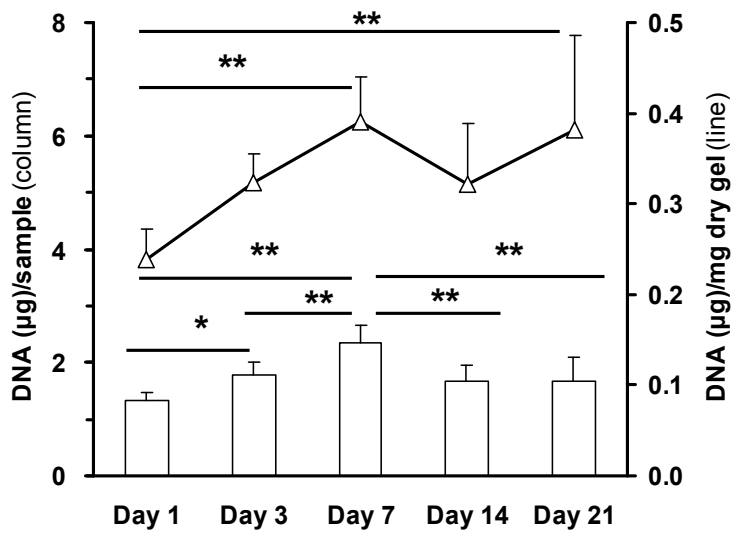

Figure 3.7. Quantitative evaluation of DNA content ( $\mu \mathrm{g}$, columns) and DNA content normalized to the dry gel mass ( $\mu \mathrm{g} / \mathrm{mg}$ dry gel mass, line) per cell/gel sample after in vitro culturing for $1,3,7,14$ and 21 days in chondrocyte expansion medium. $(* p<0.05, * * p<0.01)$

\subsubsection{Swelling and degradation of cell/gel constructs}

Chondrocytes are capable of expression of HAse that can degrade hyaluronic acid [44, 45]. In order to prove the biodegradability of the HA-based hydrogels with chondrocytes, swelling ratios of the hydrogels in the presence of chondrocytes (cell/gel constructs) were studied during cell culture over a period of 3 weeks. As a negative control, the swelling ratios of the hydrogels without the cells were studied in parallel.
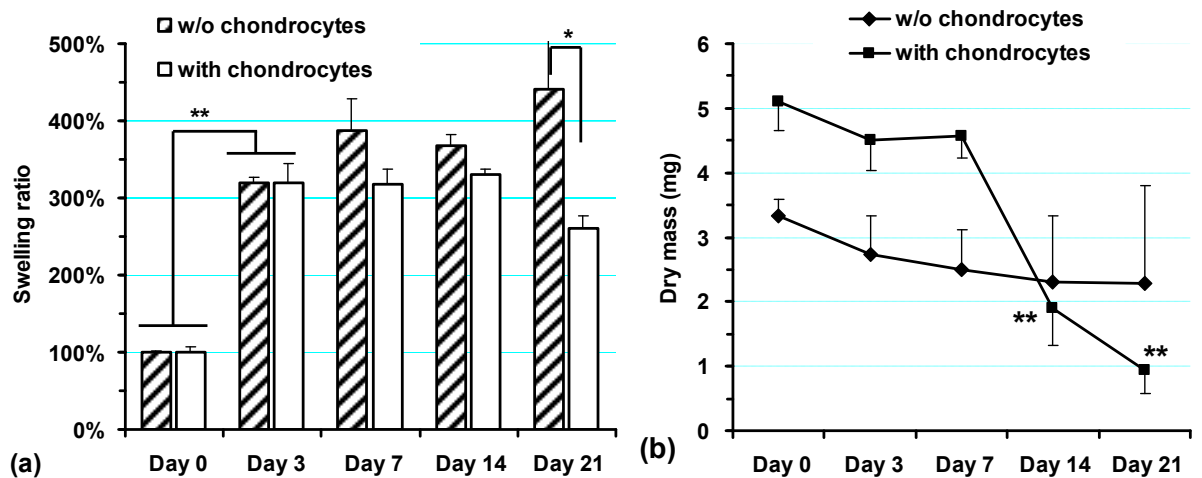

Figure 3.8. Swelling (a) and degradation (b) profiles of hydrogels from HA185k-SH DS 28 and PEG5k-4VS (molar ratio of SH to VS is kept at 1.2) with or without chondrocytes cultured in chondrocyte expansion medium $(\mathrm{n}=3)$. In the case of gels with cells, the cell seeding density was $5 \times 10^{6} / \mathrm{ml}$. ((a) $* p<0.05, * * p<0.01$; (b) $* * p<0.01$ with chondrocytes: day 14 or $21 v s$. day 0,3 or 7 ). 
As shown in Figure 3.8a, there was no difference in the swelling ratio of the hydrogels in the absence or presence of chondrocytes up to 7 days. Thereafter, the swelling ratios of the hydrogels in the presence of chondrocytes were significantly decreased compared to the control, indicating the degradation of the hydrogels and the breakdown of the gel networks. The biodegradation of the hydrogels in the presence of chondrocytes was further confirmed by monitoring the dry mass of the hydrogels (Figure 3.8b). In the presence of cells, up to 7 days, the dry gel mass remained constant. It started to decrease after day 7 and significantly decreased at day 14 and 21. This is most likely due to the production of HAse by the incorporated chondrocytes. As a negative control, the hydrogels without cells did not show significant difference in the dry mass along the culturing period up to 3 weeks $(p>0.05)$.

\subsubsection{Matrix production}

The ability of the hydrogels to function as a scaffold for cartilage tissue formation was investigated by histology using immunofluorescent staining after culturing cell/gel constructs for 14 or 21 days in differentiation medium.

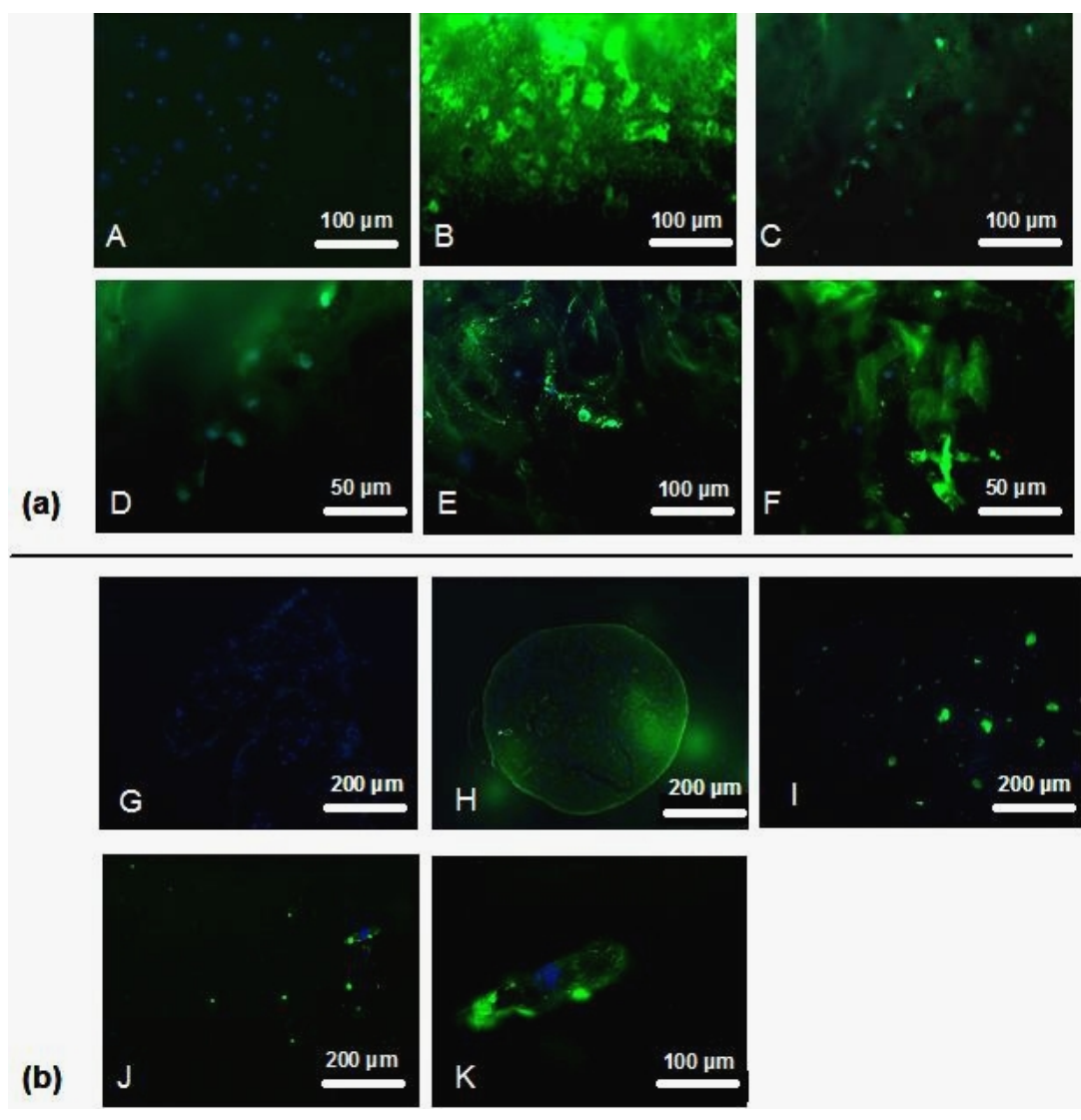


(Figure 3.9 continued)

Figure 3.9. (a) Chondroitin sulfate staining of HA185k-SH DS 28/PEG5k-4VS hydrogels (4\% (w/v)) at day $14(\mathrm{C}$ and $\mathrm{D})$ and $21(\mathrm{E}$ and $\mathrm{F})$. The section of bovine cartilage without or with incubation with primary antibodies was used as a negative (A) and positive (B) control, respectively. The chondroitin sulfate fluoresced green and the nuclei blue. (b) Collagen type II immunofluorescent staining of HA185k-SH DS 28/PEG5k-4VS hydrogels (4\% (w/v)) at day 14 (I) and 21 (J and K). The section of human chondrocyte pellet (day 21) without or with incubation with primary antibodies was used as a negative $(\mathrm{G})$ and positive $(\mathrm{H})$ control, respectively. The collagen type II fluoresced green and the nuclei blue. In all cases, the molar ratio of SH to VS is kept at 1.2). Cell seeding density was $5 \times 10^{6} / \mathrm{mL}$.

As shown in Figure 3.9a, the hydrogels stained positive for the presence of chondroitin sulfate and the intensity seemed to increase from day 14 to day 21 . Collagen type II was also detected after 14 and 21 days' culturing, as shown in Figure 3.9b.

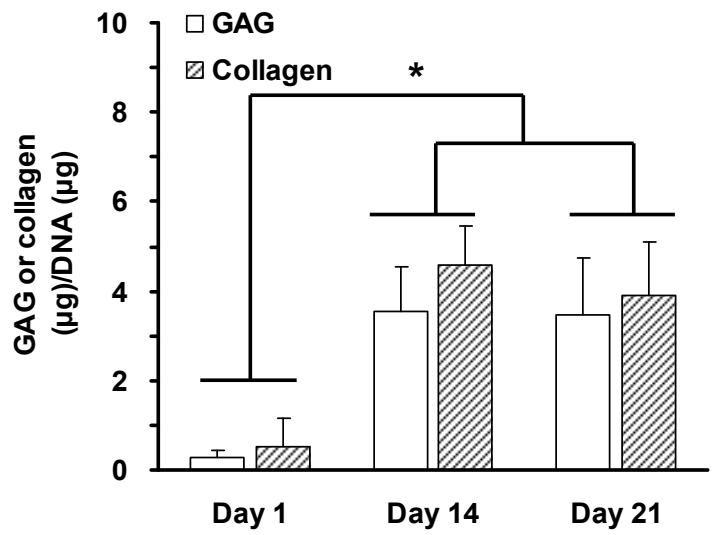

Figure 3.10. GAG and total collagen accumulation normalized to DNA content in chondrocyteincorporated HA185k-SH DS28/PEG5k-4VS hydrogels after in vitro culturing for 1, 14 and 21 days in differentiation medium. (Cell seeding density: $5 \times 10^{6} / \mathrm{mL}, * p<0.05$ ).

The level of extracellular matrix (GAG and total collagen) produced by chondrocytes that remained in the HA185k-SH DS 28/PEG5k-4VS hydrogels after 1, 14 and 21 days' culture was quantitatively determined by biochemical assays. Due to variation in the cell seeding density and gel volume, it was difficult to compare the efficiency of chondrocytes under different conditions. Hence, matrix content was also normalized to the total DNA content of the samples to determine the efficiency of matrix accumulation (Figure 3.10). The GAG/DNA value was significantly higher at day 14 and 21 compared to that at day 1 . A similar trend in the collagen/DNA value was observed. As compared to other HA-based hydrogel systems, for example, photocrosslinked HA gels, the GAG production was lower than the values reported in the literature ( $c a . \mathrm{GAG} / \mathrm{DNA}=20 \mu \mathrm{g} / \mu \mathrm{g}$ ) [30], probably due to the shorter culturing periods ( 3 vs. 6 wks). However, total collagen synthesis was 
comparable with the values reported in the literature [30]. In contrast to this paper on photocrosslinked HA hydrogels, in which high levels of GAG and collagen production were only found in $2 \mathrm{wt} \%$ gel systems, in our study, GAG and collagen production could be detected in $4 \%(\mathrm{w} / \mathrm{v})$ hydrogels.

\subsection{Conclusions}

The Michael addition reaction is a highly effective crosslinking method to prepare hydrogels from thiolated hyaluronic acid (HA) and vinyl sulfone functionalized poly(ethylene glycol) (PEG). Gelation times, enzymatic degradation by hyaluronidase and storage moduli can be controlled by the molecular weight of the starting HA and PEG, degree of substitution and polymer concentration. Chondrocytes were successfully incorporated into the hydrogels and it was shown that the hydrogels had good biocompatibility. Collagen type II and chondroitin sulphate accumulated over time in the gels. Biochemical assays further confirmed the production of glycosaminoglycans. This study has demonstrated that the HA-SH/PEG-VS hydrogels have the potential capability to be used as an injectable biomaterial for cartilage tissue engineering.

\subsection{References}

[1] Melrose J, Chuang C, Whitelock J. Tissue Engineering of Cartilages Using Biomatrices. J. Chem. Tech. Biotech. 2008;83: 444-463.

[2] Lee S-H, Shin H. Matrices and Scaffolds for Delivery of Bioactive Molecules in Bone and Cartilage Tissue Engineering. Adv. Drug Deliver. Rev. 2007;59: 339-359.

[3] Chung C, Burdick JA. Engineering Cartilage Tissue. Adv. Drug Deliver. Rev. 2008;60: 243-262.

[4] Hennink WE, van Nostrum CF. Novel Crosslinking Methods to Design Hydrogels. Adv. Drug Deliver. Rev. 2002;54: 13-36.

[5] Sontjens SHM, Nettles DL, Carnahan MA, Setton LA, Grinstaff MW. Biodendrimer-Based Hydrogel Scaffolds for Cartilage Tissue Repair. Biomacromolecules 2006;7: 310-316.

[6] Park H, Temenoff JS, Tabata Y, Caplan AI, Mikos AG. Injectable Biodegradable Hydrogel Composites for Rabbit Marrow Mesenchymal Stem Cell and Growth Factor Delivery for Cartilage Tissue Engineering. Biomaterials 2007;28: 3217-3227.

[7] Yamaoka H, Asato H, Ogasawara T, Nishizawa S, Takahashi T, Nakatsuka T, Koshima I, Nakamura K, Kawaguchi H, Chung U-I, Takato T, and Hoshi K. Cartilage Tissue Engineering Using Human Auricular Chondrocytes Embedded in Different Hydrogel Materials. J. Biomed. Mater. Res. A 2006;78A: 1-11.

[8] Dadsetan M, Szatkowski JP, Yaszemski MJ, Lu L. Characterization of Photo-CrossLinked Oligo[Poly(Ethylene Glycol) Fumarate] Hydrogels for Cartilage Tissue Engineering. Biomacromolecules 2007;8: 1702-1709.

[9] Ifkovits JL, Burdick JA. Review: Photopolymerizable and Degradable Biomaterials for Tissue Engineering Applications. Tissue Eng. 2007;13: 2369-2385. 
[10] Elisseeff J, McIntosh W, Anseth K, Riley S, Ragan P, Langer R. Photoencapsulation of Chondrocytes in Poly(Ethylene Oxide)-Based Semi-Interpenetrating Networks. J. Biomed. Mater. Res. 2000;51: 164-171.

[11] Elisseeff J, Anseth K, Sims D, McIntosh W, Randolph M, Langer R. Transdermal Photopolymerization for Minimally Invasive Implantation. Proc. Natl. Acad. Sci. USA 1999;96: 3104-3107.

[12] Nettles DL, Vail TP, Morgan MT, Grinstaff MW, Setton LA. Photocrosslinkable Hyaluronan as a Scaffold for Articular Cartilage Repair. Ann. Biomed. Eng. 2004;32: 391-397.

[13] Bryant SJ, Anseth KS. Hydrogel Properties Influence ECM Production by Chondrocytes Photoencapsulated in Poly(Ethylene Glycol) Hydrogels. J. Biomed. Mater. Res. 2002;59: 63-72.

[14] Bryant SJ, Anseth KS. Controlling the Spatial Distribution of ECM Components in Degradable Peg Hydrogels for Tissue Engineering Cartilage. J. Biomed. Mater. Res. A 2003;64A: 70-79.

[15] Bryant SJ, Durand KL, Anseth KS. Manipulations in Hydrogel Chemistry Control Photoencapsulated Chondrocyte Behavior and Their Extracellular Matrix Production. J. Biomed. Mater. Res. A 2003;67A: 1430-1436.

[16] Fedorovich NE, Oudshoorn MH, van Geemen D, Hennink WE, Alblas J, Dhert WJA. The Effect of Photopolymerization on Stem Cells Embedded in Hydrogels. Biomaterials 2009;30: 344-353.

[17] Mather BD, Viswanathan K, Miller KM, Long TE. Michael Addition Reactions in Macromolecular Design for Emerging Technologies. Prog. Polym. Sci. 2006;31: 487-531.

[18] Park Y, Lutolf MP, Hubbell JA, Hunziker EB, Wong M. Bovine Primary Chondrocyte Culture in Synthetic Matrix Metalloproteinase-Sensitive Poly(Ethylene Glycol)-Based Hydrogels as a Scaffold for Cartilage Repair. Tissue Eng. 2004;10: 515.

[19] Hiemstra C, van der Aa LJ, Zhong Z, Dijkstra PJ, Feijen J. Rapidly in Situ-Forming Degradable Hydrogels from Dextran Thiols through Michael Addition. Biomacromolecules 2007;8: 1548-1556.

[20] Hiemstra C, van der Aa LJ, Zhong Z, Dijkstra PJ, Feijen J. Novel in Situ Forming, Degradable Dextran Hydrogels by Michael Addition Chemistry: Synthesis, Rheology, and Degradation. Macromolecules 2007;40: 1165-1173.

[21] Levesque SG, Shoichet MS. Synthesis of Cell-Adhesive Dextran Hydrogels and Macroporous Scaffolds. Biomaterials 2006;27: 5277-5285.

[22] Burdick JA, Anseth KS. Photoencapsulation of Osteoblasts in Injectable RgdModified Peg Hydrogels for Bone Tissue Engineering. Biomaterials 2002;23: 43154323.

[23] Camenisch TD, McDonald JA. Hyaluronan. Is Bigger Better? Am. J. Respir. Cell Mol. Biol. 2000;23: 431-433.

[24] Bollet AJ, Bonner WM, Jr., Nance JL. The Presence of Hyaluronidase in Various Mammalian Tissues. J. Biol. Chem. 1963;238: 3522-3527.

[25] Akmal M, Singh A, Anand A, Kesani A, Aslam N, Goodship A, and Bentley G. The Effects of Hyaluronic Acid on Articular Chondrocytes. J. Bone Joint Surg. Br. 2005;87-B: 1143-1149.

[26] Yoo HS, Lee EA, Yoon JJ, Park TG. Hyaluronic Acid Modified Biodegradable Scaffolds for Cartilage Tissue Engineering. Biomaterials 2005;26: 1925-1933.

[27] Toole BP. Hyaluronan in Morphogenesis. Semin. Cell Dev. Biol. 2001;12: 79-87. 
[28] Chung C, Mesa J, Miller GJ, Randolph MA, Gill TJ, Burdick JA. Effects of Auricular Chondrocyte Expansion on Neocartilage Formation in Photocrosslinked Hyaluronic Acid Networks. Tissue Eng. 2006;12: 2665-2673.

[29] Chung C, Mesa J, Randolph MA, Yaremchuk M, Burdick JA. Influence of Gel Properties on Neocartilage Formation by Auricular Chondrocytes Photoencapsulated in Hyaluronic Acid Networks. J. Biomed. Mater. Res. A 2006;77A: 518-525.

[30] Chung C, Erickson IE, Mauck RL, Burdick JA. Differential Behavior of Auricular and Articular Chondrocytes in Hyaluronic Acid Hydrogels. Tissue Eng. A 2008;14: 1121-1131.

[31] Sahoo S, Chung C, Khetan S, Burdick JA. Hydrolytically Degradable Hyaluronic Acid Hydrogels with Controlled Temporal Structures. Biomacromolecules 2008;9: 1088-1092.

[32] Chung C, Burdick JA. Influence of Three-Dimensional Hyaluronic Acid Microenvironments on Mesenchymal Stem Cell Chondrogenesis. Tissue Eng. A 2009;15: 243-254.

[33] Liu Y, Shu XZ, Prestwich GD. Osteochondral Defect Repair with Autologous Bone Marrow-Derived Mesenchymal Stem Cells in an Injectable, in Situ, Cross-Linked Synthetic Extracellular Matrix. Tissue Eng. 2006;12: 3405-3416.

[34] Shimada E, Matsumura G. Viscosity and Molecular Weight of Hyaluronic Acids. J. Biochem. 1975;78: 513-517.

[35] Shu XZ, Liu Y, Luo Y, Roberts MC, Prestwich GD. Disulfide Cross-Linked Hyaluronan Hydrogels. Biomacromolecules 2002;3: 1304-1311.

[36] Ellman GL. A Colorimetric Method for Determining Low Concentrations of Mercaptans. Arch. Biochem. Biophys. 1958;74: 443-450.

[37] Lutolf MP, Raeber GP, Zisch AH, Tirelli N, Hubbell JA. Cell-Responsive Synthetic Hydrogels. Adv. Mater. 2003;15: 888-892.

[38] Jin R, Moreira Teixeira LS, Dijkstra PJ, Karperien M, van Blitterswijk CA, Zhong $\mathrm{ZY}$, and Feijen J. Injectable Chitosan-Based Hydrogels for Cartilage Tissue Engineering. Biomaterials 2009;30: 2544-2551.

[39] Edwards CA, O'Brien Jr WD. Modified Assay for Determination of Hydroxyproline in a Tissue Hydrolyzate. Clin. Chim. Acta 1980;104: 161-167.

[40] Pieper JS, Hafmans T, Veerkamp JH, van Kuppevelt TH. Development of TailorMade Collagen-Glycosaminoglycan Matrices: EDC/NHS Crosslinking, and Ultrastructural Aspects. Biomaterials 2000;21: 581-593.

[41] Zheng Shu X, Liu Y, Palumbo FS, Luo Y, Prestwich GD. In Situ Crosslinkable Hyaluronan Hydrogels for Tissue Engineering. Biomaterials 2004;25: 1339-1348.

[42] Menzel EJ, Farr C. Hyaluronidase and Its Substrate Hyaluronan: Biochemistry, Biological Activities and Therapeutic Uses. Cancer Lett. 1998;131: 3-11.

[43] Burdick JA, Chung C, Jia X, Randolph MA, Langer R. Controlled Degradation and Mechanical Behavior of Photopolymerized Hyaluronic Acid Networks. Biomacromolecules 2005;6: 386-391.

[44] Flannery CR, Little CB, Hughes CE, Caterson B. Expression and Activity of Articular Cartilage Hyaluronidases. Biochem. Biophys. Res. Comm. 1998;251: 824829.

[45] Tanimoto K, Suzuki A, Ohno S, Honda K, Tanaka N, Doi T, Nakahara-Ohno M, Yoneno K, Nakatani Y, Ueki M, Yanagida T, Kitamura R, and Tanne K. Hyaluronidase Expression in Cultured Growth Plate Chondrocytes During Differentiation. Cell Tissue Res. 2004;318: 335-342. 


\section{Chapter 4}

\section{Enzyme-mediated Fast In-situ Formation of Hydrogels From Dextran-tyramine Conjugates *}

Dextran hydrogels were formed in situ by enzymatic crosslinking of dextran-tyramine conjugates and their mechanical, swelling and degradation properties were evaluated. Two types of dextran-tyramine conjugates (Mn, dextran=14k, Mw/Mn=1.45), i.e. dextrantyramine linked by a urethane bond (denoted as Dex-TA) or by an ester-containing diglycolic group (denoted as Dex-DG-TA), with different degrees of substitution (DS) were prepared. Hydrogels were rapidly formed under physiological conditions from Dex-TA DS 10 or 15 and Dex-DG-TA DS 10 at or above a concentration of $2.5 \mathrm{wt} \%$ in the presence of $\mathrm{H}_{2} \mathrm{O}_{2}$ and horseradish peroxidase (HRP). The gelation time ranged from $5 \mathrm{sec}$ to $9 \mathrm{~min}$ depending on the polymer concentration and HRP/TA and $\mathrm{H}_{2} \mathrm{O}_{2} /$ TA ratios. Rheological analysis showed that these hydrogels are highly elastic. The storage modulus $\left(G^{\prime}\right)$, which varied from 3 to $41 \mathrm{kPa}$, increased with increasing polymer concentration, increasing $H R P / T A$ ratio and decreasing $\mathrm{H}_{2} \mathrm{O}_{2} /$ TA ratio. The swelling/degradation studies showed that under physiological conditions, Dex-TA hydrogels are rather stable with less than $25 \%$ loss of gel weight in 5 months, whereas Dex-DG-TA hydrogels are completely degraded within 4-10 d. These results demonstrate that enzymatic crosslinking is an efficient way to obtain fast in-situ formation of hydrogels. These dextran-based hydrogels are promising for use as injectable systems for biomedical applications including tissue engineering and protein delivery.

\subsection{Introduction}

Hydrogels are widely employed as materials for numerous biomedical applications, due to their excellent properties, such as good biocompatibility, high water content and excellent permeability for nutrients and metabolites [1-3]. From the clinical point of view, in-situ forming hydrogels, often referred to as injectable hydrogels, appear to be more desirable for many biomedical applications over conventional preformed hydrogels. For example, they can be implanted simply by injection, allow homogeneous incorporation of

\footnotetext{
* This chapter has been published: Rong Jin, Christine Hiemstra, Zhiyuan Zhong and Jan Feijen, Biomaterials, 2007, 28, 2791-2800.
} 
bioactive molecules and/or cells, and provide the possibility of good alignment with the surrounding tissue.

In the past decade, different methods have been applied to obtain in-situ forming hydrogels. These methods can be classified into two categories: (1) chemical crosslinking such as photocrosslinking [4-6], Michael-type reactions [7, 8], Schiff-base formation reactions [9, 10], and (2) physical crosslinking such as ionic interactions [11, 12], hydrophobic interactions [13-15] and stereocomplexation [16-19]. Physically crosslinked hydrogels are usually formed under mild conditions providing a friendly environment to cells and bioactive molecules. However, they generally have a low mechanical strength and changes in the external environment (e.g. ionic strength, $\mathrm{pH}$, temperature) may give rise to disruption of the hydrogel network. Chemically crosslinked hydrogels, on the other hand, may exhibit enhanced mechanical strength and better stability. In order to obtain a chemically crosslinked hydrogel, the use of additives such as photo-initiators, crosslinking agents, and/or organic solvents are often required. These additives may be cytotoxic, resulting in a non-biocompatible hydrogel. Photo-crosslinking as a method to obtain hydrogels may also lead to a local increase of temperature, which subsequently may damage neighboring cells and tissues [20].

An emerging approach for in-situ formation of hydrogels is based on enzyme-catalyzed crosslinking reactions. Sperinde et al. described the formation of hydrogels from glutaminamide-functionalized poly(ethylene glycol) (PEG) and poly(lysine-cophenylalanine) using transglutaminase (TG) in the presence of calcium ions as cofactors [21]. TG-mediated covalent crosslinking occurred via the formation of an amide linkage between the carboxamide groups of peptidyl glutamine residues and primary amine groups of lysine residues. Hydrogels based on PEG-peptide conjugates and polypeptides using TG were reported by Sanborn et al. [22] and McHale et al. [23], respectively. The formation of hydrogels via TG-mediated crosslinking required 9 to $30 \mathrm{~min}$. Hydrogels have also been obtained by horseradish peroxidase (HRP)-catalyzed crosslinking reactions [24, 25]. HRP is a single-chain $\beta$-type hemoprotein that catalyzes the coupling of phenol or aniline derivatives via decomposition of hydrogen peroxide [26]. Kaplan et al. reported the formation of hydrogels from poly(aspartic acid) functionalized with tyramine, tyrosine or aminophenol side groups by the use of $\mathrm{H}_{2} \mathrm{O}_{2}$ in the presence of HRP [24]. Fast gelation (e.g. $1 \mathrm{~min}$ ) could be obtained at $\mathrm{pH} 6.5$ with a HRP concentration of $2 \mathrm{mg} / \mathrm{mL}$ and a molar ratio of $\mathrm{H}_{2} \mathrm{O}_{2}$ and tyramine (TA) of 0.5 . However, the authors showed that the rate of gelation at pH 7.14 was much lower. Uyama et al. reported injectable hyaluronic acid hydrogels which were formed by enzymatic crosslinking of hyaluronic acid-tyramine conjugates [25]. The hydrogels did not cause adverse tissue reactions or visible inflammation after subcutaneous injection into mice. 
Dextran is a natural polysaccharide which is well soluble in water and amenable to various types of chemical modifications. Dextran can be excreted through the kidneys up to molecular weights of $c a$. 30,000 g/mol [27]. Dextran hydrogels have been obtained by radical polymerization of dextran (meth)acrylate or maleic acid derivatives [4, 6, 28], Michael addition between dextran-vinyl sulfone derivatives and PEG thiols [19], or by stereocomplexation of grafted oligo(D/L-lactic acid) [16]. These dextran-based hydrogels have been used for drug or protein delivery [29-32] and tissue engineering [33, 34]. For example, Hovgaard et al. reported colon-specific delivery of hydrocortisone from 1,6hexamethylenediisocyanate crosslinked dextran hydrogels [30]. Hennink et al. reported dextran-lactate stereocomplexed hydrogels for lysozyme and IgG delivery [31]. Schoichet et al. have prepared macroporous dextran hydrogels by copolymerizing methacrylated dextran with aminoethyl methacrylate (AEMA) for neural tissue regeneration [33].

In this chapter, we report novel in-situ forming dextran hydrogels based on dextrantyramine conjugates via enzymatic crosslinking. Two dextran-tyramine conjugates, i.e. dextran-tyramine linked by a urethane bond (denoted as Dex-TA) and by an estercontaining diglycolic group (denoted as Dex-DG-TA), were prepared. Hydrogels were rapidly formed under physiological conditions from Dex-TA DS 10 or 15 and Dex-DG-TA DS 10 by using horseradish peroxidase (HRP) and $\mathrm{H}_{2} \mathrm{O}_{2}$. The gelation time ranged from 5 sec to 9 min. The hydrogels were characterized in terms of their rheological, swelling and degradation properties.

\subsection{Materials and methods}

Materials. Dextran $\left(M_{n}\right.$, dextran $\left.=14 k, M_{w} / M_{n}=1.45\right)$ was dried by azeotropic distillation from dry toluene. 4-Dimethylamino pyridine (DMAP), $p$-nitrophenyl chloroformate (PNC) and N,N'-dicyclohexylcarbodiimide (DCC) were purchased from Fluka. Tyramine (TA), hydrogen peroxide $\left(\mathrm{H}_{2} \mathrm{O}_{2}\right)$, pyridine (anhydrous), deuterium oxide $\left(\mathrm{D}_{2} \mathrm{O}\right)$, phosphorus pentoxide, lithium chloride $(\mathrm{LiCl})$ and $\mathrm{N}$-hydroxysuccinimide (NHS) were obtained from Aldrich-Sigma. Diglycolic anhydride (DGA) was obtained from Acros. Horseradish peroxidase (HRP, type VI, 298 purpurogallin unit/mg solid) was purchased from Aldrich and used without further purification. Phosphate buffered saline (PBS, 150mM, pH 7.4) was purchased from B. Braun Co. N,N-Dimethylformamide (DMF) was dried over $\mathrm{CaH}_{2}$, distilled under vacuum and stored over molecular sieves $(4 \AA)$. $\mathrm{LiCl}$ was dried at $80^{\circ} \mathrm{C}$ under vacuum in the presence of phosphorus pentoxide. All other solvents were used as received.

Synthesis of dextran-tyramine conjugates linked by a urethane group (Dex-TA). Dextran-tyramine conjugates linked by a urethane group (Dex-TA) were synthesized as previously reported [35]. Dextran was reacted with $p$-nitrophenyl chloroformate (PNC) to 
form $p$-nitrophenyl carbonate derivatives, which were then treated with tyramine by aminolysis. Typically, dextran $(5.0 \mathrm{~g}, 92.6 \mathrm{mmol} \mathrm{OH})$ was dissolved in DMF (500 mL, containing $\mathrm{LiCl} 20 \mathrm{~g} / \mathrm{L}$ ) at $90{ }^{\circ} \mathrm{C}$ under nitrogen. After dextran was dissolved, the mixture was cooled and thermostated at $0^{\circ} \mathrm{C}$. PNC $(2.2 \mathrm{~g}, 11.1 \mathrm{mmol})$ and pyridine $(0.9 \mathrm{~g}, 11.1$ mmol) were added to the solution while stirring. The feeding molar ratio of PNC to hydroxyl groups in dextran was 0.12 . The reaction was conducted overnight. The dextran activated with $p$-nitrophenyl carbonate groups (denoted as dex-PNC) was precipitated in cold ethanol, filtered and carefully washed with ethanol and diethyl ether, and then dried in a vacuum oven. DS ( ${ }^{1} \mathrm{H}$ NMR): 10. Yield: $5.24 \mathrm{~g}(95 \%) .{ }^{1} \mathrm{H}$ NMR (DMSO-d $\left.\mathrm{d}_{6}\right): 3.00-4.00$ (m, dextran glucosidic protons), 4.91 (s, dextran anomeric proton), 7.58 and 8.32 (m, aromatic protons of $\mathrm{PNC}$ ).

Subsequently, dex-PNC DS 10 (5.0 g, $2.8 \mathrm{mmol}$ PNC) was dissolved in $56 \mathrm{~mL}$ of DMF and tyramine $(0.7 \mathrm{~g}, 5.0 \mathrm{mmol})$ was added under nitrogen. The reaction was conducted overnight. The product was precipitated in cold ethanol, filtered and carefully washed with ethanol and diethyl ether. The Dex-TA conjugates were further purified by ultrafiltration (MWCO 3000) against deionized water and isolated after lyophilization. The composition of Dex-TA conjugates was established by ${ }^{1} \mathrm{H}$ NMR. DS ( ${ }^{1} \mathrm{H}$ NMR): 10 . Yield: $3.92 \mathrm{~g}$ (78\%). ${ }^{1} \mathrm{H}$ NMR $\left(\mathrm{D}_{2} \mathrm{O}\right): \delta 2.75$ and $3.05\left(\mathrm{~m},-\mathrm{CH}_{2}-\mathrm{CH}_{2}-\right)$, 3.30-4.10 (m, dextran glucosidic protons), 5.00 (s, dextran anomeric proton), 6.86 and 7.17 (m, tyramine aromatic protons).

Dex-TA DS 15 was synthesized in a similar manner as described for Dex-TA DS 10 using a feed molar ratio of PNC to hydroxyl groups in dextran of 0.18 .

Synthesis of dextran-tyramine conjugates linked by a diglycolic group (Dex-DG-TA). Dextran-tyramine conjugates linked by a diglycolic group (Dex-DG-TA) were synthesized by first reacting dextran with diglycolic anhydride (DGA) and subsequent coupling with tyramine using DCC/NHS as coupling reagents. Dextran (5 g, $92.6 \mathrm{mmol} \mathrm{OH})$ was dissolved in DMF $(500 \mathrm{~mL}$, containing $\mathrm{LiCl} 20 \mathrm{~g} / \mathrm{L})$ at $90^{\circ} \mathrm{C}$ under nitrogen. After dextran was dissolved, the mixture was placed in an ice bath and DMAP (1.7 g, $13.9 \mathrm{mmol})$ was added to the solution. The mixture was stirred for $10 \mathrm{~min}$ and DGA (1.6 g, $13.9 \mathrm{mmol})$ dissolved in DMF was added. The reaction was conducted overnight. The product (denoted as dex-DG) was collected by precipitation in cold ethanol, filtration and drying under vacuum. DS ( ${ }^{1} \mathrm{H}$ NMR): 10. Yield: $5.07 \mathrm{~g}(94 \%)$. ${ }^{1} \mathrm{H}$ NMR $\left(\mathrm{D}_{2} \mathrm{O}\right): 3.40-4.15$ (m, dextran glucosidic protons), 4.37 ( $\left.\mathrm{s},-\mathrm{CH}_{2}-\mathrm{O}-\mathrm{CH}_{2}-\right), 5.00$ (s, dextran anomeric proton).

Next, dex-DG DS 10 (5.0 g, $2.8 \mathrm{mmol} \mathrm{COOH})$ was dissolved in $200 \mathrm{~mL}$ of DMF/LiCl. The carboxyl groups of dex-DG were activated using DCC/NHS (molar ratio: $\mathrm{DCC} / \mathrm{NHS} / \mathrm{COOH}=1.5 / 1.8 / 1)$ and then coupled with amino groups of tyramine $(0.6 \mathrm{~g}, 4.2$ mmol). The formed dicyclohexylurea (DCU) salt was removed by filtration and the DexDG-TA conjugates were collected by precipitation in cold ethanol, filtration and drying 
under vacuum. The composition of Dex-DG-TA conjugates was established by ${ }^{1} \mathrm{H}$ NMR. DS ( ${ }^{1} \mathrm{H}$ NMR): 10 . Yield: $4.20 \mathrm{~g}(79 \%) .{ }^{1} \mathrm{H}$ NMR $\left(\mathrm{D}_{2} \mathrm{O}\right): \delta 2.72$ and $3.05\left(\mathrm{~m},-\mathrm{CH}_{2}-\mathrm{CH}_{2}-\right)$, 3.40-4.15 (m, dextran glucosidic protons), 4.37 (s, $\left.-\mathrm{CH}_{2}-\mathrm{O}-\mathrm{CH}_{2}-\right), 5.00$ (s, dextran anomeric proton), 6.91 and 7.23 ( $\mathrm{m}$, tyramine aromatic protons).

Polymer characterizations. ${ }^{1} \mathrm{H}$ NMR $(300 \mathrm{MHz})$ and ${ }^{13} \mathrm{C}$ NMR $(75 \mathrm{MHz})$ spectra were recorded on a Varian Inova spectrometer (Varian, Palo, Alto, USA). The signals of solvent residues were used as reference peaks for the ${ }^{1} \mathrm{H}$ NMR chemical shift and were set at $\delta 4.79$ for water and $\delta 2.50$ for DMSO.

The degree of substitution (DS), which is defined as the number of substituents per 100 AHG rings in dextran, was determined using ${ }^{1} \mathrm{H}$ NMR by comparing the integrals of signals at $\delta$ 5.0 and $\delta$ 6.5-7.5 for Dex-TA and Dex-DG-TA, $\delta 4.9$ and $\delta$ 7.5-8.3 for dex-PNC, and $\delta$ 5.0 and $\delta$ 4.2-4.4 for dex-DG.

Hydrogel formation and gelation time. Hydrogel samples $(0.5 \mathrm{~mL})$ were prepared in vials at room temperature $\left(\sim 25^{\circ} \mathrm{C}\right)$. In a typical example, to a PBS solution of dextrantyramine conjugate $(400 \mu \mathrm{L}, 12.5 \mathrm{wt} \%)$, freshly prepared PBS solution of $\mathrm{H}_{2} \mathrm{O}_{2}(52 \mu \mathrm{L}$ of 1 wt $\%$ stock solution) and HRP (48 $\mu \mathrm{L}$ of $0.6 \mathrm{mg} / \mathrm{mL}$ of stock solution) were added and the mixture was gently vortexed. The final concentration of dextran-tyramine conjugate was 10 $\mathrm{wt} \%$. The time to form a gel (denoted as gelation time) was determined using the vial tilting method $[25,36]$. No flow within 1 min upon inverting the vial was regarded as the gel state.

Gel content and water uptake. To determine the gel content, samples of about $0.5 \mathrm{~g}$ of hydrogel made from Dex-TA DS 10 were lyophilized and weighed $\left(\mathrm{W}_{\mathrm{d}}\right)$. The dry hydrogels were then extensively extracted with $6 \mathrm{~mL}$ of DMSO for a week to remove uncrosslinked polymer. The solvent was replaced twice. Then the samples were washed 3 times with ethanol and dried under vacuum to a constant weight $\left(\mathrm{W}_{\mathrm{g}}\right)$. The gel content was expressed as $\mathrm{W}_{\mathrm{g}} / \mathrm{W}_{\mathrm{d}} \times 100 \%$.

The water uptake of the Dex-TA DS 10 hydrogels was determined as follows. After lyophilization, the dry hydrogels $\left(\mathrm{W}_{\mathrm{d}}\right)$ were immersed in $3 \mathrm{~mL}$ of PBS at $37{ }^{\circ} \mathrm{C}$ for $2 \mathrm{~d}$ in order to reach the swelling equilibrium. Swollen samples were first removed from PBS and after removal of surface water, the samples were weighted $\left(\mathrm{W}_{\mathrm{s}}\right)$. The water uptake of the hydrogels was calculated as follows: $\left(\mathrm{W}_{\mathrm{s}}-\mathrm{W}_{\mathrm{d}}\right) / \mathrm{W}_{\mathrm{d}} \times 100 \%$.

Swelling and Degradation assays of dextran-tyramine hydrogels. Hydrogel samples $(0.5 \mathrm{~mL})$ were prepared in vials according to the procedure above and accurately weighed $\left(\mathrm{W}_{\mathrm{i}}\right)$. The samples were subsequently incubated in $2 \mathrm{~mL}$ of $\mathrm{PBS}$ at $37^{\circ} \mathrm{C}$. At regular time intervals, the buffer solution was removed from the samples and the weight of the hydrogels was determined $\left(\mathrm{W}_{\mathrm{t}}\right)$ to calculate the swelling ratio $(\mathrm{S})$, which is defined as $\mathrm{W}_{\mathrm{t}} / \mathrm{W}_{\mathrm{i}}$. The degradation of hydrogels was also investigated by swelling experiments. The degradation time of the hydrogels is defined as the time needed for complete degradation 
$\left(\mathrm{W}_{\mathrm{t}}=0\right)$. After weighing, fresh PBS solutions were added to the hydrogels. The experiments were performed in triplicate.

Rheological analysis. Rheological experiments were carried out with a US 200 rheometer (Anton Paar) using parallel plates $\left(25 \mathrm{~mm}\right.$ diameter, $0^{\circ}$ ) configuration at $37^{\circ} \mathrm{C}$ in the oscillatory mode. In a typical example, $104 \mu \mathrm{L}$ of $\mathrm{H}_{2} \mathrm{O}_{2}$ stock solution ( $1 \mathrm{wt} \%$, in PBS) and $96 \mu \mathrm{L}$ of HRP stock solution $\left(0.6 \mathrm{mg} / \mathrm{mL}\right.$, in PBS) were mixed. The HRP/ $\mathrm{H}_{2} \mathrm{O}_{2}$ solution was then immediately mixed with $800 \mu \mathrm{L}$ of a solution of dex-TA (DS 15, 12.5 $w t \%$, in PBS) using a double syringe $(2.5 \mathrm{~mL}, 1: 4$ volume ratio) equipped with a mixing chamber (Mixpac). After the samples were applied to the rheometer, the upper plate was immediately lowered to a measuring gap size of $0.5 \mathrm{~mm}$, and the measurement was started. To prevent evaporation, a layer of oil was introduced around the polymer sample. The evolution of the storage $\left(\mathrm{G}^{\prime}\right)$ and loss $\left(\mathrm{G}^{\prime \prime}\right)$ modulus was recorded as a function of time. A frequency of $0.5 \mathrm{~Hz}$ and a strain of $0.1 \%$ were applied in order to maintain the linear viscoelastic regime. A frequency sweep on the hydrogels was performed from 0.01 to 10 $\mathrm{Hz}$ at $0.1 \%$ strain.

\subsection{Results and discussion}

\subsubsection{Synthesis and characterization of dextran-tyramine conjugates Dex-TA and Dex-DG-TA}

In this study, two types of dextran-tyramine conjugates, i.e. dextran-tyramine linked by a urethane bond (denoted as Dex-TA) or by an ester-containing diglycolic group (denoted as Dex-DG-TA), were prepared. The synthesis of Dex-TA is illustrated in Figure 4.1a. Hydroxyl groups of dextran were activated with $p$-nitrophenyl chloroformate (PNC) to form $p$-nitrophenyl carbonate derivatives (dex-PNC). Dex-PNC conjugates with degree of substitution (DS, defined as the number of substituents per 100 anhydroglucose, AHG, units in dextran) of 10 and 15 were obtained when feed molar ratios of PNC to hydroxyl groups in dextran were 0.12 and 0.18 , respectively. This indicates that Dex-PNC of different DS can be prepared by simply varying feed molar ratios of PNC to hydroxyl groups in dextran. ${ }^{13} \mathrm{C}$ NMR indicates that $p$-nitrophenyl carbonate groups are mainly linked to $\mathrm{C}_{2}$ carbon atoms, which is in accordance with the results previously reported [35, 37]. Subsequently, dex-PNC was treated with an excess amount of tyramine, which led to the formation of Dex-TA conjugates. The structure of Dex-TA conjugate was confirmed by ${ }^{1} \mathrm{H}$ NMR. Figure 4.2a shows that besides signals attributable to dextran (peaks 1, 2 and 3), new peaks at $\delta$ 2.75-3.05 (peaks 4 and 5) and 6.86-7.17 (peaks 6 and 7) due to the presence of tyramine groups were clearly detected. The DS of Dex-TA conjugates can be determined by comparing the integrals of signals at $\delta 5.00$ and $\delta 6.86-7.17$. The results show that Dex- 
TA with DS 10 and 15 are obtained from dex-PNC with DS 10 and 15, respectively. This indicates that aminolysis of dextran $p$-nitrophenyl carbonate derivatives using tyramine is a quantitative reaction.

Dex-DG-TA conjugates were synthesized in two steps (Figure 4.1b). Dextran was first reacted with diglycolic anhydride (DGA) to obtain dex-DG containing carboxylic acid groups. Dex-DG with DS 10 was prepared at a feed molar ratio of DGA to hydroxyl groups in dextran of 0.15 . Dex-DG DS 10 was then coupled with excess tyramine using N,N'dicyclohexylcarbodiimide/N-hydroxysuccinimide (DCC/NHS) as coupling reagents to give Dex-DG-TA conjugates. The ${ }^{1} \mathrm{H}$ NMR spectrum of Dex-DG-TA (Figure 4.2b) clearly shows peaks at $\delta 4.37$ (peak 4') attributable to the methylene protons of the diglycolic units and peaks at $\delta$ 2.72-3.05 (peaks 5' and 6') and 6.91-7.23 (peaks 7' and 8') due to the presence of the tyramine substituents. The DS of Dex-DG-TA, determined by comparing the integrals of signals at $\delta 5.00$ and $\delta 6.91-7.23$ was 10 , indicating a quantitative coupling of dex-DG with tyramine.

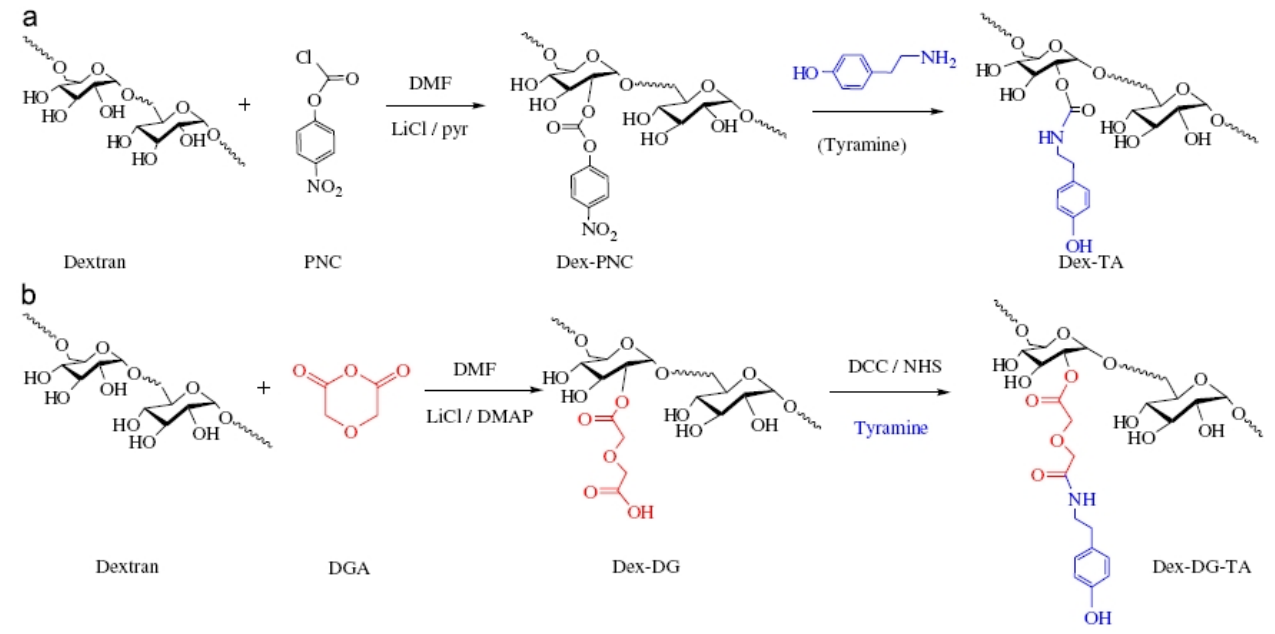

Figure 4.1. Preparation of dextran-tyramine conjugates (a) Dex-TA and (b) Dex-DG-TA.

\subsubsection{Hydrogel formation and gelation time}

Hydrogels were prepared by the horseradish peroxidase (HRP)-mediated coupling reaction of phenol moieties in dextran-tyramine conjugates in PBS (Figure 4.3) [26, 38]. Coupling of phenols can take place either via a carbon-carbon bond at the ortho positions or via a carbon-oxygen bond between the carbon atom at the ortho position and the phenoxy oxygen [39, 40]. Enzymatic crosslinking of dextran-tyramine conjugates, i.e. Dex-TA DS 10, Dex-TA DS 15 and Dex-DG-TA DS 10, were investigated, wherein different polymer concentrations $(2 \sim 15 \mathrm{wt} \%), \mathrm{HRP} / \mathrm{TA}$ ratios $(0.125 \sim 2.0 \mathrm{mg} / \mathrm{mmol})$ and $\mathrm{H}_{2} \mathrm{O}_{2} / \mathrm{TA}$ ratios 
(0.6 6.0 $\mathrm{mol} / \mathrm{mol})$ were applied. The gelation time was determined by the vial tilting method.

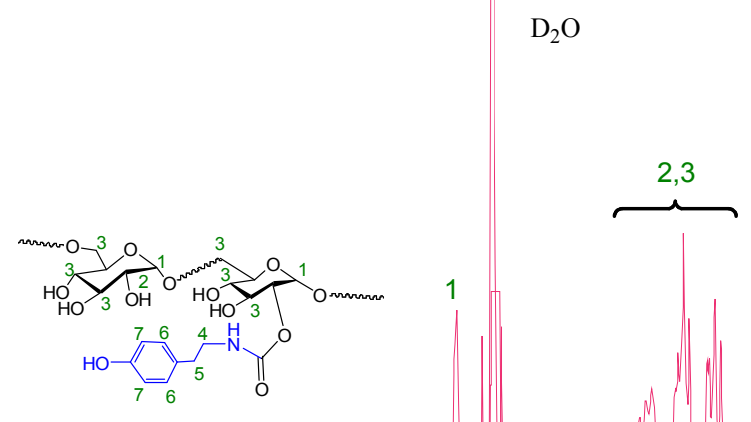

(a) $6 \quad 7$

45
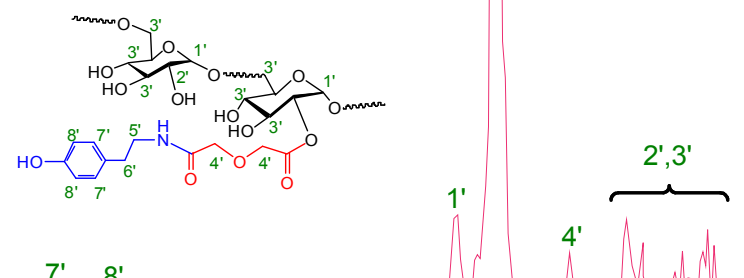

$7^{\prime} \quad 8^{\prime}$

$5^{\prime} 6^{\prime}$

(b)

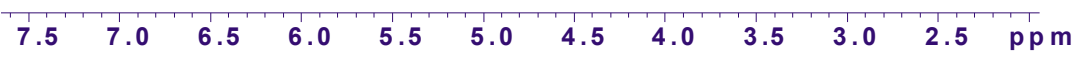

Figure 4.2. ${ }^{1} \mathrm{H}$ NMR spectra of (a) Dex-TA and (b) Dex-DG-TA in D2O.
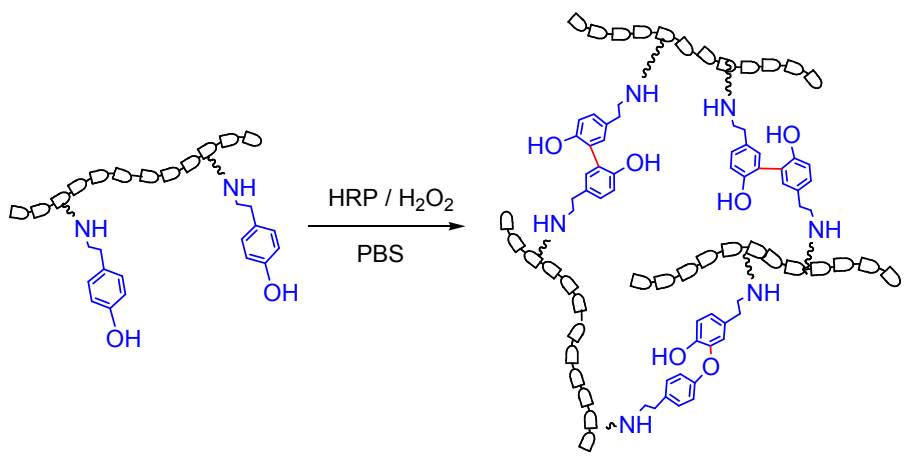

Figure 4.3. Enzymatic crosslinking of dextran-tyramine conjugates.

Figure 4.4a shows that the gelation time decreases when increasing the HRP/TA ratio from 0.125 to $2.0 \mathrm{mg} / \mathrm{mmol}$ at a constant polymer concentration of $10 \mathrm{wt} \%$ and $\mathrm{a}_{2} \mathrm{O}_{2} / \mathrm{TA}$ 
molar ratio of 0.6. This may be due to the increased rate of $\mathrm{H}_{2} \mathrm{O}_{2}$ decomposition and production of phenoxy radicals for coupling with increasing HRP/TA ratio. Notably, DexTA hydrogels were formed within $1 \mathrm{~min}$ when the HRP/TA ratio was at or above 0.50 $\mathrm{mg} / \mathrm{mmol}$. Increasing the $\mathrm{H}_{2} \mathrm{O}_{2} /$ TA ratio at a constant polymer concentration of $10 \mathrm{wt} \%$ and a HRP/TA ratio of $0.5 \mathrm{mg} / \mathrm{mmol}$, on the other hand, resulted in an increase of the gelation time (Figure 4.4b). This is likely due to excessive oxidation of HRP by $\mathrm{H}_{2} \mathrm{O}_{2}$. It has been reported that HRP can be oxidized to an inactivated form upon exposure to an excess amount of $\mathrm{H}_{2} \mathrm{O}_{2}$ [41, 42]. The optimal $\mathrm{H}_{2} \mathrm{O}_{2}$ /TA molar ratio appeared to be 0.6 wherein rapid gelation occurred for all dextran-tyramine conjugates. Moreover, under this condition, the dose of $\mathrm{H}_{2} \mathrm{O}_{2}(34,48$ and $35 \mathrm{mM}$ for Dex-TA DS 10, Dex-TA DS 15 and Dex-DG-TA DS 10, respectively) appears to be non-toxic, as was observed for the hyaluronic acidtyramine based hydrogel system in vivo $\left(70 \mathrm{mM} \mathrm{H}_{2} \mathrm{O}_{2}\right)$ [25]. In the experiments described hereafter, a HRP/TA ratio of $0.5 \mathrm{mg} / \mathrm{mmol}$ and $\mathrm{H}_{2} \mathrm{O}_{2} / \mathrm{TA}$ ratio of $0.6 \mathrm{~mol} / \mathrm{mol}$ were used unless otherwise mentioned. Figure $4.4 \mathrm{c}$ reveals that increasing the polymer concentration at fixed ratios of $\mathrm{HRP} / \mathrm{TA}$ and $\mathrm{H}_{2} \mathrm{O}_{2} / \mathrm{TA}$ decreases the gelation time. At polymer concentrations of $10-15 \mathrm{wt} \%$, the gelation took place within $1 \mathrm{~min}$ for all three dextrantyramine conjugates. Furthermore, it should be noted that hydrogels could also be formed rapidly at low polymer concentrations. For example, Dex-TA DS 10 gelled within $70 \mathrm{~s}$ at a polymer concentration of $2 \mathrm{wt} \%$.

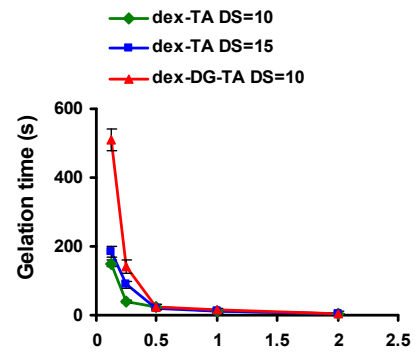

(a)

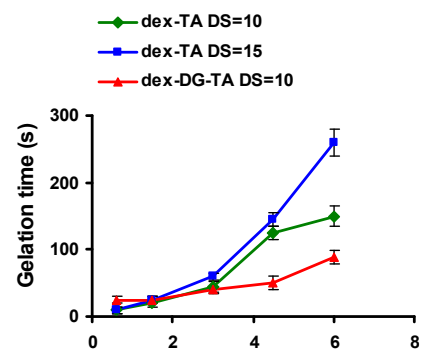

(b)

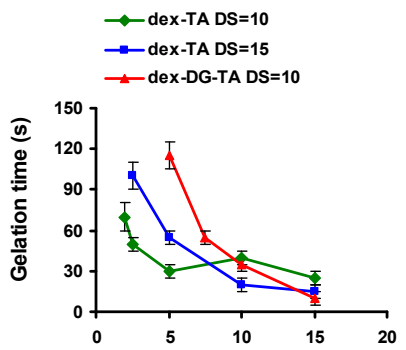

(c)

Polymer concentration (wt\%)

Figure 4.4. The gelation time of dextran-tyramine conjugates under various conditions: (a) Gelation time of $10 \mathrm{wt} \%$ Dex-TA DS 10 and 15 and Dex-DG-TA DS 10 with $\mathrm{H}_{2} \mathrm{O}_{2} / \mathrm{TA}=0.6 \mathrm{~mol} / \mathrm{mol}$ as a function of HRP/TA ratio; (b) Gelation time of $10 \mathrm{wt} \%$ Dex-TA DS 10 and 15 and Dex-DG-TA DS 10 with $\mathrm{HRP} / \mathrm{TA}=0.5 \mathrm{mg} / \mathrm{mmol}$ as a function of $\mathrm{H}_{2} \mathrm{O}_{2} / \mathrm{TA}$ ratio; (c) Gelation time of Dex-TA DS 10 and 15 and Dex-DG-TA DS 10 with $\mathrm{HRP} / \mathrm{TA}=0.5 \mathrm{mg} / \mathrm{mmol}$ and $\mathrm{H}_{2} \mathrm{O}_{2} / \mathrm{TA}=0.6 \mathrm{~mol} / \mathrm{mol}$ as a function of polymer concentration.

Fast gelation is preferred especially for in-situ forming hydrogels, since slow gelation in vivo may result in diffusion of hydrogel precursors or bioactive molecules to surrounding areas or failure of gel formation. The enzymatic crosslinking of dextran-tyramine conjugates resulted in relatively fast gelation as compared to the time required for many 
previously reported in-situ forming hydrogels. For example, Chung et al. reported a gelation time of $12 \mathrm{~min}$ for dextran hydroxyethyl methacrylate using a redox initiator although fast gelation could be achieved by greatly increasing the concentration of initiators [43]. Kim et al. reported that the gelation of acrylated dextran by photocrosslinking took place within $5 \mathrm{~min}$ at a high polymer concentration of $40 \%(\mathrm{w} / \mathrm{v})$ [4]. The hydrogels formed by a Michael type addition between vinylsulfone-functionalized PEG and cysteinecontaining peptides required 13 min to complete the gelation process under physiological conditions [44].

\subsubsection{Gel content and water uptake}

The gel content and water uptake of the hydrogels made from Dex-TA DS 10 were studied. Figure 4.5a shows the variation of gel content and water uptake of hydrogels prepared from $10 \mathrm{wt} \%$ Dex-TA solutions in PBS as a function of the HRP/TA ratio. The gel content and water uptake did not vary much with the different HRP concentrations used. The gel content was high (92.6 to $98.6 \%$ ), indicating that almost all polymers chains are incorporated into the gel network. The water uptake increased slightly with decreasing $\mathrm{HRP} / \mathrm{TA}$ ratio. On the other hand, it can be seen in Figure $4.5 \mathrm{~b}$ that the gel content decreased from $98.6 \%$ to $75.6 \%$ when the $\mathrm{H}_{2} \mathrm{O}_{2} /$ TA ratio was increased from 0.6 to 6.0 $\mathrm{mol} / \mathrm{mol}$. Also the water uptake increased with increasing $\mathrm{H}_{2} \mathrm{O}_{2} /$ TA ratio. This may be attributed to a decreased crosslinking efficiency of the Dex-TA polymers resulting from excessive oxidation of HRP.
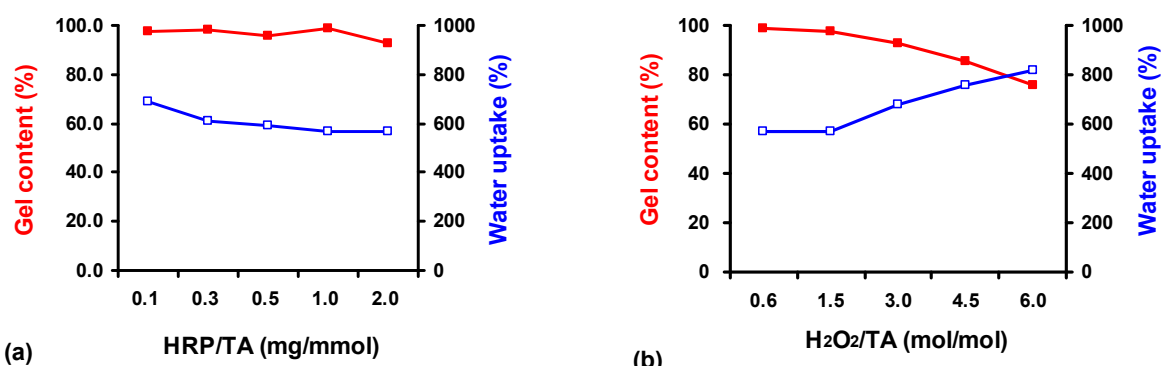

Figure 4.5. Gel content (---) and water uptake (-口-) of hydrogels made from $10 \mathrm{wt} \%$ Dex-TA DS 10 in PBS: (a) hydrogels prepared with a $\mathrm{H}_{2} \mathrm{O}_{2} /$ TA ratio of $0.6 \mathrm{~mol} / \mathrm{mol}$ as a function of the HRP/TA ratio (mg/mmol); (b) hydrogels prepared with a HRP/TA ratio of $0.5 \mathrm{mg} / \mathrm{mmol}$ as a function of the $\mathrm{H}_{2} \mathrm{O}_{2} /$ TA ratio ( $\left.\mathrm{mol} / \mathrm{mol}\right)$.

\subsubsection{Rheological analysis}

The mechanical properties of the dextran-based hydrogels were studied by oscillatory rheology experiments on polymer solutions containing various amounts of $\mathrm{HRP}$ and $\mathrm{H}_{2} \mathrm{O}_{2}$ 
in PBS at $37^{\circ} \mathrm{C}$. A solution of dextran-tyramine conjugate and a mixture of $\mathrm{HRP}$ and $\mathrm{H}_{2} \mathrm{O}_{2}$ solutions (in PBS) were applied to the rheometer using a double syringe equipped with a mixing chamber. The kinetics of hydrogel formation was followed by monitoring the storage modulus $\left(\mathrm{G}^{\prime}\right)$ and loss modulus $\left(\mathrm{G}^{\prime \prime}\right)$ in time. Figure 4.6 shows the storage and loss modulus as function of time of a $10 \mathrm{wt} \%$ dex-TA DS 15 solution crosslinked at a $\mathrm{H}_{2} \mathrm{O}_{2} /$ TA ratio of $0.6 \mathrm{~mol} / \mathrm{mol}$ and a HRP/TA ratio of 0.125 or $0.5 \mathrm{mg} / \mathrm{mmol}$. At a HRP/TA ratio of $0.125 \mathrm{mg} / \mathrm{mmol}$, the storage modulus of the hydrogels increased rapidly during the initial $30 \mathrm{sec}$. The gel point, defined as the crossover point of $\mathrm{G}^{\prime}$ and $\mathrm{G}^{\prime \prime}$, was observed after ca. 20s. The storage modulus quickly leveled off after $2 \mathrm{~min}$, indicating that the crosslinking reaction was complete. At a higher HRP/TA ratio of $0.5 \mathrm{mg} / \mathrm{mmol}$, an immediate gelation after injection was observed.

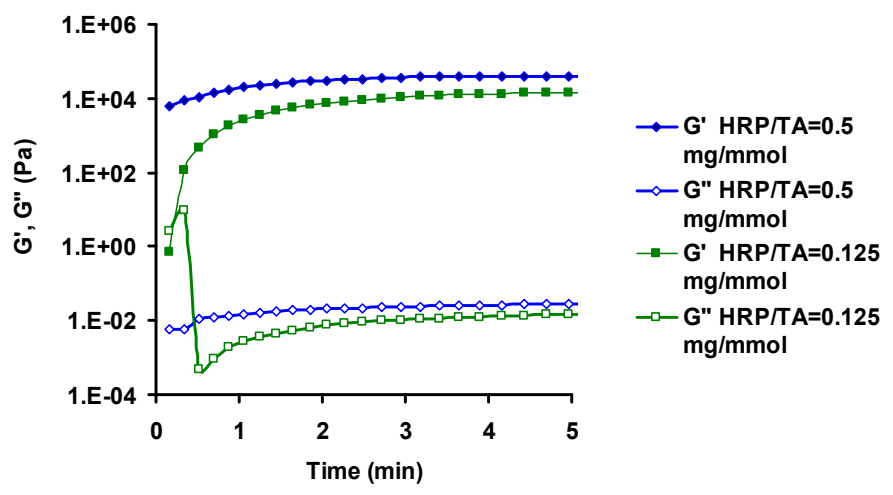

Figure 4.6. The storage modulus $\left(\mathrm{G}^{\prime}\right)$ and loss modulus $\left(\mathrm{G}^{\prime \prime}\right)$ of Dex-TA hydrogels $(10 \mathrm{wt} \% \mathrm{in}$ PBS, DS $15, \mathrm{H}_{2} \mathrm{O}_{2} / \mathrm{TA}=0.6 \mathrm{~mol} / \mathrm{mol}$ ) as a function of time. A frequency of $0.5 \mathrm{~Hz}$ and a strain of $0.1 \%$ at $37^{\circ} \mathrm{C}$ were applied.

Figure 4.7 shows that at fixed $\mathrm{H}_{2} \mathrm{O}_{2} / \mathrm{TA}(0.6 \mathrm{~mol} / \mathrm{mol})$ and HRP/TA $(0.5 \mathrm{mg} / \mathrm{mmol})$ ratios, the storage modulus of hydrogels made from Dex-TA DS 15 increases with increasing polymer concentration. For example, the hydrogels formed from Dex-TA DS 15 at polymer concentrations of $2.5 \mathrm{wt} \%$ and $10 \mathrm{wt} \%$ showed storage moduli of ca. 2.4 and 41 $\mathrm{kPa}$, respectively. The damping factor $\left(\tan \delta=\mathrm{G}^{\prime \prime} / \mathrm{G}^{\prime}\right)$ of the hydrogels decreased with increasing polymer concentration, indicating higher network perfection at higher polymer concentration. The storage modulus of hydrogels prepared at high concentrations $(>10 \mathrm{wt} \%)$ could not be accurately measured due to the instantaneous gelation.

The influences of HRP/TA and $\mathrm{H}_{2} \mathrm{O}_{2}$ /TA ratios on the storage and loss modulus of the Dex-TA DS 15 hydrogels were investigated at a polymer concentration of $10 \mathrm{wt} \%$. Figure $4.8 \mathrm{a}$ shows that the storage modulus of Dex-TA hydrogels increased from $17 \mathrm{kPa}$ to $41 \mathrm{kPa}$ when increasing HRP/TA ratio from 0.125 to $0.5 \mathrm{mg} / \mathrm{mmol}$. It appears from these results that the HRP/TA ratio has a direct effect on the mechanical properties of the hydrogels. 
Figure $4.8 \mathrm{~b}$ shows that a higher $\mathrm{H}_{2} \mathrm{O}_{2}$ /TA ratio used in hydrogel formation results in DexTA hydrogels with a relatively lower storage modulus. For example, the hydrogel prepared with a $\mathrm{H}_{2} \mathrm{O}_{2} /$ TA ratio of 4.5 and $1.5 \mathrm{~mol} / \mathrm{mol}$ have a storage modulus of 3.6 and $21 \mathrm{kPa}$, respectively. As previously mentioned, excess $\mathrm{H}_{2} \mathrm{O}_{2}$ may cause excessive oxidation and inactivation of HRP and thereby give rise to decreased crosslinking efficiency.

In addition, the results show that an increase in the DS slightly increases the storage modulus of the Dex-TA hydrogels. At a polymer concentration of $10 \mathrm{wt} \%$, a HRP/TA ratio of $0.125 \mathrm{mg} / \mathrm{mmol}$ and $\mathrm{H}_{2} \mathrm{O}_{2} / \mathrm{TA}$ ratio of $0.6 \mathrm{~mol} / \mathrm{mol}$, the hydrogels made from Dex-TA DS 10 and 15 showed storage moduli of 13 and $17 \mathrm{kPa}$, respectively.

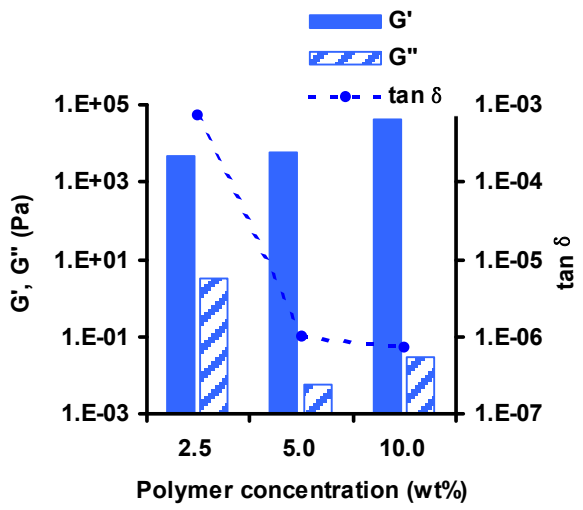

Figure 4.7. The storage modulus ( $\mathrm{G}^{\prime}$, solid bar), loss modulus ( $\mathrm{G}^{\prime \prime}$, slashed bar) and damping factor $(\tan \delta, \bullet)$ of Dex-TA hydrogels (DS $15, \mathrm{H}_{2} \mathrm{O}_{2} / \mathrm{TA}=0.6 \mathrm{~mol} / \mathrm{mol}, \mathrm{HRP} / \mathrm{TA}=0.5 \mathrm{mg} / \mathrm{mmol}$ ) as a function of polymer concentration. A frequency of $0.5 \mathrm{~Hz}$ and a strain of $0.1 \%$ at $37^{\circ} \mathrm{C}$ were applied.
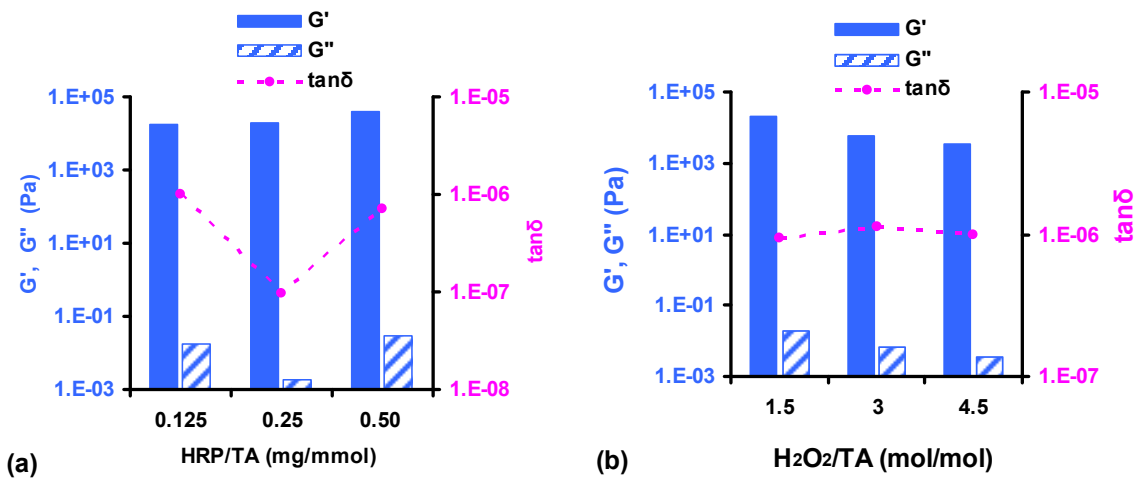

(b)

$\mathrm{H}_{2} \mathrm{O}_{2} / \mathrm{TA}(\mathrm{mol} / \mathrm{mol})$

Figure 4.8. The storage modulus ( $\mathrm{G}^{\prime}$, solid bar), loss modulus ( $\mathrm{G}^{\prime \prime}$, slashed bar) and damping factor $(\tan \delta, \bullet)$ of the Dex-TA hydrogels (DS $15,10 \mathrm{wt} \%$ ) as a function of (a) HRP/TA ratio $\left(\mathrm{H}_{2} \mathrm{O}_{2} / \mathrm{TA}=0.6\right.$ $\mathrm{mol} / \mathrm{mol}$ ) and (b) $\mathrm{H}_{2} \mathrm{O}_{2} / \mathrm{TA}$ ratio (HRP/TA=0.5 $\mathrm{mg} / \mathrm{mmol}$ ).

Similar to dex-TA, the storage modulus of dex-DG-TA DS 10 hydrogels also increased with increasing polymer concentration and HRP/TA ratio (Figure 4.9). These hydrogels 
have a low damping factor, indicating that they are highly elastic. For example, hydrogels prepared from $10 \mathrm{wt} \%$ Dex-DG-TA DS 10 at a HRP/TA ratio of $0.5 \mathrm{mg} / \mathrm{mmol}$ and a $\mathrm{H}_{2} \mathrm{O}_{2} /$ TA ratio of $0.6 \mathrm{~mol} / \mathrm{mol}$ have a storage modulus of $5.2 \mathrm{kPa}$ with a very low damping factor. Notably, at the same polymer concentration, HRP/TA and $\mathrm{H}_{2} \mathrm{O}_{2}$ /TA ratios, Dex-DGTA DS 10 hydrogels displayed a lower storage modulus than Dex-TA DS 10 hydrogels (e.g. $2.0 \mathrm{kPa} v s .16 \mathrm{kPa}$ at a polymer concentration of $10 \mathrm{wt} \%$, a HRP/TA ratio of $0.25 \mathrm{mg} / \mathrm{mmol}$ and $\mathrm{H}_{2} \mathrm{O}_{2} /$ TA ratio of $0.6 \mathrm{~mol} / \mathrm{mol}$ ).

A frequency sweep from 0.01 to $10 \mathrm{~Hz}$ was also performed on both dex-TA and dex-DGTA hydrogels at a small oscillatory strain of $0.1 \%$. The results showed that both hydrogels exhibit constant $\mathrm{G}^{\prime}$ and $\mathrm{G}^{\prime \prime}$ independent of frequency ranging from 0.01 to $10 \mathrm{~Hz}$, further confirming the highly elastic character of the hydrogels.

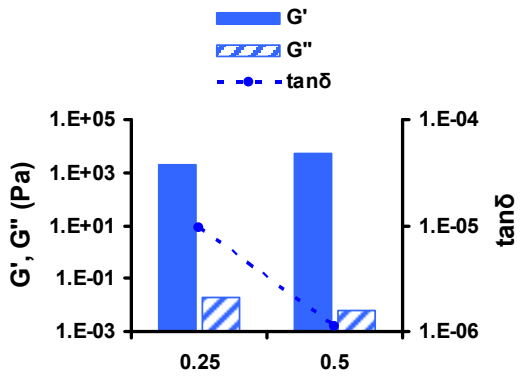

(a)

$\mathrm{HRP} / \mathrm{TA}(\mathrm{mg} / \mathrm{mmol})$

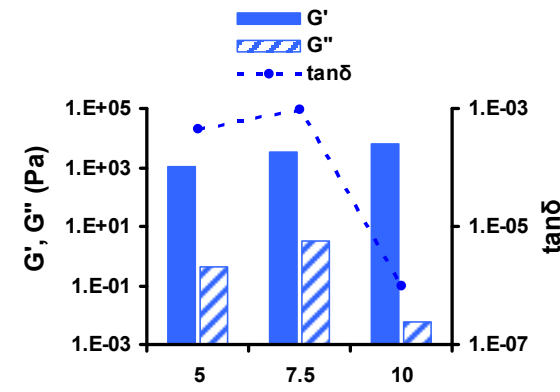

(b)

Polymer concentration (wt\%)

Figure 4.9. The storage modulus $\left(\mathrm{G}^{\prime}\right.$, solid bar), loss modulus $\left(\mathrm{G}^{\prime \prime}\right.$, slashed bar) and damping factor $(\tan \delta, \bullet)$ of the Dex-DG-TA hydrogels (DS $10, \mathrm{H}_{2} \mathrm{O}_{2} / \mathrm{TA}=0.6 \mathrm{~mol} / \mathrm{mol}$ ) as a function of (a) HRP/TA ratio $(10 \mathrm{wt} \%)$ and (b) polymer concentration (HRP/TA $=0.5 \mathrm{mg} / \mathrm{mmol})$.

\subsubsection{Swelling and degradation assays}

To study the swelling/degradation properties of Dex-TA DS 10 and dex-DG-TA DS 10 hydrogels, $2 \mathrm{~mL}$ of PBS was applied on the top of the $0.5 \mathrm{~mL}$ prepared hydrogels. Hydrogels were stored at $37^{\circ} \mathrm{C}$ and weighed at regular intervals. After weighing, fresh PBS was applied to the hydrogels. The swelling ratio is expressed as $\mathrm{W}_{t} / \mathrm{W}_{\mathrm{i}}$, wherein $\mathrm{W}_{\mathrm{t}}$ is the weight of hydrogel at time $t$ and $\mathrm{W}_{\mathrm{i}}$ is the weight of the initial hydrogels.

Figure 4.10 shows that the Dex-TA DS 10 hydrogel had a low swelling ratio, ranging from 1.1 to 1.5 . The swelling ratios of hydrogels prepared with different HRP/TA ratios or polymer concentrations were comparable. These Dex-TA hydrogels were rather stable with swelling ratio decreasing to 0.75 in 5 months. The overall slow degradation of the hydrogels could be attributed to the slow degradation of the urethane bonds in the hydrogels. 
The swelling and degradation behavior of the Dex-DG-TA DS 10 hydrogels is shown in Figure 4.11. In the examined range of the HRP/TA and $\mathrm{H}_{2} \mathrm{O}_{2}$ /TA ratios, the Dex-DG-TA hydrogels revealed very low initial swelling ratios. The swelling ratio decreased gradually due to degradation of the hydrogels and hydrogels were completely degraded in less than 10 d. The hydrogels formed at lower HRP /TA ratio or higher $\mathrm{H}_{2} \mathrm{O}_{2} /$ TA ratio degraded faster. For example, Dex-DG-TA hydrogels prepared with HRP/TA ratio of 0.125 and 2.0 $\mathrm{mg} / \mathrm{mmol}$ were completely degraded after 4 and $10 \mathrm{~d}$, respectively (Figure $4.11 \mathrm{a}$ ). Dex-DGTA hydrogels obtained at a $\mathrm{H}_{2} \mathrm{O}_{2} /$ TA ratio of 0.6 and $6.0 \mathrm{~mol} / \mathrm{mol}$ had a degradation time of 10 and $5 \mathrm{~d}$, respectively (Figure 4.11b). The slower degradation of Dex-DG-TA hydrogels at higher HRP/TA ratios results from higher crosslinking densities in the hydrogels, which was also demonstrated by the rheological analysis.

The degradation time of Dex-DG-TA hydrogels is much shorter than that of Dex-TA hydrogels. This is in line with our expectation, since ester groups hydrolyze much faster than urethane groups. These results indicate that the degradation time of the dextrantyramine-based hydrogels can be easily modulated to give stable hydrogels or rapidly degrading hydrogels.

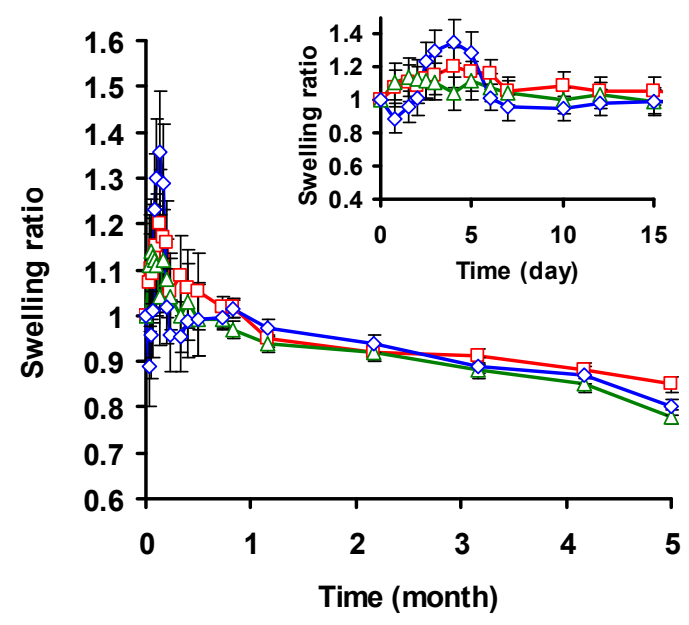

Figure 4.10. The swelling and degradation behavior of Dex-TA hydrogels (DS 10, $10 \mathrm{wt} \%$ in PBS, $\left.\mathrm{H}_{2} \mathrm{O}_{2} / \mathrm{TA}=0.6 \mathrm{~mol} / \mathrm{mol}\right)$ at $37^{\circ} \mathrm{C}$ with different $\mathrm{HRP} / \mathrm{TA}$ ratio $(\mathrm{mg} / \mathrm{mmol},-\nabla-\mathbf{0 . 2 5} ;-\square-\mathbf{0 . 5})$ or polymer concentration ( $\mathrm{wt} \%,-\Delta-\mathbf{5 . 0} ;-\square-\mathbf{1 0})$. 

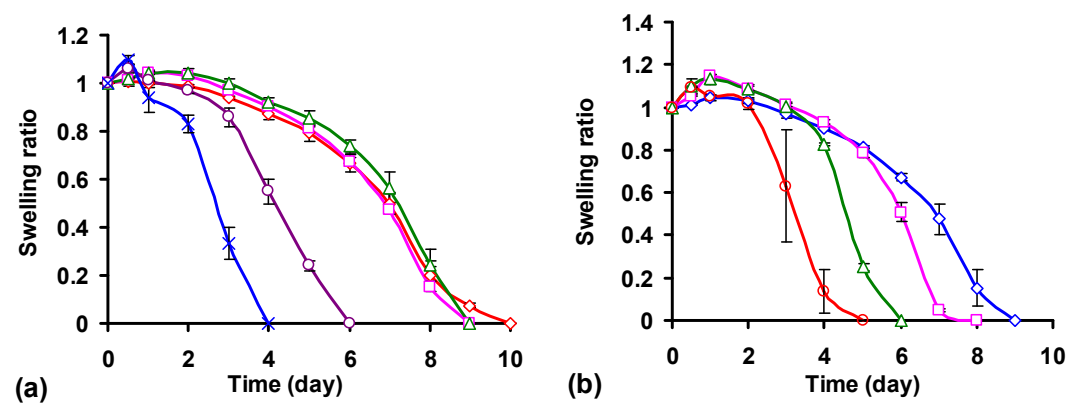

Figure 4.11. The swelling and degradation behavior of Dex-DG-TA (DS 10, $10 \mathrm{wt} \%$ ) hydrogels in PBS at $37^{\circ} \mathrm{C}$ : (a) $\mathrm{H}_{2} \mathrm{O}_{2} / \mathrm{TA}=0.6 \mathrm{~mol} / \mathrm{mol}$, HRP/TA ratio $(\mathrm{mg} / \mathrm{mmol}):-\times-\mathbf{0 . 1 2 5} ;-0-\mathbf{0 . 2 5} ;-\Delta-\mathbf{0 . 5}$; $\square-1.0 ;-\checkmark-2.0$; (b) $\mathrm{HRP} / \mathrm{TA}=0.5 \mathrm{mg} / \mathrm{mmol}, \mathrm{H}_{2} \mathrm{O}_{2} / \mathrm{TA}$ ratio $(\mathrm{mol} / \mathrm{mol}):-\diamond-\mathbf{0 . 6}$; $-\square-1.5 ;-\Delta-\mathbf{3 . 0}$; $0-4.5$.

\subsection{Conclusions}

Novel in-situ forming dextran hydrogels based on dextran-tyramine conjugates (Dex-TA and Dex-DG-TA) were prepared. Dextran-tyramine conjugates with different degrees of tyramine substitution can be easily synthesized and in a controlled manner. The hydrogels were obtained by enzymatic crosslinking under physiological conditions using HRP as a catalyst and $\mathrm{H}_{2} \mathrm{O}_{2}$ as an oxidant. No chemical initiators or organic solvents are required. The gelation is fast with gelation times ranging from $5 \mathrm{sec}$ to $9 \mathrm{~min}$, depending on the $\mathrm{HRP} / \mathrm{TA}$ and $\mathrm{H}_{2} \mathrm{O}_{2} / \mathrm{TA}$ ratios and polymer concentration. The high gel content indicated that almost all polymer chains were incorporated into the gel. These dextran-tyraminebased hydrogels were highly elastic with a storage modulus ranging from 3 to $41 \mathrm{kPa}$. The degradation time of the hydrogels can be easily adjusted to give either a rapidly degrading Dex-DG-TA hydrogel or a stable Dex-TA hydrogel. In conclusion, the results demonstrate that this enzymatic crosslinking method is an efficient way to prepare fast in-situ forming dextran-tyramine-based hydrogels, which have great potential for biomedical applications, such as tissue engineering and drug or protein delivery.

\subsection{References}

[1] Hoffman AS. Hydrogels for Biomedical Applications. Adv. Drug Deliver. Rev. 2002;54: 3-12.

[2] Kamath AR, Park K. Biodegradable Hydrogels in Drug Delivery. Adv. Drug Deliver. Rev. 1993;11: 59-84.

[3] Wichterle O, Lim D. Hydrophilic Gels in Biologic Use. Nature 1960;185: 117-123. 
[4] Kim SH, Won CY, Chu CC. Synthesis and Characterization of Dextran-Based Hydrogel Prepared by Photocrosslinking. Carbohydr. Polym. 1999;40: 183-190.

[5] Burkoth AK, Anseth KS. Review of Photocrosslinked Polyanhydrides: In Situ Forming Degradable Networks. Biomaterials 2000;21: 2395-2404.

[6] Kim SH, Won CY, Chu CC. Synthesis and Characterization of Dextran-Maleic Acid Based Hydrogel. J. Biomed. Mater. Res. B 1999;46: 160-170.

[7] Shu XZ, Liu Y, Palumbo FS, Luo Y, Prestwich GD. In Situ Crosslinkable Hyaluronan Hydrogels for Tissue Engineering. Biomaterials 2004;25: 1339-1348.

[8] Cai S, Liu Y, Shu XZ, Prestwich GD. Injectable Glycosaminoglycan Hydrogels for Controlled Release of Human Basic Fibroblast Growth Factor Biomaterials 2005;26: 6054-6067.

[9] Balakrishnan B, Jayakrishnan A. Self-Cross-Linking Biopolymers as Injectable in Situ Forming Biodegradable Scaffolds. Biomaterials 2005;26: 3941-3951.

[10] Lee KY, Alsberg E, Mooney DJ. Degradable and Injectable Poly(Aldehyde Guluronate) Hydrogels for Bone Tissue Engineering. J. Biomed. Mater. Res. B 2001;56: 228-233.

[11] van Tomme SR, van Steenbergen MJ, de Smedt SC, van Nostrum CF, Hennink WE. Self-Gelling Hydrogels Based on Oppositely Charged Dextran Microspheres Biomaterials 2005;26: 2129-2135.

[12] Kuo CK, Ma PX. Ionically Crosslinked Alginate Hydrogels as Scaffolds for Tissue Engineering: Part I. Structure, Gelation Rate and Mechanical Properties. Biomaterials 2001;22: 511-521.

[13] Ruel-Gariepy E, Leroux JC. In Situ-Forming Hydrogels-Review of TemperatureSensitive Systems. Eur. J. Pharm. Biopharm. 2004;58: 409-426.

[14] Jeong B, Bae YH, Kim SW. Drug Release from Biodegradable Injectable Thermosensitive Hydrogel of Peg-Plga-Peg Triblock Copolymers. J. Control. Release 2000;63: 155-163.

[15] Jeong B, Kim SW, Bae YH. Thermosensitive Sol-Gel Reversible Hydrogels. Adv. Drug Deliver. Rev. 2002;54: 37-51.

[16] de Jong SJ, de Smedt SC, Demeester J, van Nostrum CF, Kettenes-van den Bosch JJ, Hennink WE. Biodegradable Hydrogels Based on Stereocomplex Formation between Lactic Acid Oligomers Grafted to Dextran. J. Control. Release 2001 1-3.

[17] de Jong SJ, de Smedt SC, Wahls MWC, Demeester J, Kettenes-van den Bosch JJ, Hennink WE. Novel Self-Assembled Hydrogels by Stereocomplex Formation in Aqueous Solution of Enantiomeric Lactic Acid Oligomers Grafted to Dextran. Macromolecules 2000;33: 3680-3686.

[18] Li S, Vert M. Synthesis, Characterization, and Stereocomplex-Induced Gelation of Block Copolymers Prepared by Ring-Opening Polymerization of L(D)-Lactide in the Presence of Poly(Ethylene Glycol) Macromolecules 2003;36.

[19] Hiemstra C, Zhong Z, Li L, Dijkstra PJ, Feijen J. In-Situ Formation of Biodegradable Hydrogels by Stereocomplexation of PEG-(PLLA)8 and Peg(PDLA)8 Star Block Copolymers. Biomacromolecules 2006;7: 2790-2795.

[20] Łukaszczyk J, Smiga M, Jaszcz K, Adler H-JP, Jahne E, Kaczmarek M. Evaluation of Oligo(Ethylene Glycol) Dimethacrylates Effects on the Properties of New Biodegradable Bone Cement Compositions. Macromol. Biosci. 2005;5: 64-69.

[21] Sperinde JJ, Griffith LG. Synthesis and Characterization of Enzymatically-CrossLinked Poly(Ethylene Glycol) Hydrogels. Macromolecules 1997;30: 5255-5264. 
[22] Sanborn TJ, Messersmith PB, Barron AE. In Situ Crosslinking of a Biomimetic Peptide-PEG Hydrogel Via Thermally Triggered Activation of Factor XIII Biomaterials 2002;23: 2703-2710.

[23] McHale MK, Setton LA, Chilkoti A. Synthesis and in Vitro Evaluation of Enzymatically Cross-Linked Elastin-Like Polypeptide Gels for Cartilaginous Tissue Repair. Tissue Eng. 2005;11: 1768-1779.

[24] Sofia SJ, Singh A, Kaplan DL. Peroxidase-Catalyzed Crosslinking of Functionalized Polyaspartic Acid Polymers. J. Macromol. Sci. 2002;A39: 1151-1181.

[25] Kurisawa M, Chung JE, Yang YY, Gao SJ, Uyama H. Injectable Biodegradable Hydrogels Composed of Hyaluronic Acid-Tyramine Conjugates for Drug Delivery and Tissue Engineering Chem. Commun. 2005;34: 4312-4314.

[26] Kobayashi S, Uyama H, Kimura S. Enzymatic Polymerization. Chem. Rev. 2001;101: 3793-3818.

[27] Yamaoka T, Tabata Y, Ikada Y. Comparison of Body Distribution of Poly(Vinyl Alcohol) with Other Water-Soluble Polymers after Intravenous Administration. J. Pharm. Pharmacol. 1995;47: 479-486.

[28] van Dijk-Wolthuis WNE, Franssen O, Talsma H, van Steenbergen MJ, Kettenes-van den Bosch JJ, Hennink WE. Synthesis, Characterization and Polymerization of Glycidyl Methacrylate Derivatized Dextran. Macromolecules 1995;28: 6317-6322.

[29] Hennink WE, Jong SJD, Bos GW, Veldhuis TFJ, van Nostrum CF. Biodegradable Dextran Hydrogels Crosslinked by Stereocomplex Formation for the Controlled Release of Pharmaceutical Proteins. Int. J. Pharm. 2004;277: 99-104.

[30] Hovgaard L, Brondsted H. Dextran Hydrogels for Colon-Specific Drug-Delivery. J. Control. Release 1995;36: 159-166.

[31] de Jong SJ, van Eerdenbrugh B, van Nostrum CF, Kettenes-van den Bosch JJ, Hennink WE. Physically Crosslinked Dextran Hydrogels by Stereocomplex Formation of Lactic Acid Oligomers: Degradation and Protein Release Behavior. J. Control. Release 2001;71: 261-275.

[32] Kim SH, Chu CC. In Vitro Release Behavior of Dextran-Methacrylate Hydrogels Using Doxorubicin and Other Model Compounds. J. Biomater. Appl. 2000;15: 2346.

[33] Levesque SG, Shoichet MS. Synthesis of Cell-Adhesive Dextran Hydrogels and Macroporous Scaffolds. Biomaterials 2006;27: 5277-5285.

[34] Mairea M, Chaubet F, Mary P, Blanchat C, Alain Meuniera, Logeart-Avramoglou D. Bovine Bmp Osteoinductive Potential Enhanced by Functionalized Dextran-Derived Hydrogels. Biomaterials 2005;26: 5085-5092.

[35] Ramirez J, Sanchez-Chaves M, Arranz F. Dextran Functionalized by 4-Nitrophenyl Carbonate Groups-Aminolysis Reactions. Angew. Makromol. Chem. 1995;225: 123-130.

[36] Jeong B, Bae Y, Kim S. Thermoreversible Gelation of PEG-PLGA-PEG Triblock Copolymer Aqueous Solutions. Macromolecules 1999;32: 7064-7069.

[37] Ramirez JC, Chaves MS, Arranz F. Functionalization of Dextran with Chloroacetate Groups: Immobilization of Bioactive Carboxylic Acids. Polymer 1994;35: 26512655.

[38] Gross AJ, Sizer IW. The Oxidation of Tyramine, Tyrosine, and Related Compounds by Peroxidase. J. Biol. Chem. 1959;234: 1611-1614.

[39] Mita N, Tawaki S, Uyama H, Kobayashi S. Precise Structure Control of Enzymatically Synthesized Polyphenols. Bull. Chem. Soc. Jpn. 2004;77: 1523-1527. 
[40] Fukuoka T, Uyama H, Kobayashi S. Polymerization of Polyfunctional Macromolecules: Synthesis of a New Class of High Molecular Weight Poly(Amino Acid)s by Oxidative Coupling of Phenol-Containing Precursor Polymers. Biomacromolecules 2005;5: 977-983.

[41] Baynton KJ, Bewtra JK, Biswas $\mathrm{N}$, Taylor KE. Inactivation of Horseradish Peroxidase by Phenol and Hydrogen Peroxide: A Kinetic Investigation. Biochim. Biophys. Acta 1994;1206: 272-278.

[42] Arnao MB, Acosta M, del Rio JA, Varon R, Garcia F. A Kinetic Study on the Suicide Inactivation of Peroxidase by Hydrogen Peroxide. Biochim. Biophys. Acta 1990;1041: 43-47.

[43] Chung JT, Vlugt-Wensink KDF, Hennink WE, Zhang Z. Effect of Polymerization Conditions on the Network Properties Dex-HEMA Microspheres and MacroHydrogels. Int. J. Pharm. 2005;288: 51-61.

[44] Lutolf MP, Raeber GP, Zisch AH, Tirelli N, Hubbell JA. Cell-Responsive Synthetic Hydrogels. Adv. Mater. 2003;15: 888-892. 


\section{Chapter 5}

\section{Enzymatically Crosslinked Dextran-tyramine Hydrogels as Injectable Scaffolds for Cartilage Tissue Engineering*}

Enzymatic crosslinking of dextran-tyramine (Dex-TA) conjugates in the presence of horseradish peroxidase and hydrogen peroxide was successively applied in the preparation of hydrogels. Depending on the molecular weight of the dextran $\left(M_{n, \text { GPC }}\right.$ of 14000 or 31000 $\mathrm{g} / \mathrm{mol}$ ) and the degree of substitution (DS of 5, 10 or 15) with tyramine (TA) groups, the gelation times ranged from $20 \mathrm{~s}$ to $1 \mathrm{~min}$. Hydrogels prepared from Dex31k-TA with a DS of 10 had storage moduli up to $60 \mathrm{kPa}$. Similar values were found when chondrocytes were incorporated into the hydrogels. Chondrocyte-seeded Dex-TA hydrogels were prepared at a molar ratio of $\mathrm{H}_{2} \mathrm{O}_{2} /$ TA of 0.2 and cultured in a chondrocyte medium. A live-dead assay and a MTT assay revealed that almost all chondrocytes retained their viability after 2 weeks. SEM analysis showed that the encapsulated chondrocytes were capable of maintaining their round shape. Histology and immunofluorescent staining demonstrated the production of glycosaminoglycans (GAGs) and collagen type II after culturing for 14 and 21 days. Biochemical analysis showed that GAG accumulation increased with time inside Dex-TA hydrogels. Besides, GAG/DNA for Dex-TA hydrogels was higher than that for agarose at day 28. These results indicate that Dex-TA hydrogels are promising $3 D$ scaffolds for cartilage tissue engineering applications.

\subsection{Introduction}

Injured cartilage tissue is known to have a limited capacity of self-healing due to its avascular nature. Tissue engineering holds great promise for the regeneration of damaged cartilage. In this approach mature or progenitor cells are incorporated in a tissue-engineered scaffold that can be placed at the cartilage defect site. An ideal scaffold for cartilage regeneration is expected to have a controlled degradability, provides an adequate mechanical strength, promotes cell survival and differentiation, and allows nutrient diffusion, adhesion and integration with the surrounding native cartilage [1].

\footnotetext{
${ }^{*}$ This chapter is in preparation: Rong Jin, Liliana S. Moreira Teixeira, Pieter J. Dijkstra, Zhiyuan Zhong, Clemens A. van Blitterswijk, Marcel Karperien and Jan Feijen, Tissue Eng.
} 
Hydrogels are biocompatible hydrated, elastic three-dimensional networks that mimic the micro-environment for cells in soft tissues. Over the past decades, a number of hydrogels as scaffolds for cartilage tissue engineering have been developed [1-4]. Among these materials, injectable hydrogels, which can be placed locally as a viscous solution and gel in situ, have received much attention $[5,6]$. They can be applied using a minimally invasive procedure and can readily fill in cartilage defects of various sizes and shapes. Moreover, cultured cells can be homogenously distributed in the hydrogels by suspending cells in the precursor solutions prior to injection and gelation.

In the development of injectable hydrogels for cartilage regeneration, several approaches have been employed using natural or synthetic polymers such as chitosan $[7,8]$, hyaluronic acid [9-11] and poly(ethylene glycol)-based copolymers [12-14]. Radical polymerization using redox- or photo-initiators is one of the most commonly used methods to prepare chemically crosslinked injectable hydrogels [10, 15-17]. Burdick et al. reported on photopolymerized hyaluronic acid-based hydrogels. The mechanical properties of the hydrogels could be adjusted by varying the hyaluronic acid concentration and molecular weight. An increase in the network cross-linking density resulted in higher compressive moduli. However, this compromised the cell viability due to a limited exchange of nutrients and waste products to the surrounding culture media [15]. Hong et al. prepared methacrylated chitosan hydrogels using a redox initiator at low concentrations. A significant decrease in the DNA content of encapsulated chondrocytes after in vitro culturing for 6 days was observed because of cell loss or cell death [17].

Alternatively, injectable hydrogels can be prepared under mild conditions via Michaeltype addition reactions [18-20]. Hubbell et al. reported on biodegradable PEG-peptide injectable hydrogels via Michael-type addition for cartilage repair [20]. The reaction between thiols and vinyl sulfone groups had no adverse effect on the chondrocytes in the gels, and culturing periods over one month showed that $>90 \%$ cells were still viable. However, gelation times to form stable gels from these materials appeared rather long ( $c a$. $20 \mathrm{~min})[21]$.

Recently, a new approach which makes use of enzymatic crosslinking was introduced to prepare injectable hydrogels [22-28]. We previously reported on the enzyme-mediated insitu formation of hydrogels from dextran-tyramine conjugates (Dex-TA) [25]. In this approach, horseradish peroxidase (HRP) in combination with hydrogen peroxide $\left(\mathrm{H}_{2} \mathrm{O}_{2}\right)$ was used to induce crosslinking of the tyramine (TA) units conjugated to the dextran. By varying the ratios of $\mathrm{HRP} / \mathrm{TA}, \mathrm{H}_{2} \mathrm{O}_{2} / \mathrm{TA}$ and the degree of substitution (DS) of tyramine groups to the dextran, the gelation times, mechanical properties (e.g. storage and loss moduli) and degradation properties of the hydrogels can be tuned. 
In this study, the potential application of the injectable Dex-TA hydrogels for cartilage tissue engineering was evaluated. Therefore, Dex-TA hydrogels with different molecular weights $\left(\mathrm{M}_{\mathrm{n}}\right)$ and conjugated with different numbers of tyramine groups were prepared. Physical properties like gelation times, storage moduli, glucose diffusion and morphology of the hydrogels were studied. The viability and metabolic activity of in-situ incorporated chondrocytes in these Dex-TA hydrogels were determined using live-dead and MTT assays. The morphology of the chondrocytes and the formation of a cartilaginous specific matrix (glycosaminoglycan and collagen type II) in the cell/gel constructs in time were also examined.

\subsection{Materials and methods}

Materials. Dextrans $\left(\mathrm{M}_{\mathrm{n}, \mathrm{GPC}}=1.4 \times 10^{4} \mathrm{~g} / \mathrm{mol}, \mathrm{M}_{\mathrm{w}} / \mathrm{M}_{\mathrm{n}}=1.45\right.$, denoted as Dex $14 \mathrm{k}$, and $\mathrm{M}_{\mathrm{n}}$, ${ }_{\mathrm{GPC}}=3.1 \times 10^{4} \mathrm{~g} / \mathrm{mol}, \mathrm{M}_{\mathrm{w}} / \mathrm{M}_{\mathrm{n}}=1.38$, denoted as Dex31k) were purchased from Fluka. Dextran-tyramine conjugates (denoted as Dex-TA) were prepared as reported previously [25]. Hydrogen peroxide $\left(\mathrm{H}_{2} \mathrm{O}_{2}\right)$, dextranase (10-25 units/mg solid) and deuterium oxide $\left(\mathrm{D}_{2} \mathrm{O}\right)$ were obtained from Aldrich-Sigma. Horseradish peroxidase (HRP, type VI, 300 purpurogallin unit/mg solid) was purchased from Aldrich and used without further purification. Phosphate buffered saline (PBS, pH 7.4, without calcium or magnesium) was purchased from Invitrogen. Bovine chondrocytes were isolated as previously reported and cultured in a chondrocyte expansion medium composed of DMEM high glucose (Invitrogen), $10 \mathrm{mM}$ HEPES (Invitrogen), 10\% fetal bovine serum (FBS, Cambrex), 100 $\mathrm{U} / \mathrm{mL}$ penicillin (Invitrogen), $100 \mu \mathrm{g} / \mathrm{mL}$ streptomycin (Invitrogen), $0.2 \mathrm{mM}$ ascorbic acid (ASAP, Sigma), $0.1 \mathrm{mM}$ non-essential amino acids (NEAA, Sigma) and $0.4 \mathrm{mM}$ proline (Sigma) [26].

Hydrogel formation and characterization. Hydrogel samples $(\sim 0.5 \mathrm{~mL})$ were prepared in vials by the addition of a mixture of $\mathrm{H}_{2} \mathrm{O}_{2}$ and HRP in PBS to stock solutions of Dex-TA. In a typical example, to a PBS solution of Dex14k-TA DS15 (400 $\mu \mathrm{L}, 12.5 \mathrm{wt} \%)$, a freshly prepared solution of $\mathrm{H}_{2} \mathrm{O}_{2}$ ( $61.5 \mu \mathrm{L}$ of $0.4 \mathrm{wt} \%$ stock solution) and HRP (40.5 $\mu \mathrm{L}$ of 0.25 $\mathrm{mg} / \mathrm{mL}$ stock solution) in PBS were added. The contents were gently mixed. The final concentration of Dex-TA was $10 \mathrm{wt} \%$. The amount of HRP used was fixed at $0.25 \mathrm{mg}$ per mmol of tyramine moieties. Molar ratios of $\mathrm{H}_{2} \mathrm{O}_{2} /$ TA ranging from 0.1 to 0.5 were applied in the preparation of the hydrogels. The time to form a gel (denoted as gelation time) was determined using the vial tilting method. No flow within 1 min upon inverting the vial was regarded as the gel state. Semi-spherical hydrogel samples of $4 \mathrm{~mm}$ in diameter and $2 \mathrm{~mm}$ in height were prepared for microstructural characterization. Freeze-dried hydrogels were prepared by first freezing the gels at $-20^{\circ} \mathrm{C}$ for 4 hours and then in liquid nitrogen, followed by freeze-drying. The constructs were analyzed with a Philips XL 30 ESEM-FEG scanning 
electron microscopy (SEM) operating at a voltage of $10 \mathrm{kV}$. Samples were gold sputtered (Carringdon) before SEM analysis.

Nutrient transport. The diffusion of glucose in Dex-TA hydrogels was measured. The diffusion setup is similar as described in literature and is made of two Perspex chambers of $70 \mathrm{~mL}$ each, divided by a Perspex plate, and held together with screws [29]. One chamber (A) contained the glucose solution (initial concentration: $10 \mathrm{~g} / \mathrm{L}$ in $\mathrm{H}_{2} \mathrm{O}$ ), whereas the other (B) contained distilled water. The Dex-TA hydrogel (average thickness $\sim 0.5 \mathrm{~mm}$, which was measured by a micrometer (Mitutoyo Corp.)) was placed in a circular opening in the Perspex plate (diameter $17 \mathrm{~mm}$ ) and subsequently immersed in PBS at $37{ }^{\circ} \mathrm{C}$ to allow swelling. The PBS was changed every day to remove uncrosslinked/unreacted residues. After 3 days, the Perspex plate with the gel was removed from the PBS solution, and the gel was supported by a round mesh (Flow-Mesh ${ }^{\mathrm{TM}}$ gel and membrane support, Sigma), and placed between the A and B chambers. Both chambers were double-walled and kept at $37^{\circ} \mathrm{C}$ with circulating water. The glucose concentrations in chambers $\mathrm{A}$ and $\mathrm{B}$ were determined using an enzymatic assay (PGO Enzymes, Sigma) and analyzed at $\lambda=450 \mathrm{~nm}$ using a UV spectrophotometer (Varian Cary 300 scan) [30]. The glucose diffusion was determined by measuring the glucose concentration after $72 \mathrm{~h}$. The percentage of glucose diffused after $72 \mathrm{~h}$ was expressed as the glucose concentration in chamber B divided by the equilibrium concentration of $5 \mathrm{~g} / \mathrm{L}$ times $100 \%$.

Rheological analysis. Rheological experiments were carried out with a MCR 301 rheometer (Anton Paar) using a parallel plate $\left(25 \mathrm{~mm}\right.$ diameter, $\left.0^{\circ}\right)$ configuration and at $37^{\circ} \mathrm{C}$ in the oscillatory mode. In a typical experiment, $123 \mu \mathrm{L}$ of a $\mathrm{H}_{2} \mathrm{O}_{2}$ stock solution $(0.4$ $\mathrm{wt} \%$, in PBS) and $81 \mu \mathrm{L}$ of a HRP stock solution $(0.25 \mathrm{mg} / \mathrm{mL}$, in PBS ) were mixed. The $\mathrm{HRP} / \mathrm{H}_{2} \mathrm{O}_{2}$ solution was then immediately mixed with $800 \mu \mathrm{L}$ of a solution of Dex $14 \mathrm{k}-\mathrm{TA}$ DS 15 (12.5 wt\% in PBS) using a double syringe (2.5 mL, 1:4 volume ratio) equipped with a mixing chamber (Mixpac). After the sample was applied to the rheometer, the upper plate was immediately lowered to a measuring gap size of $0.5 \mathrm{~mm}$, and the measurement was started. To prevent evaporation of water, a layer of oil was introduced around the polymer sample. Similar experiments were performed with chondrocytes (cell density $5 \times 10^{6} / \mathrm{mL}$ ) in the polymer solution using the same procedure as described above. The evolution of the storage $\left(\mathrm{G}^{\prime}\right)$ and loss $\left(\mathrm{G}^{\prime \prime}\right)$ moduli were recorded as a function of time. A frequency of 0.5 $\mathrm{Hz}$ and a strain of $0.1 \%$ were applied in order to maintain the linear viscoelastic regime.

In situ chondrocyte incorporation. Hydrogels containing bovine chondrocytes were prepared under sterile conditions by mixing a Dex-TA/cell suspension with a freshly prepared mixture of HRP and $\mathrm{H}_{2} \mathrm{O}_{2}$. Solutions of Dex-TA were made using medium and HRP and $\mathrm{H}_{2} \mathrm{O}_{2}$ stock solutions were made using PBS. All solutions were sterilized by filtration through filters with a pore size of $0.22 \mu \mathrm{m}$. Chondrocytes were incorporated in 
hydrogels prepared analogously as without cells. As an example: Chondrocyte/polymer suspensions were prepared by mixing $200 \mu \mathrm{L}$ of a Dex14k-TA DS 15 solution (25 wt\%) with $200 \mu \mathrm{L}$ of medium containing chondrocytes. To $100 \mu \mathrm{L}$ of the resulting cell/polymer suspension, $25 \mu \mathrm{L}$ of a $\mathrm{HRP} / \mathrm{H}_{2} \mathrm{O}_{2}$ mixture was added and the suspension was gently mixed. The HRP $/ \mathrm{H}_{2} \mathrm{O}_{2}$ mixture was prepared by adding $61.5 \mu \mathrm{L}$ of the HRP stock solution to 40.5 $\mu \mathrm{L}$ of the $\mathrm{H}_{2} \mathrm{O}_{2}$ stock solution. Before gelation, the precursor was quickly transferred to a culture plate. The final polymer concentration was $10 \mathrm{wt} \%$ and the cell seeding density in the gels was $5 \times 10^{6} / \mathrm{mL}$. For cytotoxicity and morphology studies, the cell/gel constructs were cultured in a chondrocyte expansion medium (see Section 2.1). For matrix production studies, the constructs were cultured in a chondrocyte differentiation medium composed of DMEM high glucose with $0.1 \mu \mathrm{M}$ dexamethasone (Sigma), $100 \mu \mathrm{g} / \mathrm{mL}$ sodium pyruvate (Sigma), $0.2 \mathrm{mM}$ ascorbic acid, $50 \mathrm{mg} / \mathrm{mL}$ insulin-transferrin-selenite (ITS+Premix, BD biosciences), $100 \mathrm{U} / \mathrm{ml}$ penicillin, $100 \mu \mathrm{g} / \mathrm{ml}$ streptomycin and $10 \mathrm{ng} / \mathrm{mL}$ transforming growth factor $\beta 3$ (TGF- $\beta 3, R \& D$ system). In all experiments, samples were incubated at $37^{\circ} \mathrm{C}$ and $5 \% \mathrm{CO}_{2}$, and the medium was replaced every 2 or 3 days.

Cytotoxicity assay. A viability study on Dex-TA hydrogels encapsulated chondrocytes (Passage 3-4) was performed with a live-dead assay and an MTT (3-(4,5-dimethyl-2thiazolyl)-2,5-diphenyl-2H-tetrazolium bromide) assay. For the Live/Dead assay, at days 7 and 14, the hydrogel constructs were rinsed with PBS and stained with calcein AM/ethidium homodimer using the Live/Dead assay Kit (Invitrogen), according to the manufactures' instructions [31]. Agarose hydrogels $(0.5 \mathrm{wt} \%)$ with a similar chondrocyte density were used as a control. Hydrogel/cell constructs were visualized using fluorescence microscopy (Zeiss). As a result living cells fluoresce green and the nuclei of dead cells red. An MTT staining was performed using 1\% (total medium volume) of a MTT solution (5 $\mathrm{mg} / \mathrm{mL}$, Gibco) and an incubation time of $2 \mathrm{~h}$. Hydrogel/cell constructs were then visualized using a light microscope.

To quantitatively measure the metabolic activity of chondrocytes encapsulated in the hydrogels, samples were first washed with PBS and 10\% (total medium volume, without phenol red) MTT solutions were added to the hydrogels. The constructs were incubated at $37^{\circ} \mathrm{C}$. After $4 \mathrm{~h}$, MTT solutions were removed and $500 \mu \mathrm{L}$ of dextranase solution (100 $\mathrm{U} / \mathrm{mL}$ in PBS) was added to each gel to disrupt the gels. After centrifugation and removal of the solutions, the formazan formed by cells presenting mitochondrial metabolic activity was thoroughly extracted from the gel pieces by addition of DMSO under vortexing. The extracts were centrifuged and the supernatants were transferred to a 96-well plate. The absorbance at $540 \mathrm{~nm}$ was recorded using a microplate reader (Bio-TEK Instruments). Values were corrected for background staining of hydrogels without chondrocytes. The experiments were performed in triplicate. The percentage of metabolic activity (\%) of 
chondrocytes was calculated relative to values determined for cells cultured in agarose gels (control) at day 1 (considered as a starting value for metabolic activity).

Chondrocyte morphology. The morphology of the chondrocytes in the hydrogels was studied using a Philips XL 30 ESEM-FEG scanning electron microscope (SEM) or a LEO Gemini 1550 FEG-SEM. After 14 days' in vitro culturing in expansion medium, the hydrogel/cell constructs were fixed with formalin by sequential dehydration and critical point drying. These samples were gold sputtered (Carringdon) and analyzed with SEM.

Histology and immunofluorescent staining. After 14 and 21 days, the hydrogel/cell constructs were washed with PBS and fixed in a $10 \%$ buffered formalin solution for 1 hour. After dehydration with a standard series of ethanol followed by butanol incubation overnight, samples were embedded in paraffin and sectioned using a microtome to yield sections of $5 \mu \mathrm{m}$ in thickness. Sections were stained with Alcian Blue (Sigma-Aldrich, used as $1 \% \mathrm{w} / \mathrm{v}$ solution) for $30 \mathrm{~min}$, and destained for $5 \mathrm{~min}$ in $1 \%$ acetic acid. Afterwards, the sections were washed with water and dehydrated. The staining for glycosaminoglycans (GAGs) was examined under a light microscope (Nikon Eclipse E400).

For immunofluorescence analysis of collagen type II, sections were rehydrated with xylene and a standard series of ethanol. Afterwards, the samples were treated with $10 \mathrm{mM}$ citric acid buffer ( $\mathrm{pH}$ 6.0) for $10 \mathrm{~min}$, and then washed with PBS/BSA 1\%. Col2A1 monoclonal antibody (Purified mouse immunoglobulin IgG1, clone 3HH1-F9, Abnova) was diluted at 1:100 in PBS/BSA $1 \%$ and let to react overnight at room temperature. After washing twice for $5 \mathrm{~min}$ in PBS/BSA 1\%, the sections were incubated with Alexa Fluor 488-Goat anti-Mouse IgG1 $(\gamma 1)$ (Invitrogen, Molecular Probes, 1:1000) for $1 \mathrm{~h}$. After extensive washing, the sections were mounted with VECTASHIELD Mounting Medium containing 4',6'-diamidino-2-phenylindole dihydrochloride (DAPI, Vector Laboratories, Burlingame, CA) to stain the nuclei. The sections not incubated with primary antibodies were used as a negative control and a pellet of human chondrocytes cultured for 21 days in chondrocyte differentiation medium was used as a positive control.

Biochemical analysis. To quantitatively analyze the GAG production inside the hydrogels, a DMMB assay was performed. The constructs were taken from the chondrocyte differentiation medium after 14, 21 and 28 days. Samples were washed with PBS and frozen at $-80^{\circ} \mathrm{C}$. After thawing, the constructs were digested in proteinase-K (Sigma) at 56 ${ }^{\circ} \mathrm{C}(>16 \mathrm{~h})$. Quantification of total DNA was done by a Cyquant dye kit (Molecular Probes) using a fluorescent plate reader (Perkin-Elmer). The amount of GAG was determined spectrophotometrically after reaction with a dimethylmethylene blue dye (DMMB, SigmaAldrich). The intensity of the color was quantified immediately in a microplate reader (BioTEK Instruments) by measuring the absorbance at $540 \mathrm{~nm}$. The amount of GAG was calculated based on a calibration curve using chondroitin sulphate A or B (Sigma-Aldrich). 
All values were corrected for the background staining of gels without cells and normalized to the DNA amount (expressed as the GAG/DNA $(\mu \mathrm{g} / \mu \mathrm{g})$ ratio). Data $(\mathrm{n}=3$, measured in triplicates) are expressed as mean \pm standard deviation (SD). Statistical significance was determined by one-way ANOVA with Turkey's post-hoc analysis.

\subsection{Results and discussion}

\subsubsection{Hydrogel formation and gelation time}

In foregoing research, it was shown that the enzymatic crosslinking of dextran-tyramine (Dex-TA) conjugates using horseradish peroxidase (HRP) and hydrogen peroxide $\left(\mathrm{H}_{2} \mathrm{O}_{2}\right)$ is a highly efficient method to prepare in-situ forming hydrogels [25]. The gelation time depends on relative ratios of $\mathrm{HRP}$ and $\mathrm{H}_{2} \mathrm{O}_{2}$ to tyramine (TA) groups present. In this study, Dex-TA conjugates with different molecular weights of dextran $\left(\mathrm{M}_{\mathrm{n}}\right.$ of $14 \mathrm{k}$ and $\left.31 \mathrm{k}\right)$ and degrees of substitution (DS) of tyramine groups, i.e. Dex14k-TA with a DS of 5, 10 or 15 tyramine groups and Dex31k-TA with a DS of 5 or 10 tyramine groups, were synthesized (Scheme 5.1a) [25]. The hydrogels were prepared by mixing PBS solutions of Dex-TA conjugates and freshly-made PBS solutions of HRP and $\mathrm{H}_{2} \mathrm{O}_{2}$ (Scheme 5.1b). To apply these hydrogels as an injectable matrix material for cartilage tissue engineering, the crosslinking reaction was optimized with respect to suitable gelation times and use of hydrogen peroxide. It was expected that the use of high concentrations of $\mathrm{H}_{2} \mathrm{O}_{2}$ would have a detrimental effect on chondrocytes during the crosslinking reaction $[32,33]$. To this end, the gelation times of Dex-TA at low molar ratios of $\mathrm{H}_{2} \mathrm{O}_{2} /$ TA ranging from 0.05 to 0.5 were investigated. Concentrations of Dex-TA conjugates of $10 \mathrm{wt} \%$ and $0.25 \mathrm{mg}$ of HRP per mmol tyramine moieties were applied in the hydrogel preparation. The gelation times of the Dex-TA hydrogels were determined by the vial tilting method.

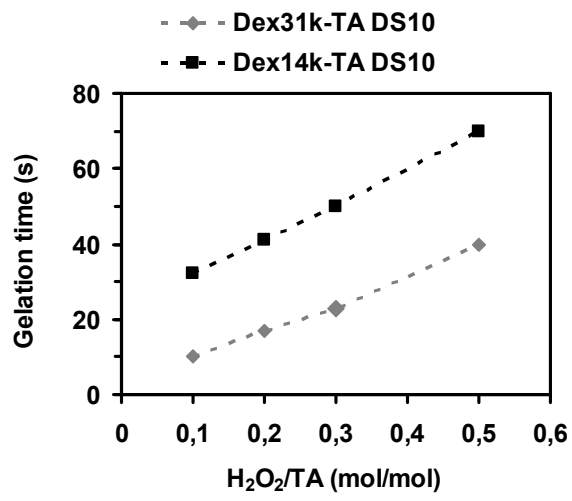

Figure 5.1. Gelation times of Dex-TA conjugates ( $10 \mathrm{wt} \%$ ) as a function of the $\mathrm{H}_{2} \mathrm{O}_{2} /$ TA molar ratio. Reaction conditions: $0.25 \mathrm{mg}$ HRP per mmol phenol groups; $37^{\circ} \mathrm{C}$, PBS. 
As shown in Figure 5.1, the gelation times of the hydrogels prepared from Dex14k-TA and Dex31k-TA conjugates $(\mathrm{DS}=10)$ increased with increasing molar ratios of $\mathrm{H}_{2} \mathrm{O}_{2} / \mathrm{TA}$ from 0.1 to 0.5 . No gelation occurred when $\mathrm{H}_{2} \mathrm{O}_{2} /$ TA ratios at and below 0.05 were used (data not shown). Moreover, at the same $\mathrm{H}_{2} \mathrm{O}_{2}$ /TA ratio, a shorter gelation time was observed for the hydrogels comprising a higher molecular weight Dex-TA. Additionally, the DS values of the Dex14k-TA and Dex31k-TA conjugates have an influence on the gelation time of the hydrogels (Table 5.1). By increasing the number of tyramine groups conjugated to the dextran from 5 to 15 per 100 anhydroglucose rings of dextran, the gelation times of the hydrogels of the Dex14k-TA conjugates decreased from about 60 to 20 seconds. Taken together, the hydrogels prepared from Dex14k-TA with a DS of 10 or 15 , and Dex31k-TA with a DS of 10 showed short gelation times and were regarded suitable as injectable cell carriers for the retention of cells inside the gels. Since fast gelation (less than $60 \mathrm{sec})$ was generally observed at a $\mathrm{H}_{2} \mathrm{O}_{2} /$ TA molar ratio of $0.2\left(\left[\mathrm{H}_{2} \mathrm{O}_{2}\right]=12\right.$ and $16 \mathrm{mM}$ for Dex-TA DS 10 and DS 15, respectively), this ratio was used in the preparation of cell/gel constructs and evaluation of their properties.

(a)

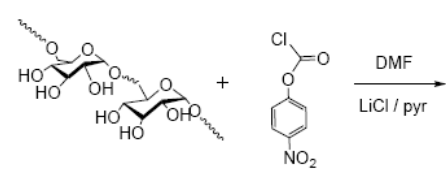

Dextran

PNC

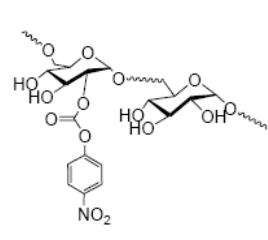

Dex-PNC

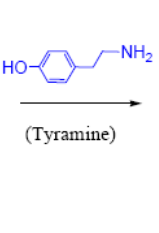

Dex-TA

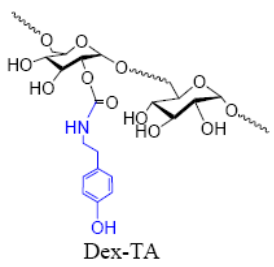

Dex-TA

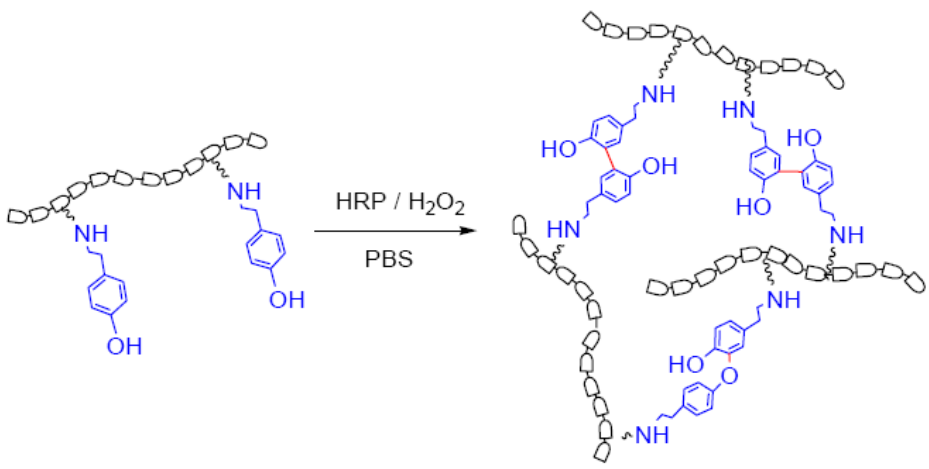

(b)

Scheme 5.1. Synthesis of dextran-tyramine conjugates (Dex-TA) and hydrogel formation via enzymatic crosslinking.

\subsubsection{Hydrogel characterization}

The mechanical properties of the Dex-TA hydrogels were studied by oscillatory rheology experiments at $37^{\circ} \mathrm{C}[34]$. The storage moduli of Dex-TA hydrogels are listed in Table 5.1. 
The storage moduli of the Dex-TA hydrogels largely increased with increasing DS of tyramine groups from 5 to 15 . For example, the storage moduli of the Dex14k-TA hydrogels increased from about $1.4 \mathrm{kPa}$ to $40 \mathrm{kPa}$ by increasing the DS from 5 to 15 . An even higher storage modulus of about $60 \mathrm{kPa}$ was obtained in the hydrogels prepared from Dex31k-TA with a DS of 10. Interestingly, the Dex-TA hydrogels containing chondrocytes $\left(5 \times 10^{6}\right.$ cells $/ \mathrm{mL}$ gel) had storage and loss moduli that were close to the gels without cells (data not shown), indicating that the presence of chondrocytes in the hydrogels did not influence their mechanical properties.

The morphology of freeze-dried hydrogels prepared from the Dex-TA conjugates was determined using scanning electron microscopy (SEM) (Figure 5.2). In all cases, the DexTA hydrogels appeared to be highly porous and had a well-interconnected pore structure. It appeared that the pore size of these hydrogels is mainly influenced by the DS rather than by the $M_{n}$ of the polymers. Freeze-dried samples of hydrogels prepared from Dex14k-TA with a DS of 5 had a larger average pore size $(351 \pm 71 \mu \mathrm{m})$ than those of Dex14k-TA with a DS of $10(206 \pm 93 \mu \mathrm{m})$ (Figure $5.2 \mathrm{~b}$ vs. c) and the hydrogel prepared from Dex31k-TA with a DS of 10 had an average pore size similar to the Dex14k-TA with the same DS of 10 (Figure 5.2 a vs. b).
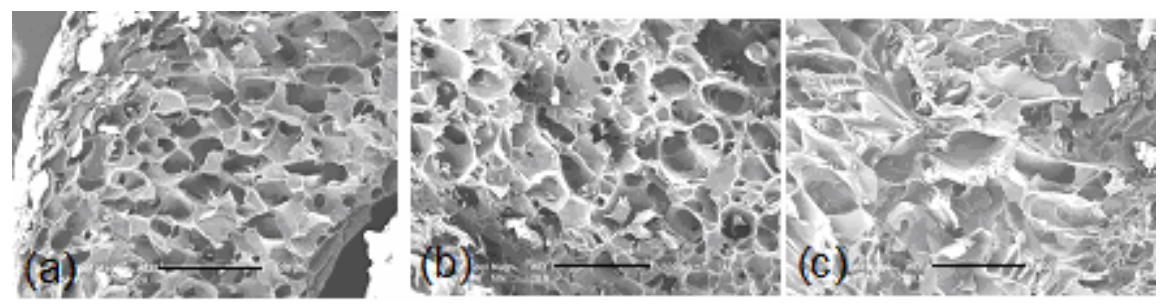

Figure 5.2. SEM images of freeze dried hydrogel samples: (a) Dex31k-TA DS 10, (b) Dex14k-TA DS 10 and (c) Dex14k-TA DS 5. Reaction conditions: $0.25 \mathrm{mg}$ HRP per mmol phenol groups; molar ratio of $\mathrm{H}_{2} \mathrm{O}_{2} / \mathrm{TA}=0.2$. (Scale bar $\left.500 \mu \mathrm{m}\right)$

To allow cell growth over prolonged periods of time, sufficient nutrient diffusion in the hydrogels is highly desired. The permeability of the Dex-TA hydrogels was evaluated by determining the glucose diffusion through the hydrogels. The setup consisted of two chambers separated by a plate with a circular opening in which a hydrogel film was placed. Glucose is a representative nutrient in the cell culture medium. Figure 5.3 shows typical results of the glucose diffusion in time through a Dex14k-TA DS 15 hydrogel. As can be expected, the concentration of the glucose in chamber A decreased over time, while there was a corresponding increase in the concentration of glucose in chamber B. After $72 \mathrm{~h}$, the glucose concentrations in both chambers almost reached a plateau. The diffusion coefficient of glucose through a Dex14k-TA DS 15 hydrogel was determined in time from the glucose concentrations in both chambers [35]. The diffusion coefficient was calculated to be 
$3.2 \times 10^{-6} \mathrm{~cm}^{2} / \mathrm{s}$, which was close to that of glucose diffusion in cartilage tissue $\left(\sim 2 \times 10^{-6}\right.$ $\mathrm{cm}^{2} / \mathrm{s}$ ) [36]. In Table 5.1, the percentage of glucose diffused after $72 \mathrm{~h}$ using various DexTA hydrogels is presented. Similar values of $79 \%$ were determined for hydrogels prepared from Dex14k-TA and Dex31k-TA with a DS value of 10. A slightly lower percentage of $74 \%$ was determined for the Dex14k-TA hydrogels with a higher DS of 15 . The slower diffusion can be attributed to a more compact network of the hydrogel prepared from Dex14k-TA DS 15 than that of Dex14k-TA DS 10. In all cases, the glucose diffusion reached over $70 \%$ of the equilibrium glucose concentration within $72 \mathrm{~h}$, indicating that cells may efficiently interact with nutrients in these hydrogels.

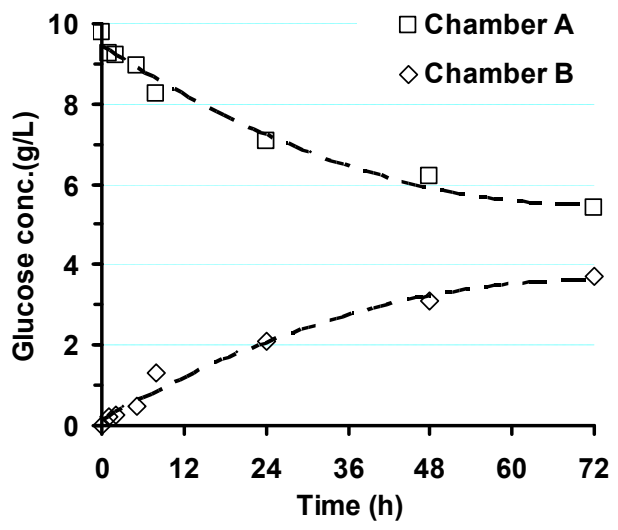

Figure 5.3. Typical graph of glucose (in water) diffusion from chamber A towards the chamber B using a Dex14k-TA DS 15 hydrogel as function of time at $37^{\circ} \mathrm{C}$.

Table 5.1. Gelation times, storage moduli and glucose diffusion for Dex-TA hydrogels ${ }^{\text {a }}$

\begin{tabular}{c|c|c|c|c}
\hline & DS $^{\mathrm{b}}$ & $\begin{array}{c}\text { Gelation } \\
\text { time }(\mathrm{s})\end{array}$ & $\begin{array}{c}\text { Storage modulus } \\
\mathrm{G}^{\prime}(\mathrm{kPa})\end{array}$ & $\begin{array}{c}\text { Percentage of glucose } \\
\text { diffused after } 72 \mathrm{~h}^{\mathrm{c}}\end{array}$ \\
\hline \multirow{3}{*}{ Dex14k-TA } & 5 & 60 & 1.4 & n.d. \\
\cline { 2 - 5 } & 10 & 41 & 15.1 & $79 \%$ \\
\cline { 2 - 5 } & 15 & 20 & 40.2 & $74 \%$ \\
\hline \hline \multirow{2}{*}{ Dex31k-TA } & 5 & 42 & 8.2 & $83 \%$ \\
\cline { 2 - 5 } & 10 & 17 & 60.4 & $79 \%$ \\
\hline
\end{tabular}

a: Reaction conditions: $10 \mathrm{wt} \%$ polymer concentration; molar ratio of $\mathrm{H}_{2} \mathrm{O}_{2} / \mathrm{TA}$ is $0.2 ; 0.25$ mg HRP per mmol phenol groups; $37^{\circ} \mathrm{C}$, PBS

b: DS (Degree of substitution, defined as the number of tyramine units per 100 anhydroglucose rings in dextran) was determined using ${ }^{1} \mathrm{H}$ NMR.

c: The percentage of glucose diffused after $72 \mathrm{~h}$ was expressed as the ratio of the glucose concentration in chamber B and the equilibrium conc. of $5 \mathrm{~g} / \mathrm{L}$, multiplied by $100 \%$. 


\subsubsection{Cell viability of chondrocytes in Dex-TA hydrogels}

Chondrocytes were cultured in the hydrogels of Dex14k-TA and Dex31k-TA with different DS for 14 days. Cell survival of the chondrocytes in the hydrogels was evaluated using a live-dead assay, in which living cells stained green and dead cells red. As is shown in Figure 5.4, over 95\% cells in these hydrogels were alive, similar to those embedded in an agarose gel which was used as a control. Moreover, a homogeneous distribution of metabolically active chondrocytes that stained purple with a MTT solution was observed in all Dex-TA hydrogels after 1, 7 and 14 days (Figure 5.5). Cell viability experiments, evaluated by the MTT assay, showed that the metabolic activities (\%) of chondrocytes in the hydrogels of Dex31k-TA DS 10, Dex14k-TA DS 10 and Dex14k-TA DS 15 were comparable to the agarose control over the culturing periods, indicating good biocompatibility and low cytotoxicity (Figure 5.6a). Notably, the metabolic activity values of chondrocytes in the Dex14k-TA DS 10 hydrogel after 14 days in culture is statistically higher than the value at day $1(p<0.05)$. These results suggested that chondrocyte proliferation might occur in the Dex14k-TA DS 10 hydrogels. Support for this hypothesis was found by the live-dead assay. Nests of doublets that are indicative of chondrocyte division were observed in the Dex14k-TA DS 10 hydrogel after 14 days in culture (Figure $6 b)$.
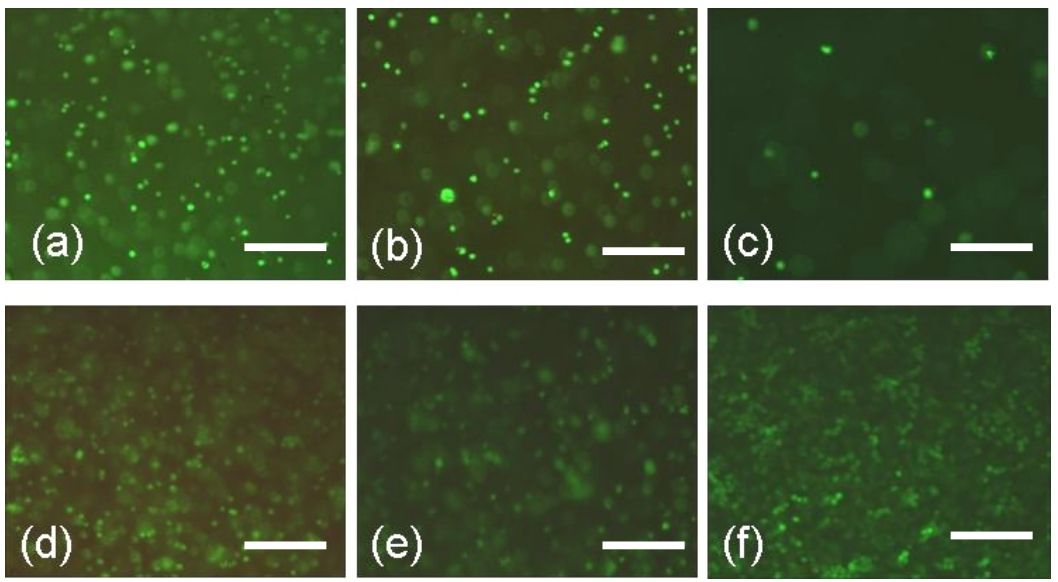

Figure 5.4. Live-dead assay of chondrocytes in Dex-TA hydrogels at day 14: (a) Dex14k-TA DS 15, (b) Dex14k-TA DS 10, (c) Dex14k-TA DS 5, (d) Dex31k-TA DS 10 and (e) Dex31k-TA DS 5. Agarose gels $(0.5 \mathrm{wt} \%)$ were used as a control (f). Reaction conditions: $0.25 \mathrm{mg}$ HRP per mmol phenol groups; molar ratio of $\mathrm{H}_{2} \mathrm{O}_{2} / \mathrm{TA}=0.2$. Cells were stained with calcein-AM/ethidium Homodimer (living cells stained green and dead cells red). The chondrocyte seeding density was $5 \times 10^{6}$ cells $/ \mathrm{mL}$. Scale bar: $200 \mu \mathrm{m}$. 
Day 1

Dex31k-TA

DS 10

Dex14k-TA

DS 10

Dex14k-TA

DS 15

Figure 5.5. MTT staining of chondrocytes in Dex31k-TA DS 10, Dex14k-TA DS 15 and DS 10 hydrogels after 1,7 and 14 days in culture. Metabolically active cells stained purple. Reaction conditions: $\mathrm{H}_{2} \mathrm{O}_{2} /$ TA molar ratio is $0.2 ; 0.25 \mathrm{mg}$ HRP per mmol phenol groups. The chondrocyte seeding density was $5 \times 10^{6}$ cells $/ \mathrm{mL}$.

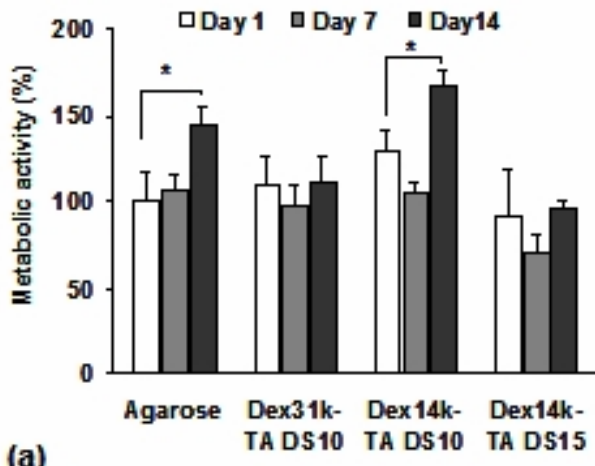

(a)
Day 7
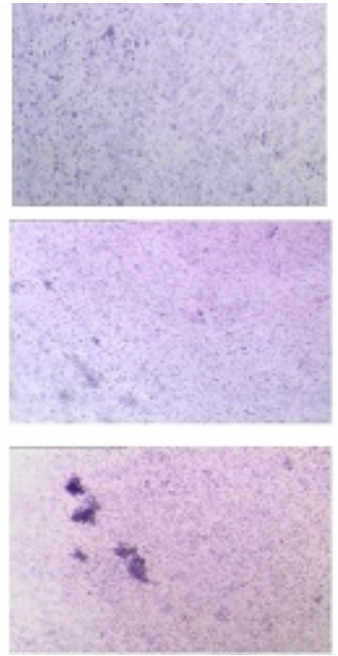

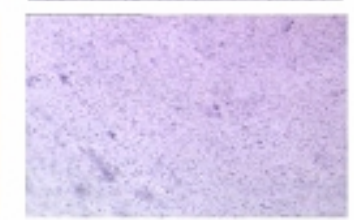

Day 14
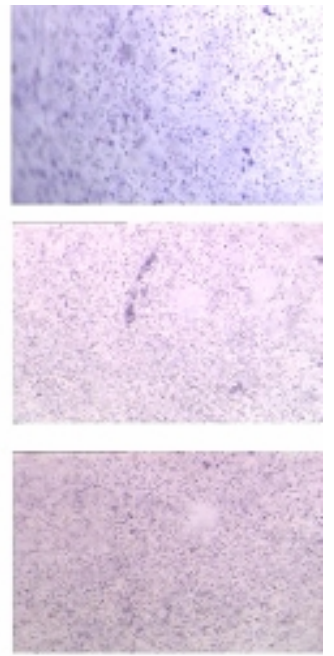
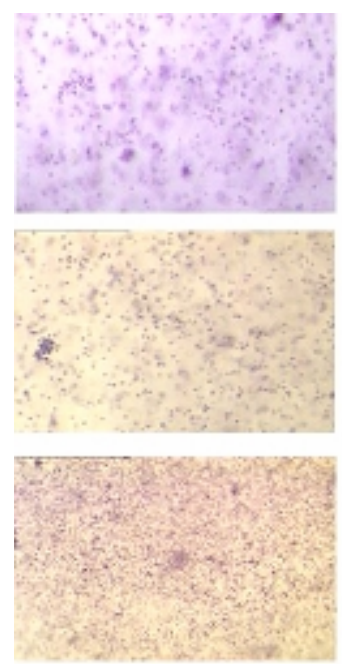


\subsubsection{Chondrocyte morphology and matrix production}

In native cartilage, chondrocytes are surrounded by an extracellular matrix that consists of negatively charged glycosaminoglycan (GAG), like hyaluronic acid and chondroitin sulfate, as well as collagen type II fibrils. The ability of these Dex-TA hydrogels to function as a scaffold for cartilage tissue formation was investigated by examining the cell morphology and the ability to produce a cartilaginous specific matrix.

It is known that chondrocytes in culture may rapidly lose chondrocytic characteristics and obtain a fibroblast-like phenotype, a process termed "dedifferentiation" [37]. A round cell shape is correlated with the maintenance of the chondrocyte phenotype. The morphology of the chondrocytes incorporated in the Dex-TA and agarose hydrogels was evaluated by SEM after culturing for 14 days in chondrocyte expansion medium. In Figure 5.7 it is shown that the chondrocytes incorporated in Dex31k-TA DS 10 and Dex14-TA DS 10 and 15 hydrogels exhibited a distinctly round cell shape. Notably, as a typical example, the chondrocytes inside Dex14k-TA DS 15 hydrogels after culturing for 21 days, were located adjacent to a fibrous pericellular matrix (Figure 5.8a) [38]. SEM examinations revealed that this fibrous matrix consisted of collagen fibrils, which was confirmed by the observation of the typical D-period in the fibrils (Figure 5.8b-c).

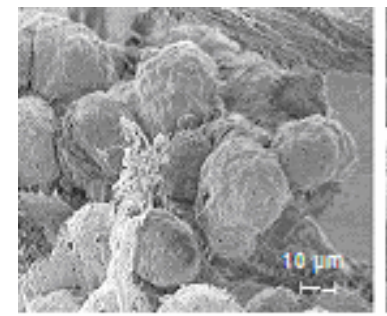

Dex31k-TA DS 10

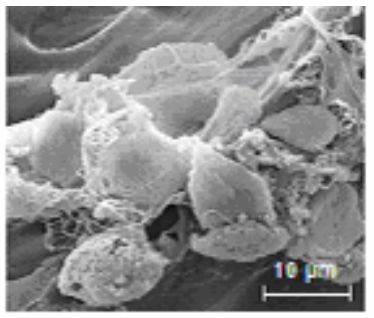

Dexl4k-TA DS 10

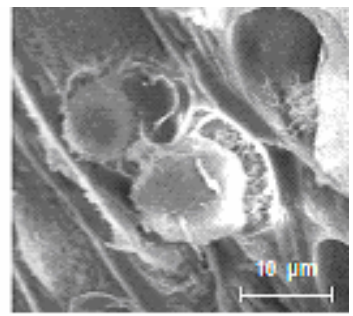

Dexl4k-TA DS 15

Figure 5.7. SEM images of chondrocytes in Dex-TA hydrogels after 14 days' culture.
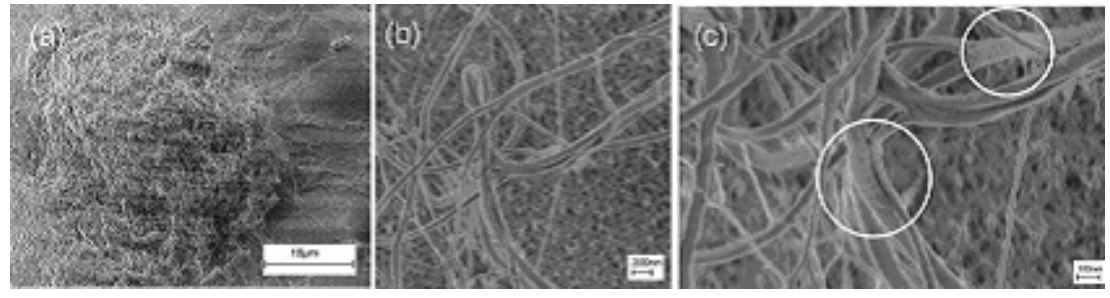

Figure 5.8. SEM images of (a) a single chondrocyte in a Dex14k-TA DS 15 hydrogel (21 days) was surrounded by a fibrous matrix on the gel surface, (b) fibrous matrix at high magnification (c) Circles point to collagen fibrils with a visible D-period at high magnification. 
GAG production by chondrocytes in the Dex-TA hydrogels was examined by histology using Alcian Blue staining. Histology showed that the chondrocytes incorporated in these Dex-TA hydrogels produced abundant ECMs rich in GAGs after 14 and 21 days, as confirmed by the dense GAG staining in these gels (Figure 5.9). No staining was observed for the Dex-TA gels without chondrocytes or for the Dex-TA/cell constructs at day 1 (data not shown). Moreover, at day 14, the GAGs were mainly located in the pericellular matrix around spherical cells, but at day 21 , the GAGs were more evenly distributed throughout the gels both in the pericellular and interterritorial matrix.

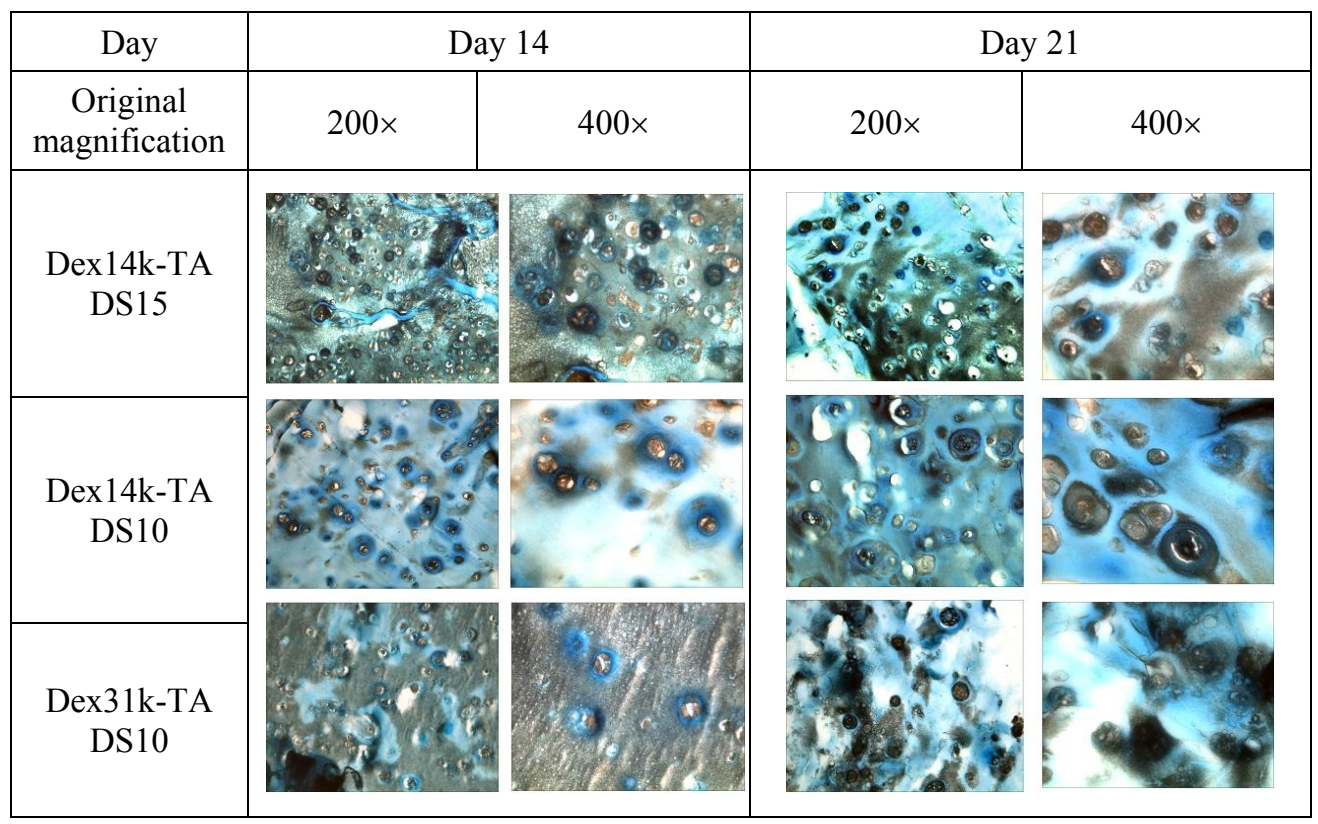

Figure 5.9. Alcian blue staining of Dex-TA hydrogels with chondrocytes after culturing for 14 and 21 days in differentiation medium. GAGs were stained blue/green. The chondrocyte seeding density was $5 \times 10^{6}$ cells $/ \mathrm{mL}$.

The synthesis of collagen by chondrocytes in the Dex-TA hydrogels was also examined. The type of collagen present in articular cartilage is primarily collagen type II [39]. An immunofluorescent staining demonstrated the presence of collagen type II inside Dex-TA hydrogels (Figure 5.10a). In the positive control, the nuclei of the chondrocytes fluoresced blue due to the counterstaining with DAPI and the collagen type II fluoresced green. In the negative control, only the staining of the nuclei was observed. These results indicated that chondrocytes cultured inside Dex-TA hydrogels were capable of maintaining their phenotype and producing a cartilaginous specific matrix. 

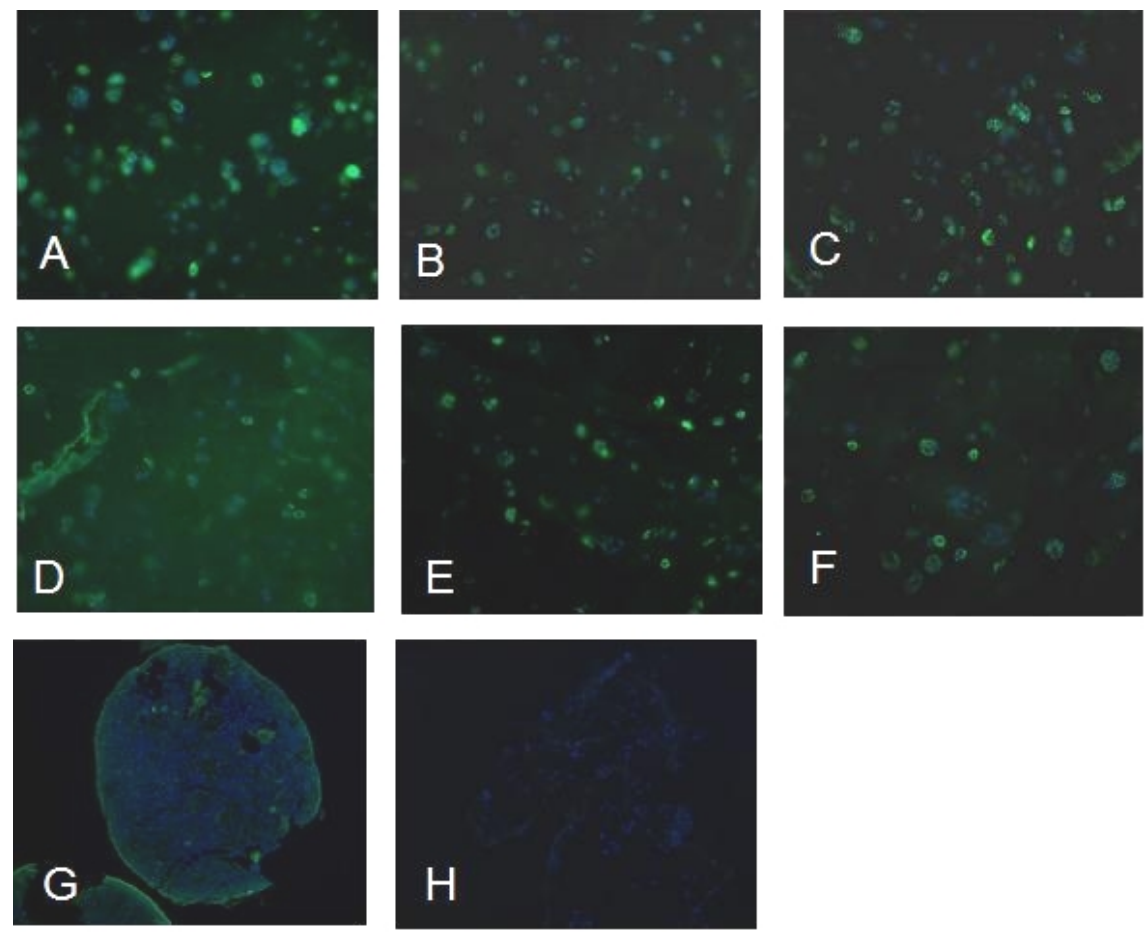

Figure 5.10. Collagen type II staining of Dex14k-TA DS 15 (A and D), Dex14k-TA DS 10 (B and E), and Dex31k-TA DS 10 (C and F) hydrogels after culturing for 14 (A-C) and 21 (D-F) days in differentiation medium; The chondrocyte seeding density was $5 \times 10^{6}$ cells $/ \mathrm{mL}$. A pellet of human chondrocytes cultured for 21 days in chondrocyte differentiation medium was used as a positive control $(\mathrm{G})$ and the section without incubation with primary antibodies was used as a negative control (H). Collagen type II fluoresced green and nuclei of the cells were stained with DAPI (blue).

The amounts of glycosaminoglycan (GAG) secreted by chondrocytes inside the hydrogels at different times in culture were determined by a DMMB assay. Agarose gel, a well-known polysaccharide hydrogel system for chondrocyte culturing, was used as a positive control [40, 41]. In Figure 5.11a the time-dependent accumulation of the GAG in the Dex-TA and agarose hydrogels is presented. All hydrogels demonstrated a significant increase in GAG production with increasing culturing times from 14 to 28 days $(p<0.05)$. These results are consistent with the histology results using Alcian blue staining, which showed a denser staining of GAGs at day 21 than that at day 14. Notably, the GAG contents in the hydrogels from Dex14k-TA DS 10 and Dex31k-TA DS 10 are significantly higher than that in the agarose gel at day $28(p<0.05)$. The GAG amount for these Dex-TA hydrogels at the same culturing time did not differ. 

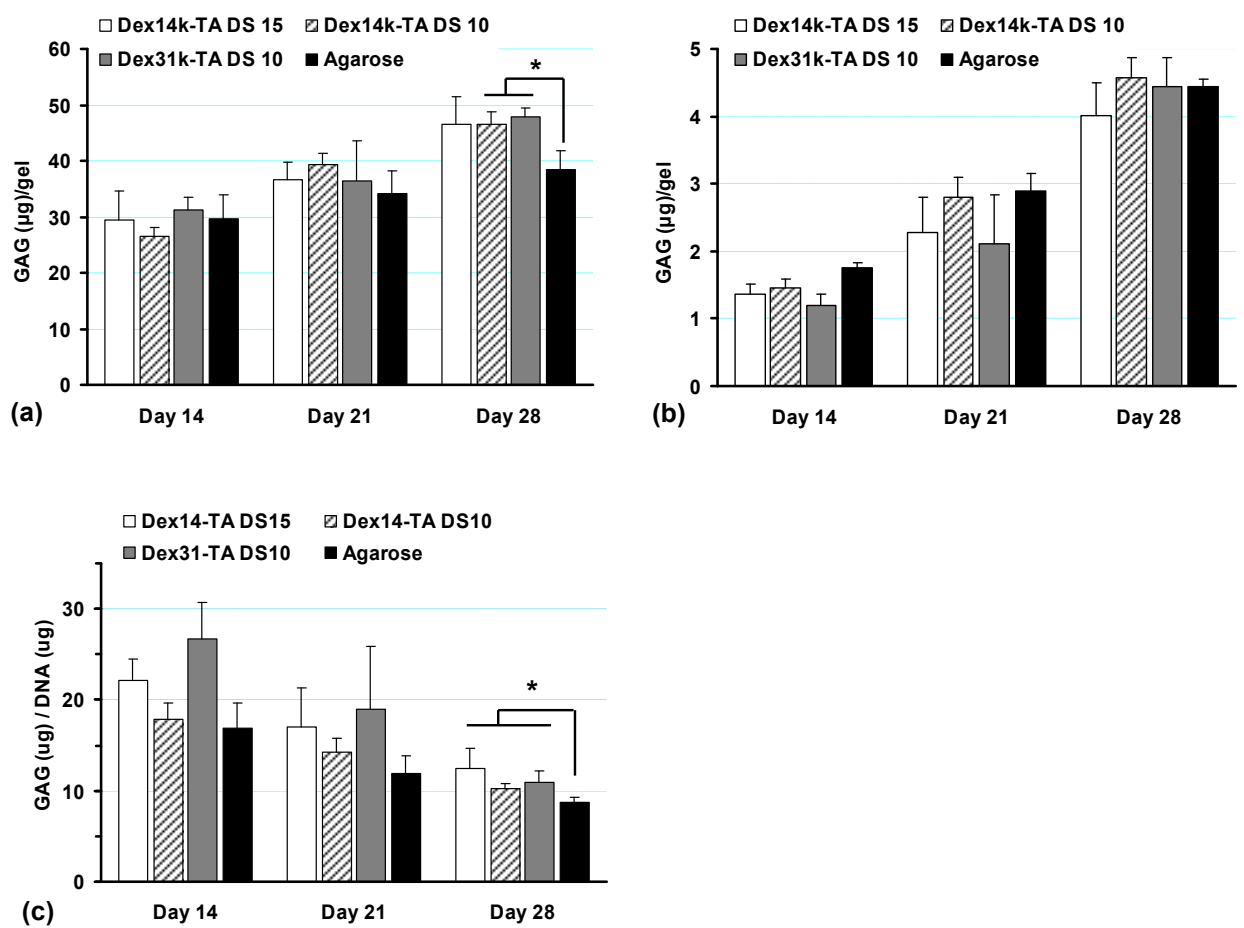

Figure 5.11. GAG accumulation in Dex-TA and agarose hydrogels containing chondrocytes after in vitro culturing for 14, 21 and 28 days in differentiation medium. (a) GAG and (b) DNA content per hydrogel sample; (c) GAG accumulation normalized to the DNA content per gel sample. (Cell seeding density: $5 \times 10^{6} / \mathrm{mL}$, ANOVA: ${ }^{*} p<0.05$ )

To compare the described hydrogels with other injectable hydrogel systems reported in literature, the amounts of GAG in each gel were normalized to their DNA content (GAG/DNA) at the different culturing time points (Figure 5.11c). The GAG/DNA values remained statistically constant at day 14 and day $21(p>0.05)$. However, the values decreased at day 28 compared to day $14(p<0.05)$ because of the increased DNA content per gel as a result of cell proliferation (Figure 5.11b) [42]. Moreover, the GAG/DNA ratios for Dex-TA hydrogels were higher than for agarose gels (10.9-12.5 $\mu \mathrm{g} / \mu \mathrm{g}$ for Dex-TA vs. $8.7 \mu \mathrm{g} / \mu \mathrm{g}$ for agarose, $p<0.05)$ at day 28 . The GAG/DNA values for the Dex-TA hydrogels at day $14(17.8-26.7 \mu \mathrm{g} / \mu \mathrm{g})$ are comparable with those for other injectable hydrogel systems, such as self-assembled peptide hydrogels $(\sim 22 \mu \mathrm{g} / \mu \mathrm{g}$ at day 15) and photopolymerized PEG hydrogels (ca. $\sim 26 \mu \mathrm{g} / \mu \mathrm{g}$ at day 14) $[43,44]$.

Taken together, these results reveal the high potential of these injectable Dex-TA hydrogels for cartilage tissue engineering. 


\subsection{Conclusions}

The enzymatic crosslinking of dextran-tyramine (Dex-TA) conjugates in the presence of horseradish peroxidase and hydrogen peroxide is a highly efficient method to prepare insitu forming hydrogels. Increasing the molecular weight of dextran and degree of substitution of tyramine moieties resulted in decreasing gelation times and increasing storage moduli. Chondrocytes incorporated in the hydrogels showed a high cell viability after 2 weeks and retained their round cell morphology. Besides, the cells were capable of producing a cartilaginous specific matrix rich in GAGs and collagen type II. These studies indicated that injectable hydrogels from Dex-TA conjugates have a high potential as injectable scaffolds for cartilage tissue engineering.

\subsection{References}

[1] Drury JL, Mooney DJ. Hydrogels for Tissue Engineering: Scaffold Design Variables and Applications. Biomaterials 2003;24: 4337-4351.

[2] Frenkel SR, Di Cesare PE. Scaffolds for Articular Cartilage Repair. Ann. Biomed. Eng. 2004;32: 26-34.

[3] Lee S-H, Shin H. Matrices and Scaffolds for Delivery of Bioactive Molecules in Bone and Cartilage Tissue Engineering. Adv. Drug Deliver. Rev. 2007;59: 339-359.

[4] J Elisseeff, Puleo C, Yang F, Sharma B. Advances in Skeletal Tissue Engineering with Hydrogels. Orthod. Craniofac. Res. 2005;8: 150-161.

[5] Van Tomme SR, Storm G, Hennink WE. In Situ Gelling Hydrogels for Pharmaceutical and Biomedical Applications. Int. J. Pharm. 2008;355: 1-18.

[6] Kretlow JD, Klouda L, Mikos AG. Injectable Matrices and Scaffolds for Drug Delivery in Tissue Engineering. Adv. Drug Deliver. Rev. 2007;59: 263-273.

[7] Francis Suh JK, Matthew HWT. Application of Chitosan-Based Polysaccharide Biomaterials in Cartilage Tissue Engineering: A Review. Biomaterials 2000;21: 2589-2598.

[8] Chen J-P, Cheng T-H. Thermo-Responsive Chitosan-graft-Poly $(N$ Isopropylacrylamide) Injectable Hydrogel for Cultivation of Chondrocytes and Meniscus Cells. Macromol. Biosci. 2006;6: 1026-1039.

[9] Chung C, Mesa J, Miller GJ, Randolph MA, Gill TJ, Burdick JA. Effects of Auricular Chondrocyte Expansion on Neocartilage Formation in Photocrosslinked Hyaluronic Acid Networks. Tissue Eng. 2006;12: 2665-2673.

[10] Chung C, Mesa J, Randolph MA, Yaremchuk M, Burdick JA. Influence of Gel Properties on Neocartilage Formation by Auricular Chondrocytes Photoencapsulated in Hyaluronic Acid Networks. J. Biomed. Mater. Res. A 2006;77A: 518-525.

[11] Chung C, Erickson IE, Mauck RL, Burdick JA. Differential Behavior of Auricular and Articular Chondrocytes in Hyaluronic Acid Hydrogels. Tissue Eng. A 2008;14: 1121-1131.

[12] Fisher JP, Jo S, Mikos AG, Reddi AH. Thermoreversible Hydrogel Scaffolds for Articular Cartilage Engineering. J. Biomed. Mater. Res. A 2004;71 A: 268-274.

[13] Park H, Temenoff JS, Holland TA, Tabata Y, Mikos AG. Delivery of TGF-[Beta]1 and Chondrocytes Via Injectable, Biodegradable Hydrogels for Cartilage Tissue Engineering Applications. Biomaterials 2005;26: 7095-7103. 
[14] Dadsetan M, Szatkowski JP, Yaszemski MJ, Lu L. Characterization of Photo-CrossLinked Oligo[poly(ethylene glycol) Fumarate] Hydrogels for Cartilage Tissue Engineering. Biomacromolecules 2007;8: 1702-1709.

[15] Burdick JA, Chung C, Jia X, Randolph MA, Langer R. Controlled Degradation and Mechanical Behavior of Photopolymerized Hyaluronic Acid Networks. Biomacromolecules 2005;6: 386-391.

[16] Hong Y, Mao Z, Wang H, Gao C, Shen J. Covalently Crosslinked Chitosan Hydrogel Formed at Neutral $\mathrm{Ph}$ and Body Temperature. J. Biomed. Mater. Res. A 2006;79A: 913-922.

[17] Hong Y, Song H, Gong Y, Mao Z, Gao C, Shen J. Covalently Crosslinked Chitosan Hydrogel: Properties of in Vitro Degradation and Chondrocyte Encapsulation. Acta Biomater. 2007;3: 23-31.

[18] Hiemstra C, vanderAa LJ, Zhong Z, Dijkstra PJ, Feijen J. Novel in Situ Forming, Degradable Dextran Hydrogels by Michael Addition Chemistry: Synthesis, Rheology, and Degradation. Macromol. 2007;40: 1165-1173.

[19] Hiemstra C, vanderAa LJ, Zhong Z, Dijkstra PJ, Feijen J. Rapidly in Situ-Forming Degradable Hydrogels from Dextran Thiols through Michael Addition. Biomacromolecules 2007;8: 1548-1556.

[20] Park Y, Lutolf MP, Hubbell JA, Hunziker EB, Wong M. Bovine Primary Chondrocyte Culture in Synthetic Matrix Metalloproteinase-Sensitive Poly(ethylene glycol)-Based Hydrogels as a Scaffold for Cartilage Repair. Tissue Eng. 2004;10: 515-522.

[21] Nicodemus GD, Bryant SJ. Cell Encapsulation in Biodegradable Hydrogels for Tissue Engineering Applications. Tissue Eng. B 2008;14: 149-165.

[22] Lee F, Chung JE, Kurisawa M. An Injectable Enzymatically Crosslinked Hyaluronic Acid-Tyramine Hydrogel System with Independent Tuning of Mechanical Strength and Gelation Rate. Soft Mat. 2008;4: 880-887.

[23] Sakai S, Ogushi Y, Kawakami K. Enzymatically Crosslinked Carboxymethylcellulose-Tyramine Conjugate Hydrogel: Cellular Adhesiveness and Feasibility for Cell Sheet Technology. Acta Biomater. 2009;5: 554-559.

[24] Sakai S, Kawakami K. Synthesis and Characterization of Both Ionically and Enzymatically Cross-Linkable Alginate. Acta Biomater. 2007;3: 495-501.

[25] Jin R, Hiemstra C, Zhong Z, Feijen J. Enzyme-Mediated Fast in Situ Formation of Hydrogels from Dextran-Tyramine Conjugates. Biomaterials 2007;28: 2791-2800.

[26] Jin R, Moreira Teixeira LS, Dijkstra PJ, Karperien M, van Blitterswijk CA, Zhong ZY, and Feijen J. Injectable Chitosan-Based Hydrogels for Cartilage Tissue Engineering. Biomaterials 2009;30: 2544-2551.

[27] Sakai S, Yamada Y, Zenke T, Kawakami K. Novel Chitosan Derivative Soluble at Neutral Ph and in-Situ Gellable Via Peroxidase-Catalyzed Enzymatic Reaction. J. Mater. Chem. 2009; 19: 230-235.

[28] Sakai S, Hirose K, Taguchi K, Ogushi Y, Kawakami K. An Injectable, In Situ Enzymatically Gellable, Gelatin Derivative for Drug Delivery and Tissue Engineering. Biomaterials 2009;30: 3371-3377.

[29] Papenburg BJ, Vogelaar L, Bolhuis-Versteeg LAM, Lammertink RGH, Stamatialis D, Wessling M. One-Step Fabrication of Porous Micropatterned Scaffolds to Control Cell Behavior. Biomaterials 2007;28: 1998-2009.

[30] Alexandre E, Schmitt B, Boudjema K, Merrill EW, Lutz PJ. Hydrogel Networks of Poly(Ethylene Oxide) Star-Molecules Supported by Expanded 
Polytetrafluoroethylene Membranes: Characterization, Biocompatibility Evaluation and Glucose Diffusion Characteristics. Macromol. Biosci. 2004;4: 639-648.

[31] Jukes JM, Moroni L, van Blitterswijk CA, de Boer J. Critical Steps toward a TissueEngineered Cartilage Implant Using Embryonic Stem Cells. Tissue Eng. A 2008;14: 135-147.

[32] Burdon RH. Superoxide and Hydrogen Peroxide in Relation to Mammalian Cell Proliferation. Free Radic. Biol. Med. 1995;18: 775-794.

[33] Asada S, Fukuda K, Oh M, Hamanishi C, Tanaka S. Effect of Hydrogen Peroxide on the Metabolism of Articular Chondrocytes. Inflamm. Res. 1999;48: 399-403.

[34] van de Manakker F, Vermonden T, el Morabit N, van Nostrum CF, Hennink WE. Rheological Behavior of Self-Assembling PEG-b-Cyclodextrin/PEG-Cholesterol Hydrogels. Langmuir 2008;24: 12559-12567.

[35] Baker RW, Lonsdale HK (1974) Controlled Release of Biologically Active Agents, Plenum Press, New York.

[36] Maroudas A. Distribution and Diffusion of Solutes in Articular Cartilage. Biophys. J. 1970;10: 365-379.

[37] Yoon Y-M, Kim S-J, Oh C-D, Ju J-W, Song WK, Yoo YJ, Huh T-L, and Chun J-S. Maintenance of Differentiated Phenotype of Articular Chondrocytes by Protein Kinase $\mathrm{C}$ and Extracellular Signal-Regulated Protein Kinase. J. Biol. Chem. 2002;277: 8412-8420.

[38] DiMicco MA, Kisiday JD, Gong H, Grodzinsky AJ. Structure of Pericellular Matrix around Agarose-Embedded Chondrocytes. Osteoarthr. Cartilage 2007;15: 1207-1216.

[39] Aigner T, Stove J. Collagens--Major Component of the Physiological Cartilage Matrix, Major Target of Cartilage Degeneration, Major Tool in Cartilage Repair. Adv. Drug Deliver. Rev. 2003;55: 1569-1593.

[40] Buschmann MD, Gluzband YA, Grodzinsky AJ, Kimura JH, Hunziker EB. Chondrocytes in Agarose Culture Synthesize a Mechanically Functional Extracellular Matrix. J. Orthop. Res. 1992;10: 745-758.

[41] Benya PD, Shaffer JD. Dedifferentiated Chondrocytes Reexpress the Differentiated Collagen Phenotype When Cultured in Agarose Gels. Cell 1982;30: 215-224.

[42] Toh WS, Yang Z, Liu H, Heng BC, Lee EH, Cao T. Effects of Culture Conditions and Bone Morphogenetic Protein 2 on Extent of Chondrogenesis from Human Embryonic Stem Cells. Stem Cells 2007;25: 950-960.

[43] Kisiday J, Jin M, Kurz B, Hung H, Semino C, Zhang S, and Grodzinsky AJ. SelfAssembling Peptide Hydrogel Fosters Chondrocyte Extracellular Matrix Production and Cell Division: Implications for Cartilage Tissue Repair. Proc. Natl. Acad. Sci. USA 2002;99: 9996-10001.

[44] Bryant SJ, Anseth KS. Hydrogel Properties Influence ECM Production by Chondrocytes Photoencapsulated in Poly(ethylene glycol) Hydrogels. J. Biomed. Mater. Res. 2002;59: 63-72. 


\section{Chapter 6}

\section{Injectable Chitosan-based Hydrogels for Cartilage Tissue Engineering *}

Water-soluble chitosan derivatives, chitosan-graft-glycolic acid (GA) and phloretic acid (PA) (CH-GA/PA), were designed to obtain biodegradable injectable chitosan hydrogels through enzymatic crosslinking with horseradish peroxidase (HRP) and $\mathrm{H}_{2} \mathrm{O}_{2}$. CH-GA/PA polymers were synthesized by first conjugating glycolic acid (GA) to native chitosan to render the polymer soluble at pH 7.4, and subsequent modification with phloretic acid (PA). The CH-GA43/PA10 with a degree of substitution (DS, defined as the number of substituted $\mathrm{NH}_{2}$ groups per 100 glucopyranose rings of chitosan) of GA of 43 and DS of PA of 10 showed a good solubility at $\mathrm{pH}$ values up to 10. Short gelation times (e.g. $10 \mathrm{~s}$ at a polymer concentration of $3 \mathrm{wt} \%)$, as recorded by the vial tilting method, were observed for the $\mathrm{CH}$ GA43/PA10 hydrogels using HRP and $\mathrm{H}_{2} \mathrm{O}_{2}$. It was shown that these hydrogels can be readily degraded by lysozyme. In vitro culturing of chondrocytes in CH-GA43/PA10 hydrogels revealed that after 2 weeks the cells were viable and retained their round shape. These features indicate that CH-GA/PA hydrogels are promising as an artificial extracellular matrix for cartilage tissue engineering.

\subsection{Introduction}

Tissue engineering is a promising method for cartilage regeneration. In this approach, a scaffold as a temporary artificial extra-cellular matrix (ECM) is needed to accommodate cultured cells and guide their growth [1]. To allow cell survival in the artificial ECM, it is required to use scaffolds, which have properties resembling the native extracellular matrix such as a high water content and sufficient transport of nutrients and waste products. Because hydrogels, water-swollen networks of crosslinked hydrophilic polymers, are in general compatible with proteins, cells and surrounding tissues [2, 3], they are regarded as highly suitable materials for artificial ECMs for tissue engineering.

Recently, injectable hydrogels that are in situ formed after injection at the defect site have received much attention in tissue engineering [4]. Injectable hydrogels have the

\footnotetext{
* This chapter has been published: Rong Jin, Liliana S. Moreira Teixeira, Pieter J. Dijkstra, Marcel Karperien, Clemens A. van Blitterswijk, Zhiyuan Zhong and Jan Feijen, Biomaterials, 2009, 30, 2544-2551.
} 
advantage that implantation surgery can be replaced by a simple minimally invasive injection procedure. Moreover, the incorporation of cells and bioactive molecules like growth factors can be readily performed and the gels can be formed in any desired shape in good alignment with the surrounding tissue.

Chitosan has been widely investigated for biomedical applications such as controlled drug and protein delivery [5-7], non-viral gene delivery [8] and tissue engineering [9-12]. Chitosan is a polycationic polysaccharide comprising glucosamine and $\mathrm{N}$ acetylglucosamine residues. Moreover, chitosan can be enzymatically degraded in vivo by lysozyme [13, 14], a polycationic protein present in the ECM of human cartilage $[15,16]$. These features make chitosan a potential material for use in cartilage tissue engineering to modulate chondrocyte morphology, differentiation and stimulating chondrogenesis. In vitro studies demonstrated that chitosan-based matrices not only efficiently support chondrogenic activity $[12,17]$, but also allow the expression of cartilage ECM proteins by chondrocytes [17]. Chondrocytes that are cultured in chitosan scaffolds may maintain their inherent round morphology [10]. Cui et al. showed that surface modification of PLLA films with chitosan leads to increased cell adhesion, proliferation, and correspondingly, improved glucosaminoglycan (GAG) production and collagen type II synthesis as compared to unmodified PLLA film [18]. A major drawback of chitosan is its poor solubility in neutral solutions. The chitosan backbone has to be derivatized with hydrophilic moieties to afford water-soluble chitosans [19].

In the past years, many investigators have developed injectable chitosan-based hydrogels for cartilage repair [20-23]. Injectable chitosan hydrogels have been prepared by either physical or chemical crosslinking methods. The reversible physical interactions in poly(Nisopropyl-acrylamide) or PEG grafted chitosan derivatives have been used to prepare physically crosslinked hydrogels $[5,20,22,24]$. Such physical gels generally exhibit a low stability, low mechanical strength and fast degradation. In another approach, chemically crosslinked injectable chitosan hydrogels were prepared using redox-initiated crosslinking $[21,25]$ and photo-initiated crosslinking [6, 11, 26, 27]. Moreover, gelation time, gel modulus and hydrogel degradability of these chemically crosslinked hydrogels can be adjusted by the molecular weight of polymers and the crosslinking densities. For example Hong et al. prepared methacrylated chitosan-based hydrogels using ammonium persulfate and N,N,N',N'-tetramethylethylenediamine and showed that by increasing the concentration of the initiator, the gelation time could be reduced and the enzymatic degradation of the resulting hydrogels decreased. However, a concomitant high cytotoxicity with low cell viability $(<30 \%)$ at a high concentration of initiator was observed after a short cell culturing time of 4 days [21]. 
We previously reported on fast in-situ forming hydrogels from dextran-tyramine conjugates [28]. These hydrogels were formed within $1 \mathrm{~min}$ at optimal conditions upon enzymatic coupling of tyramine phenol moieties using horseradish peroxidase (HRP) and hydrogen peroxide $\left(\mathrm{H}_{2} \mathrm{O}_{2}\right)$. Moreover, the hydrogels showed a high gel content and mechanical strength. In this study, we report on injectable biodegradable hydrogels based on chitosan derivatives using enzymatic crosslinking for cartilage regeneration. The gelation and degradation rates of these newly developed chitosan-based hydrogels as well as their mechanical properties were determined. Additionally, the in vitro cytocompatibility of the gels and the morphology of incorporated chondrocytes in time were studied.

\subsection{Materials and methods}

Materials. Chitosan (low molecular weight, viscosity $=20-200 \mathrm{cP}, 1 \mathrm{wt} \%$ in $1 \mathrm{vol} \%$ acetic acid) was obtained from Aldrich. The degree of deacetylation (DD) of chitosan was estimated from ${ }^{1}$ HNMR spectra as described elsewhere [29]. N-Ethyl-N'-(3dimethylaminopropyl) carbodiimide hydrochloride (EDAC, Fluka), N-hydroxysuccinimide (NHS, Aldrich), phloretic acid (PA, Fluka), glycolic acid (GA, Fluka), hydrogen peroxide $\left(\mathrm{H}_{2} \mathrm{O}_{2}, 30 \mathrm{wt} \%\right.$, Aldrich) and deuterium oxide $\left(\mathrm{D}_{2} \mathrm{O}\right.$, Aldrich) were purchased with the highest purity available and used without further purification. Horseradish peroxidase (HRP, type VI, 298 purpurogallin unit/mg solid) was purchased from Aldrich and used as received. Phosphate buffered saline (PBS, pH 7.4) was purchased from B. Braun Co. All other solvents were used as received. Buffers used were a phosphate buffer $(\mathrm{pH} 2)$, acetate buffer (pH 5.0), MES buffer ( $\mathrm{pH}$ 6.5), PBS buffer ( $\mathrm{pH}$ 7.4) and a CHES buffer ( $\mathrm{pH} \mathrm{9.0)} \mathrm{all} \mathrm{at} \mathrm{an}$ ionic strength of $150 \mathrm{mM}$.

Synthesis of chitosan conjugates. Chitosan conjugates were prepared in two steps by first reacting chitosan with glycolic acid followed by a reaction with phloretic acid. In both steps the molar ratios of reagents to the $\mathrm{NH}_{2}$ groups of chitosan were varied to obtain the desired degree of derivatization.

As a typical example, $1.5 \mathrm{~g}$ of chitosan $\left(\mathrm{DD}=85 \%\right.$ from ${ }^{1} \mathrm{H}$ NMR) was dissolved in 600 $\mathrm{mL}$ of water containing GA (1.65 g, $0.022 \mathrm{~mol})$ overnight. To the solution EDAC (6.33 g, $0.033 \mathrm{~mol})$ and NHS (3.99 g, $0.026 \mathrm{~mol})$ were added. The resulting solution was stirred for $48 \mathrm{~h}$ at room temperature. The reaction mixture was then neutralized with a $1 \mathrm{M} \mathrm{NaOH}$ solution to $\mathrm{pH}$ 7. In order to remove unreacted GA, the solution was ultra filtrated (MWCO $30 \mathrm{kDa}$ ), first with $50 \mathrm{mM} \mathrm{NaCl}$ and then deionized water. Finally, the glycolic acid grafted chitosan (CH-GA) was freeze-dried. DS: 43 ( ${ }^{1} \mathrm{H}$ NMR). Yield: 68\%. ${ }^{1} \mathrm{H}$ NMR $\left(\mathrm{D}_{2} \mathrm{O} / \mathrm{CD}_{3} \mathrm{COOD}(95 / 5 \mathrm{v} / \mathrm{v})\right): \delta=4.9$ (chitosan anomeric proton, overlaps with water peak), 3.0 and 3.4-4.2 (chitosan glucopyranose ring protons), $4.2\left(\mathrm{NHCOCH}_{2} \mathrm{OH}\right), 2.0$ $\left(\mathrm{NHCOC}_{3}\right)$. 
By changing the molar feed ratio of carboxylic groups of GA to chitosan amino groups from 1:3 to 2.5:1, chitosan derivatives with different DSs of 10, 19 and 43 were obtained. The yield of CH-GA varied from 68 to $95 \%$.

To a solution of $1 \mathrm{~g}$ of CH-GA43 dissolved in $100 \mathrm{~mL}$ of water, PA (410 mg, $2.5 \mathrm{mmol}$ ) was added and stirred overnight. To the resulting solution, EDAC (725 mg, $3.7 \mathrm{mmol})$ and NHS (345 mg, $3.0 \mathrm{mmol}$ ) were added. The mixture was stirred for $48 \mathrm{~h}$ at room temperature. The resulting mixture was neutralized with $1 \mathrm{M} \mathrm{NaOH}$ and the chitosan derivative $\mathrm{CH}-\mathrm{GA} / \mathrm{PA}$ was isolated using the procedures described above. DS: $10\left({ }^{1} \mathrm{H}\right.$ NMR). Yield: $76 \% . \quad{ }^{1} \mathrm{H} \quad \mathrm{NMR} \quad\left(\mathrm{D}_{2} \mathrm{O} / \mathrm{CD}_{3} \mathrm{COOD} \quad(95 / 5 \quad \mathrm{v} / \mathrm{v})\right): \quad \delta=6.8$ and 7.2 $\left(\mathrm{CH}_{2} \mathrm{CH}_{2} \mathrm{C}_{6} \underline{\mathrm{H}}_{4} \mathrm{OH}\right), 4.9$ (chitosan anomeric proton, overlaps with water peak), 3.0 and 3.44.2 (chitosan glucopyranose ring protons), $4.2\left(\mathrm{NHCOCH}_{2} \mathrm{OH}\right), 2.4-2.9\left(\mathrm{C}_{2} \mathrm{CH}_{2} \mathrm{C}_{6} \mathrm{H}_{4} \mathrm{OH}\right)$, $2.0\left(\mathrm{NHCOC}_{3}\right)$.

Polymer characterizations. ${ }^{1} \mathrm{H}$ NMR (300 MHz) spectra were recorded on a Varian Inova spectrometer (Varian, Palo Alto, USA). Samples of 10-20 mg each were dissolved in $0.8 \mathrm{~mL}$ of $\mathrm{D}_{2} \mathrm{O}$ containing $5 \%(\mathrm{v} / \mathrm{v}) \mathrm{CD}_{3} \mathrm{COOD}$. The signals of solvent residues were used as reference for the ${ }^{1} \mathrm{H}$ NMR chemical shifts and were set at $\delta 4.79$ for water.

The degrees of substitution (DSs) of GA and PA, defined as the number of substituted $\mathrm{NH}_{2}$ groups per 100 glucopyranose rings of chitosan, were determined using ${ }^{1} \mathrm{H}$ NMR by comparing the integrals of signals at $\delta 2.0$ (acetamide groups of chitosan) with $\delta 4.2$ (methylene protons of GA) for $\mathrm{CH}-\mathrm{GA}$, and $\delta$ 6.5-7.5 (aromatic protons of PA) for $\mathrm{CH}$ GA/PA, respectively. To indicate the DS of GA and PA, the samples are coded by adding numbers to the $\mathrm{CH}-\mathrm{GA} / \mathrm{PA}$ polymer as presented in Table 6.1 .

pH dependent solubility. The solubility of unmodified and modified chitosan at a fixed concentration and different $\mathrm{pH}$ values was measured according to a procedure described in literature [11]. Briefly, chitosan, $\mathrm{CH}-\mathrm{GA}$ and $\mathrm{CH}-\mathrm{GA} / \mathrm{PA}$ were separately dissolved in water $(1 \mathrm{mg} / \mathrm{mL})$ and the $\mathrm{pH}$ was adjusted to 3 with $0.1 \mathrm{M} \mathrm{HCl}$ to give clear solutions. A solution of $0.1 \mathrm{M} \mathrm{NaOH}$ was gradually added to the stirred polymer solution until precipitation occurred. The $\mathrm{pH}$ value was measured using a $\mathrm{pH}$ meter (Metrohm $702 \mathrm{SM}$ Titrino). Upon addition of $0.1 \mathrm{M}$ of $\mathrm{NaOH}$ the concentration of the chitosan and its derivatives did not decrease below $70 \%$ of the original concentration $(1 \mathrm{mg} / \mathrm{mL})$.

Hydrogel formation and gelation time. Hydrogel samples $(0.5 \mathrm{~mL})$ were prepared in vials at $37{ }^{\circ} \mathrm{C}$. In a typical procedure, to $400 \mu \mathrm{L}$ of a $1.25 \mathrm{wt} \%$ solution of CH-GA43/PA10 in PBS, a freshly prepared mixture of $\mathrm{H}_{2} \mathrm{O}_{2}(38.5 \mu \mathrm{L}$ of a $0.075 \mathrm{wt} \%$ stock solution $)$ and HRP $(61.5 \mu \mathrm{L}$ of a $15.6 \mu \mathrm{g} / \mathrm{mL}$ stock solution) was added and the mixture was gently mixed. The final concentration of CH-GA43/PA10 was $1 \mathrm{wt} \%$. The time to form a gel (denoted as gelation time) was determined using the vial tilting method. No flow within $1 \mathrm{~min}$ upon inverting the vial was regarded as the gel state. In all experiments using different 
concentrations of $\mathrm{CH}-\mathrm{GA} 43 / \mathrm{PA} 10$ always $0.5 \mathrm{mg}$ HRP per mmol phenol groups and a $\mathrm{H}_{2} \mathrm{O}_{2} /$ phenol molar ratio of 0.5 were applied.

Gel content and water uptake. To determine the gel content, samples of about $0.5 \mathrm{~g}$ of a hydrogel made from CH-GA43/PA10 were lyophilized and weighted $\left(\mathrm{W}_{\mathrm{d}}\right)$. The dry hydrogels were then extensively extracted with $6 \mathrm{~mL}$ of a $1 \%(\mathrm{v} / \mathrm{v})$ acetic acid solution at room temperature for 3 days to remove uncrosslinked polymer. The solution was replaced each day. The samples were subsequently washed 3 times with deionized water and lyophilized $\left(\mathrm{W}_{\mathrm{g}}\right)$. The gel content was expressed as $\mathrm{W}_{\mathrm{g}} / \mathrm{W}_{\mathrm{d}} \times 100 \%$.

Dried hydrogel samples were immersed in $2 \mathrm{~mL}$ buffer solutions having $\mathrm{pH}$ values of 2.0, $5.0,6.5,7.4$ or 9.0 at $37^{\circ} \mathrm{C}$ for 1 day in order to reach equilibrium swelling. After removal of surface water, the samples were weighted $\left(\mathrm{W}_{\mathrm{s}}\right)$. The water uptake of dried hydrogels was expressed as $\left(\mathrm{W}_{\mathrm{s}}-\mathrm{W}_{\mathrm{g}}\right) / \mathrm{W}_{\mathrm{g}} \times 100 \%$ [30].

In vitro degradation. Hydrogel samples (about $0.5 \mathrm{~g}$ ) were prepared in vials according to the procedure described in Section 2.5 and accurately weighted $\left(\mathrm{W}_{\mathrm{i}}\right)$. Subsequently, 2 $\mathrm{mL}$ of PBS solutions containing different concentrations of lysozyme $(0.5 \sim 2 \mathrm{mg} / \mathrm{mL})$ were applied on top of the hydrogels and then incubated at $37^{\circ} \mathrm{C}$. At regular time intervals, the buffer solution was removed from the samples and the hydrogels were weighted $\left(\mathrm{W}_{\mathrm{t}}\right)$. The percentage of original gel weight remaining is expressed as $\mathrm{W}_{\mathrm{t}} / \mathrm{W}_{\mathrm{i}} \times 100 \%$. The medium was replaced twice a week and the experiments were performed in triplicate.

Rheological analysis. Rheological experiments were carried out with an MCR 301 rheometer (Anton Paar) using parallel plates $\left(25 \mathrm{~mm}\right.$ diameter, $\left.0^{\circ}\right)$ configuration at $37^{\circ} \mathrm{C}$ in the oscillatory mode. In a typical example, $77 \mu \mathrm{L}$ of a $\mathrm{H}_{2} \mathrm{O}_{2}$ stock solution $(0.075 \mathrm{wt} \%$, in PBS) and $123 \mu \mathrm{L}$ of the HRP stock solution $(15.6 \mu \mathrm{g} / \mathrm{mL}$, in PBS) were mixed. The $\mathrm{HRP} / \mathrm{H}_{2} \mathrm{O}_{2}$ solution was then immediately mixed with $800 \mu \mathrm{L}$ of a solution of $\mathrm{CH}$ GA43/PA10 (1.25 wt\%, in PBS) using a double syringe (2.5 mL, 1:4 volume ratio) equipped with a mixing chamber (Mixpac). After the samples were applied to the rheometer, the upper plate was immediately lowered to a measuring gap size of $0.5 \mathrm{~mm}$, and the measurement was started. To prevent evaporation, a layer of oil was introduced around the polymer sample. The evolution of the storage $\left(G^{\prime}\right)$ and loss $\left(G^{\prime \prime}\right)$ moduli was recorded as a function of time. A frequency of $0.5 \mathrm{~Hz}$ and a strain of $0.1 \%$ were applied in order to maintain a linear viscoelastic regime.

Chondrocyte isolation and encapsulation. Bovine cartilage was harvested from the patellar-femoral groove of calf legs. Cartilage tissue was cut into small pieces and chondrocytes were isolated by incubation in Dulbecco's modified Eagle's medium (Gibco) (DMEM) containing $0.2 \%$ collagenase type II at $37{ }^{\circ} \mathrm{C}$ for $8 \mathrm{~h}$. The isolated chondrocytes were washed, centrifuged and resuspended in DMEM with 10\% heat inactivated fetal bovine serum, 1\% Penicillin/Streptomycin (Gibco), $0.5 \mathrm{mg} / \mathrm{mL}$ fungizone (Gibco), $0.01 \mathrm{M}$ 
MEM nonessential amino acids (Gibco), $10 \mathrm{mM}$ HEPES and $0.04 \mathrm{mM}$ L-proline. The cell suspension was then seeded in culture flasks and incubated at $37{ }^{\circ} \mathrm{C}$ in humidified atmosphere $\left(95 \%\right.$ air $\left./ 5 \% \mathrm{CO}_{2}\right)$. At confluence, the cells were detached using $0.25 \mathrm{wt} \%$ trypsin in PBS, resuspended in PBS, and used for the experiments.

To encapsulate the chondrocytes, a stock PBS solution of $2.5 \mathrm{wt} \% \mathrm{CH}-\mathrm{GA} 43 / \mathrm{PA} 10$ was first exposed to UV (Bio-Rad Gel Doc 2000) for half an hour. HRP and $\mathrm{H}_{2} \mathrm{O}_{2}$ stock solutions were made in PBS and sterilized by filtration through filters with a pore size of $0.22 \mu \mathrm{m}$. Chondrocytes were incorporated in the hydrogels using the same procedure as for the gel formation in the absence of cells. Briefly, $61.5 \mu \mathrm{L}$ of the HRP stock solution was added into $38.5 \mu \mathrm{L}$ of the $\mathrm{H}_{2} \mathrm{O}_{2}$ stock solution to obtain solutions containing HRP and $\mathrm{H}_{2} \mathrm{O}_{2}$. Chondrocyte/CH-GA43/PA10 suspensions were prepared by mixing $200 \mu \mathrm{L}$ of polymer solutions with $200 \mu \mathrm{L}$ of medium containing chondrocytes. To $100 \mu \mathrm{L}$ of cell/polymer suspensions, $25 \mu \mathrm{L} \mathrm{HRP} / \mathrm{H}_{2} \mathrm{O}_{2}$ mixtures were added and the hydrogel precursor was gently mixed. Before gelation, the precursor was quickly transferred onto cover slides in the culture plate. The final concentration of CH-GA43/PA10 was $1 \mathrm{wt} \%$ and the cell seeding density in the gels was $5 \times 10^{6} / \mathrm{mL}$. The constructs were cultured in the previously described medium, standard for chondrocyte expansion. The gels were incubated at $37^{\circ} \mathrm{C}$ and $5 \% \mathrm{CO}_{2}$, and the medium was replaced every 2 or 3 days.

Cytotoxicity assay. A viability study on hydrogel encapsulated chondrocytes was performed with a Live-dead assay and the MTT (3-(4,5-dimethyl-2-thiazolyl)-2,5-diphenyl$2 \mathrm{H}$-tetrazolium bromide) assay. At days 1,3, 7, and 14, the hydrogel constructs were rinsed with PBS and stained with calcein/ethidium homodimer using the Live-dead assay Kit (Invitrogen), according to the manufactures' instructions. Agarose hydrogel/cell constructs $(0.5 \mathrm{wt} \%)$ with the same chondrocyte density were used as a control. Hydrogel/cell constructs were visualized using fluorescence microscopy (Zeiss). As a result living cells fluoresce green and the nuclei of dead cells red. MTT staining was performed using $1 \%$ (total medium volume) of MTT solution $(5 \mathrm{mg} / \mathrm{mL}$, Gibco) and an incubation time of $2 \mathrm{~h}$. Hydrogel/cell constructs were then visualized using a light microscope. The morphology of the chondrocytes in the hydrogels was studied using a Philips XL 30 ESEM-FEG scanning electron microscopy (SEM) operating at a voltage of $10 \mathrm{kV}$. After 14 days' in vitro culturing the hydrogel/cell constructs were fixed with formalin by sequential dehydration and critical point drying. These samples were gold sputtered (Carringdon) and analyzed with SEM. 


\subsection{Results and discussion}

\subsubsection{Synthesis and characterization of chitosan conjugates}

Chitosan is an insoluble material in neutral aqueous solutions. To increase its water solubility chitosan was modified by reacting glycolic acid GA with the primary amino groups of chitosan using EDAC/NHS activation (Figure 6.1). The reaction was performed in diluted GA solutions with different molar feed ratios of GA to amino groups of chitosan and without adding other acidic components since chitosan readily dissolved in the acidic GA solution having a $\mathrm{pH}$ value of approximately 4. After 2 days reaction, the resulting chitosan derivatives (CH-GA) were purified by ultrafiltration and isolated after freezedrying. The ${ }^{1} \mathrm{H}$ NMR spectrum of $\mathrm{CH}-\mathrm{GA}$ showed that a new signal at $\delta 4.2$ was present corresponding to the methylene protons of the glycolamide units. The degree of substitution (DS) of GA, defined as the number of glycolamide moieties per 100 glucopyranose rings of chitosan, was determined from the ${ }^{1} \mathrm{H}$ NMR spectra by comparing the integrals of signals at $\delta 2.0$ and 4.2, attributed to the protons of acetamide group $\left(\mathrm{NHCOCH}_{3}\right)$ in chitosan and methylene protons $\left(\mathrm{COC}_{2} \mathrm{OH}\right)$ in GA moieties, respectively. The DS of CH-GA increased from 10 to 43 when the $[\mathrm{GA}] /\left[\mathrm{NH}_{2}\right]$ feed ratio was increased from 0.3 to 2.5 (Table 6.1 ).

(i)

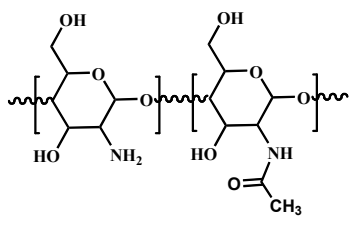

CH

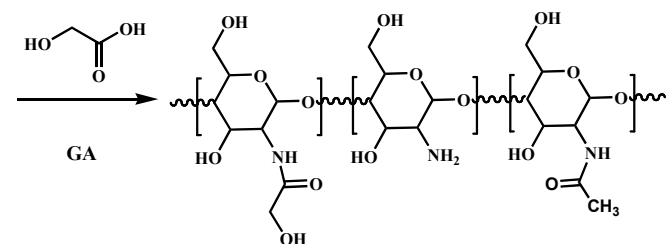

CH-GA

(ii)
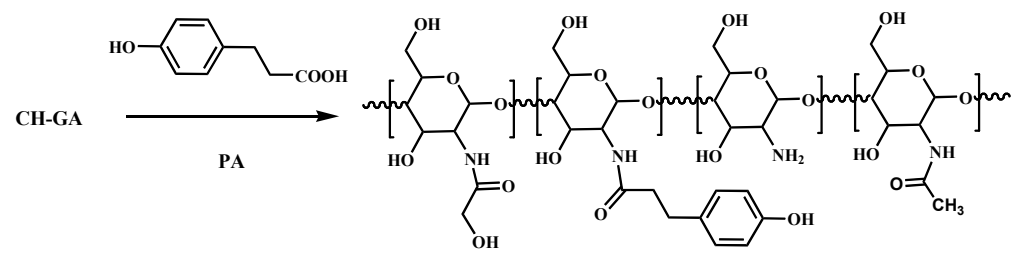

CH-GA/PA

Figure 6.1. Synthesis of glycolic acid grafted chitosan (CH-GA) and subsequent conjugation of phloretic acid (PA) to give CH-GA/PA.

The $\mathrm{pH}$ dependent solubility of the $\mathrm{CH}-\mathrm{GA}$ polymers was evaluated by titration of a 1 $\mathrm{mg} / \mathrm{mL}$ polymer solution with a $\mathrm{NaOH}$ solution. The $\mathrm{pH}$ value at which the $\mathrm{CH}-\mathrm{GA}$ started to precipitate was used as an indication of the water solubility of the chitosan derivatives. Native chitosan with a degree of deacetylation of $85 \%$ dissolves in water $(1 \mathrm{mg} / \mathrm{mL})$ up to a maximum $\mathrm{pH}$ of 6.4. The limited solubility at higher $\mathrm{pH}$ values is due to the formation of 
intra macromolecular and inter chain hydrogen bonds between the amino and hydroxyl groups [31]. By converting the free amine groups to glycolamide groups the intermolecular H-bonds will be disrupted, which improves the water solubility of the chitosan derivatives. It was found that the solubility of the CH-GAs at a concentration of $1 \mathrm{mg} / \mathrm{mL}$ increased with an increase in the degree of substitution of GA to the chitosan backbone. The $\mathrm{CH}$ GA19 was soluble up to $\mathrm{pH} 7$ while $\mathrm{CH}-\mathrm{GA} 43$ was still soluble up to a maximum $\mathrm{pH}$ value of 10 (Table 6.1).

Based on these results, chitosan derivatives $\mathrm{CH}-\mathrm{GA} 43$ were selected for further modification. Phloretic acid (PA) was then coupled by activation of its carboxylic acid group using EDAC/NHS and subsequent reaction with the remaining amine groups of $\mathrm{CH}$ GA43. The extent of coupling of PA moieties was followed by ${ }^{1} \mathrm{H}$ NMR using the new peaks at $\delta 6.8$ and 7.2 of the aromatic protons of the phenol groups. Accordingly, the degree of substitution of PA was determined by comparing the integral ratios of the phenol and Nacetyl proton signals. A degree of substitution of 10 was obtained when the molar feeding ratio of carboxylic acid groups of $\mathrm{PA}$ to chitosan amino groups was 0.5 . At a concentration of $1 \mathrm{mg} / \mathrm{mL}$ the $\mathrm{CH}-\mathrm{GA} 43 / \mathrm{PA} 10$ was soluble up to a $\mathrm{pH}$ value of 10 and could be easily dissolved in water or PBS at a polymer concentration of $30 \mathrm{mg} / \mathrm{mL}$.

Table 6.1. Preparation of chitosan-based conjugates ${ }^{\text {a }}$

\begin{tabular}{|c|c|c|c|c|}
\hline Sample code & $\begin{array}{c}{[\mathrm{GA}] /[\mathrm{NH} 2]} \\
\text { feed ratio }\end{array}$ & $\begin{array}{c}\mathrm{DS}^{\mathrm{b}}(\mathrm{GA} \\
\text { or PA) }\end{array}$ & Yield & $\begin{array}{c}\text { Maximum } \mathrm{pH} \text { for } \\
\text { solubilization }\end{array}$ \\
\hline CH-GA10 & 0.3 & 10 & $95 \%$ & 7 \\
CH-GA19 & 1.0 & 19 & $82 \%$ & 8 \\
CH-GA43 & 2.5 & 43 & $68 \%$ & 10 \\
\hline \hline CH-GA43/PA10 & 0.5 & 10 & $76 \%$ & 10 \\
\hline
\end{tabular}

a: Polymer concentration was $10 \mathrm{mg} / \mathrm{mL} \mathrm{H}_{2} \mathrm{O}$, molar ratio of EDAC/NHS/COOH=1.5/1.2/1

b: DS (degree of substitution) was determined from ${ }^{1} \mathrm{H}$ NMR.

c: Polymer concentration was $1 \mathrm{mg} / \mathrm{mL}$

\subsubsection{Hydrogel formation and gelation time}

Fast in-situ gelation is required in order to maintain the cells and bioactive molecules at the injection site. We previously showed that the enzymatic crosslinking of dextrantyramine conjugates using $\mathrm{HRP}$ and $\mathrm{H}_{2} \mathrm{O}_{2}$ provided a fast and efficient way to obtain an insitu forming hydrogel under physiological conditions [28]. Moreover, the gelation time of dextran-tyramine conjugates could be adjusted by changing the ratios of $\mathrm{HRP}$ and $\mathrm{H}_{2} \mathrm{O}_{2}$ to phenol groups, and the polymer concentration. Using a $1 \mathrm{wt} \% \mathrm{CH}-\mathrm{GA} 43 / \mathrm{PA} 10$ solution in PBS, $0.5 \mathrm{mg}$ HRP per mmol phenol groups and a $\mathrm{H}_{2} \mathrm{O}_{2} /$ phenol molar ratio of 0.5 , a hydrogel was formed in approximately $4 \mathrm{~min}$ as determined by the vial tilting method. Increasing the polymer concentration from 1 to $3 \mathrm{wt} \%$, and maintaining the other reaction 
conditions the same, revealed a large decrease in gelation time from 4 min to $10 \mathrm{~s}$ (Figure $6.2)$.

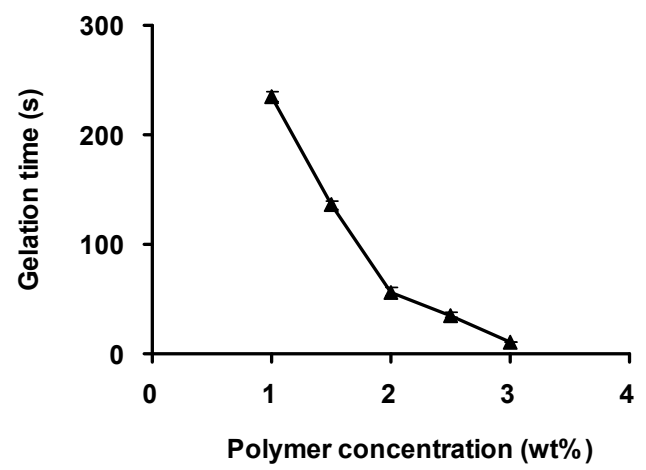

Figure 6.2. Gelation times of $\mathrm{CH}-\mathrm{GA} 43 / \mathrm{PA} 10$ hydrogels as a function of polymer concentration. Reaction conditions: molar ratio of $\mathrm{H}_{2} \mathrm{O}_{2}$ /phenol is $0.5 ; 0.5 \mathrm{mg}$ HRP per mmol phenol groups; $37^{\circ} \mathrm{C}$, PBS.

\subsubsection{Gel content and water uptake}

The gel content of crosslinked CH-GA43/PA10 hydrogels was determined gravimetrically by extracting the gels with $1 \%(\mathrm{v} / \mathrm{v})$ acetic acid for 3 days. Figure $6.3 \mathrm{a}$ shows that the gel content increased with increasing polymer concentrations from $1 \mathrm{wt} \%$ to $3 \mathrm{wt} \%$ and the highest content exceeding $70 \%$ was obtained at a polymer concentration of 3 $w t \%$. This indicates that network formation is more efficient at higher polymer concentrations.
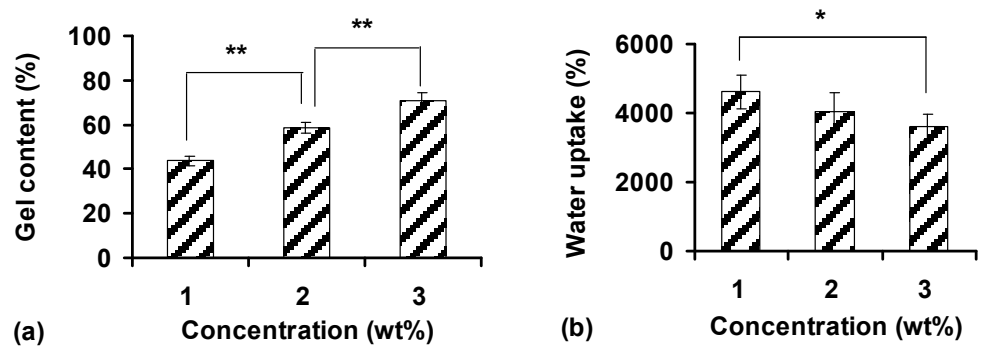

Figure 6.3. Gel content (a) and equilibrium water uptake (b) of extracted CH-GA43/PA10 hydrogels as a function of initial polymer concentration at $\mathrm{pH} 7.4$ and $37^{\circ} \mathrm{C}$ (Student's $t$-test, ${ }^{*} \mathrm{p}<0.05$, ** $\mathrm{p}<0.01)$.

The ability to hold sufficient amounts of water inside the network structure is an important parameter to characterize hydrogels. The effect of the initial polymer concentration on the water uptake of hydrogels is shown in Figure $6.3 \mathrm{~b}$. The water uptake of the extracted CH-GA43/PA10 hydrogels decreased from 4600 to $3600 \%$ with increasing initial polymer concentration from 1 to $3 \mathrm{wt} \%$. These results indicate that the networks 
formed at a higher polymer concentration have a higher crosslink density.

It is known that chitosan amino groups have a pKa value of 6.5. As a result, the crosslinked chitosan gels were expected to have a $\mathrm{pH}$ dependent swelling behavior. The effect of $\mathrm{pH}$ on the water uptake of $\mathrm{CH}-\mathrm{GA} 43 / \mathrm{PA} 10$ hydrogels is presented in Figure 6.4. When placed in buffers with $\mathrm{pH}$ values ranging from 6.5 to 9 , the hydrogels showed a comparable water uptake value. However, water uptake of the gels increased almost twice when the gels were swollen in acidic buffers with a $\mathrm{pH}$ value of 2 or 5 . The protonation of amino groups leads to electrostatic repulsion and expansion of the polymer chains and consequently more water can diffuse into the network, leading to an increase in water uptake [32].

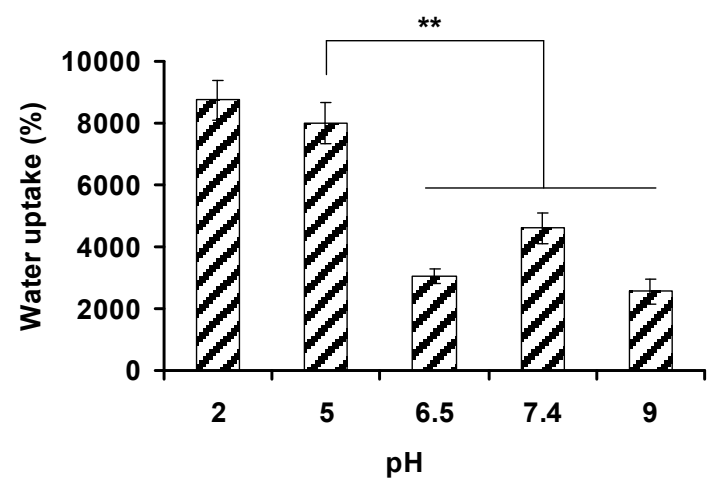

Figure 6.4. Water uptake of extracted $\mathrm{CH}-\mathrm{GA} 43 / \mathrm{PA} 10$ hydrogels after swelling in buffers with different $\mathrm{pH}$ values at $37^{\circ} \mathrm{C}$ (Student's $t$-test, ${ }^{* *} \mathrm{p}<0.01$ ).

\subsubsection{Enzymatic degradation of chitosan hydrogels}

It has been reported that chitosans undergo enzymatic hydrolysis of the glycosidic bonds of acetylated residues present in the chitosan backbone by lysozyme [13-16]. To mimic an in vivo degradation profile, PBS solutions containing different concentrations of lysozyme were applied on top of the CH-GA43/PA10 hydrogels and incubated at $37^{\circ} \mathrm{C}$. The lysozyme concentration ranged from $0.5 \mathrm{mg} / \mathrm{mL}$ to $2 \mathrm{mg} / \mathrm{mL}$ corresponding with the lysozyme concentration in the extracellular matrix of human cartilage [16]. The degradation of CH-GA43/PA10 hydrogels in the absence or presence of lysozyme was evaluated by determining the remaining gel weight as a function of time. Figure 6.5 a shows that after 21 days in PBS the weight ratio (degraded gel weight/initial gel weight $\mathrm{x} 100 \%$ ) of a $1 \mathrm{wt} \%$ CH-GA43/PA10 hydrogel slightly decreased to $90 \%$, whereas the ratio significantly decreased to about $20-60 \%$ of the original gel weight in the presence of lysozyme. Moreover, at the same incubation time the gel weight ratios decrease with increasing concentrations of lysozyme from $0.5 \mathrm{mg} / \mathrm{mL}$ to $2 \mathrm{mg} / \mathrm{mL}$. 

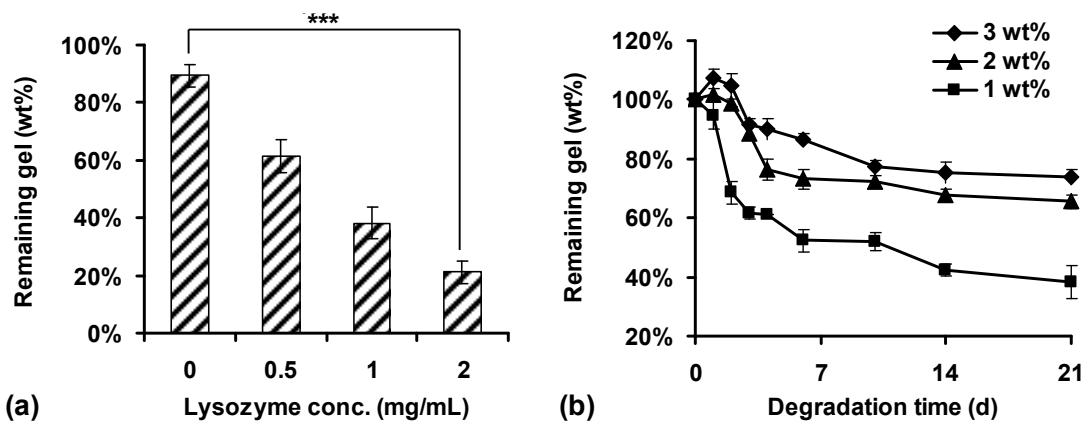

Figure 6.5. Enzymatic degradation of (a) $1 \mathrm{wt} \% \mathrm{CH}-\mathrm{GA} 43 / \mathrm{PA} 10$ hydrogels after incubation in PBS with lysozyme concentrations from 0 to $2 \mathrm{mg} / \mathrm{mL}$ for 21 days at $37^{\circ} \mathrm{C}$; (b) Degradation of $\mathrm{CH}$ GA43/PA10 hydrogels in PBS containing $1 \mathrm{mg} / \mathrm{mL}$ lysozyme as a function time for different initial polymer concentrations at $37^{\circ} \mathrm{C}$ (Student's $t$-test, $* * * \mathrm{p}<0.001$ ).

In order to investigate the influence of the initial polymer concentration on the degradation rate, PBS solutions containing $1 \mathrm{mg} / \mathrm{mL}$ lysozyme were added to $\mathrm{CH}$ GA43/PA10 hydrogels prepared at different polymer concentrations, and the remaining gel weight in time was determined (Figure 6.5b). It is noticed that there was a slight weight increase in the first 2 days for $\mathrm{CH}-\mathrm{GA} 43 / \mathrm{PA} 10$ hydrogels prepared at concentrations of 2 and $3 \mathrm{wt} \%$, which was a result of a higher degree of swelling after partial degradation of the hydrogels. Moreover, hydrogels prepared at higher polymer concentrations degraded more slowly. For example, about $80 \%$ of gel weight remained for the $3 \mathrm{wt} \% \mathrm{CH}-\mathrm{GA} 43 / \mathrm{PA} 10$ hydrogel after 3 weeks, whereas only $40 \%$ of gel weight remained for the $1 \mathrm{wt} \% \mathrm{CH}-$ GA43/PA10 hydrogel after the same time period. In vitro experiments using poly(glycolic acid) scaffold showed that chondrocytes started to produce an extracellular matrix (ECM) after 3 days [33]. Moreover, chondrocytes cultured in agarose gels synthesized a mechanically functional ECM in approximately one month [34]. Based on the preliminary results of the degradation of $\mathrm{CH}-\mathrm{GA} 43 / \mathrm{PA} 10$ hydrogels, these hydrogels are expected not to be completely degraded within one month.

\subsubsection{Rheological analysis}

The mechanical properties of the chitosan-based hydrogels were studied by oscillatory rheology experiments of polymer solutions containing $\mathrm{HRP}$ and $\mathrm{H}_{2} \mathrm{O}_{2}$ in $\mathrm{PBS}$ at $37^{\circ} \mathrm{C}$. A solution of CH-GA43/PA10 and a mixture of HRP and $\mathrm{H}_{2} \mathrm{O}_{2}$ solutions (in PBS) were applied to the rheometer using a double syringe equipped with a mixing chamber.

Generally, after mixing the reactants the storage modulus increased in time due to enzymatic crosslinking reactions of $\mathrm{CH}-\mathrm{GA} 43 / \mathrm{PA} 10$, until reaching its plateau value, marking the end of the crosslinking process. In Figure 6.6 the storage and loss moduli of 1 and $2 \mathrm{wt} \%$ chitosan hydrogels are presented. It can be seen that a higher initial polymer 
concentration resulted in a higher storage modulus of the hydrogels. In addition, the time to reach the plateau value of the storage modulus was also shortened. For example, after 7 min, chitosan hydrogels reached a storage modulus plateau value of $1.3 \mathrm{kPa}$ at $1 \mathrm{wt} \%$ polymer concentration, while hydrogels prepared from $2 \mathrm{wt} \%$ polymer solutions almost immediately reached a plateau value of $5.5 \mathrm{kPa}$ after starting the measurement. No increases in the storage moduli in time were observed for samples of CH-GA43/PA10 without HRP and $\mathrm{H}_{2} \mathrm{O}_{2}$ and $\mathrm{CH}-\mathrm{GA} 43$ with $\mathrm{HRP}$ and $\mathrm{H}_{2} \mathrm{O}_{2}$, indicating that no gelation took place (data not shown). Moreover, the damping factor (defined as $\mathrm{G}^{\prime \prime} / \mathrm{G}^{\prime}$ ), calculated from Figure 6.6, was between $1 \times 10^{-3}$ and $2 \times 10^{-3}$. The low damping factor indicates that these chitosan hydrogels are highly elastic.

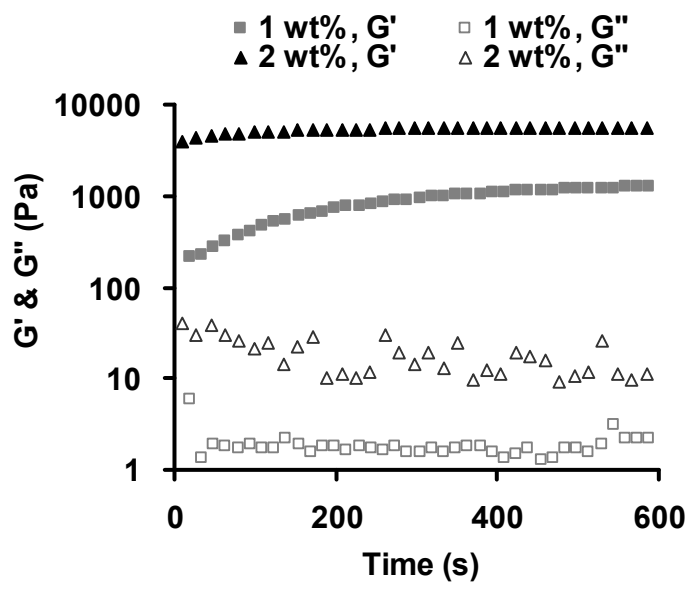

Figure 6.6. The storage modulus $\left(\mathrm{G}^{\prime}\right)$ and loss modulus $\left(\mathrm{G}^{\prime \prime}\right)$ of Dex-TA hydrogels $(10 \mathrm{wt} \%$ in PBS, DS $15, \mathrm{H}_{2} \mathrm{O}_{2} / \mathrm{TA}=0.6 \mathrm{~mol} / \mathrm{mol}$ ) as a function of time. A frequency of $0.5 \mathrm{~Hz}$ and a strain of $0.1 \%$ at $37^{\circ} \mathrm{C}$ were applied.

\subsubsection{Chondrocyte incorporation inside chitosan-based hydrogels}

In a biocompatibility study of CH-GA43/PA10 hydrogels, chondrocytes were incorporated inside the gels during the gel preparation and the hydrogel/cell constructs were cultured in medium without differentiation factors up to 2 weeks. Cell viability as a function of culture time was determined by using a Live-dead assay kit. The viable (stained green) and dead cells (stained red) were visualized by fluorescence microscopy. Figure 6.7 shows that at all culture times, predominantly living cells $(>90 \%)$ were found within the CH-GA43/PA10 hydrogels. These results show that the hydrogels have a good cytocompatibility. These findings were further confirmed with a MTT assay (Figure 6.8). Metabolically active cells which stained purple with the MTT reagent were observed throughout the hydrogel, and a uniform cell distribution was obtained. No apparent differences in the metabolic activity of chondrocytes in chitosan hydrogels and cells in the 
agarose control gels were detected. These results strongly suggest that the gelation process does not compromise cell viability and that sufficient mass transport of nutrients and oxygen to the cells inside the CH-GA43/PA10 gel matrix takes places. Therefore, the enzymatically crosslinked chitosan hydrogels have a better biocompatibility as compared to other injectable hydrogel systems based on methacrylated chitosan [21].

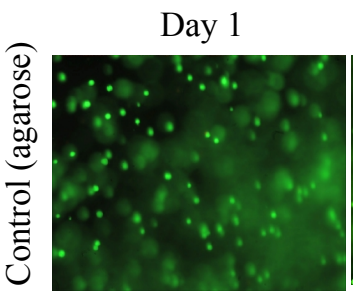

Day 3

Day 7
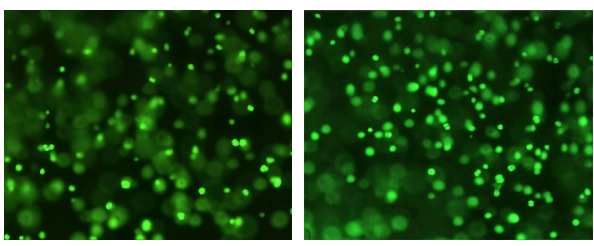

Day 14
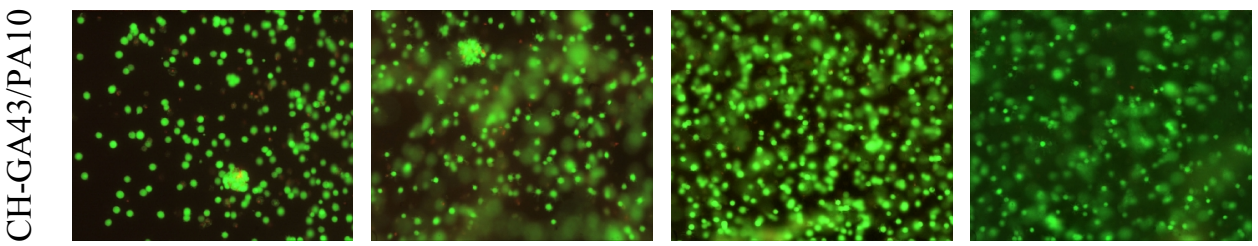

Figure 6.7. Live-dead assay showing chondrocytes incorporated in the chitosan hydrogels, after 1, 3 , 7 and 14 days in culture. Agarose hydrogels $(0.5 \mathrm{wt} \%)$ were used as a control. Cells were stained with calcein-AM/Ethidium homodimer (dead cells stained red and living cells green) and visualized using fluoresce microscopy. Cell density: $5 \times 10^{6} / \mathrm{mL}$, original magnification: $100 \times$.
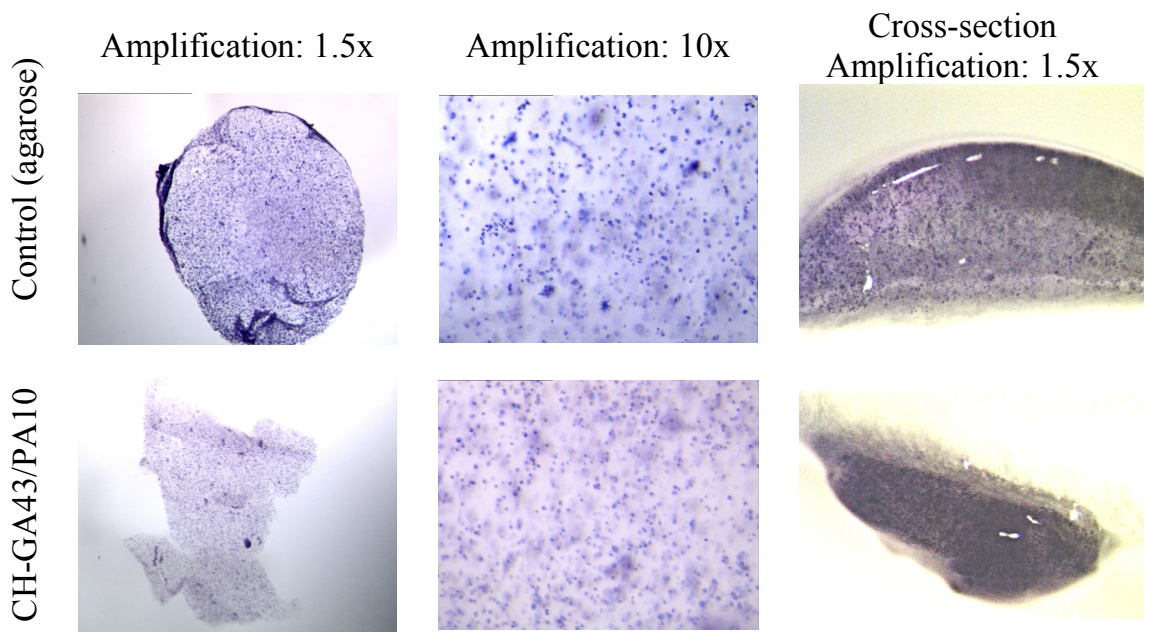

Figure 6.8. MTT assay showing the encapsulated chondrocytes in the chitosan hydrogels, after 14 days in culture. Agarose hydrogels $(0.5 \mathrm{wt} \%)$ were used as a control. Metabolically active cells stain purple and constructs were visualized using light microscopy. Cell density: $5 \times 10^{6} / \mathrm{mL}$. 
Cells, scaffolds and signaling factors are the framework of the tissue engineering triad [35]. One of the major challenges for cartilage tissue engineering is enabling the cells to behave within an artificial scaffold as they do in native cartilage. Differentiated chondrocytes are characterized by a round morphology. Preserving this feature inside hydrogels is a prerequisite for efficient chondrogenic matrix production. As observed in Figure 6.9, chondrocytes inside chitosan hydrogels still maintained a round morphology, up to 14 days. Interestingly, inside the analyzed samples the encapsulated chondrocytes appeared to attach on the materials and form clusters after 3 days in culture. The morphology of chondrocytes was further observed by SEM. Figure 6.9c shows that chondrocytes retained their round shape after being cultured for 14 days.

Day 3

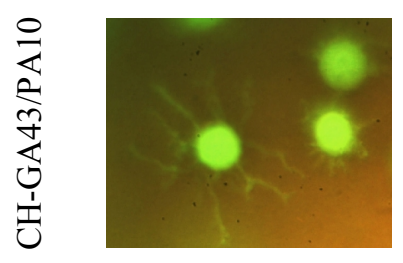

(a)
Day 14

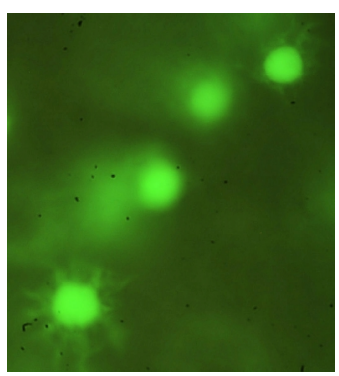

(b)
Day 14

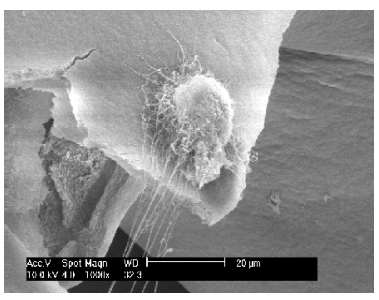

(c)

Figure 6.9. Fluorescence microscopy images (a and b) and SEM image (c) showing the chondrocyte morphology inside $1 \mathrm{wt} \%$ CH-GA43/PA10 hydrogels after 3 and 14 days in culture. For the Livedead assay, cells were stained with calcein-AM/Ethidium homodimer (dead cells stain red and living cells green). Cell density: $5 \times 10^{6} / \mathrm{mL}$, original magnification of (a) and (b): $100 \times$.

\subsection{Conclusions}

Water-soluble chitosan derivatives (CH-GA/PA) were conveniently synthesized by a two-step synthesis procedure by the sequential conjugation of glycolic acid (GA) and phloretic acid (PA) to native chitosan using EDAC/NHS. Gelation of the CH-GA43/PA10 was performed using $\mathrm{HRP}$ and $\mathrm{H}_{2} \mathrm{O}_{2}$. Gelation times can be varied from 4 min to $10 \mathrm{sec}$ by increasing the polymer concentration from 1 to $3 \mathrm{wt} \%$. The gel content, water uptake, enzymatic degradation rate and mechanical properties could be adjusted by varying the initial polymer concentration. Storage moduli of the gels in the range of 1 to $5.5 \mathrm{kPa}$ could be obtained. Primary chondrocyte culturing experiments showed that CH-GA43/PA10 hydrogels have a good biocompatibility. These studies have demonstrated that the watersoluble chitosan derivative $\mathrm{CH}-\mathrm{GA} 43 / \mathrm{PA} 10$ has a high potential as an injectable biomaterial for cartilage tissue engineering. 


\subsection{References}

[1] Langer R, Vacanti JP. Tissu Engineering. Science 1993;260: 920-926.

[2] Lee KY, Mooney DJ. Hydrogels for Tissue Engineering. Chem. Rev. 2001;101: 1869-1879.

[3] Peppas NA, Hilt JZ, Khademhosseini A, Langer R. Hydrogels in Biology and Medicine: From Molecular Principles to Bionanotechnology. Adv. Mater. 2006;18: 1345-1360.

[4] Gutowska A, Jeong B, Jasionowski M. Injectable Gels for Tissue Engineering. Anat. Rec. 2001;263: 342-349.

[5] Bhattarai N, Ramay HR, Gunn J, Matsen FA, Zhang M. PEG-Grafted Chitosan as an Injectable Thermosensitive Hydrogel for Sustained Protein Release. J. Control. Release 2005;103: 609-624.

[6] Obara K, Ishihara M, Ishizuka T, Fujita M, Ozeki Y, Maehara T, Saito Y, Yura H, Matsui T, Hattori H, Kikuchi M, and Kurita A. Photocrosslinkable Chitosan Hydrogel Containing Fibroblast Growth Factor-2 Stimulates Wound Healing in Healing-Impaired db/db Mice. Biomaterials 2003;24: 3437-3444

[7] Ishihara M, Obara K, Nakamura S, Fujita M, Masuoka K, Kanatani Y, Takase B, Hattori H, Morimoto Y, Ishihara M, Maehara T, and Kikuchi M. Chitosan Hydrogel as a Drug Delivery Carrier to Control Angiogenesis. J. Artif. Organs 2006;9: 8-16.

[8] Liu WG, K.D.Yao. Chitosan and Its Derivatives-a Promising Non-Viral Vector for Gene Transfectiom. J. Control. Release 2002;83: 1-11.

[9] Kim IY, Seo SJ, Moon HS, Yoo MK, Park IY, Kim BC, and Cho CS. Chitosan and its Derivatives for Tissue Engineering Applications. Biotech. Adv. 2008;26: 1-21.

[10] Nettles DL, Elder SH, Gilbert JA. Potential Use of Chitosan as a Cell Scaffold Material for Cartilage Tissue Engineering. Tissue Eng. 2002;8: 1009-1016.

[11] Ono K, Saito Y, Yura H, Ishikawa K, Kurita A, Akaike T, and Ishihara M. Photocrosslinkable Chitosan as a Biological Adhesive. J. Biomed. Mater. Res. A 2000;49: 289-295

[12] Lahiji A, Sohrabi A, Hungerford DS, Frondoza CG. Chitosan Supports the Expression of Extracellular Matrix Proteins in Human Osteoblasts and Chondrocytes. J. Biomed. Mater. Res. A 2000;51: 586-595.

[13] Vårum KM, Myhr MM, Smidsrød O. In Vitro Degradation Rates of Partially Nacetylated Chitosans in Human Serum. Carbohydr. Res. 1997;299: 99-101.

[14] Pangburn S, Trescony P, Heller J. Lysozyme Degradation of Partially Deacetylated Chitin, Its Films and Hydrogels. Biomaterials 1982;3: 105-108.

[15] Moss JM, Van Damme M-PI, Murphy WH, Stanton PG, Thomas P, Preston BN. Purification, Characterization, and Biosynthesis of Bovine Cartilage Lysozyme Isoforms. Arch. Biochem. Biophys. 1997;339 172-182.

[16] Greenwald RA, Josephson AS, Diamond HS, Tsang A. Human Cartilage Lysozyme. J. Clin. Invest. 1972 51: 2261-2270.

[17] Sechriest V, Miao Y, Niyibizi C, Westerhausen-Larson A, Matthew H, Evans C, Fu F, and Suh J-K. GAG-Augmented Polysaccharide Hydrogel: A Novel Biocompatible and Biodegradable Material to Support Chondrogenesis. J. Biomed. Mater. Res. A 2000;49: 534-541.

[18] Cui YL, Qi AD, Liu WG, Wang XH, Wang H, Ma DM, and Yao KD. Biomimetic Surface Modification of Poly(L-Lactic Acid) with Chitosan and Its Effects on Articular Chondrocytes in Vitro. Biomaterials 2003;24: 3859-3868. 
[19] Rinaudo M. Chitin and Chitosan: Properties and Applications. Prog. Polym. Sci. 2006;31: 603-632.

[20] Choa JH, Kim S-H, Park KD, Jung MC, Yang WI, Han SW, Noh JY, and Lee JW. Chondrogenic Differentiation of Human Mesenchymal Stem Cells Using a Thermosensitive Poly(N-Isopropylacrylamide) and Water-Soluble Chitosan Copolymer. Biomaterials 2004;25: 5743-5751.

[21] Hong Y, Song H, Gong Y, Mao Z, Gao C, Shen J. Covalently Crosslinked Chitosan Hydrogel: Properties of in Vitro Degradation and Chondrocyte Encapsulation. Acta Biomater. 2007;3: 23 -31.

[22] Chen J-P, Cheng T-H. Thermo-Responsive Chitosan-graft-Poly(NIsopropylacrylamide) Injectable Hydrogel for Cultivation of Chondrocytes and Meniscus Cells. Macromol. Biosci. 2006;6: 1026-1039.

[23] Hoemann CD, Sun J, Légaré A, McKee, Buschmann MD. Tissue Engineering of Cartilage Using an Injectable and Adhesive Chitosan-Based Cell-Delivery Vehicle. Osteoarthr. Cartilage 2005;13: 318-329

[24] Berger J, Reist M, Mayer JM, Felt O, Gurny R. Structure and Interactions in Chitosan Hydrogels Formed by Complexation or Aggregation for Biomedical Applications. Eur. J. Pharm. Biopharm. 2004;51: 35-52.

[25] Hong Y, Mao Z, Wang H, Gao C, Shen J. Covalently Crosslinked Chitosan Hydrogel Formed at Neutral Ph and Body Temperature. J. Biomed. Mater. Res. A 2006;79: 913-922

[26] Amsden BG, Sukarto A, Knight DK, Shapka SN. Methacrylated Glycol Chitosan as a Photopolymerizable Biomaterial. Biomacromolecules 2007;8: 3758-3766

[27] Kim M-S, Choi Y-J, Noh I, Tae G. Synthesis and Characterization of in Situ Chitosan-Based Hydrogel Via Grafting of Carboxyethyl Acrylate. J. Biomed. Mater. Res. A 2007;83A: 674-682.

[28] Jin R, Hiemstra C, Zhong Z, Feijen J. Enzyme-Mediated Fast in Situ Formation of Hydrogels from Dextran-Tyramine Conjugates. Biomaterials 2007;28: 2791-2800.

[29] Hirai A, Odani H, Nakajima A. Determination of Degree of Deacetylation of Chitosan by 1h Nmr Spectroscopy. Polym. Bull. 1991;26: 87-94.

[30] Zhu W, Ding J. Synthesis and Characterization of a Redox-Initiated, Injectable, Biodegradable Hydrogel. J. Appl. Polym. Sci. 2006;99: 2375-2383.

[31] Nishimura SI, Kohgo O, Kurita K. Chemospecific Manipulations of a Rigid Polysaccharide: Syntheses of Novel Chitosan Derivatives with Excellent Solubility in Common Organic Solvents by Regioselective Chemical Modifications. Macromolecules 1991;24: 4745-4748.

[32] Qu X, Wirsén A, Albertsson A-C. Structural Change and Swelling Mechanism of Ph-Sensitive Hydrogels Based on Chitosan and D,L-Lactic Acid. J. Appl. Polym. Sci. 1999; 74: 3186-3192.

[33] Riesle J, Hollander AP, Langer R, Freed LE, Vunjak-Novakovic G. Collagen in Tissue-Engineered Cartilage: Types, Structure, and Crosslinks. J. Cell Biochem. 1998;71: 313-327.

[34] Buschmann MD, Gluzband YA, Grodzinsky AJ, Kimura JH, Hunziker EB. Chondrocytes in Agarose Culture Synthesize a Mechanically Functional Extracellular Matrix. J. Orthop. Res. 1992;10: 745-758.

[35] Chung C, Burdick JA. Engineering Cartilage Tissue. Adv. Drug Deliver. Rev. 2008;60: 243-262. 


\section{Chapter 7}

\section{Chondrogenesis in Injectable Enzymatically Crosslinked Heparin/Dextran Hydrogels *}

In this study, injectable hydrogels were prepared by the horseradish peroxidasemediated co-crosslinking of dextran-tyramine (Dex-TA) and heparin-tyramine (Hep-TA) conjugates and used as scaffolds for cartilage tissue engineering. The swelling and mechanical properties of these hydrogels can be easily controlled by the Dex-TA/Hep-TA weight ratio. When chondrocytes were incorporated in these gels, cell viability and proliferation were highest for gels with a 50/50 weight ratio of Dex-TA/Hep-TA. Moreover, these hydrogels induced an enhanced production of chondroitin sulfate and a more abundant presence of collagen as compared to Dex-TA hydrogels. The results indicate that injectable Dex-TA/Hep-TA hydrogels are promising scaffolds for cartilage regeneration.

\subsection{Introduction}

Tissue engineering is a promising method for the regeneration of degenerated or lost cartilage [1, 2]. This approach generally involves the use of cells placed in threedimensional scaffolds, the latter acting as a temporary artificial extracellular matrix (ECM). Injectable hydrogels may serve as temporary scaffolds to guide cell attachment and differentiation of chondrocytes and/or their progenitor cells, resulting in newly formed cartilage tissue. Compared to preformed hydrogels, injectable hydrogels have various advantages. They can be applied via a minimally invasive surgical procedure. They can fill irregular-shaped defects and allow easy incorporation of cells and bioactive molecules [3-5]. Therefore, in recent years injectable hydrogels have received much attention in cartilage tissue engineering.

Several chemical crosslinking methods, such as photopolymerization [6-8], Schiff-base formation [9], and Michael-type addition reactions [10, 11], have been employed to obtain injectable hydrogels that gel in situ. For example, Söntjens et al. reported on photocrosslinked methacrylated polyester-poly(ethylene glycol) hydrogels which can support the growth of chondrocytes in vitro, and their production of extracellular matrix components such as glycosaminoglycan and collagen type II [8]. In another study, Tan et al.

\footnotetext{
* This chapter is in preparation: Rong Jin, Liliana S. Moreira Teixeira, Pieter J. Dijkstra, Clemens A. van Blitterswijk, Marcel Karperien and Jan Feijen, Biomacromolecules.
} 
reported on hydrogels prepared via Schiff base formation between water-soluble chitosan and oxidized hyaluronic acid and showed that chondrocytes were surviving in these hydrogels and retained their round morphology [9]. Recently, an efficient method, i.e. horseradish peroxidase (HRP)-mediated chemical crosslinking, has been developed to produce injectable hydrogels [12-19]. Using this approach, Lee et al. reported on hyaluronic acid-based injectable hydrogels for protein release [16, 17] and Sakai et al. prepared gelatin-based injectable hydrogels in vitro and indicated their potential application in tissue engineering in vivo [19]. We previously showed that fast in situ forming injectable hydrogels can be obtained via enzymatic crosslinking of dextrantyramine conjugates (Dex-TA) or chitosan-phloretic acid conjugates in the presence of HRP and hydrogen peroxide $[13,14]$. These hydrogels had good mechanical properties and low cytotoxicity $[12,14]$. Importantly, chondrocytes incorporated in the gels remained viable, were capable of maintaining their phenotype and produced cartilaginous tissue [14, 20].

Heparin is a linear glycosaminoglycan composed of repeating units of 1,4-linked uronic acids (mainly D-glucuronic, L-iduronic or L-2-sulfated iduronic) and glucosamine residues (mainly D-N-acetyl glucosamine, D-di-N-6-sulfate glucosamine) [21]. It plays an important role in the interaction with bioactive proteins which are associated with cell adhesion, proliferation and differentiation [22, 23]. Over the past decades, heparin-containing hydrogels have been widely studied for biomedical applications such as controlled release of growth factors and tissue regeneration [24-28]. For example, heparin-containing hydrogels, prepared via a Michael addition reaction, were used for controlled release of growth factors. It was shown that incorporation of small amounts of heparin substantially influenced the release of basic fibroblast growth factors [26]. In recent studies, heparin has been shown to stimulate angiogenesis, adipogenesis and osteogenesis [25, 29, 30]. For example, photocrosslinked heparin-PEG hydrogels were shown to be capable of supporting the survival of human mesenchymal stem cells and inducing their osteogenic differentiation [25]. However, limited studies were reported on the use of heparin-containing hydrogels for chondrogenesis in cartilage tissue engineering [10,31].

In this chapter, we describe biofunctional injectable hydrogels based on dextran and heparin for cartilage tissue engineering. We hypothesized that the presence of heparin in the hydrogels may promote chondrocyte proliferation and differentiation as well as enhanced cartilage regeneration. Here we describe the preparation of injectable hydrogels from a mixture of a heparin-tyramine conjugate (Hep-TA) and a dextran-tyramine conjugate (DexTA) at different weight ratios. The properties of the hydrogels such as gelation time, swelling and mechanical properties were investigated. Moreover, bovine chondrocytes were incorporated in these hydrogels to evaluate their cytocompatibility, chondrocyte proliferation and matrix production. 


\subsection{Materials and methods}

Materials. Heparin sodium (from porcine intestinal mucosa, molecular weight ranges from 3 to $30 \mathrm{~kg} / \mathrm{mol}$ ) was purchased from Celsus, Inc. $N$-ethyl- $N$ '-(3-dimethylaminopropyl) carbodiimide hydrochloride (EDAC) was purchased from Fluka. Tyramine (TA), hydrogen peroxide $\left(\mathrm{H}_{2} \mathrm{O}_{2}\right)$, 4-morpholino ethanesulfonic acid (MES) and N-hydroxysuccinimide (NHS) were obtained from Aldrich-Sigma. Horseradish peroxidase (HRP, type VI, 300 purpurogallin unit/mg solid) was purchased from Aldrich and used without further purification. All other solvents were used as received. Dextran-tyramine (denoted as DexTA) conjugates with a degree of substitution, defined as the number of tyramine units per 100 anhydroglucose rings in dextran, of 15 were prepared as previously reported [12].

Synthesis and characterization of heparin-tyramine conjugate. A heparin-tyramine conjugate (denoted as Hep-TA) was synthesized by the coupling reaction of tyramine amine groups to heparin carboxylic acid groups using EDAC/NHS activation. In a typical procedure, heparin sodium (2.0 g) was dissolved in $20 \mathrm{~mL}$ of MES (0.1 M, pH 6.0), to which EDAC (288 mg, $1.5 \mathrm{mmol})$ and NHS (227 mg, $1.5 \mathrm{mmol})$ were added. After $30 \mathrm{~min}$, $6 \mathrm{~mL}$ of a DMF solution containing tyramine $(69 \mathrm{mg}, 0.5 \mathrm{mmol})$ was added and the mixture was stirred under nitrogen. After 3 days, the mixture was neutralized with $1 \mathrm{M} \mathrm{NaOH}$ and ultrafiltrated (MWCO 1000), first with $50 \mathrm{mM} \mathrm{NaCl}$ and then deionized water. The resultant Hep-TA conjugate was obtained in the form of a foam after freeze-drying (yield: $1.9 \mathrm{~g}, 95 \%$ ). The degree of substitution of tyramine residues in the Hep-TA conjugate, defined as the number of tyramine moieties per 100 repeating units of heparin, was 15 , as determined by a UV measurement [15]. In brief, the Hep-TA conjugate was dissolved in PBS at a concentration of $2 \mathrm{mg} / \mathrm{mL}$ and the absorbance at $275 \mathrm{~nm}$ was measured using a Cary 300 Bio UV spectrophotometer (Varian). An unmodified heparin solution $(2 \mathrm{mg} / \mathrm{ml})$ was used as a blank. The absorbance was correlated to the concentration of tyramine in the conjugate using a calibration curve obtained from tyramine solutions in PBS.

Hydrogel formation and gelation time. Hydrogel samples $(\sim 0.25 \mathrm{~mL})$ of Hep-TA or Hep-TA/Dex-TA mixtures at polymer concentrations of 10 or $20 \mathrm{wt} \%$ were prepared in vials at $37{ }^{\circ} \mathrm{C}$. In a typical procedure, to a PBS solution of Hep-TA (200 $\left.\mu \mathrm{L}, 25 \mathrm{wt} \%\right)$, a freshly prepared PBS solution of $\mathrm{H}_{2} \mathrm{O}_{2}(25 \mu \mathrm{L}$ of $0.3 \%$ stock solution) and HRP $(25 \mu \mathrm{L}$ of $150 \mathrm{unit} / \mathrm{mL}$ stock solution) were added and the mixture was gently vortexed.. The time to form a gel (denoted as gelation time) was determined using the vial tilting method. No flow within 1 min upon inverting the vial was regarded as the gel state. The experiment was preformed in triplicate.

Hydrogel characterization. The heparin content of the Dex-TA/Hep-TA hydrogels was determined by a colorimetric method based on the binding of toluidine blue, with some modifications $[32,33]$. Briefly, the hydrogels prepared at Dex-TA/Hep-TA weight ratio of 
$75 / 25,50 / 50$ and 25/75 were extracted in water and then freeze-dried. Samples $(\sim 1 \mathrm{mg}, \mathrm{n}=3)$ of dried gels were incubated overnight at room temperature in $2 \mathrm{ml}$ of a $0.75 \mathrm{mg} / \mathrm{ml}$ toluidine blue solution. Subsequently, the solutions were diluted 10 times with $\mathrm{H}_{2} \mathrm{O}$ and filtrated through $0.22 \mu \mathrm{m}$ filter. The absorbance of the filtrates was measured at $630 \mathrm{~nm}$. A standard curve was prepared by mixing $1 \mathrm{ml}$ of heparin solutions with known concentrations and $1 \mathrm{ml}$ of $0.15 \mathrm{mg} / \mathrm{ml}$ toluidine blue solution in water at room temperature. After filtration through a $0.22 \mu \mathrm{m}$ filter, the absorbance of the solutions was measured at $630 \mathrm{~nm}$. The heparin content in the hydrogels was calculated based on the heparin amount obtained from the toluidine blue assay and the dry gel weight after extraction.

For swelling tests, hydrogel samples $(\sim 0.25 \mathrm{~mL})$ were prepared as described above. Subsequently, $2 \mathrm{~mL}$ of PBS was applied on top of the hydrogels and then the samples were incubated at $37^{\circ} \mathrm{C}$ for $72 \mathrm{~h}$ to reach the swelling equilibrium. The buffer solution was then removed from the samples. The hydrogels were weighed $\left(\mathrm{W}_{\mathrm{s}}\right)$ and then freeze-dried $\left(\mathrm{W}_{\mathrm{d}}\right)$. The experiments were performed in triplicate and the degree of swelling of the hydrogels was expressed as $\left(\mathrm{W}_{\mathrm{s}}-\mathrm{W}_{\mathrm{d}}\right) / \mathrm{W}_{\mathrm{d}}$.

Rheological experiments were carried out with a MCR 301 rheometer (Anton Paar) using parallel plates $\left(25 \mathrm{~mm}\right.$ diameter, $\left.0^{\circ}\right)$ configuration at $37^{\circ} \mathrm{C}$ in the oscillatory mode. A stock solution of Hep-TA/Dex-TA $(600 \mu \mathrm{L}, 25 \mathrm{wt} \%$ in PBS) at different weight ratios $(100 / 0$, $75 / 25,50 / 50,25 / 75$ and $0 / 100)$ was mixed with $150 \mu \mathrm{L}$ of an $\mathrm{HRP} / \mathrm{H}_{2} \mathrm{O}_{2}$ mixture $(75 \mu \mathrm{L}$ of 150 unit/mL $\mathrm{HRP}$ and $75 \mu \mathrm{L}$ of $\left.0.3 \% \mathrm{H}_{2} \mathrm{O}_{2}\right)$ using a double syringe $(2.5 \mathrm{~mL}, 4: 1$ volume ratio) equipped with a mixing chamber (Mixpac). After the samples were applied to the rheometer, the upper plate was immediately lowered to a measuring gap size of $0.5 \mathrm{~mm}$, and the measurement was started. To prevent evaporation of water, a layer of oil was introduced around the polymer sample. A frequency of $0.5 \mathrm{~Hz}$ and a strain of $0.1 \%$ were applied in the analysis to maintain the linear viscoelastic regime. The measurement was continued up to the time the storage moduli recorded reached a plateau value. A frequency sweep and a strain sweep were also performed on the hydrogels from 0.1 to $10 \mathrm{~Hz}$ at a strain of $0.1 \%$, and from 0.1 to $10 \%$ at a frequency of $0.5 \mathrm{~Hz}$, respectively.

Chondrocyte isolation and incorporation. Bovine chondrocytes were isolated as previously reported [14] and cultured in chondrocyte expansion medium (DMEM with 10\% heat inactivated fetal bovine serum, 1\% Penincilin/Streptomicin (Gibco), $0.5 \mathrm{mg} / \mathrm{mL}$ fungizone (Gibco), 0.01 M MEM nonessential amino acids (Gibco), $10 \mathrm{mM}$ HEPES and $0.04 \mathrm{mM}$ L-proline) at $37{ }^{\circ} \mathrm{C}$ in a humidified atmosphere $\left(95 \%\right.$ air $\left./ 5 \% \mathrm{CO}_{2}\right)$. Hydrogels containing chondrocytes were prepared under sterile conditions by mixing a polymer/cell suspension with $\mathrm{HRP} / \mathrm{H}_{2} \mathrm{O}_{2}$. Polymer solutions of Hep-TA/Dex-TA at different weight ratios $(100 / 0,75 / 25,50 / 50,25 / 75$ or $0 / 100)$ were made in medium and $\mathrm{HRP}$ and $\mathrm{H}_{2} \mathrm{O}_{2}$ stock solutions were made in PBS. All the components were sterilized by filtration through filters 
with a pore size of $0.22 \mu \mathrm{m}$. Chondrocytes (P1) were dispersed in the precursors of the hydrogels. The hydrogels were then formed using the same procedure as in the absence of cells. The final polymer concentration was $20 \mathrm{wt} \%$ and the cell seeding density in the gels was $5 \times 10^{6}$ cells $/ \mathrm{mL}$. After gelation, the hydrogels $(50 \mu \mathrm{L}$ of each) were transferred to a culture plate and $2 \mathrm{~mL}$ of chondrocyte differentiation medium (DMEM with $0.1 \mu \mathrm{M}$ dexamethasone (Sigma), $100 \mu \mathrm{g} / \mathrm{mL}$ sodium pyruvate (Sigma), $0.2 \mathrm{mM}$ ascorbic acid, 50 $\mathrm{mg} / \mathrm{mL}$ insulin-transferrin-selenite (ITS+1, Sigma), $100 \mathrm{U} / \mathrm{ml}$ penicillin, $100 \mu \mathrm{g} / \mathrm{ml}$ streptomycin, $10 \mathrm{ng} / \mathrm{mL}$ transforming growth factor $\beta 3$ (TGF- $\beta 3, R \& D$ System) was added. The samples were incubated at $37^{\circ} \mathrm{C}$ in a humidified atmosphere containing $5 \% \mathrm{CO}_{2}$. The medium was replaced every 3 or 4 days.

Cell viability and proliferation. A viability study on chondrocytes incorporated in the hydrogels was performed with a Live-dead assay. At day 3, 7 and 14, the hydrogel constructs were rinsed with PBS and stained with calcein AM/ethidium homodimer using the Live-dead assay Kit (Invitrogen), according to the manufacturers' instructions. Hydrogel/cell constructs were visualized using a fluorescence microscope (Zeiss). Living cells fluoresce green and the nuclei of dead cells red. Quantification of total DNA of the constructs cultured for 1, 7, 14 and 21 days was done using the CyQuant dye kit and a fluorescent plate reader (Perkin-Elmer) as previously reported [34].

Swelling in the presence of chondrocytes. To evaluate the swelling behavior of hydrogels with chondrocytes incorporated, $50 \mu \mathrm{L}$ of a gel/cell construct was incubated in medium at $37^{\circ} \mathrm{C}$ in a humidified atmosphere containing $5 \% \mathrm{CO}_{2}$. After 3 days, samples $(n=3)$ were taken out of the medium, weighed $\left(\mathrm{W}_{\mathrm{sc}}\right)$ and then freeze-dried $\left(\mathrm{W}_{\mathrm{dc}}\right)$. The degree of swelling was expressed as $\left(\mathrm{W}_{\mathrm{sc}}-\mathrm{W}_{\mathrm{dc}}\right) / \mathrm{W}_{\mathrm{dc}}$.

RNA extraction and reverse transcriptase-polymerase chain reaction (RT-PCR). After culturing the hydrogel/cell constructs in differentiation medium for 21 days, the samples were collected and washed with PBS. After converting the gels into pieces by pipetting, Trizol reagent (Invitrogen, Carlsbad, CA) was added to lysate the cells. Total RNA was isolated using the Nucleospin RNA II kit (Bioke) according to manufacturer's instructions. The RNA yields were determined based on the A260. Subsequently, the RNA (250 ng) was transcribed into single strand cDNA using the iScript Kit (BioRad) according to the manufacturer's recommendations. One microliter of each normalized cDNA sample was analyzed using the "SYBR Green PCR Core Kit" (Applied Biosystems) and a real-time PCR Cycler (BioRad). The expression of collagen type II and aggrecan (Table 7.1) was analyzed and normalized to the expression of the housekeeping gene glyceraldehyde-3phosphate dehydrogenase (GAPDH). The efficiency of the single PCR reactions was determined and incorporated into the calculation. 
Table 7.1. Polymerase Chain Reaction Primers

\begin{tabular}{clcc}
\hline Primer & Direction & Sequence & $\begin{array}{c}\text { Annealing } \\
\text { Temp ('C) }\end{array}$ \\
\hline \hline $\begin{array}{c}\text { Bovine } \\
\text { aggrecan }\end{array}$ & Forward & 5' GACCAGAAGCTGTGCGAGGA 3' & 60 \\
$\begin{array}{c}\text { Bovine } \\
\text { collagen, } \\
\text { type IIa1 }\end{array}$ & Forward & 5' ATCAACGGTGGCTTCCACT 3' & 60 \\
$\begin{array}{c}\text { Bovine } \\
\text { collagen, } \\
\text { type Ia1 }\end{array}$ & Forward & 5' GCGGCTACGACTTGAGCTTC 3' & 60 \\
$\begin{array}{c}\text { Bovine } \\
\text { GAPDH }\end{array}$ & Forward & 5' GCCATCACTGCCACCCAGAA 3' & 60 \\
\hline
\end{tabular}

Histological staining. Samples cultured for 21 days were fixed in $10 \%$ formalin for $1 \mathrm{~h}$. After embedding the samples in paraffin, $5 \mu \mathrm{m}$ sections were collected and rehydrated with xylene and a series of ethanol (from 100\% until 70\%). The slides were left in distilled water for 10 minutes. Afterwards, toluidine blue (Fluka, $0,1 \%$ in deionized water) was added to the sections and left to incubate for 10 minutes. The slides were then washed with water and dehydrated. Sections were analyzed using a bright field microscope.

Matrix production. The secretion of chondroitin sulfate and collagen type II by chondrocytes was evaluated by immunofluorescent staining as previously reported [34]. For biochemical analysis, the constructs cultured for 1, 7, 14 and 21 days were digested using proteinase-K [20]. The total collagen content was determined using the hydroxyproline assay [35]. The hydroxyproline content was determined via a colorimetric assay by reaction with chloramine $\mathrm{T}$ and dimethylaminobenzaldehyde. All values were corrected for the background staining of gels without cells. Data $(n=3$, measured in triplicate) are expressed as mean \pm standard deviation (SD).

Statistical analysis. Statistical differences between two groups were analyzed using a Student's $t$-test. Those among three or more groups were analyzed using the One-way Analysis of Variance (ANOVA) with Turkey's post-hoc analysis. Statistical significance was set to a $p$ value $\leq 0.05$. Results are presented as mean \pm standard deviation.

\subsection{Results and discussion}

\subsubsection{Hydrogel formation and gelation time}

The key material of this study, a heparin-tyramine (Hep-TA) conjugate, with a degree of substitution of tyramine residues of 15 (DS 15), was synthesized by the coupling reaction of 
the amino group of tyramine to the carboxylic acid groups of heparin using EDC/NHS activation. The, enzyme-mediated crosslinking of phenol moieties in the presence of HRP and $\mathrm{H}_{2} \mathrm{O}_{2}$, a method successfully used in the preparation of hydrogels from tyramine conjugated dextrans and phloretic acid conjugated chitosans [13, 14], was applied to form hydrogels from the Hep-TA conjugates at polymer concentrations of 10 and $20 \mathrm{wt} \%$. In previous research it was shown that at concentrations of HRP of $0.2 \mathrm{mg} / \mathrm{mL}$ and concentrations of $\mathrm{H}_{2} \mathrm{O}_{2}$ of $0.01 \mathrm{M}$, biocompatible hydrogel/cell constructs were obtained [20]. These concentration ranges were also applied in the preparation of the hydrogels of Hep-TA, Dex-TA and mixtures thereof.

(a)
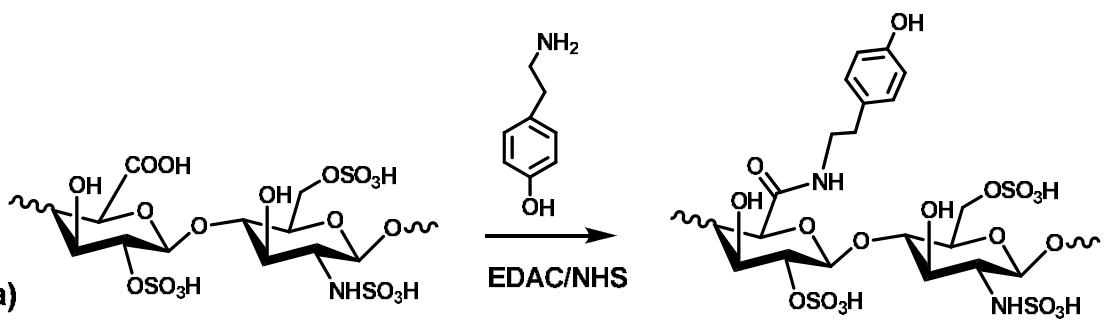

(b)
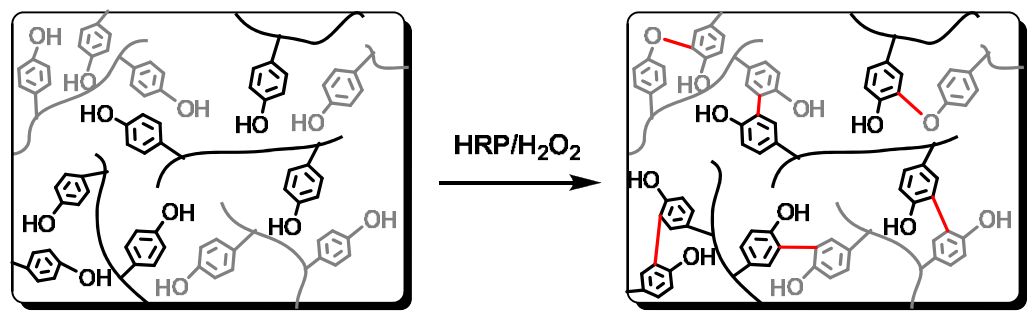

Figure 7.1. (a) Synthesis of heparin-tyramine conjugates (Hep-TA). (b) Hydrogel formation from dextran-tyramine (Dex-TA, black) and heparin-tyramine conjugates (Hep-TA, grey) via HRPmediated crosslinking in the presence of $\mathrm{H}_{2} \mathrm{O}_{2}$.
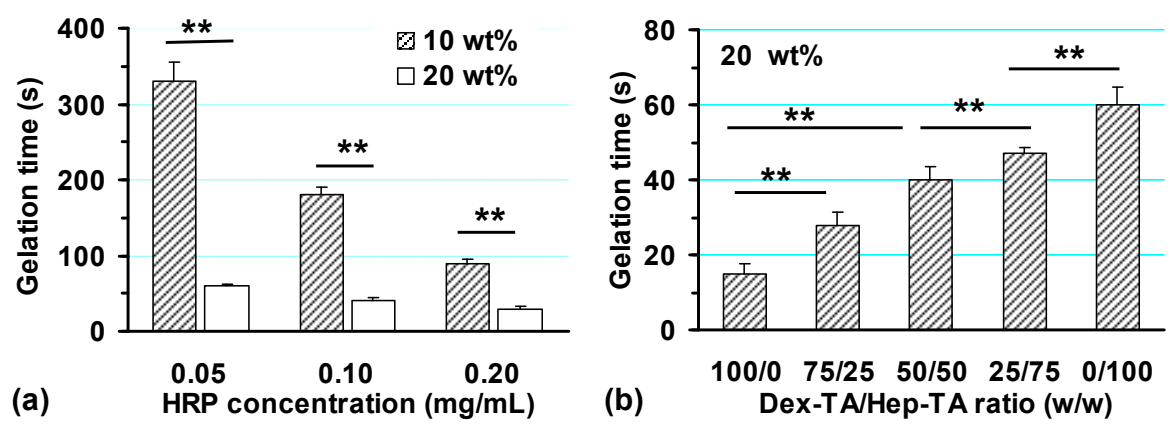

Figure 7.2. (a) Gelation times of Hep-TA hydrogels (10 and $20 \mathrm{wt} \%$ ) as a function of HRP concentration. The molar ratio of $\mathrm{H}_{2} \mathrm{O}_{2}$ /TA was kept at 0.2. (b) Gelation times of Hep-TA/Dex-TA hydrogels $(20 \mathrm{wt} \%)$ as a function of Hep-TA/Dex-TA ratio $(\mathrm{w} / \mathrm{w})$. The concentrations of HRP and $\mathrm{H}_{2} \mathrm{O}_{2}$ were kept at $0.05 \mathrm{mg} / \mathrm{mL}$ and $0.01 \mathrm{M}$, respectively. $(\mathrm{n}=3, * * p<0.01)$ 
Because a short gelation time is a prerequisite for injectable gel/cell constructs, the gelation times of the Hep-TA hydrogels, as monitored at $37^{\circ} \mathrm{C}$ by the vial tilting method, were first optimized (Figure 7.2a). It was found that, by increasing the HRP concentration from 0.05 to $0.2 \mathrm{mg} / \mathrm{mL}$, the gelation time decreased from about $340 \mathrm{~s}$ to $30 \mathrm{~s}(p<0.05)$. Moreover, shorter gelation times (less than $60 \mathrm{~s}$ ) were observed for the $20 \mathrm{wt} \%$ hydrogels than for $10 \mathrm{wt} \%$ hydrogels, which can be explained by the presence of more crosslinkable moieties in the $20 \mathrm{wt} \%$ hydrogels.

On the basis of these data, hydrogels from a mixture of Hep-TA (DS 15) and Dex-TA (DS 15) were prepared at a polymer concentration of $20 \mathrm{wt} \%$ (Figure 7.1b). The gelation times as a function of Dex-TA/Hep-TA weight ratio are presented in Figure 7.2b. Generally, these gels had shorter gelation times than the hydrogels based on Hep-TA. When the DexTA/Hep-TA ratio decreased from $75 / 25$ to $25 / 75$, the gelation times slightly increased from 30 to $50 \mathrm{~s}$. The increase in the gelation time of heparin-containing hydrogels compared to Dex-TA hydrogels may be explained by the unfavorable interactions with the active site of the enzyme caused by the acid groups in heparin chains (e.g. $-\mathrm{NHSO}_{3}{ }^{-},-\mathrm{OSO}_{3}{ }^{-}$and $\mathrm{COO}^{-}$) either through steric hindrance or charge interactions [36].

\subsubsection{Hydrogel characterization}

The incorporation of heparin in Dex-TA hydrogels was confirmed by a toluidine blue assay. The values of heparin content were close to the theoretical values at which the gels were prepared (Figure 7.3b). This indicated that Hep-TA conjugates were successfully cocrosslinked with Dex-TA conjugates to form a hydrogel.

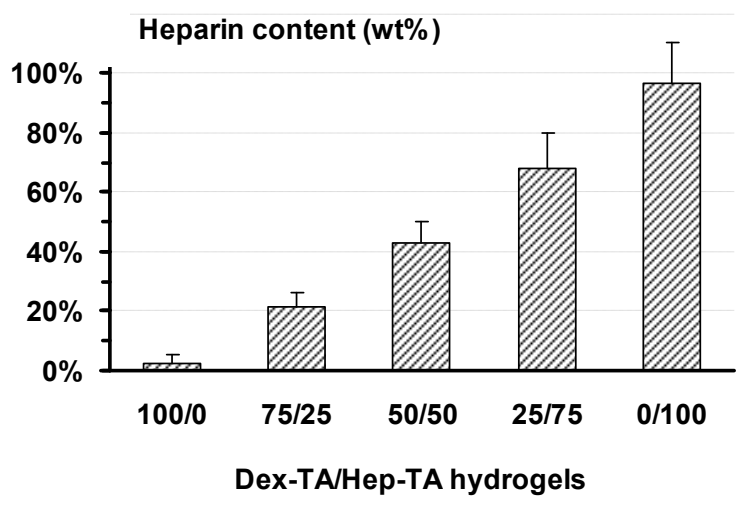

Figure 7.3. Heparin content (wt $\%$ in dry gel mass) of extracted $20 \mathrm{wt} \%$ Dex-TA/Hep-TA hydrogels.

The degrees of swelling of $20 \mathrm{wt} \%$ hydrogels at different Dex-TA/Hep-TA weight ratios are shown in Figure 7.4. The Hep-TA hydrogels had a higher degree of swelling than the Dex-TA hydrogel (16.7 vs. 4.9). Increasing the heparin content in Hep-TA in Dex-TA/Hep- 
TA hydrogels also showed an increase in the swelling values of the hydrogel $(p<0.05)$. This high degree of swelling can be either due to the low crosslinking density or due to the electrostatic repulsive force between negatively-charged carboxylic acid and sulfate groups in the heparin at the physiological $\mathrm{pH}$ of 7.4.

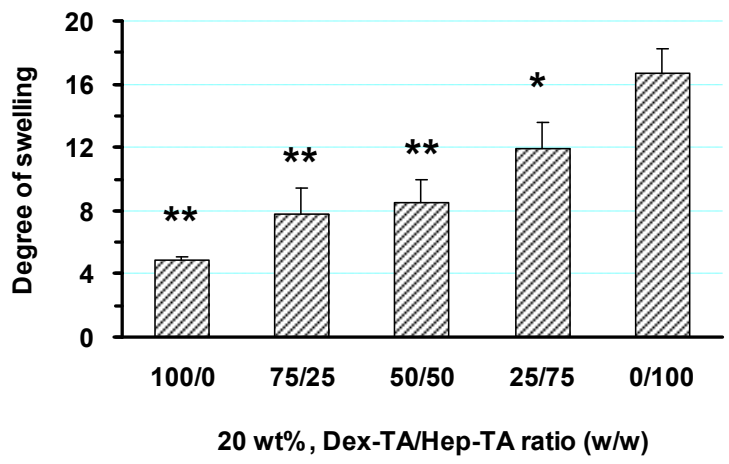

Figure 7.4. The degree of swelling of Dex-TA/Hep-TA hydrogels. $\left(\mathrm{n}=3, * p<0.05 ;{ }^{* *} p<0.01\right.$ vs. $0 / 100$ gel)

Rheological measurements were performed to study the influence of the heparin content on the mechanical properties of the hydrogels. The hydrogel prepared from Hep-TA at a concentration of $20 \mathrm{wt} \%$ showed a low storage modulus of $3.6 \mathrm{kPa}$. The storage moduli of the Dex-TA/Hep-TA hydrogels increased from 3.6 to $48 \mathrm{kPa}$ with decreasing ratio in the gels (Figure 7.5). This shows that heparin containing gels with an appropriate modulus can be obtained by selecting the proper ratio of Dex-TA and Hep-TA to form the gels.

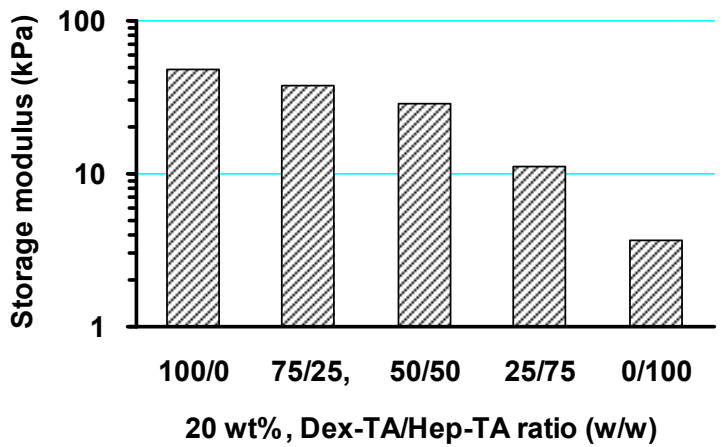

Figure 7.5. Storage moduli of Dex-TA/Hep-TA hydrogels. The concentrations of HRP and $\mathrm{H}_{2} \mathrm{O}_{2}$ were $0.05 \mathrm{mg} / \mathrm{mL}$ and $0.01 \mathrm{M}$, respectively $(\mathrm{n}=1)$.

The frequency and strain sweeps of $20 \mathrm{wt} \%$ Dex-TA/Hep-TA hydrogels are presented in Figure 7.6. From the frequency sweep experiments it is found that the hydrogels are elastic and the storage modulus is not dependent on the frequency (Figure 7.6a). The strain sweep tests show that the storage moduli of the hydrogels with a high Dex-TA/Hep-TA weight 
ratio $(50 / 50$ or $100 / 0)$ were strain independent within a strain range of $0.1-1 \%$ (Figure $7.6 b$ ). As the strain increased to $2 \%$ or even higher values, the storage moduli decreased, indicating a breakdown of the network. However, the moduli of the hydrogels with a DexTA/Hep-TA weight ratio of 25/75 and 0/100 appeared independent of the strain up to $10 \%$, suggesting that these hydrogels are quite robust. Moreover, the $G^{\prime}$ decreased more rapidly with increasing strain at a higher Dex-TA content.

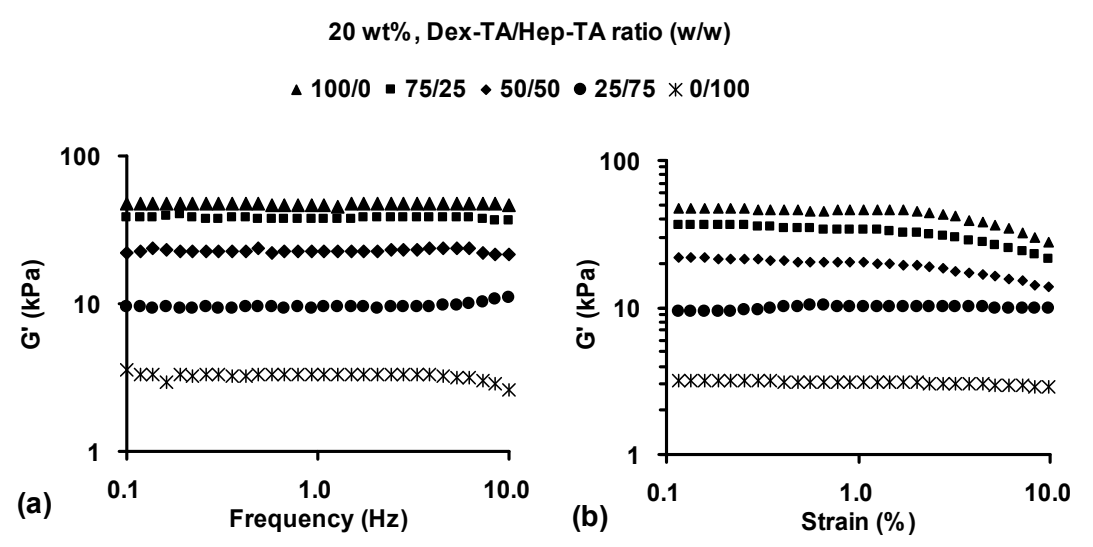

Figure 7.6. (a) Frequency sweep and (b) strain sweep of Dex-TA/Hep-TA hydrogels.

\subsubsection{Cell viability and proliferation}

Dex-TA and Dex-TA/Hep-TA hydrogels at Dex-TA/Hep-TA weight ratios of 100/0, $72 / 25,50 / 50$ and 25/75 were chosen for the biological studies. This selection was made because these gels have a shorter gelation time and a higher storage modulus compared to Hep-TA hydrogels. The biocompatibility of $20 \mathrm{wt} \%$ hydrogels was analyzed by a Livedead assay after culturing for 3, 7 and 14 days, in which live cells fluoresce green and dead cells fluoresce red. At day 3, about $10-15 \%$ dead cells were present in the Dex-TA hydrogels, while over 95\% chondrocytes remained viable in the Dex-TA/Hep-TA and HepTA hydrogels (Figure 7.7). The relatively low cell viability observed for the Dex-TA hydrogel may be attributed to the high crosslinking density of the hydrogels [37], and/or a limited nutrients supply resulting from the low degree of swelling in medium (Figure 7.8).

A CyQuant DNA assay was used to determine the viability and proliferation of chondrocytes inside the Dex-TA/Hep-TA hydrogels up to 21 days (Figure 7.9). In general, the DNA content increased in time for the hydrogels at different Dex-TA/Hep-TA ratios from $100 / 0$ to $25 / 75$, indicative of cell proliferation. The chondrocytes in the hydrogels containing both Dex-TA and Hep-TA conjugates proliferated better than in Dex-TA hydrogels at all time intervals. This can be ascribed to both the enhancement of nutrient exchange in these highly swollen hydrogels and the potential biological role of heparin on 
the chondrocytes. The 50/50 Dex-TA/Hep-TA hydrogel revealed the best proliferation of chondrocytes compared to the others $(25 / 75$ and $75 / 25)$, which suggested that there exists an optimal Dex-TA/Hep-TA ratio for cell proliferation.

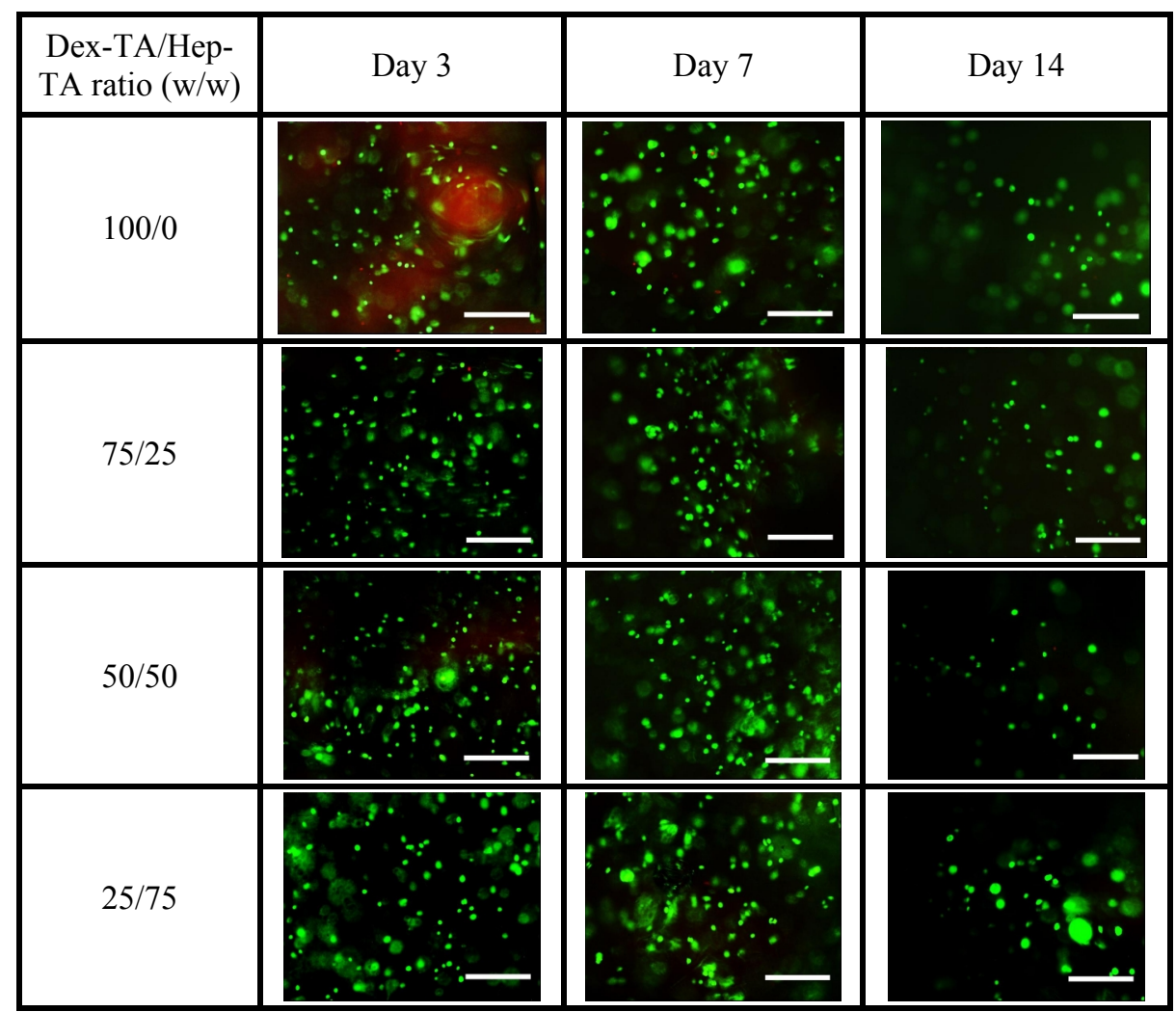

Figure 7.7. Live-dead assay showing the chondrocytes incorporated in Dex-TA/Hep-TA hydrogels after 3,7 and 14 days in culture. Cell density is $5 \times 10^{6}$ cells $/ \mathrm{mL}$ gel. Scale bar: $200 \mu \mathrm{m}$.

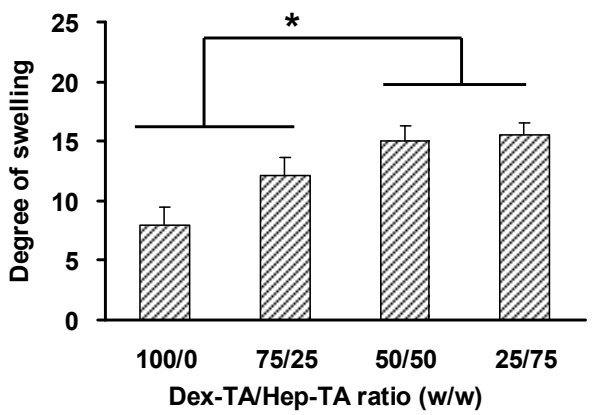

Figure 7.8. The degree of swelling of $20 \mathrm{wt} \%$ Dex-TA/Hep-TA hydrogels containing chondrocytes after incubating for 3 days in vitro. Cell seeding density: $5 \times 10^{6}$ cells $/ \mathrm{mL} .(\mathrm{n}=3, * p<0.05)$. 


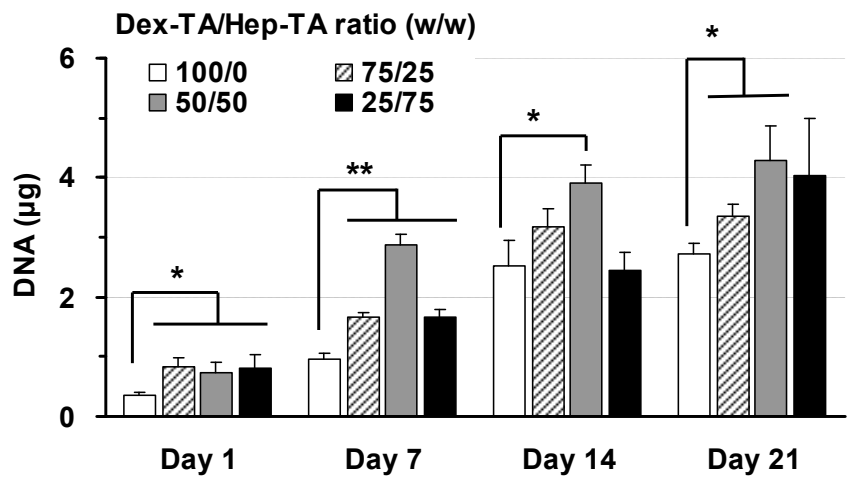

Figure 7.9. DNA content of $20 \mathrm{wt} \%$ Dex-TA/Hep-TA hydrogels containing chondrocytes after in vitro culturing for $1,7,14$ and 21 days. Cell seeding density: $5 \times 10^{6}$ cells $/ \mathrm{mL}$. $(* p<0.05, * * p<0.01)$.

\subsubsection{Matrix production}

The abilities of chondrocytes to maintain a chondrocytic phenotype and to form cartilaginous tissue in vitro were evaluated after culturing in differentiation medium up to 21 days. Gene expression of collagen type I \& II and aggrecan were analyzed using RTPCR. It is shown that the gene expression levels were dependent on the composition of the hydrogels (Figure 7.10). The chondrocytes in Dex-TA/Hep-TA hydrogels maintained significantly higher levels of aggrecan and type II collagen gene expressions compared to those in Dex-TA hydrogels $(p<0.01)$. In contrast, Dex-TA hydrogels expressed collagen transcripts mainly of type I instead of type II, suggesting a loss of chondrocyte phenotype. Additionally, the heparin present in the hydrogels was found to up-regulate aggrecan and collagen type II mRNA levels in a content-dependent manner. For example, it was observed that aggrecan gene expression was maximized when the Dex-TA/Hep-TA weight ratio was 50/50 while collagen type II gene expression was highest for hydrogels with Dex-TA/HepTA weight ratio of $50 / 50$ and $25 / 75$.

Toluidine blue was used to stain deposited proteoglycans by chondrocytes in DexTA/Hep-TA hydrogels cultured for 21 days (Figure 7.11). Proteoglycans staining purple/blue were observed in Dex-TA hydrogels. Unfortunately, in Dex-TA/Hep-TA hydrogels, due to the presence of heparin, which is stained positive using toluidine blue, the gels showed intense background staining. Thus, immunofluorescence staining of chondroitin sulfate and collagen type II was used to detect the accumulation of newly formed cartilaginous matrix. The results confirmed the production of cartilaginous matrix in Dex-TA/Hep-TA hydrogels (Figure 7.12 and 7.13). The 50/50 and 25/75 Dex-TA/HepTA hydrogels showed a more intense staining of chondroitin sulfate and collagen type II than the $100 / 0$ and $75 / 25$ gels. In addition, chondroitin sulfate in $100 / 0$ and $75 / 25$ hydrogels 
was only present in the pericellular region, while in 50/50 and 25/75 hydrogels, the chondroitin sulfate was evenly distributed over the pericellular and extracellular region. Since the 50/50 and 25/75 Dex-TA/Hep-TA hydrogels showed a degree of swelling of 16, statistically higher than 100/0 and 75/25 gels ( 9 and 13, respectively) (Figure 7.8), 50/50 and 25/75 hydrogels may induce more facilitated proteoglycan diffusion into the extracellular regions, thereby resulting in a more even distribution. This observation is similar to that observed for PEG-based hydrogels. These materials induced facilitated proteoglycan diffusion into the extracellular regions of the scaffolds at a degree of swelling higher than 9.3 [38].

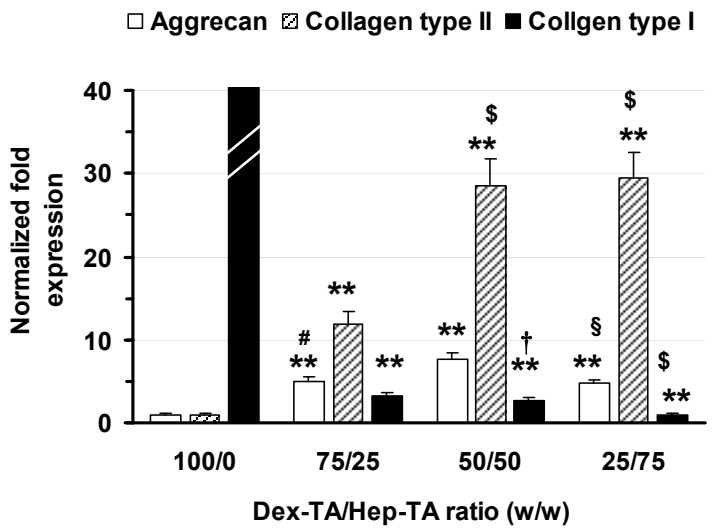

Figure 7.10. Real-time PCR of cartilage specific markers (aggrecan and collagen type I \& II) by incorporated chondrocytes in $20 \mathrm{wt} \%$ Dex-TA/Hep-TA hydrogels after 21 days in culture. The expressions of collagen type I \& II and aggrecan were normalized to the expression of the housekeeping gene GAPDH. ( $* * p<0.01$ vs. 100/0 gel; \# $p<0.05$ vs. 50/50 gel; $\S p<0.01 v s$. 50/50 gel; $\$ p<0.01$ vs. $75 / 25$ gel; $\uparrow p<0.05$ vs. $75 / 25$ gel).
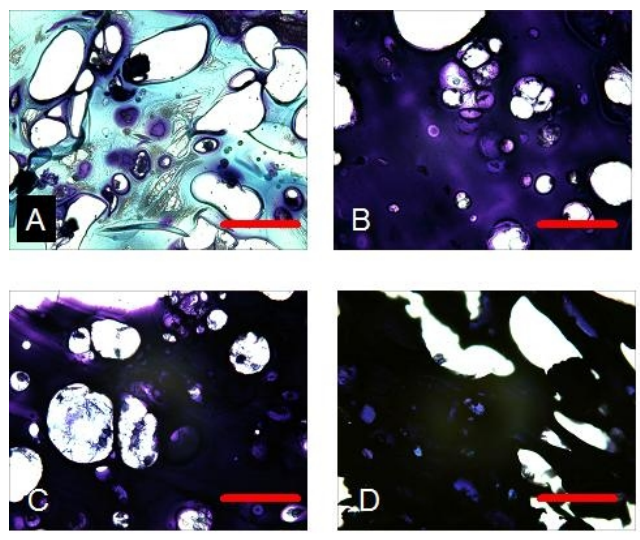

Figure 7.11. Toluidine blue staining of the hydrogels with Dex-TA/Hep-TA weight ratios of 100/0 (A), 75/25 (B), 50/50 (C) and 25/75 (D) after culturing for 21 days. Scale bar: $100 \mu \mathrm{m}$. 

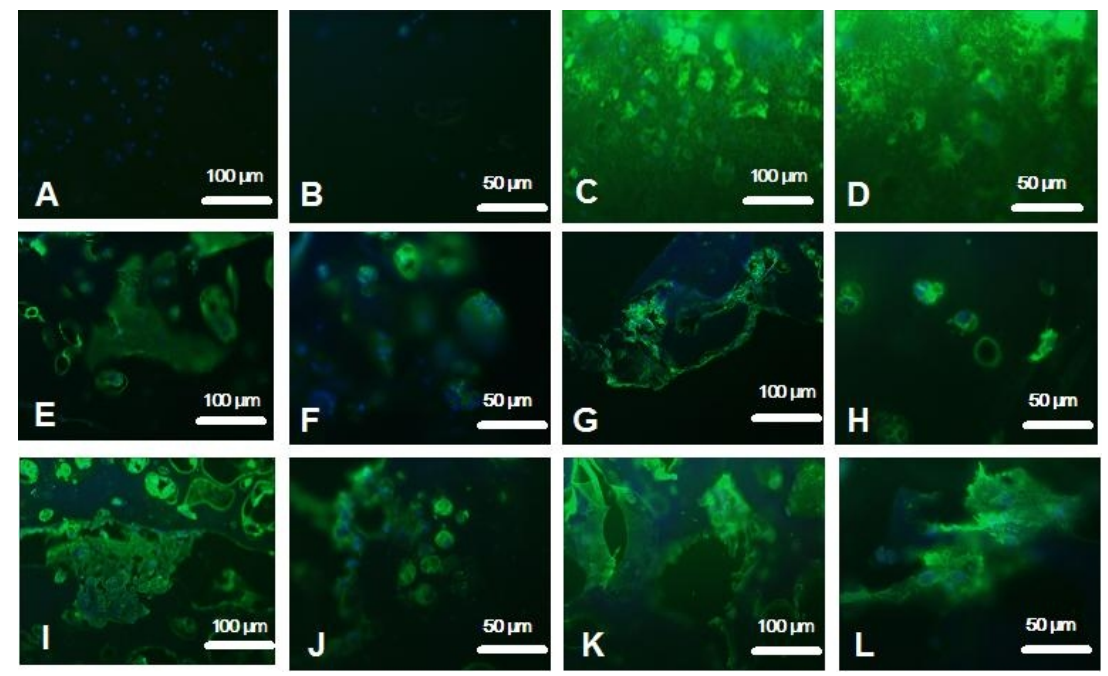

Figure 7.12. Chondroitin sulfate immunofluorescent staining of the Dex-TA/Hep-TA hydrogels containing chondrocytes after in vitro culturing for 21 days. Different Dex-TA/Hep-TA ratios: 100/0 (E and F), 75/25 ( $\mathrm{G}$ and $\mathrm{H}$ ), 50/50 (I and J) and 25/75 (K and L). The section of bovine cartilage without or with incubation with primary antibodies was used as a negative (A and B) and positive (C and D) control, respectively.
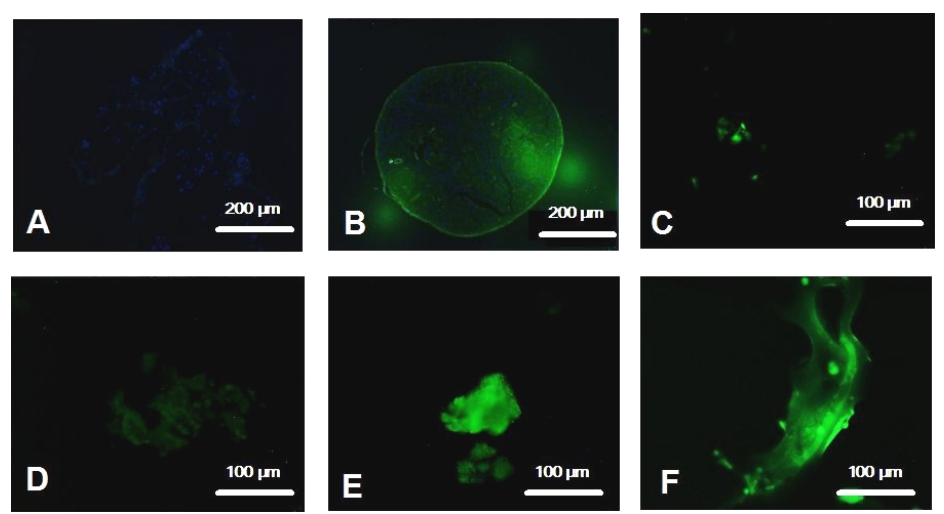

Figure 7.13. Collagen type II immunofluorescent staining of the Dex-TA/Hep-TA hydrogels containing chondrocytes after in vitro culturing for 21 days. Different Dex-TA/Hep-TA ratios: 100/0 (C), 75/25 (D), 50/50 (E) and 25/75 (F). The section of pellet human chondrocytes at 21 days without or with incubation with primary antibodies was used as a negative (A) and positive (B) control, respectively.

The total collagen content was determined by a hydroxyproline assay, in which hydroxyproline makes up $12.5 \mathrm{wt} \%$ of collagen [35]. The total collagen accumulation increased in time and reached the highest value at day 21 at all gel compositions (Figure 7.14a). Hydrogels comprising both Dex-TA and Hep-TA showed significantly higher collagen production compared to Dex-TA hydrogels $(p<0.05)$. Moreover, the highest 
collagen production was obtained from the 50/50 and 25/75 Dex-TA/Hep-TA hydrogel. This is consistent with the results for collagen type II staining and the RT-PCR findings for collagen type II gene expression. When normalized to the DNA content, the total collagen content was statistically similar in all five systems at each time point (Figure 7.14b).

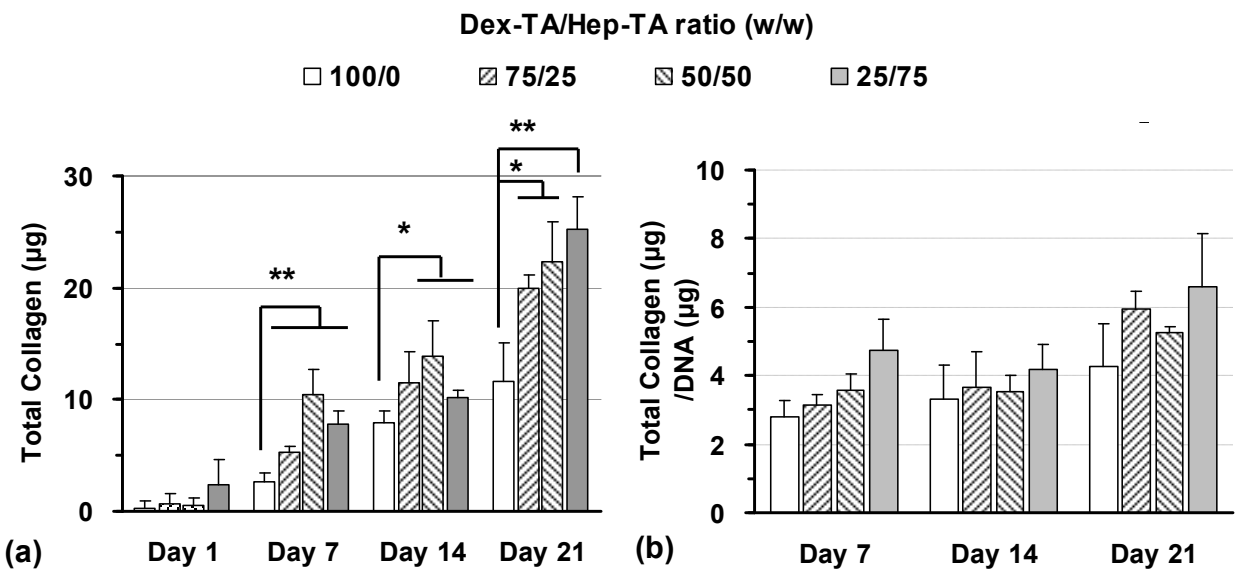

Figure 7.14. (a) Total collagen and (b) total collagen normalized to the DNA content in DexTA/Hep-TA hydrogels containing chondrocytes after in vitro culturing for 1, 7, 14 and 21 days. Cell seeding density: $5 \times 10^{6}$ cells $/ \mathrm{mL}$. $(* p<0.05, * * p<0.01)$.

The improvement of chondrocyte performance in the Dex-TA/Hep-TA hydrogels with respect to Dex-TA hydrogels may be due to several reasons. First, heparin can interact with ECM components such as fibronectin and collagen via either electrostatic or specific interactions. Through these interactions, heparin can modulate cell signaling, cell-matrix interactions and matrix assembly [30, 39, 40]. Second, the incorporation of negatively charged heparin moieties into Dex-TA hydrogels contributes to the increase in hydrogel swelling and the decrease of the storage modulus. This may result in a gel network with appropriate crosslinking density which allows good transportation of nutrients to the chondrocytes. Third, heparin can bind growth factors supplemented in medium or secreted by chondrocytes such as TGF- $\beta 3$. TGF- $\beta 3$ is a protein that regulates many aspects of cellular activity, including cell proliferation, differentiation, and ECM deposition in the process of cartilage regeneration [41, 42]. Thus, the hydrogel system serves as a reservoir for these crucial proteins, creating a biomimetic microenvironment favorable for chondrogenesis.

\subsection{Conclusions}

We have shown that injectable hydrogels containing a naturally occurring glycosaminoglycan, heparin, can be prepared via enzymatic crosslinking of Dex-TA and 
Hep-TA conjugates. The results showed that incorporation of heparin into the hydrogels greatly improved the hydrogel swelling properties, which is favorable for good nutrient transportation for cell culture. On the other hand, the combination of Dex-TA and Hep-TA afforded hydrogels with faster gelation and a higher storage modulus compared to Hep-TA hydrogels. Bovine chondrocytes were incorporated in these gels during gelation. The results showed that the hydrogel with a Dex-TA/Hep-TA weight ratio of 50/50 induced the best chondrocyte viability and proliferation, and an enhanced matrix production as compared to the hydrogels from Dex-TA conjugates. These results indicate that Dex-TA/Hep-TA hydrogels have a high potential as matrices for cartilage tissue engineering.

\subsection{References}

[1] Chung C, Burdick JA. Engineering Cartilage Tissue. Adv. Drug Deliver. Rev. 2008;60: 243-262.

[2] Tuli R, Li W-J, Tuan RS. Current State of Cartilage Tissue Engineering. Arthritis. Res. Ther. 2003;5: 235-238.

[3] Kretlow JD, Klouda L, Mikos AG. Injectable Matrices and Scaffolds for Drug Delivery in Tissue Engineering. Adv. Drug Deliver. Rev. 2007;59: 263-273.

[4] Van Tomme SR, Storm G, Hennink WE. In Situ Gelling Hydrogels for Pharmaceutical and Biomedical Applications. Int. J. Pharm. 2008;355: 1-18.

[5] Yu L, Ding J. Injectable Hydrogels as Unique Biomedical Materials. Chem. Soc. Rev. 2008;37: 1473-1481.

[6] Wang D-A, Varghese S, Sharma B, Strehin I, Fermanian S, Gorham J, Fairbrother DH, Cascio B, and Elisseeff JH. Multifunctional Chondroitin Sulphate for Cartilage Tissue-Biomaterial Integration. Nat. Mater. 2007;6: 385-392.

[7] Li Q, Wang J, Shahani S, Sun DDN, Sharma B, Elisseeff JH, and Leong KW. Biodegradable and Photocrosslinkable Polyphosphoester Hydrogel. Biomaterials 2006;27: 1027-1034.

[8] Sontjens SHM, Nettles DL, Carnahan MA, Setton LA, Grinstaff MW. Biodendrimer-Based Hydrogel Scaffolds for Cartilage Tissue Repair. Biomacromolecules 2006;7: 310-316.

[9] Tan H, Chu CR, Payne KA, Marra KG. Injectable in Situ Forming Biodegradable Chitosan-Hyaluronic Acid Based Hydrogels for Cartilage Tissue Engineering. Biomaterials 2009;30: 2499-2506.

[10] Kim M, Shin Y, Hong B, Kim Y-J, Chun J-S, Tae G, and Kim YH. In Vitro Chondrocyte Culture in a Heparin-Based Hydrogel for Cartilage Regneration. Tissue Eng. C In press.

[11] Park Y, Lutolf MP, Hubbell JA, Hunziker EB, Wong M. Bovine Primary Chondrocyte Culture in Synthetic Matrix Metalloproteinase-Sensitive Poly(ethylene glycol)-Based Hydrogels as a Scaffold for Cartilage Repair. Tissue Eng. 2004;10: 515-522.

[12] Jin R, Moreira Teixeira LS, Dijkstra PJ, Karperien M, Zhong Z, Feijen J. Fast inSitu Formation of Dextran-Tyramine Hydrogels for in Vitro Chondrocyte Culturing. J. Control. Release 2008; 132: e24-e26.

[13] Jin R, Hiemstra C, Zhong Z, Feijen J. Enzyme-Mediated Fast in Situ Formation of Hydrogels from Dextran-Tyramine Conjugates. Biomaterials 2007;28: 2791-2800. 
[14] Jin R, Moreira Teixeira LS, Dijkstra PJ, Karperien M, van Blitterswijk CA, Zhong ZY, and Feijen J. Injectable Chitosan-Based Hydrogels for Cartilage Tissue Engineering. Biomaterials 2009;30: 2544-2551.

[15] Darr A, Calabro A. Synthesis and Characterization of Tyramine-Based Hyaluronan Hydrogels. J. Mater. Sci.: Mater. M. 2009;20: 33-44.

[16] Lee F, Chung JE, Kurisawa M. An Injectable Enzymatically Crosslinked Hyaluronic Acid-Tyramine Hydrogel System with Independent Tuning of Mechanical Strength and Gelation Rate. Soft Matter. 2008;4: 880-887.

[17] Lee F, Chung JE, Kurisawa M. An Injectable Hyaluronic Acid-Tyramine Hydrogel System for Protein Delivery. J. Control. Release 2009;134: 186-193.

[18] Sakai S, Yamada Y, Zenke T, Kawakami K. Novel Chitosan Derivative Soluble at Neutral Ph and in-Situ Gellable Via Peroxidase-Catalyzed Enzymatic Reaction. J. Mater. Chem. 2009;19: 230-235.

[19] Sakai S, Hirose K, Taguchi K, Ogushi Y, Kawakami K. An Injectable, in Situ Enzymatically Gellable, Gelatin Derivative for Drug Delivery and Tissue Engineering. Biomaterials 2009;30: 3371-3377.

[20] Jin R, Teixeira LSM, Dijkstra PJ, Zhong Z, Blitterswijk CAv, Karperien M, and Feijen J. Enzymatically Crosslinked Dextran-Tyramine Hydrogels as Injectable Scaffolds for Cartilage Tissue Engineering. Chapter 5.

[21] Casu B. Structure and Biological Activity of Heparin. Adv. Carbohydr. Chem. Biochem. 1985;43: 51-134.

[22] Capila I, Linhardt RJ. Heparin-Protein Interactions. Angew. Chem. Int. Edit. 2002;41: 390-412.

[23] Sasisekharan R, Venkataraman G. Heparin and Heparan Sulfate: Biosynthesis, Structure and Function. Curr. Opin. Chem. Biol. 2000;4: 626-631.

[24] Benoit DSW, Anseth KS. Heparin Functionalized PEG Gels That Modulate Protein Adsorption for Hmsc Adhesion and Differentiation. Acta Biomater. 2005;1: 461-470.

[25] Benoit DSW, Durney AR, Anseth KS. The Effect of Heparin-Functionalized PEG Hydrogels on Three-Dimensional Human Mesenchymal Stem Cell Osteogenic Differentiation. Biomaterials 2007;28: 66-77.

[26] Cai S, Liu Y, Zheng Shu X, Prestwich GD. Injectable Glycosaminoglycan Hydrogels for Controlled Release of Human Basic Fibroblast Growth Factor. Biomaterials 2005;26: 6054-6067.

[27] Nie T, Baldwin A, Yamaguchi N, Kiick KL. Production of Heparin-Functionalized Hydrogels for the Development of Responsive and Controlled Growth Factor Delivery Systems. J. Control. Release 2007;122: 287-296.

[28] Lih E, Yoon Ki J, Jin Woo B, Ki Dong P. An in Situ Gel-Forming HeparinConjugated PLGA-PEG-PLGA Copolymer. J. Bioact. Compat. Pol. 2008;23: 444457.

[29] Tyagi SC, Kumar S, Katwa L. Differential Regulation of Extracellular Matrix Metalloproteinase and Tissue Inhibitor by Heparin and Cholesterol in Fibroblast Cells. J. Mol. Cell. Cardiol. 1997;29: 391-404.

[30] Luo W, Shitaye H, Friedman M, Bennett CN, Miller J, MacDougald OA, and Hankenson KD. Disruption of Cell-Matrix Interactions by Heparin Enhances Mesenchymal Progenitor Adipocyte Differentiation. Exp. Cell Res. 2008;314: 33823391. 
[31] Tan H, Lao L, Wu J, Gong Y, Gao C. Biomimetic Modification of Chitosan with Covalently Grafted Lactose and Blended Heparin for Improvement of in Vitro Cellular Interaction. Polym. Advan. Technol. 2008;19: 15-23.

[32] Hinrichs WLJ, ten Hoopen HWM, Wissink MJB, Engbers GHM, Feijen J. Design of a New Type of Coating for the Controlled Release of Heparin. J. Control. Release 1997;45: 163-176.

[33] Wissink MJB, Beernink R, Pieper JS, Poot AA, Engbers GHM, Beugeling T, van Aken WG, and Feijen J. Immobilization of Heparin to EDC/NHS-Crosslinked Collagen. Characterization and in Vitro Evaluation. Biomaterials 2001;22: 151-163.

[34] Jin R, Teixeira LSM, Krouwels A, Dijkstra PJ, Blitterswijk CAv, Karperien M, and Feijen J. Synthesis and Characterization of Hyaluronic Acid-PEG Hydrogels via Michael Addition: An Injectable Biomaterial for Cartilage Repair. Acta Biomater. Submitted.

[35] Edwards CA, O'Brien Jr WD. Modified Assay for Determination of Hydroxyproline in a Tissue Hydrolyzate. Clin. Chim. Acta 1980;104: 161-167.

[36] Sofia SJ, Singh A, Kaplan DL. Peroxidase-Catalyzed Crosslinking of Functionalized Polyaspartic Acid Polymers. J. Macromol. Sci. 2002;A39: 1151-1181.

[37] Burdick JA, Anseth KS. Photoencapsulation of Osteoblasts in Injectable RgdModified PEG Hydrogels for Bone Tissue Engineering. Biomaterials 2002;23: 43154323.

[38] Bryant SJ, Anseth KS. Hydrogel Properties Influence ECM Production by Chondrocytes Photoencapsulated in Poly(Ethylene Glycol) Hydrogels. J. Biomed. Mater. Res. 2002;59: 63-72.

[39] Woods A, Couchman JR. Syndecans: Synergistic Activators of Cell Adhesion. Trends Cell Biol. 1998;8: 189-192.

[40] Beauvais D, Rapraeger A. Syndecans in Tumor Cell Adhesion and Signaling. Reprod. Biol. Endocrin. 2004;2: 3.

[41] Yun K, Moon HT. Inducing Chondrogenic Differentiation in Injectable Hydrogels Embedded with Rabbit Chondrocytes and Growth Factor for Neocartilage Formation. J. Biosci. Bioeng. 2008;105: 122-126.

[42] Tang QO, Shakib K, Heliotis M, Tsiridis E, Mantalaris A, Ripamonti U, and Tsiridis E. TGF-B3: A Potential Biological Therapy for Enhancing Chondrogenesis. Exp. Opin. Biol. Ther. 2009;9: 689-701. 


\section{Chapter 8}

\section{Enzymatically-Crosslinked Injectable Hydrogels Based on Biomimetic Dextran-Hyaluronic Acid Conjugates for Cartilage Tissue Engineering *}

Novel polysaccharide hybrids consisting of hyaluronic acid (HA) grafted with a dextrantyramine conjugate (Dex-TA) were synthesized and investigated as injectable biomimetic hydrogels for cartilage tissue engineering. The design of these hybrids (denoted as HA-gDex-TA) is based on the molecular structure of proteoglycans present in the extracellular matrix of native cartilage. Hydrogels of HA-g-Dex-TA were rapidly formed within 2 min via enzymatic crosslinking of the tyramine residues in the presence of horseradish peroxidase and hydrogen peroxide. The gelation time, equilibrium swelling and storage modulus could be adjusted by varying the degree of substitution of tyramine residues and polymer concentration. Bovine chondrocytes incorporated in the HA-g-Dex-TA hydrogels remained viable, as shown by the Live-dead assay. Moreover, enhanced chondrocyte proliferation and matrix production were observed in the HA-g-Dex-TA hydrogels compared to Dex-TA hydrogels. These results suggest that HA-g-Dex-TA hydrogels have a high potential as injectable scaffolds for cartilage tissue engineering.

\subsection{Introduction}

Tissue engineering represents a promising approach in the treatment of damaged cartilage. This approach generally involves the use of three-dimensional (3-D) scaffolds, which can support the growth, proliferation and differentiation of incorporated chondrocytes and/or progenitor cells. Because hydrogels are 3-D elastic networks having high water content, they mimic hydrated native cartilage tissue and are considered suitable scaffolds for cartilage tissue engineering.

Injectable hydrogels are highly desirable in clinical applications since they can be applied via a minimally invasive procedure. After injection in the form of a solution, the precursor gels in situ and fills the irregularly shaped defect. Meanwhile, cells and/or bioactive molecules can be easily incorporated. Injectable hydrogels can be obtained via a chemical crosslinking method, for example, photopolymerization. In this approach, a

\footnotetext{
* This chapter is in preparation: Rong Jin, Liliana S. Moreira Teixeira, Pieter J. Dijkstra, Clemens A. van Blitterswijk, Marcel Karperien and Jan Feijen, Biomaterials.
} 
solution of a vinyl-containing polymer converts into a gel by exposure to visible or ultraviolet light in the presence of photo-initiators [1-7]. Photo-crosslinked hydrogels generally have a short gelation time and are chemically stable and mechanically strong. However, cytotoxic photo-initiators and UV light required for the photopolymerization reaction may induce cell death [8,9]. In addition, the reaction may be exothermic, which may harm the incorporated cells and induce local necrosis [10]. Alternatively, injectable hydrogels can be generated via Michael type addition reactions of thiol groups to (meth)acrylate, (meth)acrylamide, or vinyl sulfone groups [11-16]. In this approach, thiolbearing bioactive molecules such as adhesion peptides and matrix metalloproteinase substrate peptides can be relatively easily incorporated creating biomimetic hydrogels [15, 17]. However, in general the rate of gelation induced by a Michael type addition reaction was found to be too slow ( $\sim 30$ min or longer) $[14,18]$, which hampers clinical applications. Recently, an enzymatic crosslinking method, which induces fast gelation, has been developed [19-24]. We previously reported on dextran- and chitosan-based injectable hydrogels based on this approach [20, 23]. Crosslinking takes place via an oxidative coupling reaction of phenol moieties in the presence of horseradish peroxidase (HRP) and $\mathrm{H}_{2} \mathrm{O}_{2}$. These hydrogels were formed rapidly within minutes. They showed good biocompatibility and support chondrocyte survival and differentiation [23, 25, 26].

Various natural and synthetic polymers, as well as combinations thereof have been used for the preparation of injectable hydrogels [27-29]. Among these materials, polysaccharides, such as hyaluronic acid, dextran, and chitosan, have received wide-spread interest particularly for applications in cartilage tissue engineering [30]. This is based on the presence of large quantities of glycosaminoglycans (GAGs), such as hyaluronic acid, heparan sulfate, and chondroitin sulfate, in the extracellular matrix (ECM) of native cartilage. It has been demonstrated that polysaccharide-based hydrogels are biocompatible and capable of maintaining the phenotype of chondrocytes incorporated. Gel/cell constructs show accumulation of a newly-formed ECM matrix over time in vitro and/or in vivo [25, 31, 32]. Additionally, polysaccharides have abundant functional groups such as hydroxyl groups, amino groups and/or carboxylic acid groups, amenable to various types of chemical modifications. This offers the opportunity to introduce crosslinkable or bioactive moieties into polysaccharide precursors of hydrogels. In this way, biofunctional scaffolds can be created to modulate cell adhesion, migration, proliferation and differentiation as well as direct new tissue formation [33, 34].

In our current research, we present a first step towards a strategy to prepare biomimetic polysaccharide-based injectable hydrogels for cartilage tissue engineering. Novel polysaccharide hybrids were designed, in which tyramine-conjugated dextrans were grafted onto hyaluronic acid (HA). These polysaccharide hybrids resemble the macromolecular 
structure of proteoglycans (Figure 8.1) present in the ECM of native cartilage. The tyramine residues enable subsequent enzymatic crosslinking of the hybrid molecules in the presence of HRP and $\mathrm{H}_{2} \mathrm{O}_{2}$. HA was chosen because it is an important component of the ECM in cartilage tissue. HA interacts with chondrocytes through surface receptors like CD44, enabling modulation of cell activity [35-37]. In previous research, tyramine-conjugated dextrans showed a fast gelation and good mechanical properties using HRP-mediated crosslinking [20]. In this study, a hybrid of HA and dextran-tyramine (Dex-TA) conjugates would afford a biomimetic hydrogel. We hypothesized that the incorporation of HA would improve the performance of Dex-TA gels in cartilage tissue engineering. These biomimetic hydrogels may provide a supportive environment for chondrocyte proliferation and differentiation as well as matrix deposition. In this chapter, we describe the synthesis and characterization of polysaccharide hybrids from hyaluronic acid and dextran-tyramine conjugates. The hydrogels were investigated in terms of their gelation times, storage moduli and enzymatic degradation properties. Besides, bovine articular chondrocytes were encapsulated inside the hydrogels in vitro to determine cell survival and to assess matrix production.

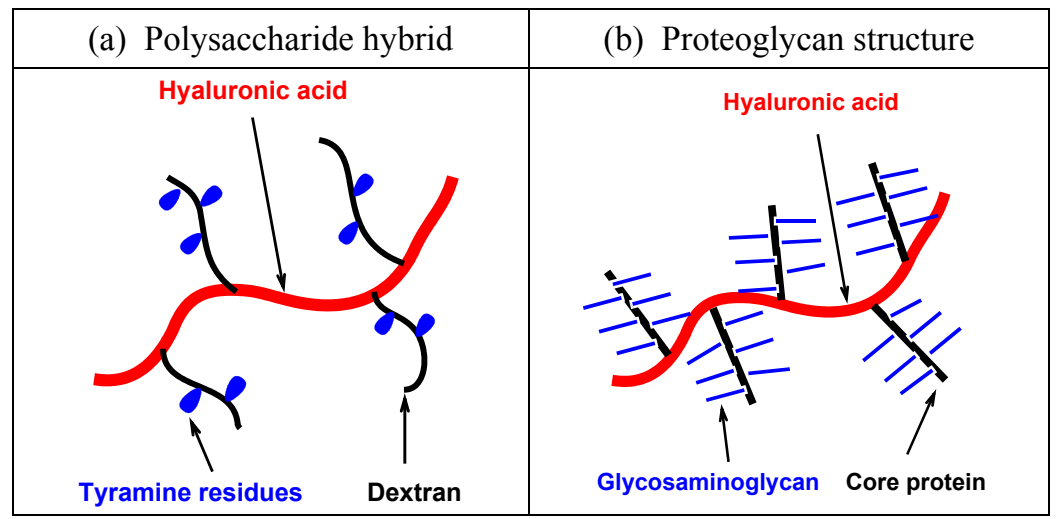

Figure 8.1. Chemical structure of (a) polysaccharide hybrids based on hyaluronic acid and dextrantyramine conjugates and (b) structure of a proteoglycan.

\subsection{Materials and methods}

Materials. Dextran $\left(\mathrm{M}_{\mathrm{r}}=6,000\right.$, Fluka $)$ was dried by azeotropic distillation from dry toluene. $N$-Boc-1,4-diaminobutane, $p$-nitrophenyl chloroformate (PNC), $N$-ethyl- $N$ '-(3dimethylaminopropyl) carbodiimide hydrochloride (EDAC) and sodium cyanoborohydride $\left(\mathrm{NaBH}_{3} \mathrm{CN}\right)$ were purchased from Fluka. Tyramine (TA), 4-morpholino ethanesulfonic acid (MES), trifluoroacetic acid (TFA), hydrogen peroxide $\left(\mathrm{H}_{2} \mathrm{O}_{2}\right)$, pyridine (anhydrous), deuterium oxide $\left(\mathrm{D}_{2} \mathrm{O}\right)$, phosphorus pentoxide, hyaluronidase (HAse, $300 \mathrm{U} / \mathrm{mg}$ ), lithium chloride $(\mathrm{LiCl})$ and N-hydroxysuccinimide (NHS) were obtained from Aldrich-Sigma. 
Horseradish peroxidase (HRP, type VI, 300 purpurogallin unit/mg solid) was purchased from Aldrich and used without further purification. Sodium hyaluronate $(15-30 \mathrm{~kg} / \mathrm{mol}$, laboratory grade) was purchased from CPN Shop. $N, N$-Dimethylformamide (DMF) was

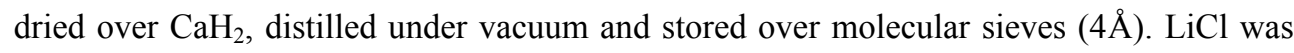
dried at $80{ }^{\circ} \mathrm{C}$ under vacuum over phosphorus pentoxide. All other solvents were used as received. Dextran-tyramine (denoted as Dex-TA) conjugates were prepared as reported previously [20].

Synthesis of amine-terminated dextran-tyramine conjugates. Amine-terminated dextran-tyramine conjugates (denoted as Dex-TA- $\mathrm{NH}_{2}$ ) were synthesized by a two-step procedure. Dex-TA conjugates were first reacted with $N$-Boc-1,4-diaminobutane and sodium cyanoborohydride to end functionalize the dextran. The protecting $t$ butyloxycarbonyl group was removed by reaction with TFA. Typically, Dex-TA (5 g), dissolved in $25 \mathrm{~mL}$ of deionized water, was treated with $N$-Boc-1,4-diaminobutane $(3.9 \mathrm{~g}$, $21 \mathrm{mmol})$ and stirred for $2 \mathrm{~h}$ under nitrogen. $\mathrm{NaBH}_{3} \mathrm{CN}(3.9 \mathrm{~g}, 63 \mathrm{mmol})$ was then added in portions, and the reaction mixture was stirred at room temperature. After $3 \mathrm{~d}$, the solution was neutralized with $1 \mathrm{M} \mathrm{HCl}$ solution to $\mathrm{pH}$ 7. The Boc-amine-terminated Dex-TA (denoted as Dex-TA-NH-Boc) was purified by ultrafiltration (MWCO 1000) and isolated as a white foam after freeze-drying. Yield: $4.4 \mathrm{~g}(88 \%) .{ }^{1} \mathrm{H}$ NMR $\left(\mathrm{D}_{2} \mathrm{O}\right): \delta$ 1.3-1.4 (Boc, $\left.\mathrm{C}\left(\mathrm{CH}_{3}\right)\right)$, 1.4-1.7 (-NH- $\left.\mathrm{CH}_{2}-\mathrm{C}_{2} \underline{\mathrm{H}}_{4}-\mathrm{CH}_{2}-\mathrm{NH}-\right), 2.6$ and $3.0\left(-\mathrm{C}_{2} \underline{\mathrm{H}}_{4}-\mathrm{C}_{6} \mathrm{H}_{4}-\mathrm{OH}\right.$ and $-\mathrm{NH}-\underline{\mathrm{C}}_{2}-$ $\mathrm{C}_{2} \mathrm{H}_{4}-\underline{\mathrm{C}}_{2}-\mathrm{NH}-\mathrm{Boc}$ ), 3.2-4.1 (dextran glucosidic protons), 5.0 (dextran anomeric proton), 6.9 and $7.2\left(-\mathrm{C}_{2} \mathrm{H}_{4}-\mathrm{C}_{6} \underline{\mathrm{H}}_{4}-\mathrm{OH}\right)$.

In the second step, Dex-TA-NH-Boc $(4.4 \mathrm{~g})$ was dissolved in $110 \mathrm{~mL}$ of deionized water and after addition of $4.4 \mathrm{~mL}$ of TFA, the mixture was stirred overnight under nitrogen. The solution was then neutralized with $4 \mathrm{M} \mathrm{NaOH}$ to $\mathrm{pH}$ 7. The obtained amine-terminated Dex-TA (denoted as Dex-TA- $\mathrm{NH}_{2}$ ) was purified by ultrafiltration (MWCO 1000) and subsequently freeze-dried. Yield: $3.4 \mathrm{~g}(78 \%)$. ${ }^{1} \mathrm{H}$ NMR $\left(\mathrm{D}_{2} \mathrm{O}\right): \delta 1.5-1.6\left(-\mathrm{NH}-\mathrm{CH}_{2}-\mathrm{C}_{2} \underline{\mathrm{H}}_{4}-\right.$ $\left.\mathrm{CH}_{2}-\mathrm{NH}_{2}\right), 2.6$ and $3.0\left(-\mathrm{C}_{2} \underline{\mathrm{H}}_{4}-\mathrm{C}_{6} \mathrm{H}_{4}-\mathrm{OH}\right.$ and $\left.-\mathrm{NH}-\mathrm{C}_{2}-\mathrm{C}_{2} \mathrm{H}_{4}-\underline{\mathrm{C}}_{2}-\mathrm{NH}_{2}\right), 3.2-4.1$ (dextran glucosidic protons), 5.0 (dextran anomeric proton), 6.9 and $7.2\left(-\mathrm{C}_{2} \mathrm{H}_{4}-\mathrm{C}_{6} \underline{\mathrm{H}}_{4}-\mathrm{OH}\right)$.

Synthesis of hyaluronic acid grafted with Dex-TA. Copolymers of hyaluronic acid grafted with Dex-TA (denoted as HA-g-Dex-TA) were synthesized by a coupling reaction of Dex-TA- $\mathrm{NH}_{2}$ with hyaluronic acid using EDAC/NHS as coupling reagent. Sodium hyaluronate $(1 \mathrm{~g})$ was dissolved in $50 \mathrm{~mL}$ of MES $(0.1 \mathrm{M}, \mathrm{pH} 6.0)$, to which EDAC $(1.8 \mathrm{~g}$, $9.4 \mathrm{mmol})$ and NHS (1.1 g, $9.4 \mathrm{mmol})$ were added. After $30 \mathrm{~min}$, a Dex-TA-NH $\mathrm{NH}_{2}$ solution ( $1.25 \mathrm{~g}$, in $10 \mathrm{~mL}$ of MES buffer) was added and the mixture was stirred under nitrogen for $3 \mathrm{~d}$. The solution was then neutralized with $1 \mathrm{M} \mathrm{NaOH}$ to $\mathrm{pH}$ 7. To remove uncoupled DexTA- $\mathrm{NH}_{2}$, the solution was ultrafiltrated (MWCO 10000), first with an aqueous solution of $50 \mathrm{mM} \mathrm{NaCl}$ and then deionized water. HA- $g$-Dex-TA was obtained as a white foam after 
freeze-drying. Yield: $1.9 \mathrm{~g}(84 \%) .{ }^{1} \mathrm{H}$ NMR $\left(\mathrm{D}_{2} \mathrm{O}\right): \delta 1.5-1.6\left(-\mathrm{NH}-\mathrm{CH}_{2}-\mathrm{C}_{2} \underline{\mathrm{H}}_{4}-\mathrm{CH}_{2}-\mathrm{NHCO}-\right.$ ), 2.0 (-NHCO-CH 3$), 2.6$ and $3.0\left(-\mathrm{C}_{2} \underline{\mathrm{H}}_{4}-\mathrm{C}_{6} \mathrm{H}_{4}-\mathrm{OH}\right.$ and $\left.-\mathrm{NH}-\underline{\mathrm{C}}_{2}-\mathrm{C}_{2} \mathrm{H}_{4}-\mathrm{C}_{2}-\mathrm{NHCO}-\right), 3.2-$ 4.1 (dextran and HA glucosidic protons), 4.4-4.6 (HA anomeric proton), 5.0 (dextran anomeric proton), 6.9 and $7.2\left(-\mathrm{C}_{2} \mathrm{H}_{4}-\mathrm{C}_{6} \underline{\mathrm{H}}_{4}-\mathrm{OH}\right)$.

Polymer characterization. ${ }^{1} \mathrm{H}$ NMR $(300 \mathrm{MHz})$ spectra were recorded on a Varian Inova spectrometer (Varian, Palo Alto, USA). The signals of solvent residues were used as reference peaks for the ${ }^{1} \mathrm{H}$ NMR chemical shift and were set at $\delta 4.79$ for water. The degree of substitution (DS) of Dex-TA, which is defined as the number of tyramine moieties per 100 anhydroglucose rings in dextran, was determined using ${ }^{1} \mathrm{H}$ NMR by comparing the integrals of signals at $\delta 5.0$ (dextran anomeric proton) and $\delta$ 6.5-7.5 (tyramine aromatic protons). The number of grafted Dex-TA chains per HA molecule was determined using ${ }^{1} \mathrm{H}$ NMR by comparing integrals of signals at $\delta 2.0$ (acetamide methyl protons of HA) and $\delta$ 5.0 (dextran anomeric proton).

The molecular weight and polydispersity of Dex-TA-NH $\mathrm{N}_{2}$ HA and HA-g-Dex-TA copolymers were determined by gel-permeation chromatography (GPC) relative to dextran standards (Fluka). GPC measurements were performed using a PL-GPC 120 Integrated GPC/SEC System (Polymer Labs) and two thermostated $\left(30{ }^{\circ} \mathrm{C}\right)$ PL-aquagel-OH columns ( $8 \mu \mathrm{m}, 300 \times 7.5 \mathrm{~mm}$, Polymer Labs). Sodium acetate buffer (NaAc, $300 \mathrm{mM}, \mathrm{pH} 4.5)$ containing $30 \%(\mathrm{v} / \mathrm{v})$ methanol was used as eluent at a flow rate of $0.5 \mathrm{~mL} / \mathrm{min}$.

Hydrogel formation and gelation time. Hydrogel samples $(\sim 0.25 \mathrm{~mL})$ were prepared in vials at $37{ }^{\circ} \mathrm{C}$. In a typical example, to a PBS solution of HA-g-Dex-TA DS $10(200 \mu \mathrm{L}$, $12.5 \mathrm{wt} \%$ ), freshly prepared solutions of $\mathrm{H}_{2} \mathrm{O}_{2}(17.5 \mu \mathrm{L}$ of $0.2 \%$ stock solution) and HRP (32.5 $\mu \mathrm{L}$ of 11 unit $/ \mathrm{mL}$ stock solution) in PBS were added and the mixture was gently vortexed. The final concentration of HA-g-Dex-TA was $10 \mathrm{wt} \%$. In all experiments 0.25 mg HRP per mmol phenol groups and $\mathrm{H}_{2} \mathrm{O}_{2}$ /phenol molar ratio of 0.2 were applied. The time to form a gel (denoted as gelation time) was determined using the vial tilting method. No flow within 1 min upon inverting the vial was regarded as the gel state. The experiments were preformed in triplicate.

Swelling and enzymatic degradation. For the swelling test, hydrogels $(\sim 0.25 \mathrm{~mL})$ of HA- $g$-Dex-TA were prepared as described above and freeze-dried $\left(\mathrm{W}_{\mathrm{d}}\right)$. Subsequently, 2 $\mathrm{mL}$ of PBS solutions were applied to the dried hydrogels, which were then incubated at 37 ${ }^{\circ} \mathrm{C}$ for $72 \mathrm{~h}$ to reach the swelling equilibrium. The buffer solution was then removed from the samples and the hydrogels were weighed $\left(\mathrm{W}_{\mathrm{s}}\right)$. The experiments were performed in triplicate and the degree of swelling was expressed as $\left(\mathrm{W}_{\mathrm{s}}-\mathrm{W}_{\mathrm{d}}\right) / \mathrm{W}_{\mathrm{d}}$.

In degradation experiments, $2 \mathrm{~mL}$ of PBS containing $100 \mathrm{U} / \mathrm{mL}$ hyaluronidase was placed on top of $0.25 \mathrm{~mL}$ of the prepared hydrogels and the samples were then incubated at $37^{\circ} \mathrm{C}$. At regular time intervals, the buffer solution was removed from the samples and the 
hydrogels were weighed. The remaining gel (\%) was calculated from the original gel weight after preparation $\left(\mathrm{W}_{\mathrm{i}}\right)$ and remaining gel weight after exposure to the enzyme containing buffer $\left(\mathrm{W}_{\mathrm{t}}\right)$, expressed as $\mathrm{W}_{\mathrm{t}} / \mathrm{W}_{\mathrm{i}} \times 100 \%$. The buffer was replaced every 2-3 days and the experiments were performed in triplicate.

Rheological analysis. Rheological experiments were carried out with a MCR 301 rheometer (Anton Paar) using parallel plates $\left(25 \mathrm{~mm}\right.$ diameter, $0^{\circ}$ ) configuration at $37^{\circ} \mathrm{C}$ in the oscillatory mode. In a typical example, $52.5 \mu \mathrm{L}$ of a $\mathrm{H}_{2} \mathrm{O}_{2}$ stock solution and $97.5 \mu \mathrm{L}$ of a HRP stock solution in PBS were mixed. The $\mathrm{HRP} / \mathrm{H}_{2} \mathrm{O}_{2}$ solution was then immediately mixed with $600 \mu \mathrm{L}$ of a solution of HA-g-Dex-TA (12.5 wt $\%$, in PBS) using a double syringe (2.5 mL, 1:4 volume ratio) equipped with a mixing chamber (Mixpac). After the samples were applied to the rheometer, the upper plate was immediately lowered to a measuring gap size of $0.5 \mathrm{~mm}$, and the measurement was started. To prevent evaporation, a layer of oil was introduced around the polymer sample. A frequency of $0.5 \mathrm{~Hz}$ and a strain of $0.1 \%$ were applied in the analysis. The measurement was allowed to proceed until the storage moduli reached a plateau value.

Chondrocyte isolation and incorporation. Bovine chondrocytes were isolated as previously reported [23] and cultured in chondrocyte expansion medium (DMEM with 10\% heat inactivated fetal bovine serum, 1\% penicillin/streptomycin (Gibco), $0.5 \mathrm{mg} / \mathrm{mL}$ fungizone (Gibco), 0.01 M MEM nonessential amino acids (Gibco), $10 \mathrm{mM}$ HEPES and $0.04 \mathrm{mM}$ L-proline) at $37{ }^{\circ} \mathrm{C}$ in a humidified atmosphere $\left(95 \%\right.$ air $\left./ 5 \% \mathrm{CO}_{2}\right)$.

Hydrogels containing chondrocytes were prepared under sterile conditions by mixing a HA- $g$-Dex-TA / cell suspension with $\mathrm{HRP} / \mathrm{H}_{2} \mathrm{O}_{2}$. Solutions of HA-g-Dex-TA were made using medium and $\mathrm{HRP}$ and $\mathrm{H}_{2} \mathrm{O}_{2}$ stock solutions were made using PBS. All the components were sterilized by filtration through filters with a pore size of $0.22 \mu \mathrm{m}$. Chondrocytes (P1) were incorporated in the hydrogels using the same procedure as that in the absence of cells. The cell/gel constructs were prepared in vials. The final concentration of HA- $g$-Dex-TA was $10 \mathrm{wt} \%$ and the cell seeding density in the gels was $5 \times 10^{6} / \mathrm{mL}$. After gelation, $1 \mathrm{~mL}$ of chondrocyte differentiation medium (DMEM with $0.1 \mu \mathrm{M}$ dexamethasone (Sigma), $100 \mu \mathrm{g} / \mathrm{mL}$ sodium pyruvate (Sigma), $0.2 \mathrm{mM}$ ascorbic acid, $50 \mathrm{mg} / \mathrm{mL}$ insulintransferrin-selenite (ITS +1 , Sigma), $100 \mathrm{U} / \mathrm{ml}$ penicillin, $100 \mu \mathrm{g} / \mathrm{ml}$ streptomycin, 10 $\mathrm{ng} / \mathrm{mL}$ transforming growth factor $\beta 3$ (TGF- $\beta 3$, Invitrogen)) was added on top of the hydrogels and the constructs were incubated at $37^{\circ} \mathrm{C}$ in a humidified atmosphere containing $5 \% \mathrm{CO}_{2}$. The medium was replaced every 3 or 4 days.

Cell viability and SEM. The effect of hydrogels on cell survival was studied using a Live-dead assay. At days 1, 7, 14 and 21, the hydrogel constructs were rinsed with PBS and stained with calcein AM/ethidium homodimer using the Live-dead assay Kit (Invitrogen), according to the manufactures' instructions. Hydrogel/cell constructs were visualized using 
fluorescence microscopy (Zeiss). As a result living cells fluoresce green and the nuclei of dead cells red.

The morphology of the chondrocytes in the hydrogels was studied using a Philips XL 30 ESEM-FEG scanning electron microscope (SEM). After 21 days' in vitro culturing in differentiation medium, the hydrogel/cell constructs were fixed with formalin followed by sequential dehydration and critical point drying. These samples were gold sputtered (Carringdon) and analyzed with SEM.

Hydrogel degradation in the presence of chondrocytes. The gel/cell constructs $(0.1$ $\mathrm{mL}$ ) were prepared in vials as described above and weighed $\left(\mathrm{W}_{\mathrm{ci}}\right)$. About $1 \mathrm{~mL}$ of chondrocyte differentiation medium was added on top of the gel and the constructs were incubated at $37{ }^{\circ} \mathrm{C}$ in a humidified atmosphere containing $5 \% \mathrm{CO}_{2}$. The medium was replaced every 3-4 days and the cell/gel constructs were weighed at regular time intervals $\left(\mathrm{W}_{\mathrm{ct}}\right)$. The swelling ratio of constructs was calculated from $\mathrm{W}_{\mathrm{ct}} / \mathrm{W}_{\mathrm{ci}}$. Afterwards, the constructs were washed extensively with water to remove the salts from the medium and then freeze-dried $\left(\mathrm{W}_{\mathrm{cdt}}\right)$. The degradation profiles of the hydrogels with chondrocytes were based on the dry gel mass which was normalized to the original wet gel weight $\left(\mathrm{W}_{\mathrm{ci}}\right)$, expressed as $\mathrm{W}_{\mathrm{cdt}} / \mathrm{W}_{\mathrm{ci}} \times 100 \%$. Dex-TA DS 15 hydrogels with chondrocytes were used as a control under the same conditions.

Matrix production. After 1, 7, 14 and 21 days, samples were washed with PBS and frozen at $-80^{\circ} \mathrm{C}$. After thawing, the constructs were digested with proteinase-K solution at $56{ }^{\circ} \mathrm{C}(>16 \mathrm{~h})$. Quantification of total DNA was done using the CyQuant dye kit (Molecular Probes) and a fluorescent plate reader (Perkin-Elmer). The amount of GAG was determined spectrophotometrically after reaction with dimethylmethylene blue dye (DMMB, SigmaAldrich). The intensity of the color was quantified immediately with a microplate reader (EL 312e Bio-TEK Instruments) by measuring the absorbance at $540 \mathrm{~nm}$. The amount of GAG was calculated using a standard of chondroitin sulphate A or B (Sigma-Aldrich). The total collagen content was determined using the hydroxyproline assay in which hydroxyproline makes up $12.5 \%$ of collagen [38]. The hydroxyproline content was determined via a colorimetric assay by reaction with chloramine $T$ and dimethylaminobenzaldehyde. All values were corrected for the background staining of gels without cells and normalized to the dry gel mass (expressed as GAG or collagen $(\mu \mathrm{g}) / \mathrm{mg}$ dry gel) or DNA content (expressed as GAG or collagen $(\mu \mathrm{g}) / \mathrm{DNA}(\mu \mathrm{g}))$. Data $(\mathrm{n}=3$, measured in triplicate) are expressed as mean \pm standard deviation (SD).

Statistical analysis. Statistical differences between two groups were analyzed using a Student's $t$-test. Those among three or more groups were analyzed using the One-way Analysis of Variance (ANOVA) with Turkey's post-hoc analysis. Statistical significance was set to a $p$ value $\leq 0.05$. Results are presented as mean \pm standard deviation. 


\subsection{Results and discussion}

\subsubsection{Synthesis and characterization of HA-g-Dex-TA copolymer}

Hyaluronic acid (HA) was grafted with a preformed dextran-tyramine (Dex-TA) conjugate via a four-step reaction, as shown in Figure 8.2.

(i)
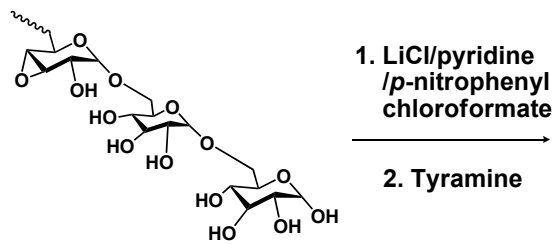

2. Tyramine

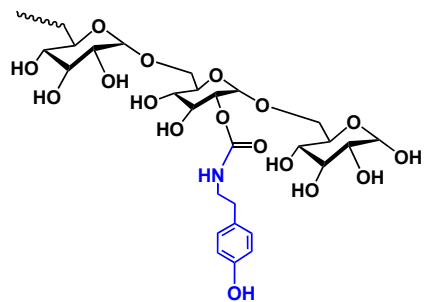

(ii)
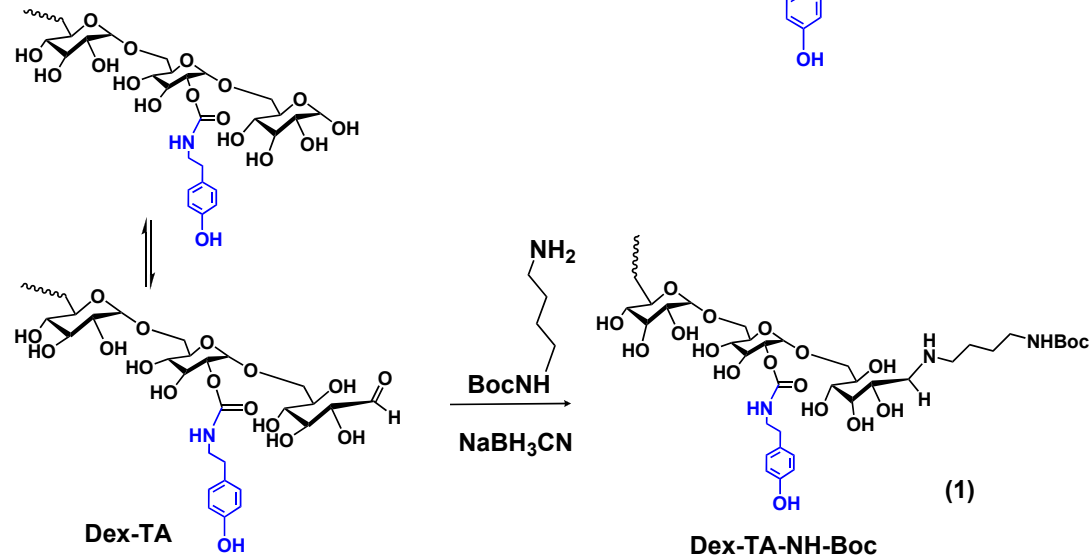

(1)

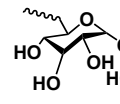

Dex-TA-NH-Boc

(iii)

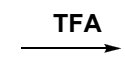

(2)
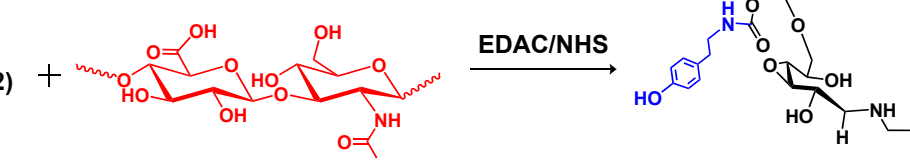

Hyaluronic acid (HA)

(iv)

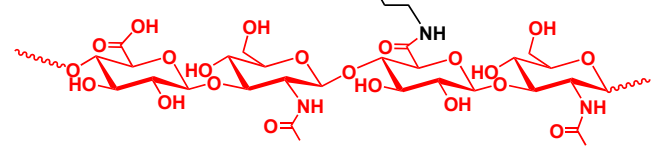

HA-g-Dex-TA

Figure 8.2. Synthesis of hyaluronic acid grafted with dextran-tyramine conjugates (HA-g-Dex-TA). 


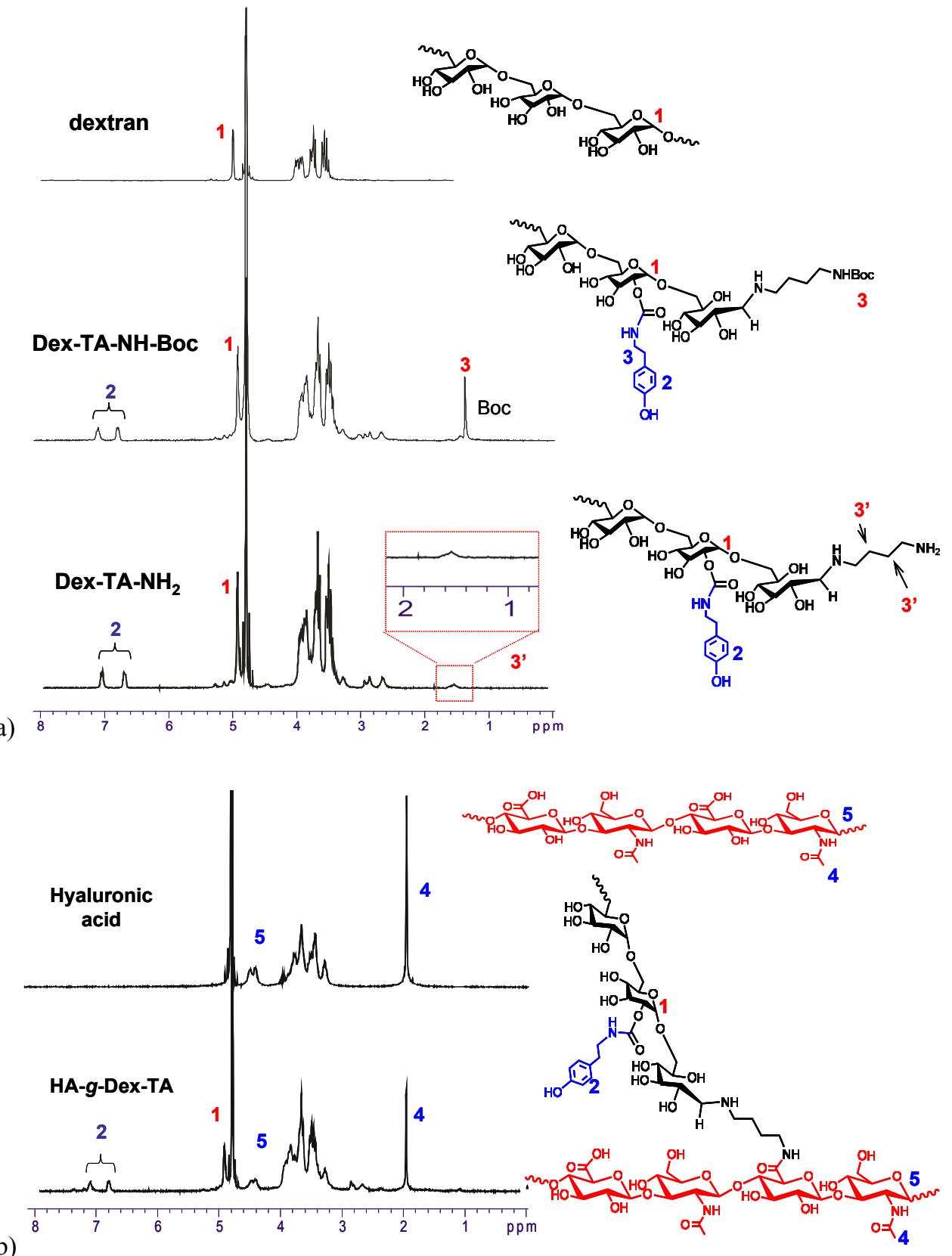

(b)

Figure 8.3. ${ }^{1} \mathrm{H}-\mathrm{NMR}$ spectra of dextran, Dex-TA, Dex-TA-NH-Boc and Dex-TA-NH $\mathrm{N}_{2}$; (b) hyaluronic acid (HA) and HA grafted with dextran-tyramine conjugates (HA-g-Dex-TA) in $\mathrm{D}_{2} \mathrm{O}$.

First, according to a previously described method, dextran $\left(\mathrm{M}_{\mathrm{r}}=6,000 \mathrm{~g} / \mathrm{mol}\right)$ was functionalized with tyramine moieties to give the Dex-TA conjugate [20]. The degree of 
substitution (DS), defined as the number of conjugated tyramine moieties per 100 anhydroglucose rings in dextran, was determined using ${ }^{1} \mathrm{H}$ NMR by comparing the integrals of signals at $\delta 5.0$ (anomeric protons, Figure 8.3a, peak 1) and $\delta$ 6.9-7.2 (aromatic protons, Figure 8.3a, peak 2). Different Dex-TA conjugates with DS values of 5, 10, 15 and 20 were prepared by changing the feed molar ratio of $p$-nitrophenyl chloroformate to hydroxyl groups in dextran from 0.05 to 0.25 . The conjugates were subsequently modified at their reducing terminal glucose residue with an excess of $N$-Boc-1,4-diaminobutane, followed by reductive amination using sodium cyanoborohydride for 3 days. After the deprotection of the Boc group using trifluoroacetic acid, conjugates with a terminal free primary amine group (denoted as Dex-TA- $\mathrm{NH}_{2}$ ) were obtained. Complete deprotection of the Boc group was confirmed by ${ }^{1} \mathrm{H}$ NMR showing the disappearance of the $t$-butyl signal at $\delta 1.4$ (Figure 8.3a, peak 3). The degree of end group conversion was over $90 \%$ as determined from ${ }^{1} \mathrm{H}$ NMR by comparing the integrals of signals at $\delta 5.0$ (anomeric protons, Figure 8.3a, peak 1) and $\delta$ 1.5-1.6 (methylene protons, Figure 8.3a, peak 3'). Finally, a coupling reaction between the primary amine groups of these Dex-TA- $\mathrm{NH}_{2}$ conjugates and the carboxylic acid groups of HA using an EDAC/NHS activation reaction at a feed molar ratio of HA to $\mathrm{NH}_{2}$ of 1:6 yielded the HA-g-Dex-TA graft copolymers. The molecular weights of these polymers were determined by gel-permeation chromatography (GPC).

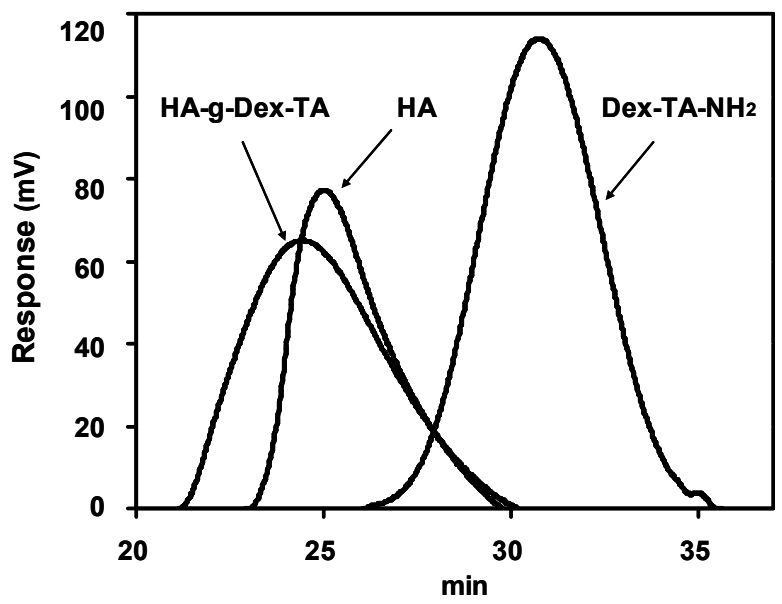

Figure 8.4. GPC chromatograms of Dex-TA- $\mathrm{NH}_{2}$ DS 10 , HA and the copolymer HA-g-Dex-TA DS 10. Eluent: NaAc buffer (300 Mm, pH 4.5, containing 30\% (v/v) methanol).

Typical elution profiles of Dex-TA- $\mathrm{NH}_{2}$ DS 10, HA and HA-g-Dex-TA DS 10 are presented in Figure 8.4. The HA- $g$-Dex-TA DS 10 polymer was eluted earlier than HA and Dex-TA- $\mathrm{NH}_{2}$ DS 10 in a unimodal GPC-trace. This indicated that the HA-g-Dex-TA polymer was successfully synthesized. The average number molecular weights of these polymers ranged from 38.4 to $40.0 \mathrm{~kg} / \mathrm{mol}$ with a relatively low polydispersity index (PDI 
1.3-1.7) (Table 8.1). The chemical structure of the HA- $g$-Dex-TA polymers was confirmed by ${ }^{1} \mathrm{H}$ NMR. In Figure $8.3 \mathrm{~b}$, it is shown that besides signals attributable to the anomeric and methyl protons of HA (peaks 4 and 5), new peaks at 5.0 (peak 1) and 6.9-7.2 (peaks 2) were present in the spectra. These peaks were attributable to the anomeric and aromatic protons from coupled Dex-TA. The number of grafted Dex-TA conjugates per HA molecule was approximately 4, as determined with ${ }^{1} \mathrm{H}$ NMR by comparing the integrals of signals at $\delta 2.0$ (methyl protons of acetamide groups in HA) and $\delta 5.0$ (dextran anomeric protons) (Table 8.1). It was found that the average number molecular weights of the HA-g-Dex-TA polymers calculated using ${ }^{1} \mathrm{H}$ NMR were in agreement with those determined by GPC measurements.

Table 8.1. Composition, molecular weight and polydispersity of HA-g-Dex-TA copolymers $^{\text {a }}$

\begin{tabular}{|c|c|c|c|c|c|}
\hline $\begin{array}{l}\text { Polymer } \\
\text { (code) }\end{array}$ & $\begin{array}{c}M_{\mathrm{n}, \mathrm{GPC}} \\
(\mathrm{kg} / \mathrm{mol})\end{array}$ & PDI & $\begin{array}{c}M_{n, N M R} \\
(k g / m o l)\end{array}$ & $\begin{array}{c}\text { Number of grafted } \\
\text { Dex-TA per HA } \\
\text { chain (n) }\end{array}$ & $\begin{array}{l}\text { Number } \\
\text { of TA per } \\
\text { HA chain }\end{array}$ \\
\hline Dextran & 3.3 & 1.7 & -- & -- & -- \\
\hline $\begin{array}{l}\text { Hyaluronic } \\
\text { acid (HA) }\end{array}$ & 25.4 & 1.8 & -- & -- & -- \\
\hline $\begin{array}{l}\text { HA- } g \text {-Dex-TA } \\
\text { DS } 5\end{array}$ & 39.2 & 1.6 & 40.4 & 4.3 & 4.3 \\
\hline $\begin{array}{c}\text { HA- } g \text {-Dex-TA } \\
\text { DS } 10\end{array}$ & 38.4 & 1.3 & 38.2 & 4.0 & 8.0 \\
\hline $\begin{array}{c}\text { HA- } g \text {-Dex-TA } \\
\text { DS } 15\end{array}$ & 39.2 & 1.6 & 38.3 & 4.2 & 12.8 \\
\hline $\begin{array}{c}\text { HA- } g \text {-Dex-TA } \\
\text { DS } 20\end{array}$ & 40.0 & 1.7 & 40.9 & 4.5 & 18.8 \\
\hline
\end{tabular}

a. Coupling reactions between HA and Dex-TA- $\mathrm{NH}_{2}$ were performed in MES with a feed molar ratio of $\mathrm{HA}$ to $\mathrm{NH}_{2}$ of 1:6.

\subsubsection{Hydrogel formation and gelation time}

Hydrogels of HA-g-Dex-TA were conveniently prepared in PBS by the horseradish peroxidase (HRP)-mediated coupling reaction of phenol moieties. According to earlier research, $0.25 \mathrm{mg}$ HRP per mmol phenol moieties and a molar ratio of $\mathrm{H}_{2} \mathrm{O}_{2} /$ TA of 0.2 were applied in this study due to the good cytocompatibility of the resulting gels [39]. The gelation time was determined by the vial tilting method. 
The enzymatic crosslinking of HA- $g$-Dex-TA led to fast gelation, i.e. the gelation times were within $2 \mathrm{~min}$ for all combinations tested (Figure 8.5). The longest gelation times were found for the HA-g-Dex-TA copolymers with a low DS, due to the decreased number of tyramine units per chain. Effects on gelation time were even more pronounced with decreasing polymer concentration. The fastest gelation, within $10 \mathrm{~s}$, occurred using HA- $g$ Dex-TA DS 20 hydrogels at a polymer concentration of $10 \mathrm{wt} \%$. Thus, an attractive feature of these HA- $g$-Dex-TA hydrogel systems is that the gelation occurred in a reasonably short time (10 s to $2 \mathrm{~min}$ ) under mild conditions. Furthermore, gelation times of the HA- $g$-DexTA hydrogels can be easily tuned by adjusting the DS of tyramine units and polymer concentration, which makes the systems highly suitable as injectable scaffolds for various applications.

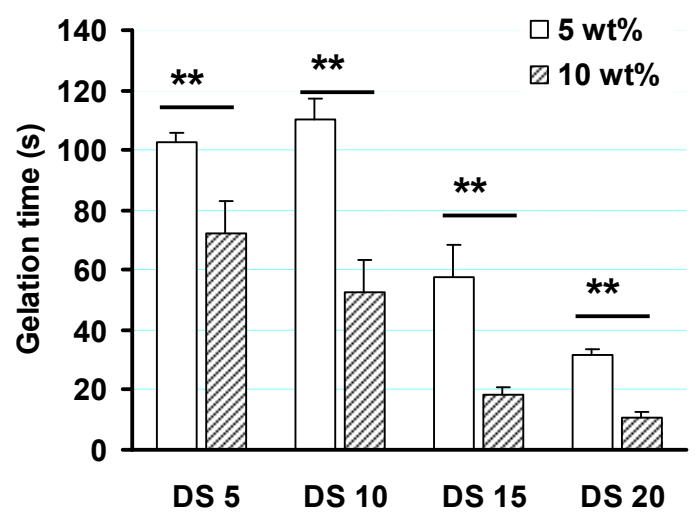

Figure 8.5. Gelation times of hydrogels based on HA-g-Dex-TA as a function of DS and concentration. $(\mathrm{n}=3, * * p<0.01)$

\subsubsection{Hydrogel characterization}

The degree of swelling of the HA- $g$-Dex-TA hydrogels in PBS was determined after $72 \mathrm{~h}$ (Figure 8.6). In general, all HA-g-Dex-TA hydrogels showed degrees of swelling ranging from 15 to 41 . These values were in the same range of photocrosslinked HA-based hydrogels [40, 41]. Additionally, the values were lower at higher DS values of tyramine units and higher polymer concentration $(p<0.05)$. This can be explained by the increased crosslinking density of the hydrogels. Compared to previously reported Dex-TA hydrogels, HA-g-Dex-TA hydrogels showed improved swelling behavior [20], which can be explained by an increase in water uptake resulting from the electrostatic repulsion of negativelycharged HA chains at $\mathrm{pH} 7.4$.

The storage moduli $\left(\mathrm{G}^{\prime}\right)$ of the HA- $g$-Dex-TA hydrogels after gelation were determined at $37{ }^{\circ} \mathrm{C}$ by rheology. As shown in Figure 8.7, hydrogels prepared at a concentration of 10 $w t \%$ showed a 2 to 3 fold higher storage modulus compared to $5 \mathrm{wt} \%$ hydrogels. 
Furthermore, by increasing the DS from 5 to 20, the corresponding G' values significantly increased. This is most likely due to the increased crosslinking density in DS 10 gels versus DS 5 gels. In general, the moduli of HA-g-Dex-TA hydrogels ranged from 370 to $18000 \mathrm{~Pa}$. This is comparable to values previously reported for dextran-tyramine hydrogels [20]. They are, however, much higher than values reported for other enzymatically-crosslinked hydrogels such as hyaluronic acid-tyramine DS 6 hydrogels (10-4000 Pa) [19].

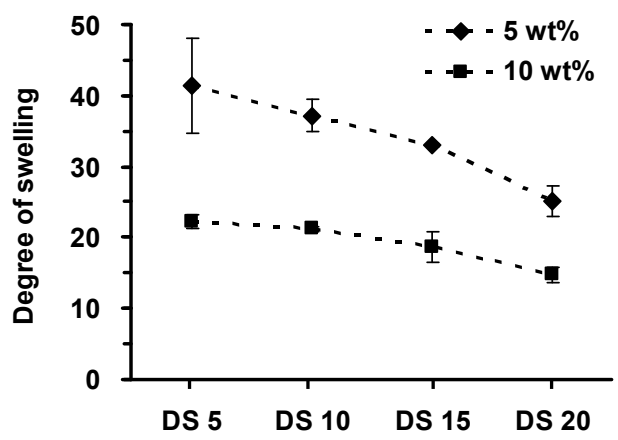

Figure 8.6. Degree of swelling of HA- $g$-Dex-TA hydrogels as a function of DS $(n=3)$.

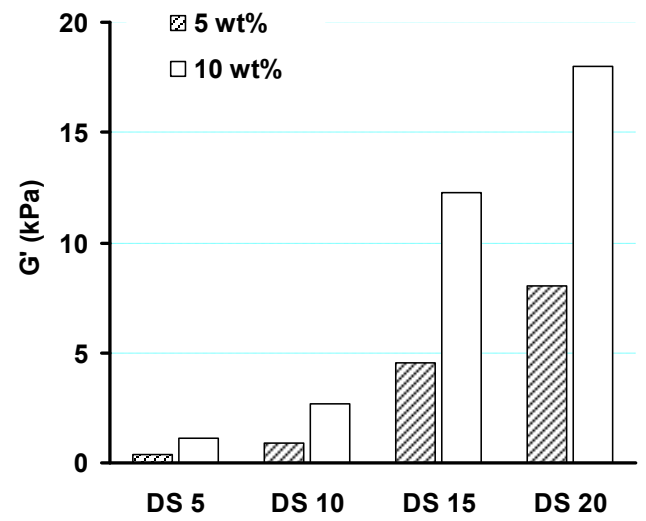

Figure 8.7. Storage modulus of HA-g-Dex-TA hydrogels as a function of DS $(n=1)$.

\subsubsection{Enzymatic degradation}

HA is biodegradable via enzymatic hydrolysis using hyaluronidase (HAse) [42]. To determine the enzymatic degradation profiles of the HA- $g$-Dex-TA hydrogels, $2 \mathrm{~mL}$ of PBS containing $100 \mathrm{U} / \mathrm{mL}$ HAse was applied on top of $0.25 \mathrm{~mL}$ of the hydrogels. The hydrogels were kept at $37{ }^{\circ} \mathrm{C}$ and their weights were monitored at regular time intervals. The remaining gel (\%) was expressed as the remaining gel weight after exposure to enzyme buffer $\left(\mathrm{W}_{\mathrm{t}}\right)$ divided by the original gel weight after preparation $\left(\mathrm{W}_{\mathrm{i}}\right)$. In buffer without the 
enzyme present, the gels swelled and the weight increased during the first 3 days, which remained stable up to 21 days (data not shown). In the presence of hyaluronidase, the gel weight first increased because of water uptake during the degradation process, and then decreased when the increase in the swelling is overtaken by the gel weight loss due to the dissolution and release of small fragments. The degradation time was defined as the time required to completely dissolve at least one of 3 samples tested. It was found that the degradation of HA- $g$-Dex-TA hydrogels depended on the DS and polymer concentration (Figure 8.8). The HA-g-Dex-TA DS 5 hydrogels prepared at polymer concentrations of 5 and $10 \mathrm{wt} \%$ were completely degraded after 4 and 6 days, respectively, while the $5 \mathrm{wt} \%$ HA-g-Dex-TA DS 10 hydrogels showed a longer degradation time of 15 days. The hydrogels of HA-g-Dex-TA at a high DS of 15 and 20 were more stable with more than 30 $w t \%$ of gel remaining after 21 days of degradation. Even after 2 months, these gels were not completely degraded (data not shown). Compared to previously reported hyaluronic acid-tyramine (HA-TA) hydrogels which were completely degraded within 1 day in the presence of $25 \mathrm{U} / \mathrm{mL}$ of HAse in PBS [19], our gels were much more stable even in the presence of a 4 -fold higher concentration of HAse $(100 \mathrm{U} / \mathrm{mL})$. The increased stability can be attributed to the presence of dextran. The improved degradation characteristics compared to HA-TA gels makes HA-g-Dex-TA hydrogels more suitable for cartilage tissue engineering.
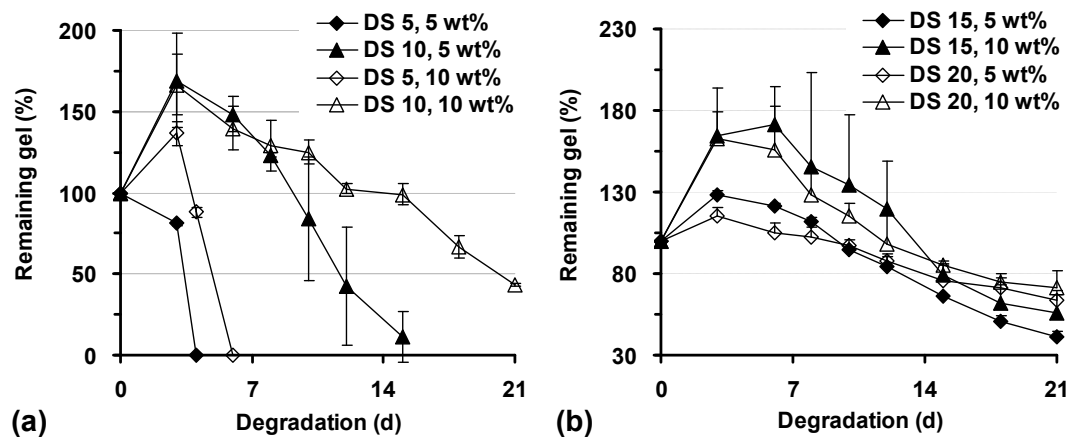

Figure 8.8. Enzymatic degradation of HA-g-Dex-TA hydrogels at DS 5, 10 (a) and DS 15, 20 (b) exposed to PBS containing $100 \mathrm{U} / \mathrm{ml}$ HAse at $37^{\circ} \mathrm{C}(\mathrm{n}=3)$.

\subsubsection{Cytotoxicity}

In cell experiments, $10 \mathrm{wt} \%$ HA-g-Dex-TA DS 15 and 20 hydrogels, which showed the best stability, were selected for the preparation of gel/cell constructs for in vitro studies. The cytocompatibility of HA-g-Dex-TA DS 15 and 20 hydrogels was investigated by the incorporation of bovine chondrocytes in HA-g-Dex-TA hydrogels at a polymer concentration of $10 \mathrm{wt} \%$. Cell survival of the chondrocytes was analyzed by a Live-dead 
assay (Figure 8.9), in which living cells fluoresce green and dead cells fluoresce red. In both HA- $g$-Dex-TA DS 15 and DS 20 hydrogels, over 95\% of chondrocytes stained green, indicating cytocompatible enzymatic crosslinking conditions.
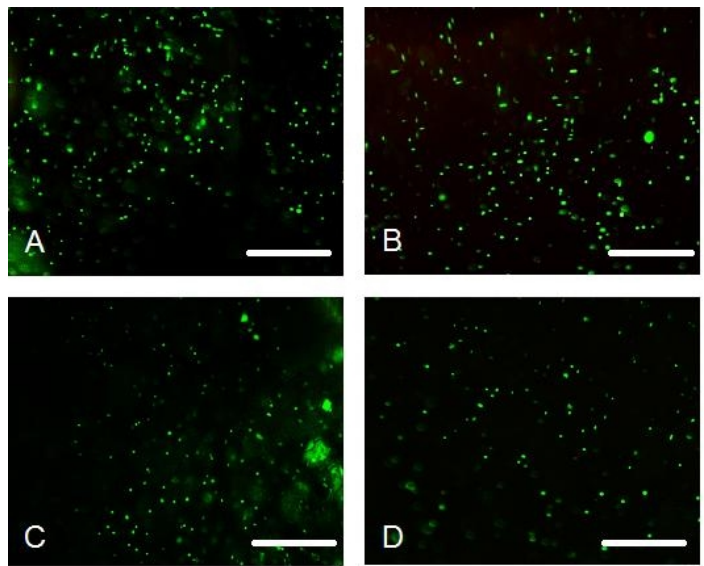

Figure 8.9. (a) Live-dead assay showing chondrocytes incorporated in HA-g-Dex-TA DS 15 (A and C) and DS 20 (B and D) hydrogels after 7 (A and B) and 14 (C and D) days in culture. Scale bar: 500 $\mu \mathrm{m}$.

\subsubsection{Chondrocyte morphology}

The cell/scaffold constructs were investigated by SEM (Figure 8.10). The chondrocytes encapsulated inside HA- $g$-Dex-TA DS15 and 20 hydrogels retained a round shape at 21 days in culture, which was also observed in Dex-TA DS 15 hydrogels [39]. High magnification of SEM images showed that the chondrocytes deposited an extracellular matrix.
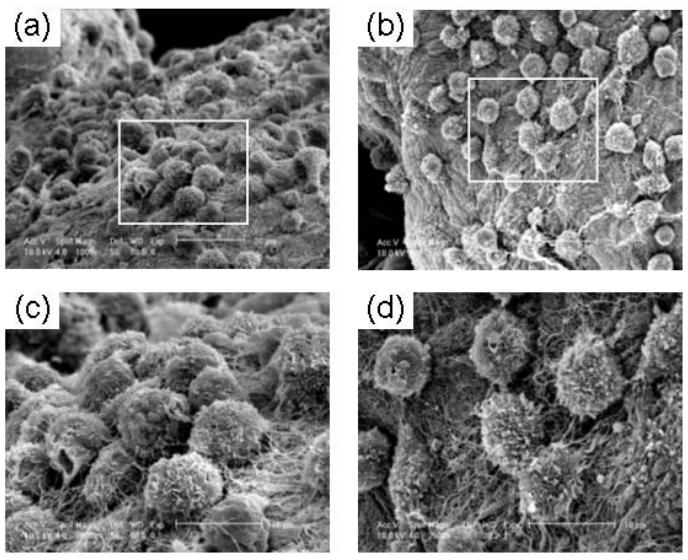

Figure 8.10. SEM images of chondrocytes incorporated in the (a) HA-g-Dex-TA DS 15 and (b) HA$g$-Dex-TA DS 20 hydrogels at day 21. High magnification SEM images of the boxed regions of Figure $9 \mathrm{a}$ and $9 \mathrm{~b}$ are shown in Figure $9 \mathrm{c}$ and $9 \mathrm{~d}$, respectively. 


\subsubsection{Swelling and degradation of hydrogels in the presence of cells}

To study the swelling and degradation behavior of the HA-g-Dex-TA hydrogels in the presence of chondrocytes, the constructs were incubated in a chondrocyte expansion medium and weighed at regular intervals. The swelling ratio of a Dex-TA DS 15 hydrogel remained almost constant during the total culturing time up to 21 days. In contrast, the swelling ratios of the HA- $g$-Dex-TA hydrogels increased from day 1 to day 7 and decreased slightly after day 14 (Figure 8.11a). The swelling behavior suggests a loss in crosslinking density with time as a result of degradation [19]. This is supported by the pronounced decrease in the swelling ratio for HA-g-Dex-TA DS 15 hydrogels at day 14 and day 21 compared to day 1 . The degradation of HA-g-Dex-TA hydrogels was further studied by determining the dry gel mass, which is normalized to the initial wet gel weight after preparation (Figure 8.11b). Dex-TA DS 15 hydrogels had a dry gel mass of $8 \%$ at day 1 , which remained stable up to 21 days. In contrast, the values for HA- $g$-Dex-TA DS 15 and 20 hydrogels decreased from $8 \%$ at day 1 to $3 \%$ and $6 \%$ at day 21 , respectively $(p<0.05)$. The significant differences $(p<0.05)$ in the swelling and degradation behavior in time between the Dex-TA and the HA- $g$-Dex-TA hydrogels are most likely explained by the presence of HAse produced by incorporated chondrocytes [43].

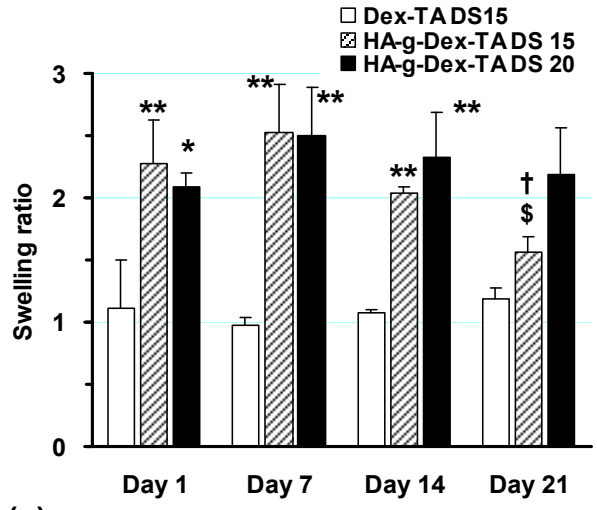

(a)

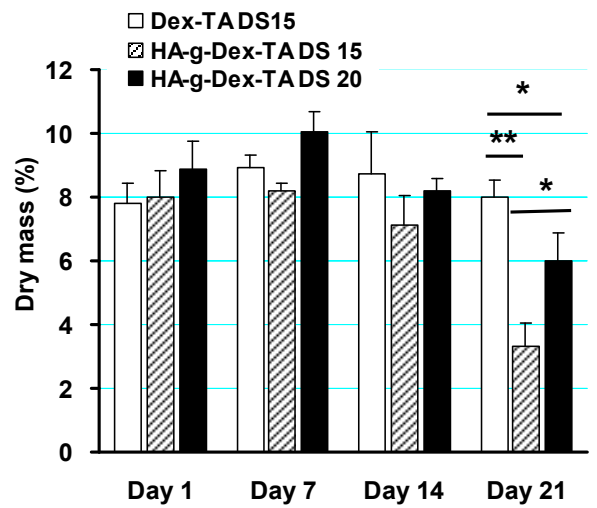

(b)

Figure 8.11. (a) Swelling and (b) degradation of Dex-TA and HA- $g$-Dex-TA hydrogels in the presence of chondrocytes as a function of culturing time. Figure 11a: ${ }^{*} p<0.05,{ }^{*} p<0.01$, vs. DexTA DS 15; $\$ p<0.05$, vs. Day $1 ; \dagger p<0.01$, vs. Day 7). Figure $11 \mathrm{~b}$ : the dry mass of the construct is normalized to the original wet gel weight after preparation. $\left({ }^{*} p<0.05, * * p<0.01\right)$

\subsubsection{Cell proliferation and matrix production}

Our earlier studies have shown that chondrocytes incorporated in Dex-TA hydrogels proliferated and maintained their phenotype without dedifferentiating to fibroblast-like cells [39]. Chondrocyte proliferation in HA-g-Dex-TA DS 15 and DS 20 hydrogels was assessed 
by a CyQuant DNA assay by measuring the DNA content of the hydrogels during the culturing period up to 21 days. The phenotype of chondrocytes incorporated was characterized in terms of their matrix production. The ECM matrix produced was analyzed by a dimethylmethylene blue assay and a hydroxyproline assay for glycosaminoglycans (GAGs) and collagen, respectively, and the values were normalized to the dry gel weight of each sample.

In the CyQuant DNA assay, the DNA content was expressed as the DNA amount normalized to the dry gel weight. Results were compared to hydrogels prepared from a dextran-tyramine conjugate Dex-TA DS $15\left(\mathrm{M}_{\mathrm{n}}\right.$, Dex $\left.=14.5 \mathrm{~kg} / \mathrm{mol}\right)$ which served as a reference [20, 25]. In general, in all these hydrogels the DNA content increased with increasing culturing time. Interestingly, at day 21, the DNA content in the HA-g-Dex-TA DS 15 hydrogel was higher than that in the Dex-TA DS15 hydrogel (Figure 8.12a). These results demonstrated the benefit of the presence of HA in Dex-TA hydrogels.

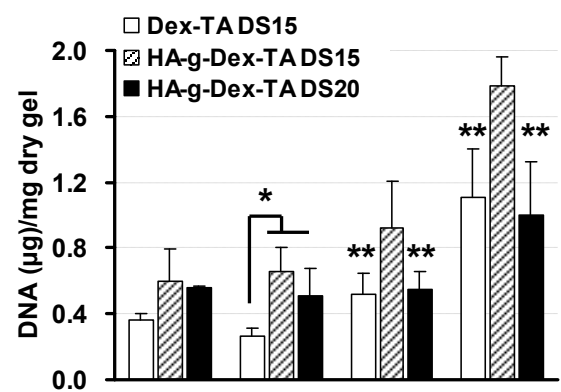

(a)
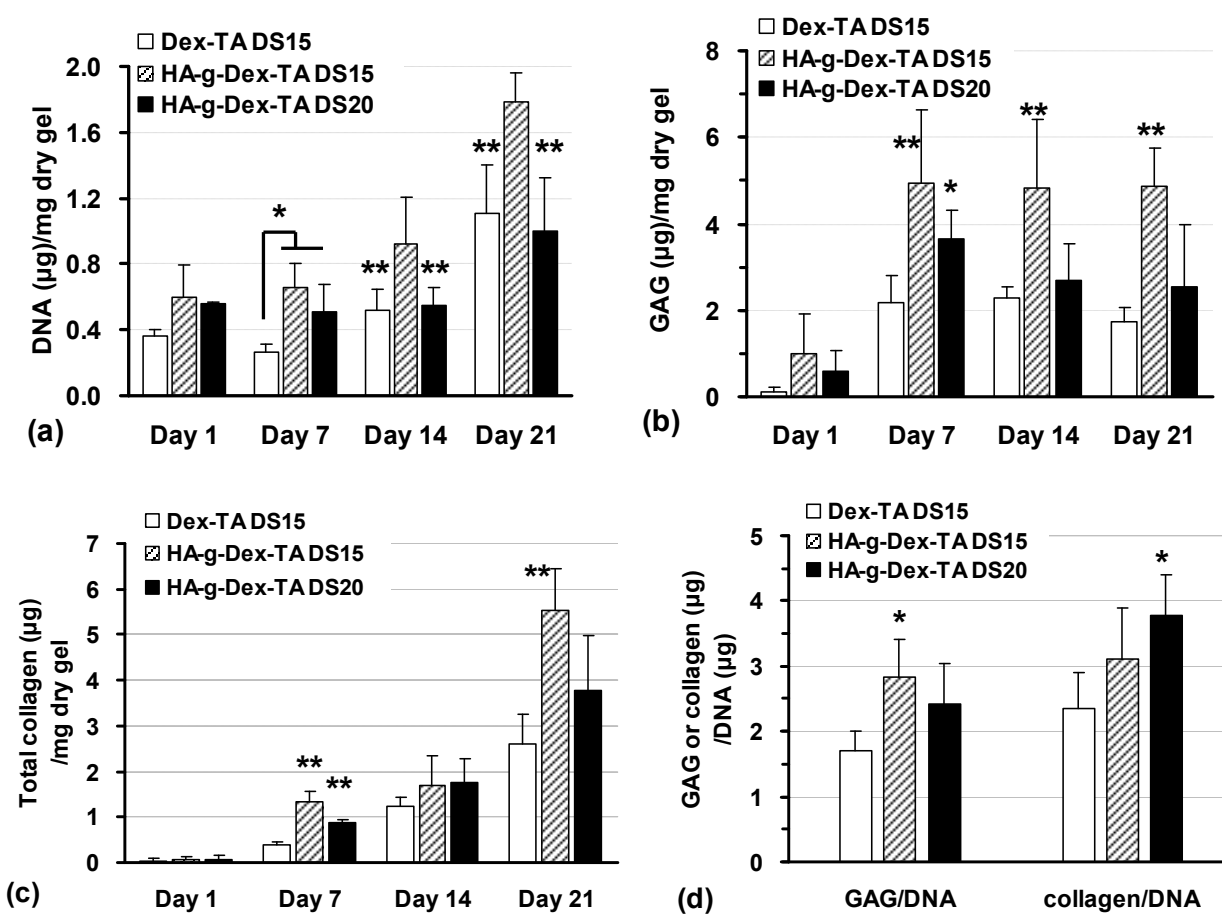

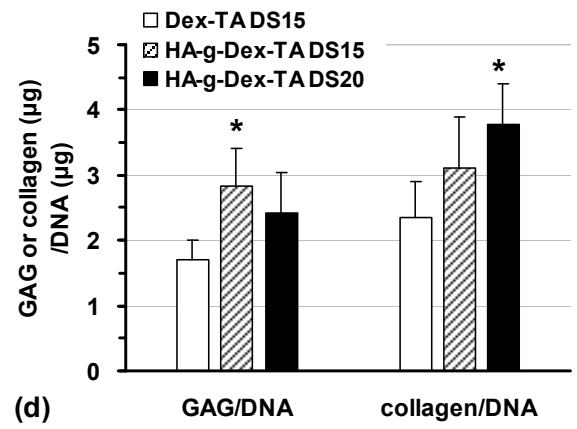

Figure 8.12. (a) DNA content normalized to dry gel weight of Dex-TA DS 15 , HA-g-Dex-TA DS 15 and 20 hydrogels containing chondrocytes after in vitro culturing for $1,7,14$ and 21 days. $\left({ }^{*} p<0.05\right.$ at day $7 ; * * p<0.01 v$ s. HA- $g$-Dex-TA DS 15 at day 14 and 21) (b) GAG and (c) total collagen accumulation (values were normalized to the dry gel weight per sample) in Dex-TA and HA- $g$-DexTA hydrogels containing chondrocytes after in vitro culturing for $1,7,14$ and 21 days. $(* * p<0.01 v s$. Dex-TA DS 15 at each time point) (d) GAG and total collagen content normalized to DNA content in Dex-TA and HA-g-Dex-TA hydrogels containing chondrocytes after in vitro culturing for 21 days. (* $p<0.05$ vs. Dex-TA DS 15). 
In the control group of GAG assay, hydrogels prepared from Dex-TA DS15, the GAG content increased from day 1 to day 7 , and then remained unchanged throughout the experimental period (Figure 8.12b). Similar trends were also observed for the HA-g-DexTA hydrogels. The HA-g-Dex-TA DS 15 hydrogels showed a statistically higher average GAG content per mg of dry gel weight than the Dex-TA DS 15 hydrogels at day 14 and 21 (4.8 vs 2.3 and 4.9 vs 1.7, respectively). The average GAG content in HA-g-Dex-TA DS 20 hydrogels was found to be 2.7 and $2.6 \mu \mathrm{g}$ per $\mathrm{mg}$ of dry gel weight at day 14 and 21 , respectively, which was close to that of Dex-TA DS 15 hydrogels. These results suggest that the DS of the Dex-TA conjugate in the HA- $g$-Dex-TA had a significant effect on the GAG production, indicating that appropriate design of the gel chemistry might lead to an optimal performance in ECM production.

The total collagen content, determined using a hydroxyproline assay, was normalized to the dry gel weight (Figure 8.12c). The results showed that the total collagen accumulation increased in time and reached the highest value at day 21 for all groups. Interestingly, the average value of total collagen content was higher in HA-g-Dex-TA DS 15 and DS 20 hydrogels than in Dex-TA DS 15 hydrogels, irrespective of the culturing time. After 7 and 21 days in culture, significant higher collagen deposition was found in HA-g-Dex-TA DS 15 than in Dex-TA DS 15 hydrogels.

For comparative studies, the GAG and total collagen content were normalized to the DNA content, as shown in Figure 8.12d. In general, enhanced matrix deposition was observed for HA-g-Dex-TA compared to Dex-TA hydrogels. At day 21, the GAG/DNA ratio was 1.6 fold higher in the HA-g-Dex-TA DS 15 hydrogels than Dex-TA hydrogels. Further, significantly higher collagen/DNA ratios were observed for HA-g-Dex-TA DS 20 hydrogels than for Dex-TA DS 15 hydrogels. Previous studies have shown that GAGs play an important role in regulating the expression of the chondrocyte phenotype and support matrix formation [44, 45]. Therefore, the application of hyaluronic acid, one of the components of a native cartilaginous matrix, could be a reason for enhanced matrix production [46-48].

Taken together, HA-g-Dex-TA hybrids were designed which resemble the macrostructure of proteoglycans as can be found in native cartilage. Biomimetic hydrogels based on these materials showed a better stability than HA-TA hydrogels and an improved chondrocyte performance than Dex-TA hydrogels. Thus they hold great promise as injectable scaffolds for cartilage tissue engineering. Importantly, the concept for the design of proteoglycan analogs can be easily extended to other polysaccharides such as heparan sulfate and chondroitin sulfate or proteins such as collagen. 


\subsection{Conclusions}

Novel injectable biomimetic hydrogels based on polysaccharide hybrids (HA-g-Dex-TA) were designed for cartilage tissue engineering. HA- $g$-Dex-TA copolymers were prepared by the conjugation of dextran-tyramine conjugates with different degrees of substitution of tyramine units (DS 5, 10, 15 and 20) to hyaluronic acid using EDAC/NHS activation. Hydrogels were obtained by enzymatic crosslinking of HA- $g$-Dex-TA under physiological conditions using $\mathrm{HRP}$ as a catalyst and $\mathrm{H}_{2} \mathrm{O}_{2}$ as an oxidant. The gelation is fast with gelation times lower than $2 \mathrm{~min}$, which can be regulated by varying the DS and polymer concentration. Hydrogels are readily degraded in the presence of hyaluronidase. Hydrogels prepared at a higher DS and concentration had higher storage moduli and stability. The behavior of chondrocytes incorporated inside HA- $g$-Dex-TA hydrogels demonstrated that the gel systems had a good biocompatibility. Compared to Dex-TA hydrogels, these biomimetic HA-g-Dex-TA hydrogels induced an enhanced cell proliferation and matrix deposition (increased glycosaminoglycan and collagen production). In conclusion, we have demonstrated that these novel injectable biomimetic hydrogels based on polysaccharide hybrids are very promising for the development of scaffolds for cartilage tissue engineering.

\subsection{References}

[1] Bryant SJ, Anseth KS. Hydrogel Properties Influence ECM Production by Chondrocytes Photoencapsulated in Poly(ethylene glycol) Hydrogels. J. Biomed. Mater. Res. 2002;59: 63-72.

[2] Bryant SJ, Anseth KS. Controlling the Spatial Distribution of ECM Components in Degradable PEG Hydrogels for Tissue Engineering Cartilage. J. Biomed. Mater. Res. A 2003;64A: 70-79.

[3] Bryant SJ, Anseth KS, Lee DA, Bader DL. Crosslinking Density Influences the Morphology of Chondrocytes Photoencapsulated in PEG Hydrogels During the Application of Compressive Strain. J. Orthop. Res. 2004;22: 1143-1149.

[4] Bryant SJ, Arthur JA, Anseth KS. Incorporation of Tissue-Specific Molecules Alters Chondrocyte Metabolism and Gene Expression in Photocrosslinked Hydrogels. Acta Biomater. 2005; 1: 243-252.

[5] Bryant SJ, Bender RJ, Durand KL, Anseth KS. Encapsulating Chondrocytes in Degrading PEG Hydrogels with High Modulus: Engineering Gel Structural Changes to Facilitate Cartilaginous Tissue Production. Biotech. Bioeng. 2004;86: 747-755.

[6] Bryant SJ, Durand KL, Anseth KS. Manipulations in Hydrogel Chemistry Control Photoencapsulated Chondrocyte Behavior and Their Extracellular Matrix Production. J. Biomed. Mater. Res. A 2003;67A: 1430-1436.

[7] Elisseeff J, Anseth K, Sims D, McIntosh W, Randolph M, Langer R. Transdermal Photopolymerization for Minimally Invasive Implantation. Proc. Natl. Acad. Sci. USA 1999;96: 3104-3107. 
[8] Fedorovich NE, Oudshoorn MH, van Geemen D, Hennink WE, Alblas J, Dhert WJA. The Effect of Photopolymerization on Stem Cells Embedded in Hydrogels. Biomaterials 2009;30: 344-353.

[9] Williams CG, Malik AN, Kim TK, Manson PN, Elisseeff JH. Variable Cytocompatibility of Six Cell Lines with Photoinitiators Used for Polymerizing Hydrogels and Cell Encapsulation. Biomaterials 2005;26: 1211-1218.

[10] Jefferiss CD, Lee AJC, Ling RSM. Thermal Aspects of Self-Curing Polymethylmethacrylate. J. Bone Joint Surg. Br. 1975;57B: 511-518.

[11] Hiemstra C, van der Aa LJ, Zhong Z, Dijkstra PJ, Feijen J. Rapidly in Situ-Forming Degradable Hydrogels from Dextran Thiols through Michael Addition. Biomacromolecules 2007;8: 1548-1556.

[12] Hiemstra C, van der Aa LJ, Zhong Z, Dijkstra PJ, Feijen J. Novel in Situ Forming, Degradable Dextran Hydrogels by Michael Addition Chemistry: Synthesis, Rheology, and Degradation. Macromolecules 2007;40: 1165-1173.

[13] Tortora M, Cavalieri F, Chiessi E, Paradossi G. Michael-Type Addition Reactions for the in Situ Formation of Poly(vinyl alcohol)-Based Hydrogels. Biomacromolecules 2007;8: 209-214.

[14] Zheng Shu X, Liu Y, Palumbo FS, Luo Y, Prestwich GD. In Situ Crosslinkable Hyaluronan Hydrogels for Tissue Engineering. Biomaterials 2004;25: 1339-1348.

[15] Lutolf MP, Lauer-Fields JL, Schmoekel HG, Metters AT, Weber FE, Fields GB, and Hubbell JA. Synthetic Matrix Metalloproteinase-Sensitive Hydrogels for the Conduction of Tissue Regeneration: Engineering Cell-Invasion Characteristics. Proc. Natl. Acad. Sci. USA 2003;100: 5413-5418.

[16] Lutolf MP, Raeber GP, Zisch AH, Tirelli N, Hubbell JA. Cell-Responsive Synthetic Hydrogels. Adv. Mater. 2003;15: 888-892.

[17] Lutolf MP, Hubbell JA. Synthesis and Physicochemical Characterization of EndLinked Poly(ethylene glycol)-Co-Peptide Hydrogels Formed by Michael-Type Addition. Biomacromolecules 2003;4: 713-722.

[18] Hahn SK, Oh EJ, Miyamoto H, Shimobouji T. Sustained Release Formulation of Erythropoietin Using Hyaluronic Acid Hydrogels Crosslinked by Michael Addition. Int. J. Pharm. 2006;322: 44-51.

[19] Lee F, Chung JE, Kurisawa M. An Injectable Enzymatically Crosslinked Hyaluronic Acid-Tyramine Hydrogel System with Independent Tuning of Mechanical Strength and Gelation Rate. Soft Matter. 2008;4: 880-887.

[20] Jin R, Hiemstra C, Zhong Z, Feijen J. Enzyme-Mediated Fast in Situ Formation of Hydrogels from Dextran-Tyramine Conjugates. Biomaterials 2007;28: 2791-2800.

[21] Ogushi Y, Sakai S, Kawakami K. Synthesis of Enzymatically-Gellable Carboxymethylcellulose for Biomedical Applications. J. Biosci. Bioeng. 2007;104: 30-33.

[22] Sakai S, Kawakami K. Synthesis and Characterization of Both Ionically and Enzymatically Cross-Linkable Alginate. Acta Biomater. 2007;3: 495-501.

[23] Jin R, Moreira Teixeira LS, Dijkstra PJ, Karperien M, van Blitterswijk CA, Zhong ZY, and Feijen J. Injectable Chitosan-Based Hydrogels for Cartilage Tissue Engineering. Biomaterials 2009;30: 2544-2551.

[24] Sakai S, Hirose K, Taguchi K, Ogushi Y, Kawakami K. An Injectable, in Situ Enzymatically Gellable, Gelatin Derivative for Drug Delivery and Tissue Engineering. Biomaterials 2009;30: 3371-3377. 
[25] Jin R, Moreira Teixeira LS, Dijkstra PJ, Karperien M, Zhong Z, Feijen J. Fast inSitu Formation of Dextran-Tyramine Hydrogels for in Vitro Chondrocyte Culturing. J. Control. Release 2008;132: e24-26.

[26] Moreira Teixeira LS, Jin R, Dijkstra PJ, Feijen J, van Blitterswijk CA, Karperien M. Chitosan-Based Hydrogels as Extracellular Matrix for Cartilage Tissue Engineering: In Vitro Biological Evaluation. Tissue Eng. A 2008;14: 711.

[27] Yu L, Ding J. Injectable Hydrogels as Unique Biomedical Materials. Chem. Soc. Rev. 2008;37: 1473-1481.

[28] Van Tomme SR, Storm G, Hennink WE. In Situ Gelling Hydrogels for Pharmaceutical and Biomedical Applications. Int. J. Pharm. 2008;355: 1-18.

[29] Kretlow JD, Klouda L, Mikos AG. Injectable Matrices and Scaffolds for Drug Delivery in Tissue Engineering. Adv. Drug Deliver. Rev. 2007;59: 263-273.

[30] Malafaya PB, Silva GA, Reis RL. Natural-Origin Polymers as Carriers and Scaffolds for Biomolecules and Cell Delivery in Tissue Engineering Applications. Adv. Drug Deliver. Rev. 2007;59: 207-233.

[31] Hong Y, Song H, Gong Y, Mao Z, Gao C, Shen J. Covalently Crosslinked Chitosan Hydrogel: Properties of in Vitro Degradation and Chondrocyte Encapsulation. Acta Biomater. 2007;3: 23-31.

[32] Hoemann CD, Sun J, Legare A, McKee MD, Buschmann MD. Tissue Engineering of Cartilage Using an Injectable and Adhesive Chitosan-Based Cell-Delivery Vehicle. Osteoarthr. Cartilage 2005;13: 318-329.

[33] Rowley JA, Madlambayan G, Mooney DJ. Alginate Hydrogels as Synthetic Extracellular Matrix Materials. Biomaterials 1999;20: 45-53.

[34] Park KM, Joung YK, Park KD, Lee SY, Lee MC. Rgd-Conjugated ChitosanPluronic Hydrogels as a Cell Supported Scaffold for Articular Cartilage Regeneration. Macromol. Res. 2008;16: 517-523.

[35] Park KM, Lee SY, Joung YK, Na JS, Lee MC, Park KD. Thermosensitive ChitosanPluronic Hydrogel as an Injectable Cell Delivery Carrier for Cartilage Regeneration. Acta Biomater. 2009;5: 1956-1965.

[36] Toole BP. Hyaluronan in Morphogenesis. Seminars in Cell \& Developmental Biology 2001;12: 79-87.

[37] Akmal M, Singh A, Anand A, Kesani A, Aslam N, Goodship A, and Bentley G. The Effects of Hyaluronic Acid on Articular Chondrocytes. J. Bone Joint Surg. Br. 2005;87-B: 1143-1149.

[38] Edwards CA, O'Brien Jr WD. Modified Assay for Determination of Hydroxyproline in a Tissue Hydrolyzate. Clin. Chim. Acta 1980;104: 161-167.

[39] Jin R, Moreira Teixeira LS, Dijkstra PJ, Karperien M, van Blitterswijk CA, Feijen J. Enzymatically Crosslinked Dextran-Tyramine Hydrogels as Injectable Scaffolds for Cartilage Tissue Engineering. Chapter 5.

[40] Jia X, Burdick JA, Kobler J, Clifton RJ, Rosowski JJ, Zeitels SM, and Langer R. Synthesis and Characterization of in Situ Cross-Linkable Hyaluronic Acid-Based Hydrogels with Potential Application for Vocal Fold Regeneration. Macromolecules 2004;37: 3239-3248.

[41] Jennie Baier L, Kathryn AB, Charles WP, Jr., Christine ES. Photocrosslinked Hyaluronic Acid Hydrogels: Natural, Biodegradable Tissue Engineering Scaffolds. Biotechnology and Bioengineering 2003;82: 578-589.

[42] Menzel EJ, Farr C. Hyaluronidase and Its Substrate Hyaluronan: Biochemistry, Biological Activities and Therapeutic Uses. Cancer Letters 1998;131: 3-11. 
[43] Tanimoto K, Suzuki A, Ohno S, Honda K, Tanaka N, Doi T, Nakahara-Ohno M, Yoneno K, Nakatani Y, Ueki M, Yanagida T, Kitamura R, and Tanne K. Hyaluronidase Expression in Cultured Growth Plate Chondrocytes During Differentiation. Cell Tissue Res. 2004;318: 335-342.

[44] Sechriest VF, Miao YJ, Niyibizi C, Westerhausen-Larson A, Matthew HW, Evans $\mathrm{CH}, \mathrm{Fu} \mathrm{FH}$, and Suh J-K. GAG-Augmented Polysaccharide Hydrogel: A Novel Biocompatible and Biodegradable Material to Support Chondrogenesis. J. Biomed. Mater. Res. 2000;49: 534-541.

[45] Mouw JK, Case ND, Guldberg RE, Plaas AHK, Levenston ME. Variations in Matrix Composition and Gag Fine Structure among Scaffolds for Cartilage Tissue Engineering. Osteoarthr. Cartilage 2005;13: 828-836.

[46] Abe M, Takahashi M, Nagano A. The Effect of Hyaluronic Acid with Different Molecular Weights on Collagen Crosslink Synthesis in Cultured Chondrocytes Embedded in Collagen Gels. J. Biomed. Mater. Res. A 2005;75A: 494-499.

[47] Liao E, Yaszemski M, Krebsbach P, Hollister S. Tissue-Engineered Cartilage Constructs Using Composite Hyaluronic Acid/Collagen I Hydrogels and Designed Poly(propylene fumarate) Scaffolds. Tissue Eng. 2007;13: 537-550.

[48] Chung C, Burdick JA. Influence of Three-Dimensional Hyaluronic Acid Microenvironments on Mesenchymal Stem Cell Chondrogenesis. Tissue Eng. A 2009; 15: 243-254. 


\section{Summary}

Tissue engineering is a promising method for the regeneration of cartilage defects. This approach generally involves the use of a three-dimensional scaffold which can act as a temporary artificial extracellular matrix (ECM) for healthy cartilage cells, chondrocytes. Hydrogels represent a class of ECM-mimicking scaffolds that are able to retain cells inside and support their growth, thereby inducing the production of such a matrix. So far many hydrogel systems based on natural or synthetic materials have been developed for cartilage regeneration. Among these systems, injectable hydrogels have received much attention since they can be used in a minimally invasive surgical procedure in clinical trials.

This thesis focuses on polysaccharide-based injectable hydrogels for cartilage regeneration. The in-situ formation of hydrogels was established via either Michael addition reaction or enzymatic crosslinking of conjugated polysaccharides. The applicability of these hydrogels for tissue engineering was studied by determining the physical and biological characteristics of these hydrogels such as gelation time, swelling and degradation, and mechanical properties. In addition, bovine chondrocytes were incorporated inside the gels and their viability and ability to produce cartilaginous matrix were evaluated in vitro.

In Chapter 1 a general background with regard to the work in this thesis is presented. The current literature on injectable hydrogels for cartilage tissue engineering is reviewed in Chapter 2. In this chapter criteria important in the design of injectable hydrogels are outlined. Also, suitable crosslinking mechanisms to obtain injectable hydrogels are reviewed in detail. Finally, an overview is given on the state of the art injectable hydrogels for cartilage regeneration. In Chapter 3 biodegradable injectable hydrogels based on the Michael addition reaction of thiolated hyaluronic acid (HA-SH) and poly(ethylene glycol)vinyl sulfone (PEG-VS) were described. Their gelation times ranged from $14 \mathrm{~min}$ to less than $1 \mathrm{~min}$, depending on the molecular weight of the HA-SH and PEG-VS, degree of substitution (DS) of the HA-SH and the total polymer concentration. Hydrogels were shown to be biodegradable in the presence of hyaluronidase. In vitro culturing of chondrocytes demonstrated a good biocompatibility of these HA-SH/PEG-VS hydrogels and a cartilaginous matrix rich in proteoglycans and collagen type II was observed to 
accumulate inside the gels in time. The low mechanical properties of these hydrogels as shown by the storage moduli of $0.17-1.6 \mathrm{kPa}$, however, is a disadvantage in a load bearing applications. Hydrogels with improved mechanical properties can be obtained from conjugated dextrans using an enzymatic crosslinking method, as described in Chapter 4. The enzymatic crosslinking method, using horseradish peroxidase (HRP) and hydrogen peroxide $\left(\mathrm{H}_{2} \mathrm{O}_{2}\right)$, appeared to be highly effective in gel formation of phenol-containing tyramine conjugated polysaccharides. In this study, dextran-tyramine conjugates, i.e. dextran-tyramine linked by a urethane bond (denoted as Dex-TA) or by an ester-containing diglycolic group (denoted as Dex-DG-TA), with different degrees of substitution (DS) were prepared. It was found that hydrogels were rapidly formed under physiological conditions with gelation time ranging from $9 \mathrm{~min}$ to $5 \mathrm{sec}$, depending on the DS and concentration. The storage modulus $\left(\mathrm{G}^{\prime}\right)$, which varied from 3 to $41 \mathrm{kPa}$, increased with increasing polymer concentration, increasing HRP/TA ratio and decreasing $\mathrm{H}_{2} \mathrm{O}_{2} /$ TA ratio. This study demonstrated that the HRP-mediated enzymatic crosslinking is an efficient method to obtain fast in-situ forming hydrogels with good mechanical properties, and that these hydrogels are promising for use as injectable systems for biomedical applications. In Chapter 5 a more detailed study directed towards a potential application of these gels in cartilage tissue engineering is described. The gelation conditions were optimized by changing the molecular weight of the dextran, DS of tyramine groups and $\mathrm{H}_{2} \mathrm{O}_{2}$ /TA ratio. Hydrogels prepared from Dex-TA at a HRP/TA ratio of $0.25 \mathrm{mg} / \mathrm{mmol}$ and a $\mathrm{H}_{2} \mathrm{O}_{2} / \mathrm{TA}$ molar ratio of 0.2 afforded hydrogels rapidly formed within $1 \mathrm{~min}$, important for an injectable system. Rheology measurements showed improved mechanical properties ( $\mathrm{G}^{\prime}$ up to $60 \mathrm{kPa}$ ) for Dex-TA hydrogels with a higher molecular weight of the precursor and a higher DS. Based on these results, Dex14k-TA DS 10 and 15, Dex31k-TA DS 10 conjugates were chosen for incorporation of chondrocytes during gel formation. The livedead assay and the MTT assay revealed a good viability of the cells in the gel. Moreover, scanning electronic microscopy (SEM) showed that the chondrocytes were capable of maintaining their round shape. Histology and immunofluorescent staining demonstrated the production of glycosaminoglycans (GAGs) and collagen type II after culturing for 14 and 21 days. Biochemical analysis showed that GAG accumulation increased with time inside these hydrogels. Besides, the GAG/DNA ratio for Dex-TA hydrogels was higher than that for agarose (positive control) at day 28. These results indicated that the Dex-TA hydrogels are highly promising $3 \mathrm{D}$ scaffolds for cartilage tissue engineering applications. To extend the applicability of the enzymatic crosslinking approach, as a methodology for injectable hydrogels for cartilage tissue engineering, research was also focused on another polysaccharide, chitosan (Chapter 6). The advantage of chitosan over dextran is that chitosan can be more readily enzymatically degraded in vivo by lysozyme, a protein present 
in the ECM of human cartilage. Besides, chitosan has a chemical structure similar as glycosaminoglycans (GAG) present in the ECM, which suggests that chitosan, as a GAG analog, may display some biofunctions suitable in the regeneration process of cartilage tissue. From this point of view, chitosan conjugates grafted with glycolic acid, to improve water solubility, and phloretic acid, for enzymatic crosslinking, were synthesized by activation of carboxylic acid groups of the appropriate molecules to react with the amine groups of chitosan. The modified chitosan polymers displayed high water solubility and short gelation times (e.g. $10 \mathrm{~s}$ at a polymer concentration of $3 \mathrm{wt} \%$ ) when enzymatically crosslinked using HRP and $\mathrm{H}_{2} \mathrm{O}_{2}$. Notably, it was found that these hydrogels can be readily degraded by lysozyme in vitro. Chondrocytes cultured inside chitosan-based hydrogels for 2 weeks were viable and retained their round cell shape.

Heparin is one of the sulfated GAGs that can interact with ECM components. First steps in the design of a hydrogel comprising such an anionically charged polysaccharide were taken by combining Dex-TA and newly prepared heparin-tyramine conjugates (Hep-TA) into a multifunctional hydrogel (Chapter 7). We hypothesized that the negatively charged heparin molecules may improve the hydrogel swelling and chondrocyte function, thus leading to a better transport of nutrients and enhanced matrix production. By adjusting the Dex-TA/Hep-TA ratio from 100/0 to $0 / 100$, the swelling and mechanical properties of the hydrogels can be controlled. Importantly, hydrogels with a Dex-TA/Hep-TA ratio of 50/50 and 25/75 showed enhanced cell proliferation and matrix production compared to other systems described in the previous chapters. In Chapter 8 a biomimetic hydrogel system based on dextran-hyaluronic acid conjugates for cartilage regeneration is described. This study highlights that polysaccharide conjugates of hyaluronic acid (HA) grafted with dextran-tyramine conjugates (denoted as HA-g-Dex-TA) have a macromolecular structure like the proteoglycans present in the ECM, thereby mimicking native cartilage tissue, which can be potentially favorable for enhanced cartilage regeneration. The HA-g-Dex-TA hydrogels were rapidly formed within 2 min via enzymatic crosslinking. Importantly, bovine chondrocytes incorporated inside the HA-g-Dex-TA hydrogels remained viable. Moreover, enhanced chondrocyte proliferation and matrix production were observed in the HA- $g$-Dex-TA hydrogels compared to the Dex-TA hydrogels. 


\section{Samenvatting}

Tissue engineering is een veelbelovende methode voor de regeneratie van kraakbeen defecten. Voor deze benadering is een driedimensionaal dragermateriaal nodig, dat dient als tijdelijke en artificiële extracellulaire matrix (ECM) voor gezonde kraakbeencellen, chondrocyten. Hydrogelen zijn ECM simulerende dragermaterialen, die de cellen vasthouden, hun groei stimuleren en zo de productie van een natuurlijke ECM induceren. Tot nu toe zijn er meerdere hydrogel systemen ontwikkeld voor kraakbeen regeneratie, gebaseerd op natuurlijke of synthetische materialen. Injecteerbare systemen zijn daarbij bijzonder interessant, daar zij toepasbaar zijn via minimaal invasieve ingrepen.

Dit proefschrift richt zich op polysacharide gebaseerde injecteerbare hydrogelen voor kraakbeen regeneratie. De in situ gelering van deze gelen werd gerealiseerd door middel van een Michael additie reactie of een enzymatische reactie van gefunctionaliseerde polysachariden. De toepasbaarheid van deze hydrogelen als tissue engineering matrices is bestudeerd door fysische (geleringstijd, zwelling, degradatie en mechanische eigenschappen) en biologische eigenschappen te bepalen. In vitro werden de levensvatbaarheid van runderchondrocyten en hun vermogen om een kraakbeenachtige matrix te vormen getest.

In Hoofdstuk 1 is de algemene achtergrond en doel van het onderzoek kort weergegeven. Een literatuuroverzicht van injecteerbare hydrogelen voor kraakbeen regeneratie wordt beschreven in Hoofdstuk 2. In dit hoofdstuk gaan we in op belangrijke criteria voor het ontwerp van injecteerbare hydrogelen. Ook worden bruikbare chemische en fysische verknopingsmechanismen in detail besproken. In Hoofdstuk 3 worden biodegradeerbare injecteerbare hydrogelen beschreven, die gebaseerd zijn op een Michael reactie tussen thiol gefunctionaliseerd hyaluronzuur (HA-SH) en vinylsulfon gefunctionaliseerd poly(ethyleen glycol) (PEG-VS). Geleringstijden voor deze gelen variëren van 14 seconden tot minder dan een minuut, afhankelijk van het molecuul gewicht van HA-SH of PEG-VS, substitutiegraad van HA-SH en de totale polymeer concentratie. De hydrogelen waren degradeerbaar in aanwezigheid van hyaluronidase. In vitro kweken van chondrocyten lieten een goede biocompatibiliteit zien voor deze HA-SH/PEG-VS hydrogelen en accumulatie van een kraakbeenachtige matrix, rijk aan proteoglycanen en collageen type II, is waargenomen in de gel. De matige mechanische eigenschappen van deze gelen, geïllustreerd door opslagmoduli van $0,17-1,6 \mathrm{kPa}$, zijn echter nadelig in gewichtsdragende toepassingen. Hydrogelen met betere mechanische eigenschappen zijn te maken uit gefunctionaliseerde dextranen door middel van een enzymatische verknoping, zoals beschreven in Hoofdstuk 4. De enzymatische verknopingsmethode, die gebruik maakt van 
mierikswortelperoxidase (HRP) en waterstofperoxide $\left(\mathrm{H}_{2} \mathrm{O}_{2}\right)$, bleek zeer efficiënt in de gelvorming van tyramine gefunctionaliseerde polysachariden. In deze studie zijn tyramine gefunctionaliseerde dextranen gemaakt, d.w.z. tyramine gekoppeld aan dextraan d.m.v. een carbamaat (Dex-TA) of d.m.v. een ester bevattende diglycolische groep (Dex-DG-TA), met verschillende substitutiegraden. De hydrogelen werden zeer snel gevormd onder fysiologische condities met geleringstijden variërend tussen 9 minuten en 5 seconden, afhankelijk van de substitutiegraad en concentratie. De opslagmodulus, variërend van 3 tot $41 \mathrm{kPa}$, stijgt met toenemende polymeerconcentratie of HRP/TA ratio en afnemende $\mathrm{H}_{2} \mathrm{O}_{2} /$ TA ratio. Deze studie laat zien dat de HRP gereguleerde enzymatische verknoping een efficiënte methode is voor snel in situ vormende hydrogelen met goede mechanische eigenschappen en dus veelbelovend zijn als injecteerbare systemen in biologische toepassingen. In een vervolg studie beschreven in Hoofdstuk 5 werd de potentiële toepassing van deze gelen in kraakbeen tissue engineering meer gedetailleerd bestudeerd. Geleringscondities werden geoptimaliseerd door het molecuulgewicht van dextraan, de substitutiegraad van de tyramine groepen en de $\mathrm{H}_{2} \mathrm{O}_{2} /$ TA ratio te variëren. Hydrogelen van Dex-TA met een HRP/TA ratio van $0,25 \mathrm{mg} / \mathrm{mmol}$ en een molaire $\mathrm{H}_{2} \mathrm{O}_{2} /$ TA ratio van 0,2 vormden zich binnen 1 minuut, wat belangrijk is voor injecteerbare systemen. Reologie experimenten lieten zien dat de mechanische eigenschappen verbeteren ( $\mathrm{G}^{\prime}$ tot $\left.60 \mathrm{kPa}\right)$ voor de Dex-TA hydrogelen met een hoger molecuulgewicht van dextraan en een hogere DS. Gebaseerd op deze resultaten zijn Dex14k-TA DS 10 en 15 en Dex31k-TA DS 10 gekozen voor het insluiten van chondrocyten tijdens de gelering. Biologische testen toonden de levensvatbaarheid van de cellen in de gel aan. Bovendien liet scanning elektronen microscopie (SEM) zien dat de chondrocyten in staat waren hun ronde vorm te behouden. Histologie en immunofluorescente aankleuring hebben laten zien dat er na 14 en 21 dagen glycosaminoglycanen (GAGs) en collageen type II zijn geproduceerd. Daarnaast was de GAG/DNA ratio voor Dex-TA hydrogelen na 28 dagen hoger dan in agarose (positieve controle). Deze resultaten duiden erop dat de Dex-TA hydrogelen veelbelovende 3D dragermaterialen zijn voor kraakbeen tissue engineering toepassingen. Om de toepasbaarheid van deze enzymatische verknopingsmethode voor injecteerbare hydrogelen breder uit te diepen, is het onderzoek ook op een tweede polysacharide gericht: chitosan (Hoofdstuk 6). Het voordeel van chitosan boven dextraan is dat chitosan in vivo sneller kan worden gedegradeerd met behulp van het enzym lysozyme, dat aanwezig is in de ECM van humaan kraakbeen. Daarnaast heeft chitosan een chemische structuur die sterk verwant is aan glycosaminoglycanen (GAGs), die aanwezig zijn in de ECM. Dit suggereert dat chitosan als GAG analoog over enkele biologische functies beschikt, die toepasbaar kunnen zijn in het regeneratieproces van kraakbeenweefsel. Met dit als uitgangspunt is chitosan gefunctionaliseerd met glycolzuur om de wateroplosbaarheid te verbeteren en met 3-(4- 
hydroxyfenyl)propionzuur voor de enzymatische verknoping, door de zuurgroepen te activeren en vervolgens met de amino groepen van chitosan te laten reageren. Dit gefunctionaliseerde chitosan vertoont een hoge wateroplosbaarheid en korte geleringstijden (bijvoorbeeld 10 seconden bij een polymeer concentratie van 3 gewichtsprocent), wanneer het enzymatisch verknoopt wordt met $\mathrm{HRP}$ en $\mathrm{H}_{2} \mathrm{O}_{2}$. Daarbovenop is gevonden dat deze hydrogelen snel degraderen in aanwezigheid van lysozyme in vitro. Chondrocyten, die twee weken gekweekt werden in deze chitosan hydrogelen, waren levensvatbaar en behielden hun ronde vorm.

Heparine is één van de gesulfoneerde GAGs die interactie vertonen met de ECM componenten. De eerste stappen naar een ontwerp van een hydrogel met een dergelijk anionisch polysacharide zijn gezet door Dex-TA te combineren met een nieuw tyramine gefunctionaliseerd heparine (Hep-TA) in een multifunctioneel hydrogel (Hoofdstuk 7). We veronderstelden dat negatief geladen heparine moleculen de hydrogel zwelling en de chondrocyt functie zouden kunnen verbeteren en dus zouden kunnen leiden tot een beter transport van voedingsstoffen en een verbeterde matrix productie. Door de Dex-TA/HepTA ratio te variëren kunnen de zwelling en de mechanische eigenschappen worden gecontroleerd. Een belangrijke vinding is dat hydrogelen met een Dex-TA/Hep-TA ratio van $50 / 50$ en $25 / 75$ een verbeterde cel proliferatie en matrix productie lieten zien vergeleken met de materialen als beschreven in de voorgaande hoofdstukken. In Hoofdstuk 8 wordt een biomimetisch hydrogel systeem beschreven voor kraakbeen regeneratie, gebaseerd op dextraan-hyaluronzuur combinaties. Deze studie laat zien dat combinatie van hyaluronzuur met dextraan-tyramine (HA-g-Dex-TA) een macromoleculaire structuur heeft, zoals de proteoglycanen van de ECM. Daarmee wordt kraakbeen nagebootst, wat gunstig kan zijn voor een betere kraakbeen regeneratie. Deze HA-g-Dex-TA hydrogelen werden snel gevormd (binnen twee minuten) via enzymatische verknoping. Tenslotte werd er een verbeterde chondrocyt proliferatie en matrix productie waargenomen in de HA-g-Dex-TA hydrogelen ten opzichte van de Dex-TA hydrogelen. 


\section{Acknowledgements}

Four years have passed quickly since I started my Ph.D studies in the University of Twente (UT, The Netherlands). I still remember, when I first came to this land, five yeas ago, I was fascinated by the fact of living abroad, getting to know new people, new places and new culture. Now, time almost comes to the end of my Ph.D period. This thesis is completed with prayers of many and sacrificial love of my family and friends, as well as with the help and support by my supervisors and colleagues. It is a pleasant aspect that I have now the opportunity to express my gratitude for all of them.

First of all, I am deeply grateful to my promotor, Prof. Dr. Jan Feijen for offering me the opportunity to pursue my Ph.D. study in the Polymer Chemistry and Biomaterials (PBM) group. Your intellectual insights and integral view on research has made a deep impression on me and led me to the interesting field full of challenges. I deeply appreciate your guidance in the scientific matters and stimulating discussions, which allows me to see different aspects of the research project in the broader perspective.

Of course this thesis wouldn't have come about without Dr. Piet Dijkstra, my daily supervisor and assistant promotor. I'm very grateful not only for your constant help and patient guidance during my $\mathrm{Ph}$. D. study, but also for your friendliness and concerns about the things that are not related to the researches. Moreover, you gave me a lot of freedom and encouragement to the work, meanwhile making my research run in a correct pathway. I really enjoy our discussions and your comments and suggestions on my experiments. I also appreciate your comments and corrections on my paper manuscripts and thesis.

My special gratefulness goes to my collaborators: Liliana Teixeira and Dr. Marcel Karperien, from Tissue Regeneration (TR) groups (UT), who have been instrumental in providing indispensable support for my research. Your valuable suggestions and excellent experimental skills enable the depth of the research work to evolve. Thank you, Liliana! Thank you for being my paranimfe. I would not have completed my thesis without your help on the cell experiments. Thank you very much for your contributions, thus, my research work can proceed smoothly and quickly. I would say working with you is a great pleasure to me. Also thank you for teaching me on the cell experiments such as chondrocyte isolation and culture, cell counting, cytotoxicity assay, immunofluorescence staining, etc. I really learn a lot on cell biology from you. I wish you success in your future work and your Ph.D thesis. Thank you, Marcel! I appreciate your guidance and suggestions on my work. Every time I have questions on the cell biology, you always kindly help me 
and make me clearly understood. Also thank you very much for your critical remarks and corrections on my manuscripts.

I would also like to thank Zhiyuan (Bill) Zhong, my daily supervisor during the first-year Ph.D period. You are an excellent researcher, having thoughtful suggestions and ideas and taking serious attitudes to scientific research. Your inspiration, enthusiasm, and supervision contributed towards the organization and completion Chapter 4 and 6 of this thesis. You arranged a very good starting of research for my Ph.D. study. Moreover, I want to thank you for your hospitality at your home.

I would like to thank all the promotion committee members who read the thesis and give me valuable suggestions.

I gratefully acknowledge the financial support by the Dutch Program for Tissue Engineering (DPTE) project. I would also like to thank Weyl Beef Products in Enschede for generously supplying us with calf and bovine cartilage.

Some people helped me and also make contributions in my Ph.D. study. I want to thank Christine Hiemstra for your active help during my first-year Ph.D period. Anita Krouwels, I want to tell you that you are such a beautiful girl. I enjoyed the time working together with you. Thank you for your efforts and contributions in Chapter 3. We finally successfully draw a nice publication. Moreover, I like to chat with you and also enjoy your singing and dancing. Froukje Geurts, although you only stay in the group for 3 months, I think we have a happy time together. Also many thanks are given to Mark Smithers and Aart van Apeldoorn, for your introduction and kind helps in the SEM analysis.

I wish to give my special thanks to my master supervisors, Prof. Dr. Johan Engbersen and Prof. Dr. Jie Yin. You gave the opportunity to study abroad and the first time to touch the field of biomaterials. Thanks you, Johan, you are a very important person in my life because it is you that let me meet Chao Lin, who is now my husband.

I'd like to thank those members in PBM and BMC group. Karin, thank you! You gave me so much help in the administration work. Zlata, you have done a lot job in chemical ordering for me so that my research work can sun in a smooth way. André Poot and Marc Ankoné, thank you very much for your guidance and advice concerning safety in the lab. Hetty, thanks for your help in computer settings. I have shared so much joyful time with my office roommates: Hans, thank you for your patience and help every time I brought some Dutch mails for English translations. Also thank you for being my paranimfen and the translation of the Semenvatting. Grégory, Martin, and my former officemate Bas and Andries, I really like the time shared with you all. It is pleasant to talk with all you guys. I want to express my thanks to all the former and present group members for the support and accompany during coffee break and study tours: Christine, Sigrid, Mark, Miguel, Marloes, 
Ingrid, Ferry, Erhan, Janine, Jung Seok, Niels, Sytze, Jos, Kim, Anita (Podt), Sandra, Arkadiy, Suzanne and Andries.

I also like to thank the people from other groups: Mukund, and Jacob (RBT group); Jojanneke, Theun, Janneke, Anouk, Jacqueline, Aart and Jeroen (TR group). It is really a lot of fun to work as well as to chat with you all. My life in Enschede becomes more colorful since I met many Chinese friends here. We enjoy dinners, parties and activities together; I really enjoy happy time with you! Thank you all, Wei Zhou and Wei Zhao (周蔚 \& 赵威, thank for picking me up at Schiphol when I first arrived in Holland and I really appreciate your kind help); Yujie Ma and Qi Chen (马玉洁 \& 陈奇, Thank you for helping me solving the problems of my laptop); Yan Song and Jing Wang (宋燕 \& 王靖), Chunlin Song (宋春林), Hongzhi Du (杜鸿志), Lanti Yang and Hao Gu (杨兰荑 \& 顾昊), Xiaolin Zhang (张啸霖), Hongmei Zhang (张红梅), Rui Guo (郭睿), Di Zhou (周弟), Ling Wu (吴凌) and his wife (Thank all for your hospitality at your home); Bin Ma (马斌) and Ling $\mathrm{Wu}$ (吴凌) (Thank you for your patience and explanation on the biological questions, of course in Chinese, $;$, and thank you for showing me how to do gene cloning, sectioning and staining, etc. I really learned a lot from you both); Zheng Zhang and Xiao Li (张铮 \& 黎晓), Boon Hua Tan (陈文华), Xuexin Duan (段学欣), Jun Liu (刘珺), Wenfeng Xia (夏文峰), Jing Song (宋婧) and Guoying Si (司国颖) (Thank you all for a lot fun we have together).

Finally, I deeply thank my parents for their endless love, support, understanding and encouragement. I also thank my dear husband, Chao Lin, who supports my work and life for ever and for ever.

Rong Jin

December, 2009

Enschede 


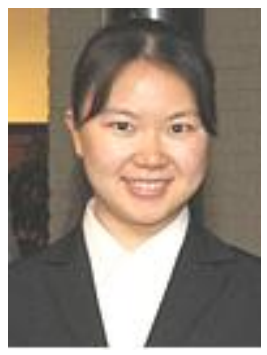

\section{Curriculum Vitae}

Rong Jin was born on $3^{\text {rd }}$ October, 1981 in Shanghai, P. R. China. In July 1999, she entered the Chemistry and Chemical Engineering Department in Shanghai Jiaotong University (Shanghai, P. R. China). In July 2003, she obtained her Bachelor degree in applied chemistry with the award of Shanghai Outstanding Graduates. In the same year, she started her Master education in the same university majoring in material science. During her master studies, in 2005, she joined in the groups of Polymer Chemistry and Biomaterials (PBM) and Biomedical Chemistry (BMC), University of Twente (Enschede, The Netherlands), as an exchange student between Shanghai Jiaotong University and University of Twente. In 2005, she obtained her Msc degree under the supervision of Professor Johan Engbersen. In 2006, she graduated from Shanghai Jiaotong University with her second Msc degree in Material Science under the supervision of Professor Jie Yin. From Jan. 2006, she started her Ph.D studies in PBM group, University of Twente (Enschede, The Netherlands), under the supervision of Professor Jan Feijen. Her research subject involves the development of injectable hydrogels for cartilage tissue engineering. 